\title{
Results of Aquifer Tests Performed Near R-Area, Savannah River Site (U)
}

\author{
Robert A. Hiergesell, Mary K. Harris, William E. Jones, Gregory P. Flach
}

August 2000

Prepared by:

Westinghouse Savannah River Company

Savannah River Site

Aiken, SC 29808

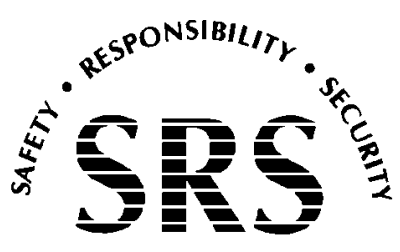

SAVANNAH RIVER SITE

Prepared for the U.S. Department of Energy Under

Contract Number DE-AC09-96SR18500 
This document was prepared in conjunction with work accomplished under Contract No.

DE-AC09-96SR18500 with the U.S. Department of Energy.

\section{DISCLAIMER}

This report was prepared as an account of work sponsored by an agency of the United States Government. Neither the United States Government nor any agency thereof, nor any of their employees, makes any warranty, express or implied, or assumes any legal liability or responsibility for the accuracy, completeness, or usefulness of any information, apparatus, product or process disclosed, or represents that its use would not infringe privately owned rights. Reference herein to any specific commercial product, process or service by trade name, trademark, manufacturer, or otherwise does not necessarily constitute or imply its endorsement, recommendation, or favoring by the United States Government or any agency

thereof. The views and opinions of authors expressed herein do not necessarily state or reflect those of the United States Government or any agency thereof.

This report has been reproduced directly from the best available copy.

Available for sale to the public, in paper, from: U.S. Department of Commerce, National Technical Information Service, 5285 Port Royal Road, Springfield, VA 22161, phone: (800)

553-6847, fax: (703) 605-6900, email: orders@ntis.fedworld.gov online ordering: http://www.ntis.gov/ordering.htm

Available electronically at http://www.doe.gov/bridge

Available for a processing fee to U.S. Department of Energy and its contractors, in paper, from: U.S. Department of Energy, Office of Scientific and Technical Information, P.O. Box 62, Oak Ridge, TN 37831-0062, phone: (865 ) 576-8401, fax: (865) 576-5728, email: reports@ adonis.osti.gov 
Results of Aquifer Tests Performed near R-Area, Savannah River Site (U) Authentication and Approvals:

Authentication and Approvals:
Robert A. Hiergesell
Author


WSRC-TR-00-00180, Rev. 0

R-Area Aquifer Tests

This Page Intentionally Left Blank 


\section{TABLE OF CONTENTS}

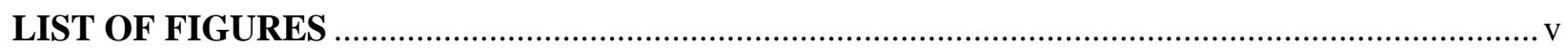

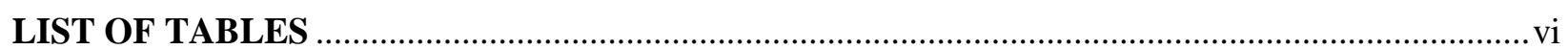

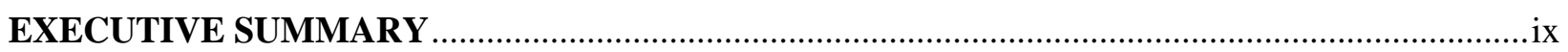

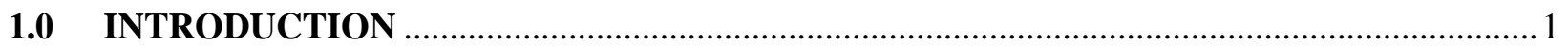

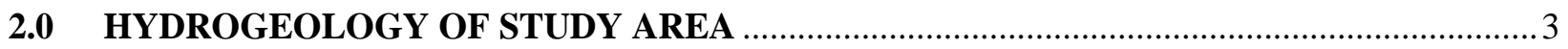

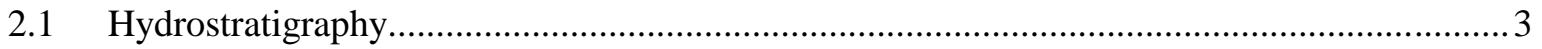

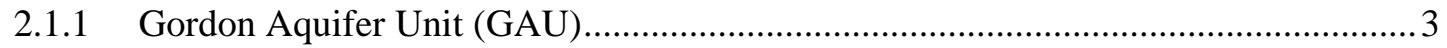

2.1.2 Gordon confining unit (GCU) ........................................................................ 4

2.1.3 "lower" aquifer zone, Upper Three Runs aquifer (LUTRA) .................................... 5

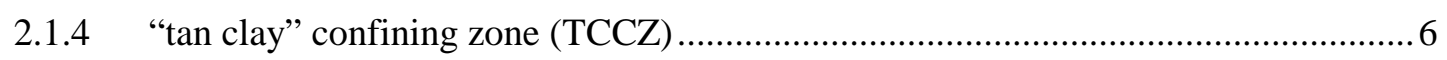

2.1.5 “upper” aquifer zone, Upper Three Runs aquifer (UTRA) .................................... 7

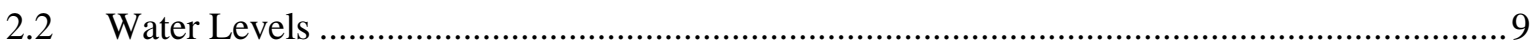

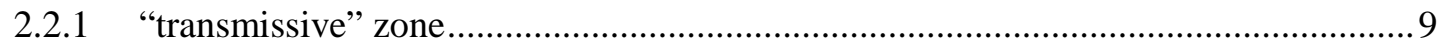

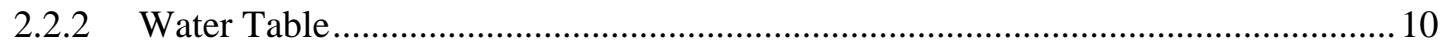

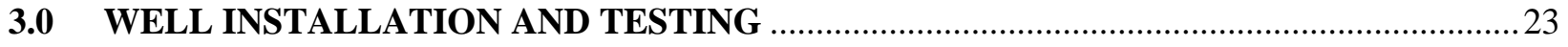

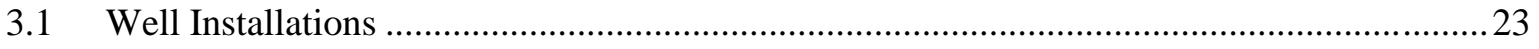

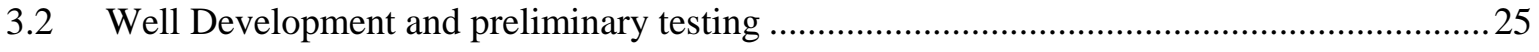

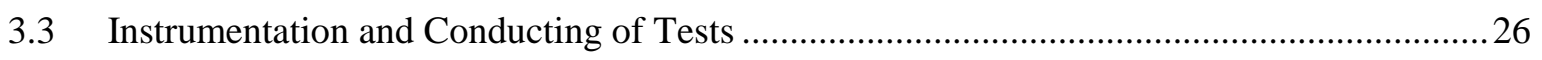

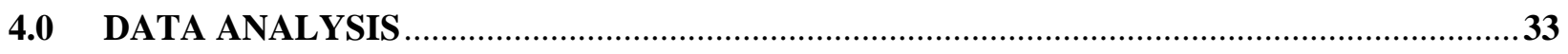

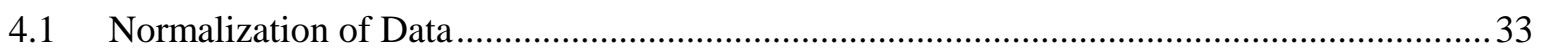

4.2 Data correction for Atmospheric Pressure variation.............................................................. 33

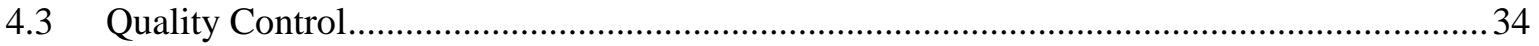

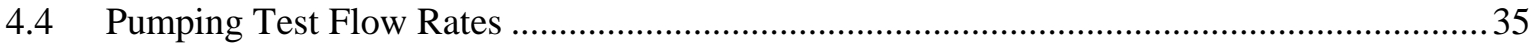

$4.5 \quad$ Water Level Responses at Observation Wells .................................................................. 36

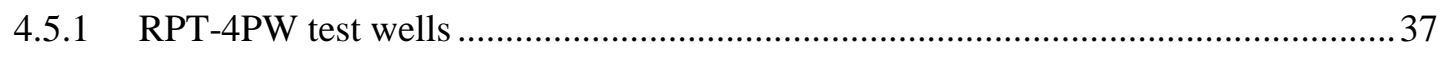

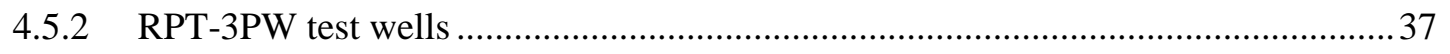

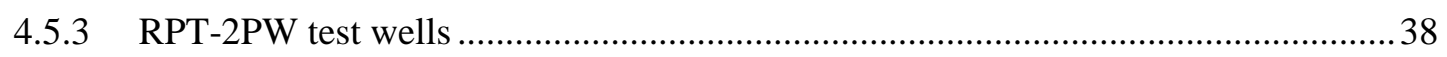

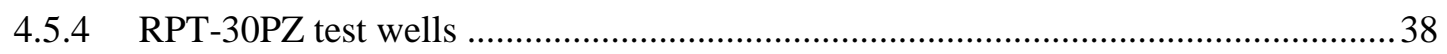

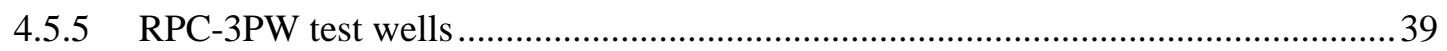

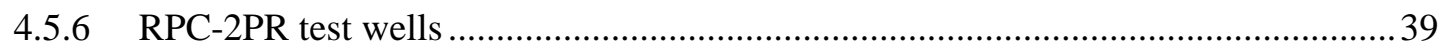

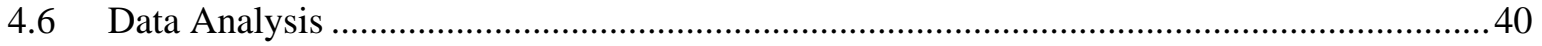


WSRC-TR-00-00180, Rev. 0

R-Area Aquifer Tests

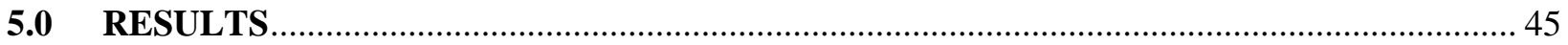

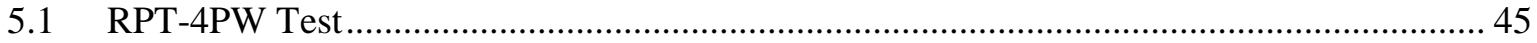

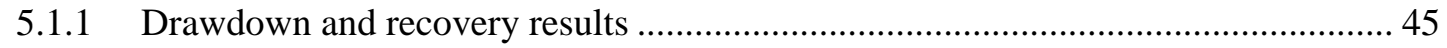

5.1.2 Hydraulic responses in adjacent aquifers ........................................................... 45

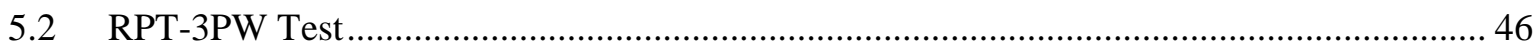

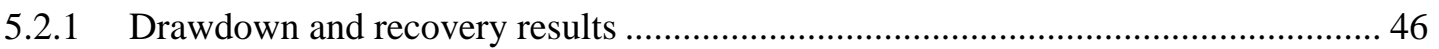

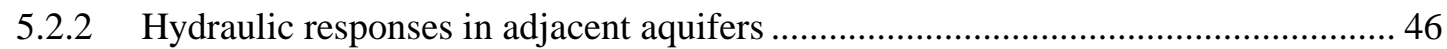

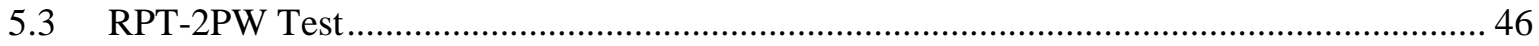

5.3.1 Drawdown and recovery results ........................................................................ 46

5.3.2 Hydraulic responses in adjacent aquifers ............................................................ 47

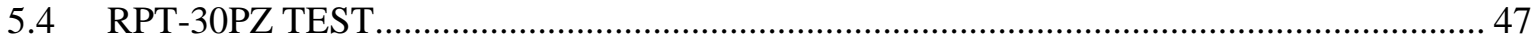

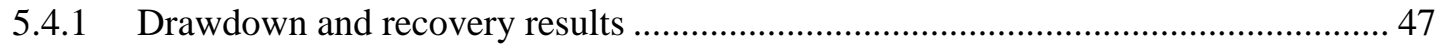

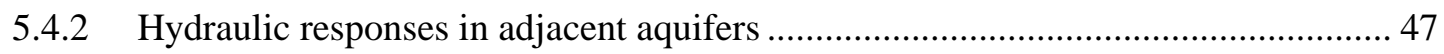

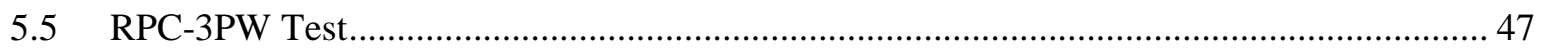

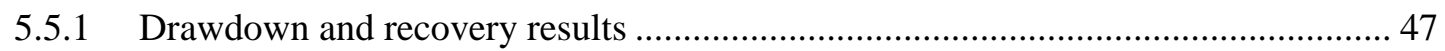

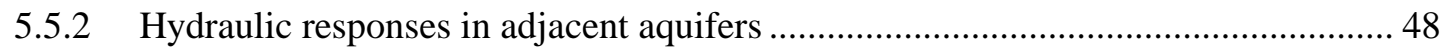

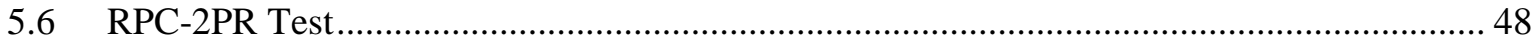

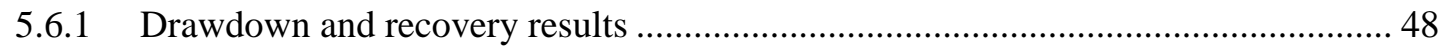

5.6.2 Hydraulic responses in adjacent aquifers ............................................................... 49

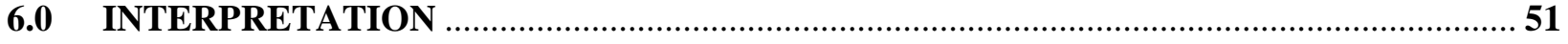

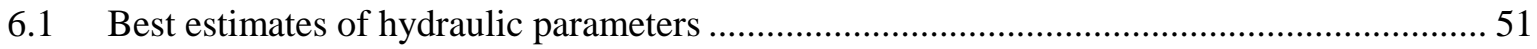

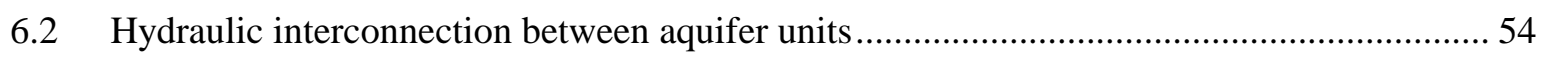

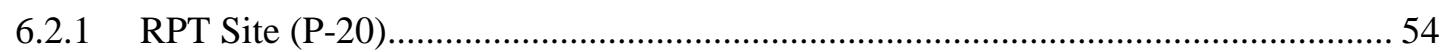

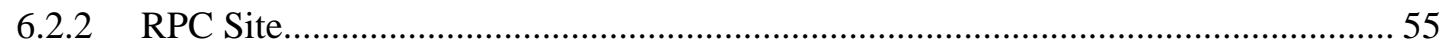

7.0 COMPARISON OF R- AREA REGIONAL FLOW MODEL TO PUMPING TEST

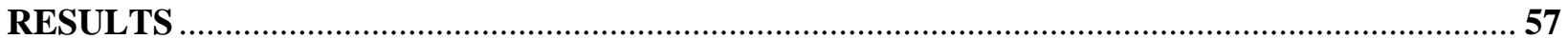

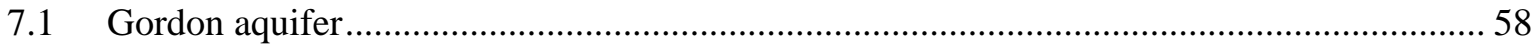

7.2 Lower Upper Three Runs Aquifer (LUTRA) .................................................................. 58

7.3 Transmissive Zone (TZ) in Upper Three Runs Aquifer ...................................................59

7.4 A/AA horizons in Upper Three Runs Aquifer................................................................ 59

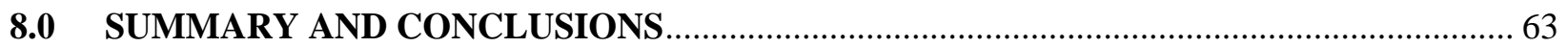

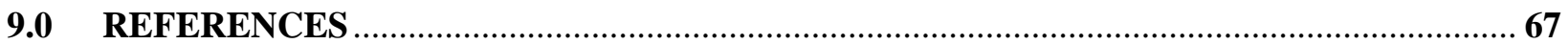




\section{LIST OF FIGURES}

Figure 1: $\quad$ Location of R Area Pump Tests Sites (RPC and RPT) …...........................................2

Figure 2: $\quad$ Lithostratigraphic and Hydrostratigraphic Correlation Chart...................................... 11

Figure 3: $\quad$ Location of Cross-Section A-A' at the RPC Pump Test Site .......................................12

Figure 4: $\quad$ Hydrostratigraphic Cross-Section A-A' at the RPC Pump Test Site ........................... 13

Figure 5: $\quad$ Location of Cross-Section B-B' and C-C' at the RPT Pump Test Site ....................... 15

Figure 6: $\quad$ Hydrostratigraphic Cross-Section B-B' at the RPT Pump Test Site ............................ 17

Figure 7: $\quad$ Hydrostratigraphic Cross-Section C-C' at the RPT Pump Test Site ............................ 19

Figure 8: $\quad$ Transmissive Zone Potentiometric Surface in R Area (Jan. 2000)..............................21

Figure 9: $\quad$ Water Table Surface in R Area (Jan. 2000) ..............................................................22

Figure 10: $\quad$ Hydraulic responses observed while pumping RPT-4PW ..........................................42

Figure 11: Hydraulic responses observed while pumping RPT-3PW.........................................42

Figure 12: $\quad$ Hydraulic responses observed while pumping RPT-2PW ..........................................43

Figure 13: $\quad$ Hydraulic responses observed while pumping RPT-30PZ .......................................... 43

Figure 14: $\quad$ Hydraulic responses observed while pumping RPT-3PW ..........................................4

Figure 15: $\quad$ Hydraulic responses observed while pumping RPT-2PR ..........................................4

Figure 16: $\quad$ Comparison of R Area Pump Test Data to Groundwater Modeling Results ................61 
WSRC-TR-00-00180, Rev. 0

R-Area Aquifer Tests

\section{LIST OF TABLES}

Table 1: Well Information for aquifer tests conducted at R-Area ................................................... 24

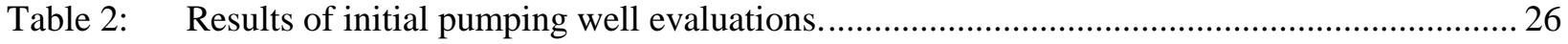

Table 3: $\quad$ Test schedules and listing of monitored wells ................................................................ 31

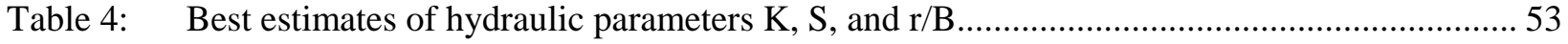

Table 5: $\quad$ Summary of R Area Pump Test Conductivity Estimates and R Area Regional

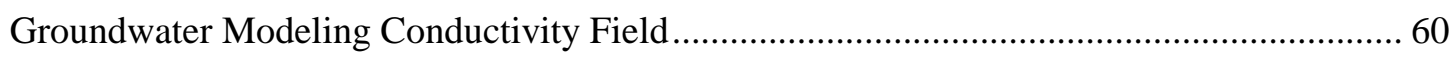


WSRC-TR-00-00180, Rev. 0

R-Area Aquifer Tests

APPENDIX A

Hydrostratigraphic Picks, CPT and Geophysical Logs

APPENDIX B

Site Specific Permeability Data

APPENDIX C

Manual water level and pumping rates for RPT tests

APPENDIX D

Manual water level and pumping rates for RPC tests

APPENDIX E

Hydrographs For Primary Observation Wells

APPENDIX F

Drawdown Analysis for Primary Observation Wells

APPENDIX G

Recovery Analysis for Primary Observation Wells 
WSRC-TR-00-00180, Rev. 0

R-Area Aquifer Tests

This Page Intentionally Left Blank 


\section{EXECUTIVE SUMMARY}

The aquifer testing described in this report was conducted in response to USEPA comments (WSRC, 1998) on the Rev. 0 R-Reactor Seepage Basins RFI/RI Report (WSRC, 1998a), Appendix G, Groundwater Contaminant Transport Modeling for the R-Reactor Seepage Basins (RRSB)/108-4R Overflow Basin Operable Unit. The R-area regional flow model described in Appendix G of the RFI/RI is based on small-scale and/or indirect measures of hydraulic conductivity, including laboratory tests, slug tests, cone penetration testing (CPT) and lithologic core descriptions. The USEPA proposed and SRS- agreed that large-scale conductivity estimates from multiple well pumping tests would be beneficial for validating the model conductivity field.

An aquifer test plan was approved by SCDHEC and USEPA in the spring of 1999. Six multiple-well, constant pumping rate tests were conducted at R-Area between December 1999 and February 2000. Fourteen new wells, 7 pumping wells and 7 observation wells were installed in close proximity to two existing well clusters, P-20 and RPC-1, near R-Area to facilitate conducting these tests. Tests were performed in the near-surface aquifers, including the A/AA Horizons, the transmissive zone of the Upper Three Runs Aquifer (TZ), the lower zone of the Upper Three Runs Aquifer (LUTRA) and the Gordon Aquifer (GAU). Although 7 pumping wells were installed, only 6 tests could be performed. A minimal pumping rate could not be sustained in the A/AA Horizon well at the RPC site.

Upon completion of the field investigations and data analysis, aquifer test hydraulic conductivities were compared to the $1998 \mathrm{R}$-area regional groundwater flow model. Good agreement was observed for the GAU and TZ aquifers. For the LUTRA the comparison was adequate, considering the heterogeneity of the unit. Excellent agreement was observed for the A/AA Horizons. Overall, the aquifer test results validate the 1998 R-area regional groundwater flow model. 
WSRC-TR-00-00180, Rev. 0

R-Area Aquifer Tests

This Page Intentionally Left Blank 
WSRC-TR-2000-00180, Rev. 0

R-Area Aquifer Tests

\subsection{INTRODUCTION}

The aquifer testing described in this report was conducted in response to U.S. Environmental Protection Agency (USEPA) comments (WSRC, 1998) on the Rev. 0 R-Reactor Seepage Basins RFI/RI Report (WSRC, 1998a), Appendix G, Groundwater Contaminant Transport Modeling for the R-Reactor Seepage Basins (RRSB)/108-4R Overflow Basin Operable Unit. The R-area regional flow model described in Appendix G of the RFI/RI is based on small-scale and/or indirect measures of hydraulic conductivity, including laboratory tests, slug tests, cone penetration testing (CPT) and lithologic core descriptions. These characterization data were correlated to conductivity and upscaled to the model grid resolution, as needed, to produce the model conductivity field. The USEPA proposed and WSRC agreed that large-scale conductivity estimates from multiple well pumping tests would be beneficial for validating the model conductivity field.

In response to the regulator comment resolution on the Rev. 0 R-Reactor Seepage Basins RFI/RI Report a pumping test plan was prepared (Hiergesell, 1999). The plan was reviewed by the regulators (SCDHEC and USEPA) and comments were incorporated. The approved test plan was implemented in the spring of 1999. Six multiple-well, constant pumping rate tests were conducted at R-Area between December 1999 and February 2000. Fourteen new wells, 7 pumping wells and 7 observation wells were installed in close proximity to two existing well clusters, P-20 and RPC-1, near R-Area to facilitate the conducting of these tests. The locations of both well clusters in relation to R-Area are indicated in Figure 1. Tests were performed in the near-surface aquifers, including the A/AA Horizons, the transmissive zone of the Upper Three Runs Aquifer (TZ), the lower zone of the Upper Three Runs Aquifer (LUTRA) and the Gordon Aquifer (GAU). Although 7 pumping wells were installed, only 6 tests could be performed. The hydraulic conductivity of the A/AA Horizons near the RPC-1 cluster was so low that not even a minimal pumping rate could be sustained in the pumping well. Upon completion of the field investigations, data analysis and interpretation were conducted to obtain hydraulic parameters for comparison to the groundwater modeling results. 
WSRC-TR-00-00180, Rev. 0

R-Area Aquifer Tests

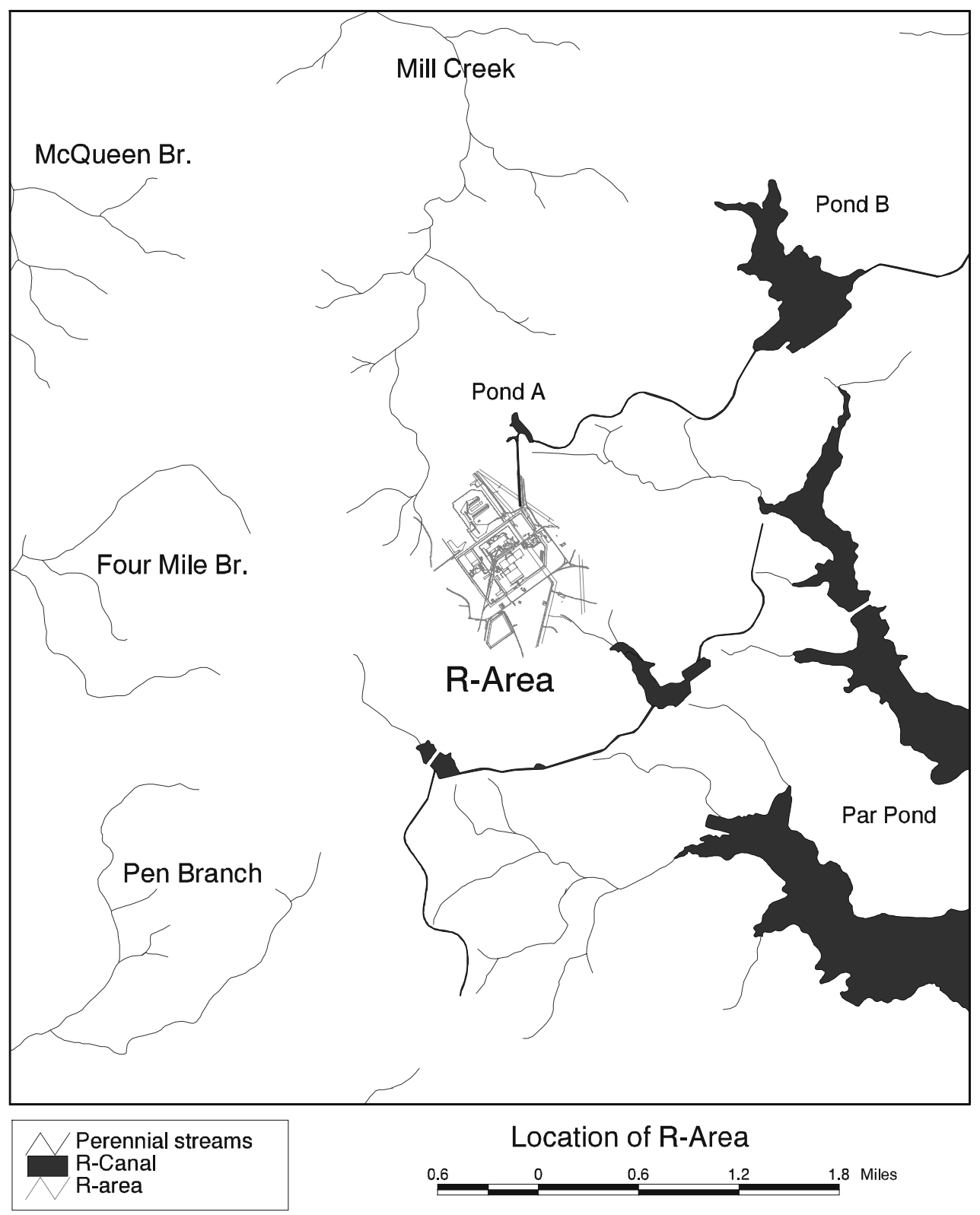

Figure 1: $\quad$ Location of R Area Pump Tests Sites (RPC and RPT) 


\subsection{HYDROGEOLOGY OF STUDY AREA}

The hydrostratigraphic units beneath $\mathrm{R}$ Area include the aquifers and aquitards of the Southeastern Coastal Plain Hydrogeologic Province. These units are described in detail in many SRS documents, including Aadland et al., (1991, 1995), Flach and Harris (1997) and Flach et al., (1999). Hydrostratigraphic units of interest are the aquifers and aquitards within the Floridan Aquifer System. These are, from deepest to shallowest, the Gordon aquifer, the Gordon confining unit, the "upper" and "lower" aquifer zones, and the "tan clay" confining zone of the Upper Three Runs Aquifer. Hydraulic parameters associated with each of these units were characterized using the data obtained in the aquifer tests described in the test plan. Figure 2 illustrates the comparison of the lithostratigraphic and hydrostratigraphic units.

The hydrostratigraphic model for the pump test design was based on the previous RFI/RI characterization and groundwater modeling efforts (WSRC, 1998a, Jones et al. 1998). Appendix A contains the hydrostratigraphic picks from the previous RFI/RI investigations and this investigation. Primarily cone penetrometer logs were utilized for new and additional hydrostratigraphic correlations at both the RPC and RPT pump test sites. However, due to difficulties encountered with lost circulation zones at the RPC site, selected intervals were rotosonically cored to facilitate well installation. Geophysical logs were used selectively at both pump test sites.

Location maps of cross-sections and cross-sections illustrating the hydrostratigraphy of the RPC and RPT pump test sites are illustrated on Figures $3-7$. The cross-sections illustrate the relation of the screened well intervals to the confining units and aquifers along with cone penetrometer logs and geophysical logs, where available. A description of the local R Area hydrostratigraphy and pump test site for each hydrostratigraphic unit of interest is provided below starting with the deepest unit.

\subsection{Hydrostratigraphy}

\subsubsection{Gordon Aquifer Unit (GAU)}

The GAU constitutes the basal unit of the Floridan aquifer system beneath R Area and is the lowermost unit described in this report. Borehole data is limited in $\mathrm{R}$ 
Area, existing only at the P-20 well cluster; hence descriptions of the GAU are derived from that data and from data obtained at other locations in the central portion of SRS. The GAU includes loose sand and clayey sand of the Congaree Formation and, where present, the sandy parts of the underlying Fourmile Branch and Snapp Formations. (Harris et al., 1990; Aadland et al., 1991, 1995). The sand within the GAU is yellowish to grayish orange and is sub- to well-rounded, moderately to poorly sorted, and medium- to coarse-grained. Pebbly layers and zones of iron and silica cemented sand are common. Interbeds of light tan to gray clay up to three $\mathrm{ft}$ in thickness are rare. The GAU contains a small amount of sporadically distributed calcareous sediment. Stringers of clay less than 6 inches in thickness are common near the base of this unit. The GAU exhibits a regional dip to the south-southeast. The thickness of this unit is variable, ranging from approximately 60 to $160 \mathrm{ft}$. This variability is likely related to depositional and structural relations with overlying and underlying units and to the presence of unconformities above and below the unit. At the P-20 cluster, the top of the GAU is at 73.7-ft msl (Appendix A, Figures 6 and 7). Slug test results indicate a hydraulic conductivity range from $1.56-4.28 \mathrm{ft} /$ day $(5.51 \mathrm{E}-04$ to $1.51 \mathrm{E}-3$ $\mathrm{cm} / \mathrm{sec}$ ) from wells RPT-4PW and RPC-4PZ, respectively (Appendix B).

\subsubsection{Gordon confining unit (GCU)}

Borehole data are limited in $\mathrm{R}$ Area for the GCU. Therefore, descriptions originate from data obtained in the central portion of SRS and at the P-20 and RPC-1 well clusters. The following descriptions are derived from core at the P20 well and cores collected at other parts of SRS adjacent to R Area. The GCU separates the GAU from the UTRA. This unit, commonly referred to as the "green clay" in previous SRS literature, includes sediment of the Warley Hill Formation (Figure 2). The unit comprises interbedded silty and clayey sand, sandy clay and clay. The clay is stiff to hard and is commonly fissile. Glauconite is a common constituent and imparts a distinctive greenish cast to the sediment; hence the informal name of "green clay" given to this unit. Zones of silicacemented sand and clay are present within the GCU in some cores taken from the central portion of the SRS. Near several of the reactor areas, the GCU includes 
some calcareous sediment and limestone, primarily calcarenaceous sand and clayey sand with subordinate calcarenaceous clay, micritic clay, and sandy micrite and limestone.

The elevation of the top of the GCU is at $81.7 \mathrm{ft} \mathrm{msl}$ at the P-20 cluster, with the bottom at $73.7 \mathrm{ft}$ msl. The elevation of the top of the GCU is at $95.3 \mathrm{ft}$ msl (depth $209 \mathrm{ft}$ bls) at RPC-01CL (Appendix A and Figures 6 and 7). Additionally, the GCU was identified during rotosonic coring at an elevation at $97.7 \mathrm{msl}$ at RPC3PZ (Figure 4).

\subsection{3 "lower" aquifer zone, Upper Three Runs aquifer (LUTRA)}

The "lower" aquifer zone of the Upper Three Runs Aquifer, (LUTRA) beneath R Area consists of siliciclastic and calcareous sediments of the Santee Formation and parts of the Dry Branch Formation beneath the "tan clay" confining zone (TCCZ) (Figure 2). This zone is highly heterogeneous due to multiple depositional environments and lithologies encountered throughout the interval. The zone represents shallow, moderate to high-energy nearshore fluvial and marine environments (Harris and others, 1997). Descriptions of drill core within $\mathrm{R}$ area indicate that the LUTRA represents a dual facies, one that is dominated by siliciclastic components and the other dominated by carbonate components resulting in highly permeable sediments directly in contact with lower permeability sediments. The sands and clayey sands are generally unconsolidated fine- to medium grained, moderate to well sorted and have good to excellent measured porosities (>30\%) and permeabilities ranging from 6.8 to $40.8 \mathrm{ft} / \mathrm{day}$ (Harris and others, 1997). In contrast the carbonate sediments are unconsolidated and consolidated with excellent measured porosities (>35\%) and moderate to low permeabilities ranging from .03 to $4.0 \mathrm{ft} / \mathrm{day}$ (Harris et al., 1997). When unconsolidated the carbonate sediments are generally mud supported (wackestones and packstones). The lithified carbonates are sometimes partially silicified with biomoldic characteristics. Both lithologies exhibit good porosity but low permeability because the pores are not interconnected or are filled with micrite (mud) that is highly porous but not very permeable. The complexity of the 
WSRC-TR-00-00180, Rev. 0

R-Area Aquifer Tests

siliciclastic and carbonate lithologies coupled with interbedded and intertonguing low permeability sediments in direct contact with high permeability sediments makes the hydrogeologic characteristics difficult to interpret.

The elevation of the top of the LUTRA at the pump test sites ranges from 165 to $206 \mathrm{ft}$ msl. with thicknesses ranging from $46 \mathrm{ft}$ to $79 \mathrm{ft}$ (Appendix A). The rotosonic core log for RPC-3PW describes the change from the overlying siliciclastic zone to the underlying sandy, biomoldic limestone at a depth of $137 \mathrm{ft}$ bls. The sandy biomoldic limestone then becomes a calcareous clayey sand at $145 \mathrm{ft}$ bls. The rotosonic core log for RPC-3PZ describes the occurrence of biomoldic limestone at a depth of $157 \mathrm{ft}$ bls, grading to a sand at $192 \mathrm{ft}$, with the GCU occurring at $211.5 \mathrm{ft}$ bls (WSRC, 2000).

Vertical hydraulic conductivity from laboratory testing is reported at 7.65E-05$2.55 \mathrm{E}-2 \mathrm{ft} /$ day $(2.7 \mathrm{E}-08-9.01 \mathrm{E}-06 \mathrm{~cm} / \mathrm{sec})$ in the upper portion of the LUTRA, and at $7.93 \mathrm{E}-03 \mathrm{ft} /$ day $(2.8 \mathrm{E}-06 \mathrm{~cm} / \mathrm{sec})$ about $18 \mathrm{ft}$ lower in the LUTRA upper portion at $\mathrm{R}$ Area (Appendix B). LUTRA slug test hydraulic conductivity measurements are reported from 5.44E-02 ft/day $(1.92 \mathrm{E}-05 \mathrm{~cm} / \mathrm{sec})(\mathrm{RPC}-3 \mathrm{PZ})$ to $51.9 \mathrm{ft} /$ day $(1.83 \mathrm{E}-02 \mathrm{~cm} / \mathrm{sec})(\mathrm{RPC}-3 \mathrm{PW}$; Appendix B).

\subsection{4 "tan clay" confining zone (TCCZ)}

The TCCZ overlies the LUTRA and is lithostratigraphically correlative to the Twiggs Clay Member of the Dry Branch Formation (Figure 2). The clay occurs as lenses and is interbedded with sands, silty sands, clayey sands, and sandy clays. Based on work conducted in this study and previous RFI/RI subsurface investigations, the upper surface of the TCCZ ranges in elevation from 157.8-ft msl to $244.0-\mathrm{ft}$ msl. while its thickness ranges from 7.0 to $56.9 \mathrm{ft}$ in $\mathrm{R}$ Area. This variability is likely related to depositional relations such as soft-sediment deformation or fluvial channels with overlying and underlying units. Additionally, carbonate dissolution associated with unconformities below the TCCZ could also influence the thickness and elevation of the interval. 
Summary statistics for vertical hydraulic conductivity of the TCCZ from the Phase I and Phase II field investigations at R Area, are presented in Appendix B (Jones et al., 1998).

\subsection{5 “upper” aquifer zone, Upper Three Runs aquifer (UTRA)}

The "upper" aquifer zone of the UTRA is subdivided into four sub-zones beneath R Area: the lowermost "transmissive" zone, the "AA" horizon, the "A" horizon and the "undifferentiated surface soils" (Figure 2).

\subsubsection{1 "transmissive" zone (TZ)}

Overlying the TCCZ is a sandy and highly permeable interval called the "transmissive" zone (TZ) that is lithostratigraphically equivalent to the Clinchfield Sand within the Dry Branch Formation (Figure 2). Strata within this interval are predominantly sands to silty sands, with interbedded clay and pebble layers. Based on cores and CPT pushes from previous RFI/RI field investigations and this subsurface investigation, the upper surface of the TZ ranges in elevation between 202 to about $273 \mathrm{ft}$ $\mathrm{msl}$ in $\mathrm{R}$ Area. The thickness of the TZ ranges from about 10 to $61 \mathrm{ft}$ in $\mathrm{R}$ Area. This variability is likely related to depositional relations such as soft-sediment deformation or fluvial channels with overlying and underlying units. Additionally, carbonate dissolution associated with unconformities below the TCCZ could also influence the thickness and elevation of the TZ.

Laboratory testing results indicate vertical permeability in the range of 1.4E-04 ft/day - 7E-01 ft/day (5.0E-08 - 2.5E-04 cm/sec). Slug testing results indicate hydraulic conductivity in the range of 2.1 to $2.89 \mathrm{ft} /$ day (7.43E-04 - 1.02E-03 cm/sec) (Appendix B).

\subsubsection{2 "AA" horizon}

Overlying the $\mathrm{TZ}$ is a more silty and clayey interval that has been termed the "AA" horizon. Lithostratigraphically, the horizon is equivalent to the 
Tobacco Road Formation (Figure 2). Based on cores and CPT pushes within R Area, the upper surface of the "AA" horizon ranges in elevation from about 225 to $288 \mathrm{ft}$ msl. The thickness of the "AA" horizon ranges from around 15 to $35 \mathrm{ft}$ in $\mathrm{R}$ Area. The variability associated with this unit is probably due to depositional relations such as soft-sediment deformation and fluvio/nearshore marine channeling. The "AA" horizon is described as clayey sand to sand that is poorly to very poorly sorted, very fine grained to pebble sized, and subangular to subrounded. The color is light red, medium red and light purple at the upper contact of the horizon in coreholes.

Estimates of vertical hydraulic conductivity of the "AA" horizon derived from laboratory permeameter tests range from $2.30 \mathrm{E}-05 \mathrm{~cm} / \mathrm{sec}$ to $3.20 \mathrm{E}-$ $06 \mathrm{~cm} / \mathrm{sec}$. Slug test results for RPC-1PW and RPC-1PZ indicate hydraulic conductivities of 2.91E-01 - 2.75E-01 ft/day (1.03E-04 - 9.72E$05 \mathrm{~cm} / \mathrm{sec}$ ), respectively (Appendix B).

\subsubsection{3 "A" horizon}

Overlying the "AA" horizon is a low hydraulic conductivity unit termed the "A" horizon, which is lithostratigraphically equivalent to the "upland" unit (Figure 2). Based on cores and CPT pushes, the upper surface of the "A" horizon ranges in elevation from 252 to $325 \mathrm{ft}$ msl. "A" horizon thickness ranges from about 14 to about $50 \mathrm{ft}$. Estimates of vertical hydraulic conductivity from laboratory permeameter testing for the " $\mathrm{A}$ " horizon range from $9.06 \mathrm{E}-03-6.51 \mathrm{E}-02 \mathrm{ft} / \mathrm{day}(3.2 \mathrm{E}-06-2.3 \mathrm{E}-05$ $\mathrm{cm} / \mathrm{sec})$, within the $6.24 \mathrm{E}-05-1.25 \mathrm{E}-02 \mathrm{ft} /$ day $(2.20 \mathrm{E}-08-4.42 \mathrm{E}-06$ $\mathrm{cm} / \mathrm{sec}$ ) range previously reported by Jones et al., (1988).

\subsubsection{4 "undifferentiated" surface soils}

The shallow "undifferentiated surface soils" consist of interbedded sands, silts, and clays that overlie the "A" horizon, with the upper surface being the topography. Based on thirty-four cores and CPT pushes, the upper 
surface of the "undifferentiated surface soils" occurs at a surface elevation of 284 to $336 \mathrm{ft}$ msl. The thickness of the "undifferentiated surface soils" ranges from 0 to $48 \mathrm{ft}$ in R Area. In the immediate vicinity of the RRSBs, the thickness ranges from approximately $45 \mathrm{ft}$, southeast of the basins, to $20 \mathrm{ft}$ thick to the northwest of the basins.

Summary statistics for estimates of hydraulic conductivity of the "undifferentiated surface soils" from the Phase I and Phase II field investigations at R Area are presented in Appendix A (Jones et al. 1998). Estimates are derived from laboratory permeameter tests conducted on samples obtained in the "undifferentiated surface soils". Hydraulic conductivity values of this unit are consistent with confining units at SRS ranging from $2.33 \mathrm{E}-01-2.81 \mathrm{E}-01 \mathrm{ft} /$ day $(8.22 \mathrm{E}-5-9.92 \mathrm{E}-5 \mathrm{~cm} / \mathrm{sec})$.

\subsection{Water Levels}

Water levels are monitored on a routine basis throughout R-Area, with most wells having their water level measured once each month. These measurements form the basis for construction of maps illustrating the potentiometric surface of the $\mathrm{TZ}$ and the water table. R-Area well coordinates and water level measurements from the spring of 1998 and from January 2000 were loaded into an ArcView project. Water levels were displayed and contours then developed for both the A/AA Horizon (water table) and the TZ using the automatic digitizer. Potentiometric maps were not developed for the LUTRA or the GAU due to the scarcity of wells in R-Area that are finished in those hydrostratigraphic units.

\subsection{1 "transmissive" zone}

The potentiometric level of the TZ in January 2000 is shown in Figure 8. The horizontal direction of groundwater movement in the TZ near R-Area is to the northeast, in the direction of the canal-turnout drainage way. This drainage way incises the A/AA Horizons into the $\mathrm{TZ}$ a short distance east of the main R-Area canal system. Stream reaches beyond the point of incision form a discharge zone for the TZ. Groundwater flows from recharge areas toward discharge areas hence 
groundwater movement in the TZ beneath R-Area is eastward toward the canalturnout drainage way. Elevations range from 275 to $250 \mathrm{ft}$ above $\mathrm{msl}$ in the area just north of $\mathrm{R}$ Area, with the average hydraulic gradient being 0.007 near the RRSBs. There are far fewer wells finished in the TZ than in the "A/AA" horizons; hence, the configuration of the potentiometric surface is known with less certainty than the configuration of the water table.

\subsubsection{Water Table}

At $\mathrm{R}$ Area the water table occurs within the uppermost hydrostratigraphic units, the "A" horizon and "AA" horizon of the "upper" aquifer zone, UTRA. The January 2000 configuration of this surface is shown in Figure 9 and is in the shape of a mound centered beneath the area of the reactor seepage basins. Water level elevations range from a high of 290 to $255 \mathrm{ft}$ above msl and horizontal flow directions radiate outward from the center of the mound. Groundwater also moves vertically downward, as indicated by the difference in hydraulic head between the Water Table and the "transmissive" zone potentiometric level. Although groundwater moves both horizontally as well as vertically within the "A/AA" Horizons, flow velocities are comparatively low. This is because the permeability of the "A/AA" Horizons is more consistent with that of an aquitard than an aquifer. The large number of wells finished in the "A/AA" horizons allows the water table configuration to be known with a relatively high degree of confidence compared to the deeper hydrostratigraphic units. 
WSRC-TR-2000-00180, Rev. 0

R-Area Aquifer Tests

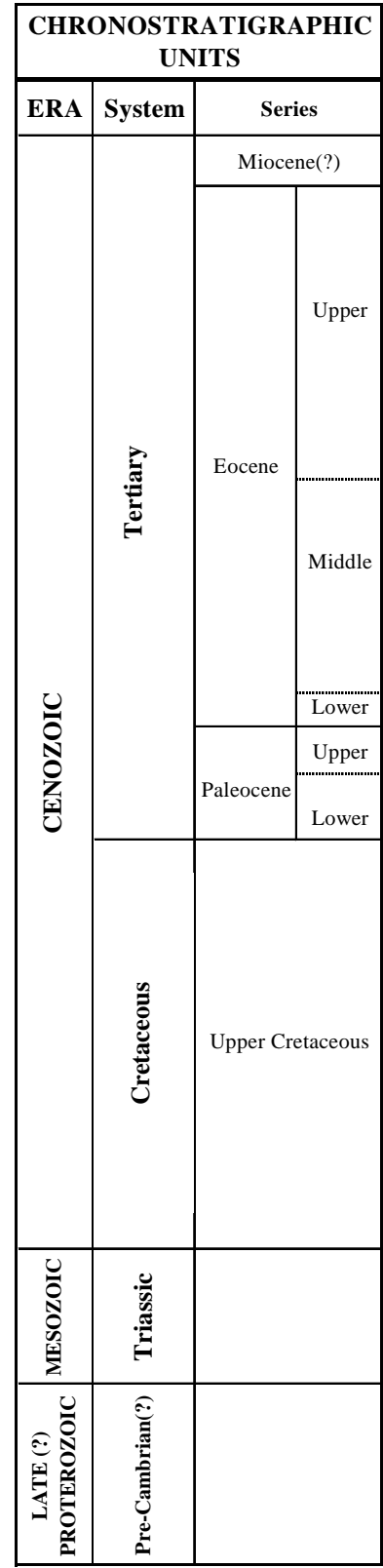

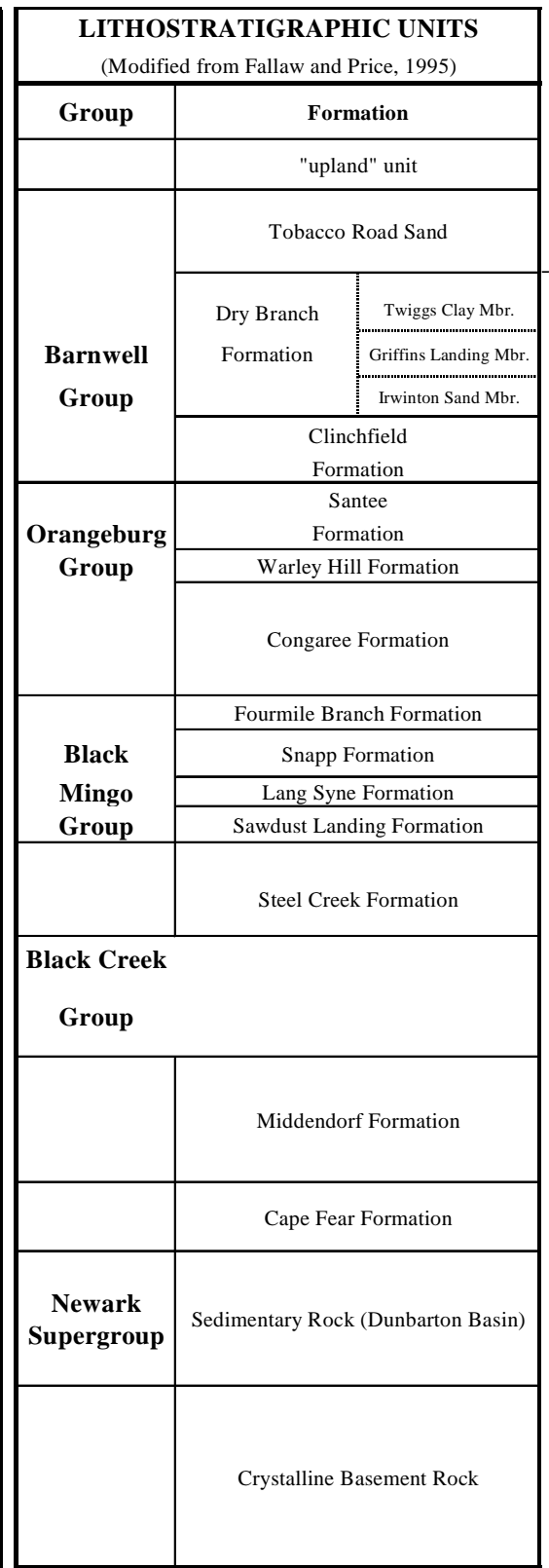

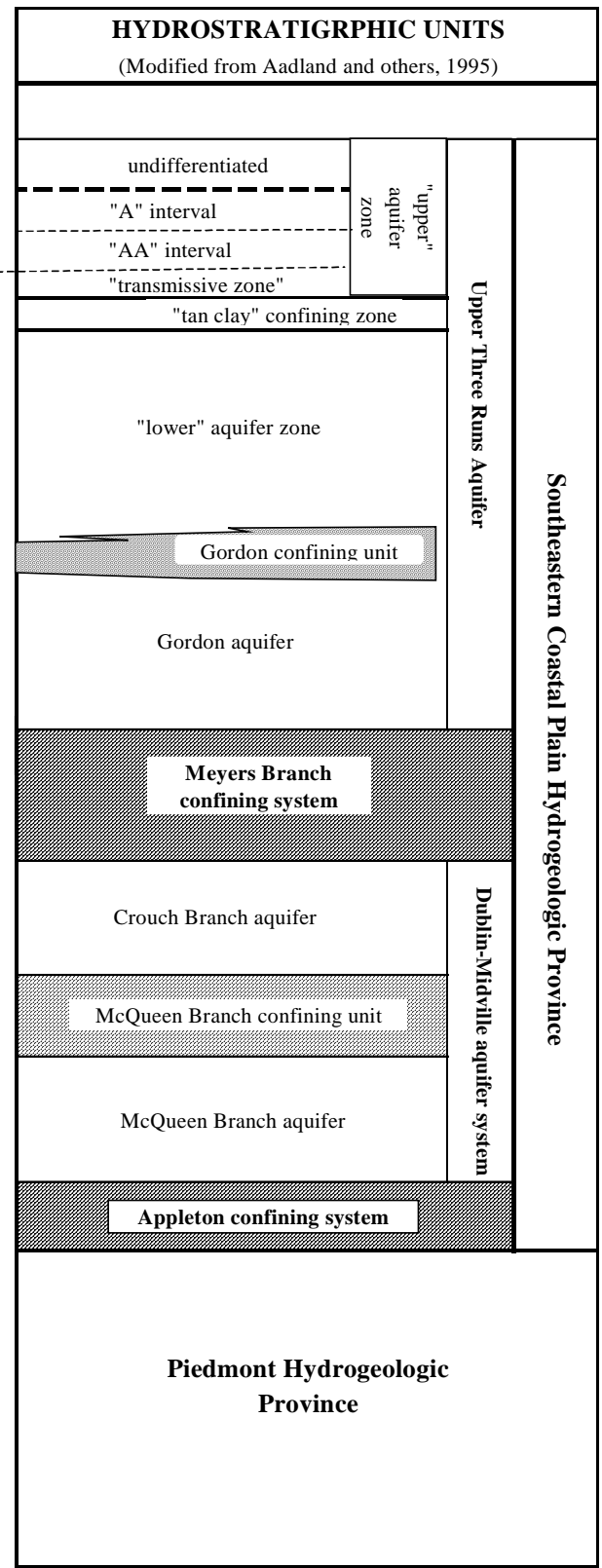

Figure 2:

Lithostratigraphic and Hydrostratigraphic Correlation Chart 
WSRC-TR-00-00180, Rev. 0

R-Area Aquifer Tests

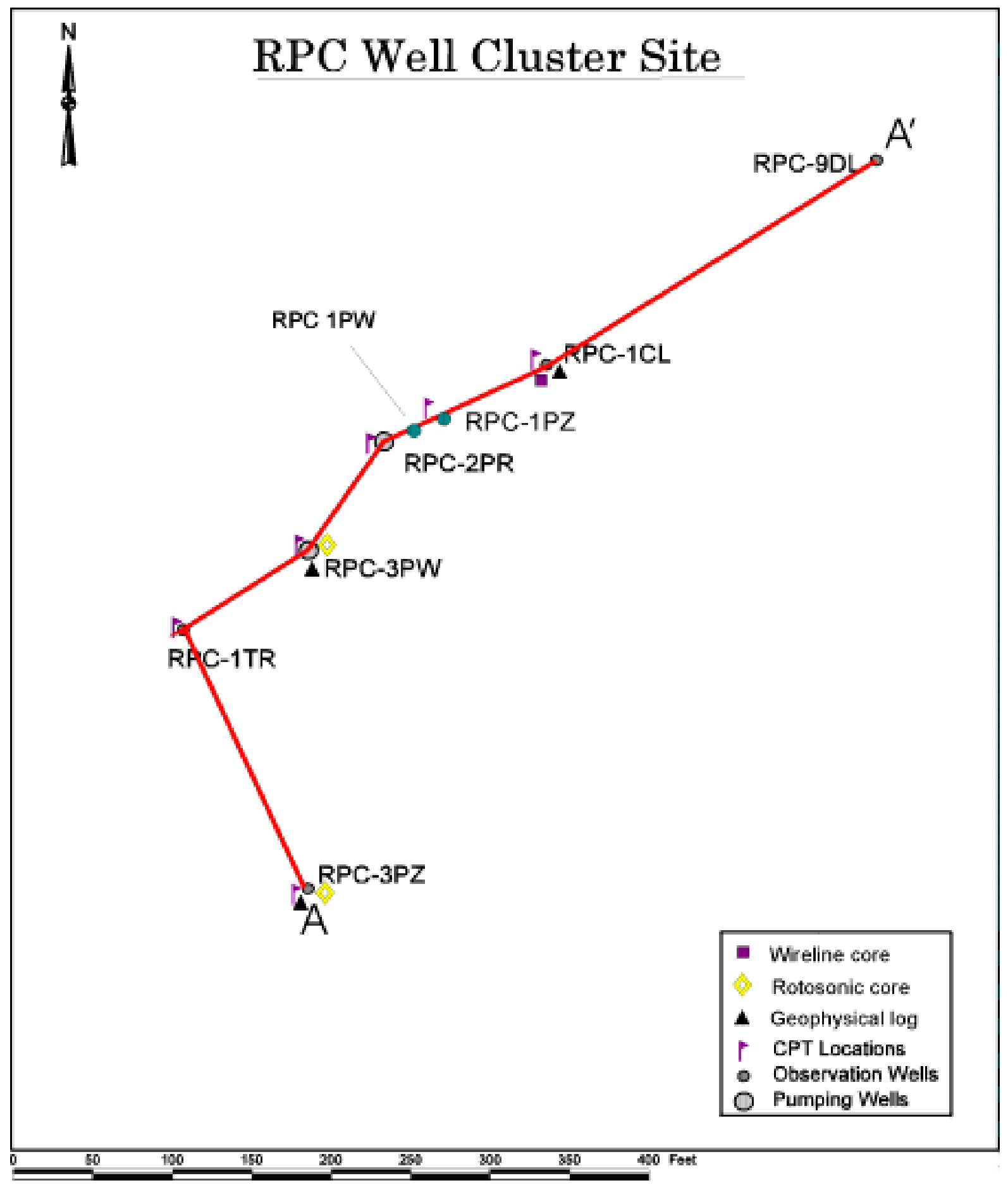

Figure 3: Location of Cross-Section A-A' at the RPC Pump Test Site 


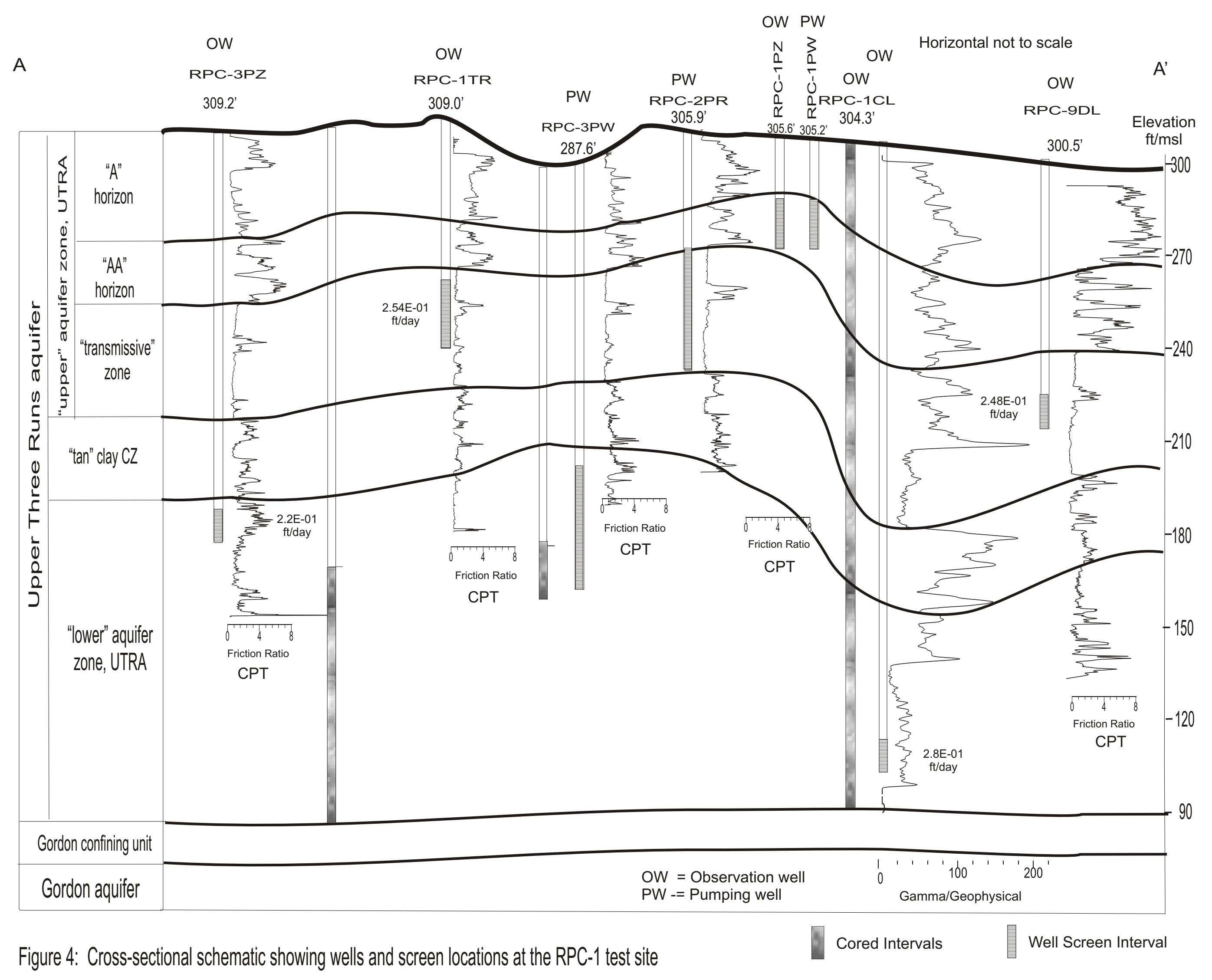


WSRC-TR-00-00180, Rev. 0

R-Area Aquifer Tests

This Page Intentionally Left Blank 
WSRC-TR-2000-00180, Rev. 0

R-Area Aquifer Tests

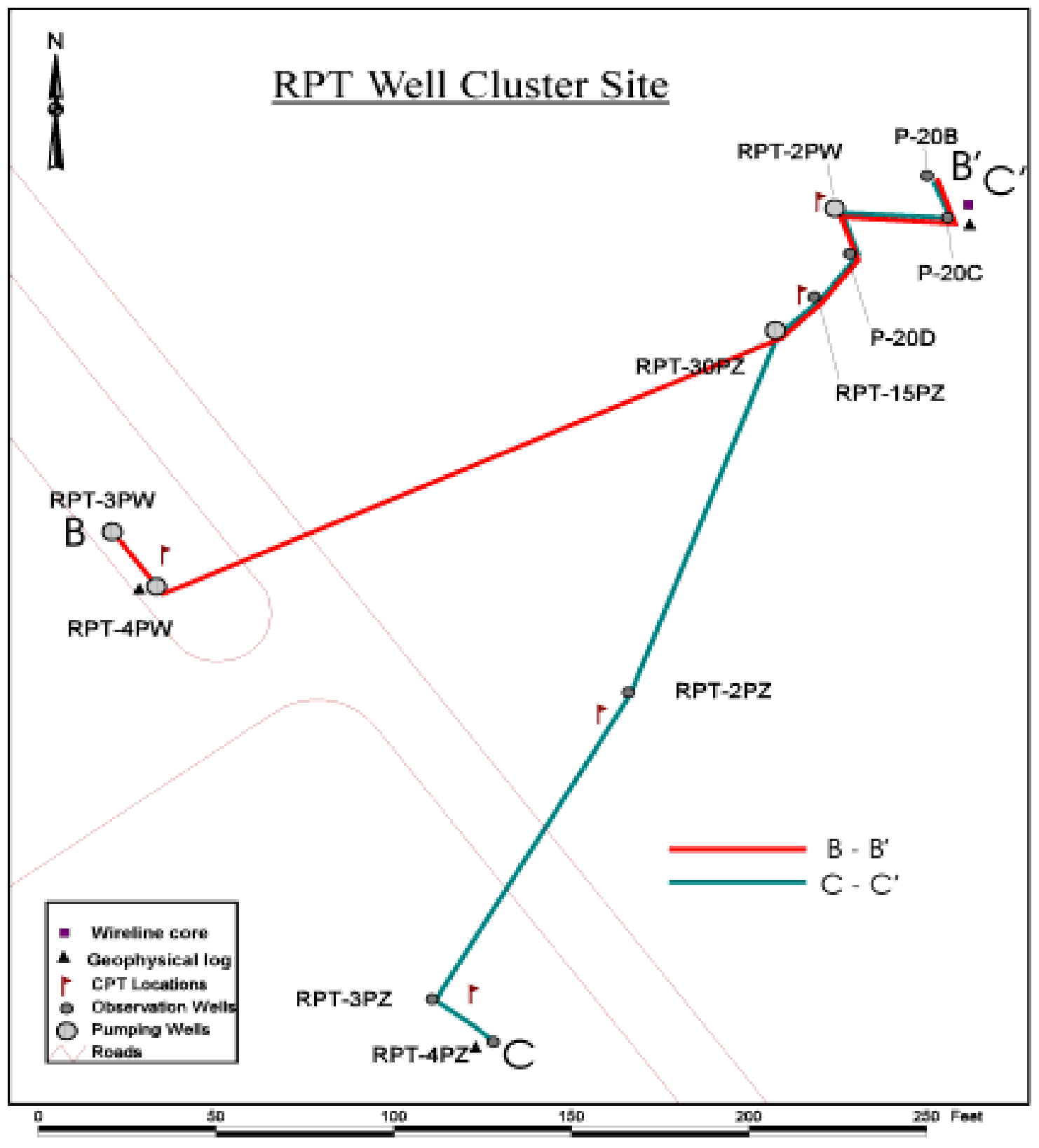

Figure 5: Location of Cross-Section B-B' and C-C' at the RPT Pump Test Site 
WSRC-TR-00-00180, Rev. 0

R-Area Aquifer Tests

This Page Intentionally Left Blank 


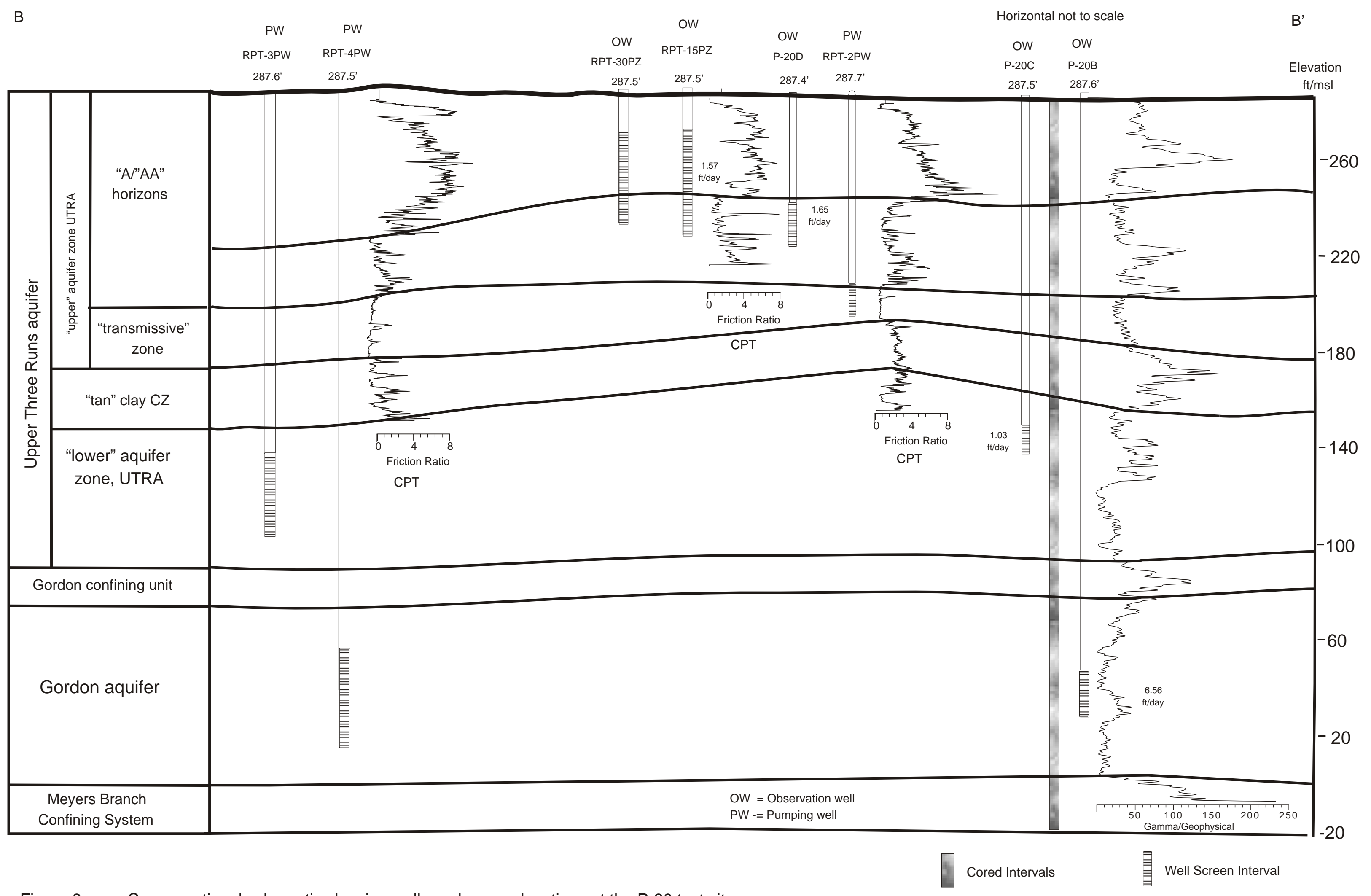

Figure 6: Cross-sectional schematic showing wells and screen locations at the P-20 test site 
WSRC-TR-00-00180, Rev. 0

R-Area Aquifer Tests

This Page Intentionally Left Blank 


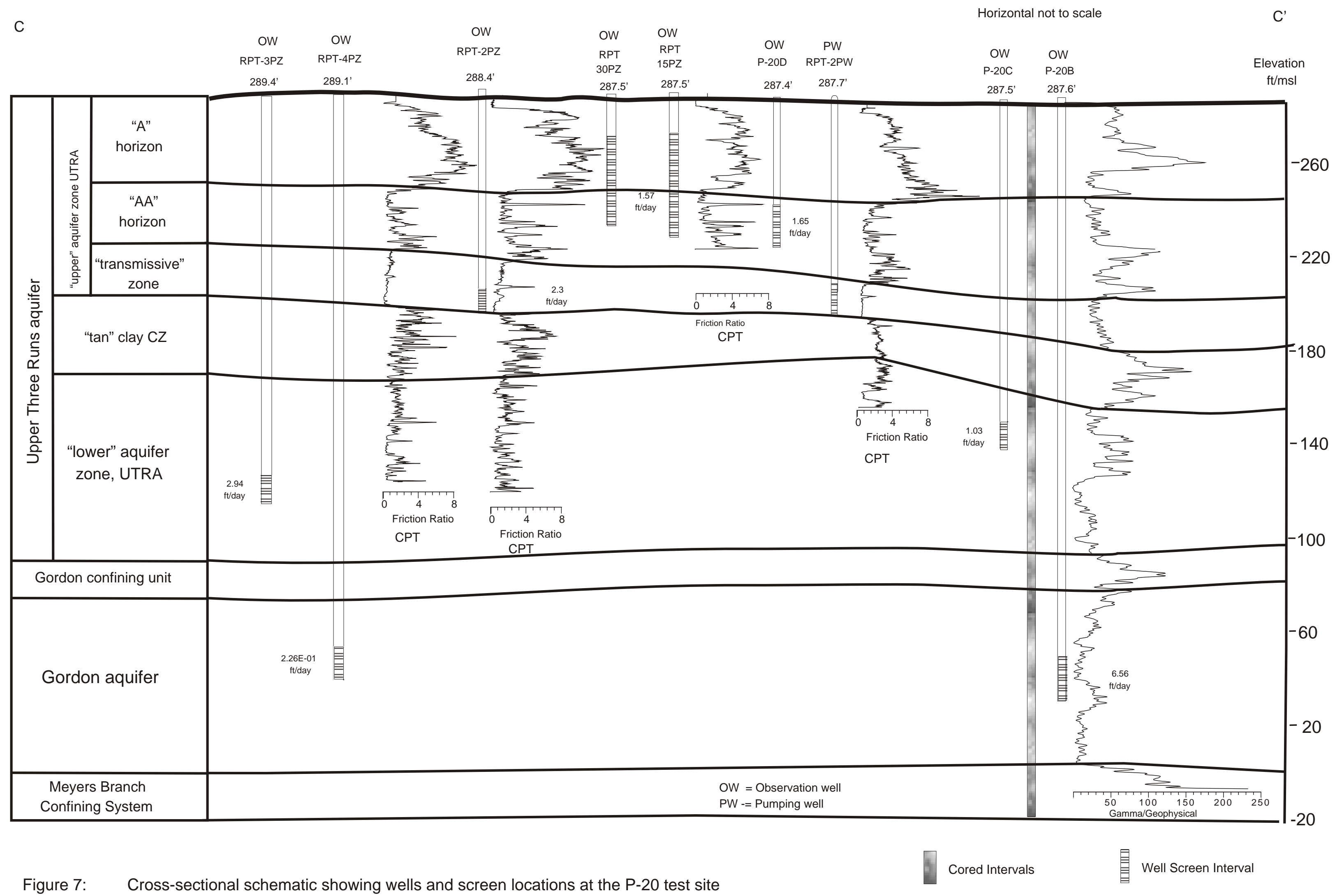


WSRC-TR-00-00180, Rev. 0

R-Area Aquifer Tests

This Page Intentionally Left Blank 
WSRC-TR-2000-00180, Rev. 0

R-Area Aquifer Tests

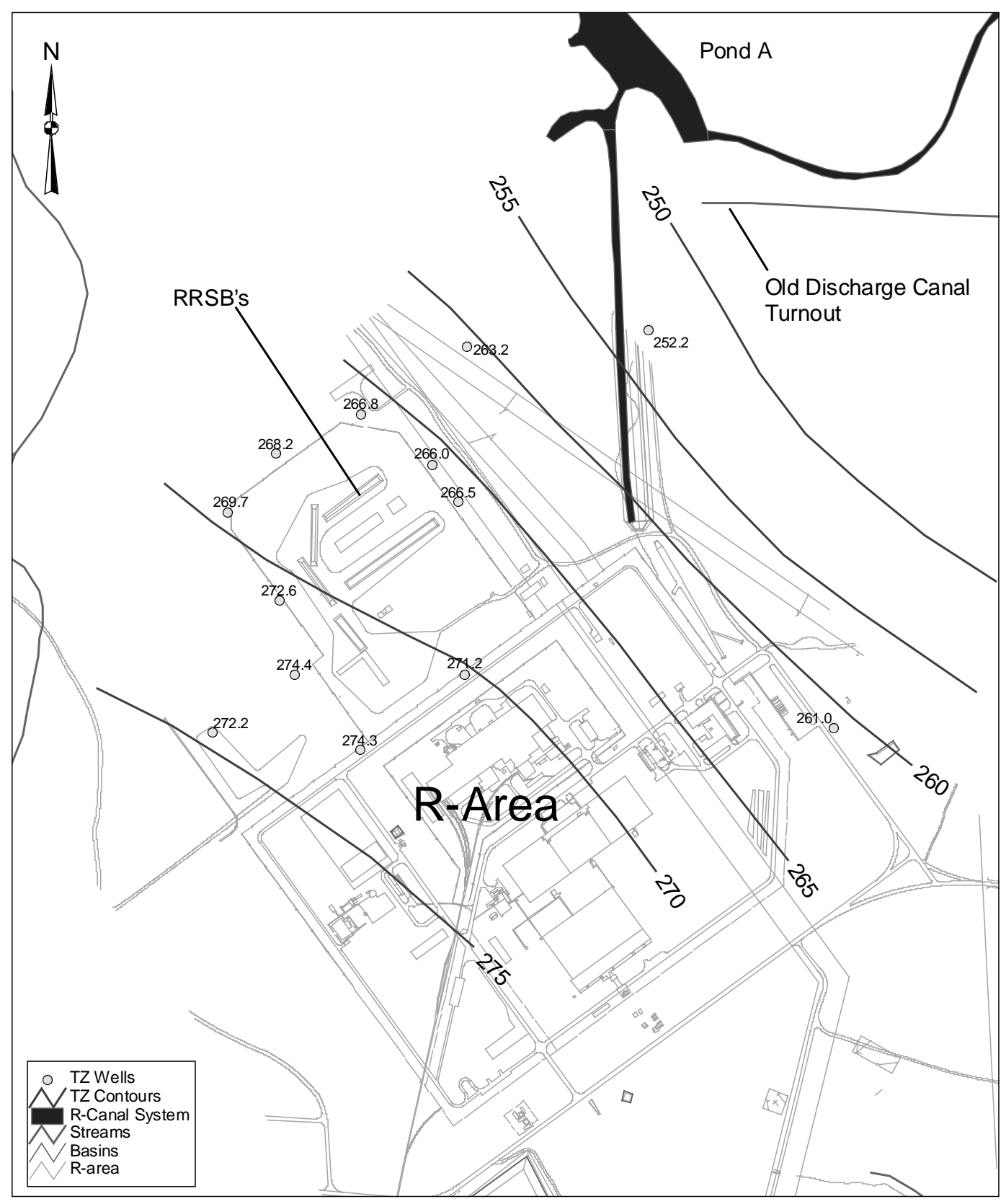

Transmissive Zone Potentiometric Surface - January, 2000

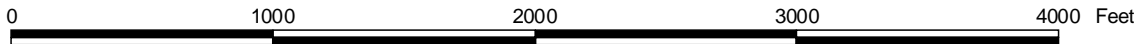

Figure 8: $\quad$ Transmissive Zone Potentiometric Surface in $R$ Area (Jan. 2000) 
WSRC-TR-00-00180, Rev. 0

R-Area Aquifer Tests

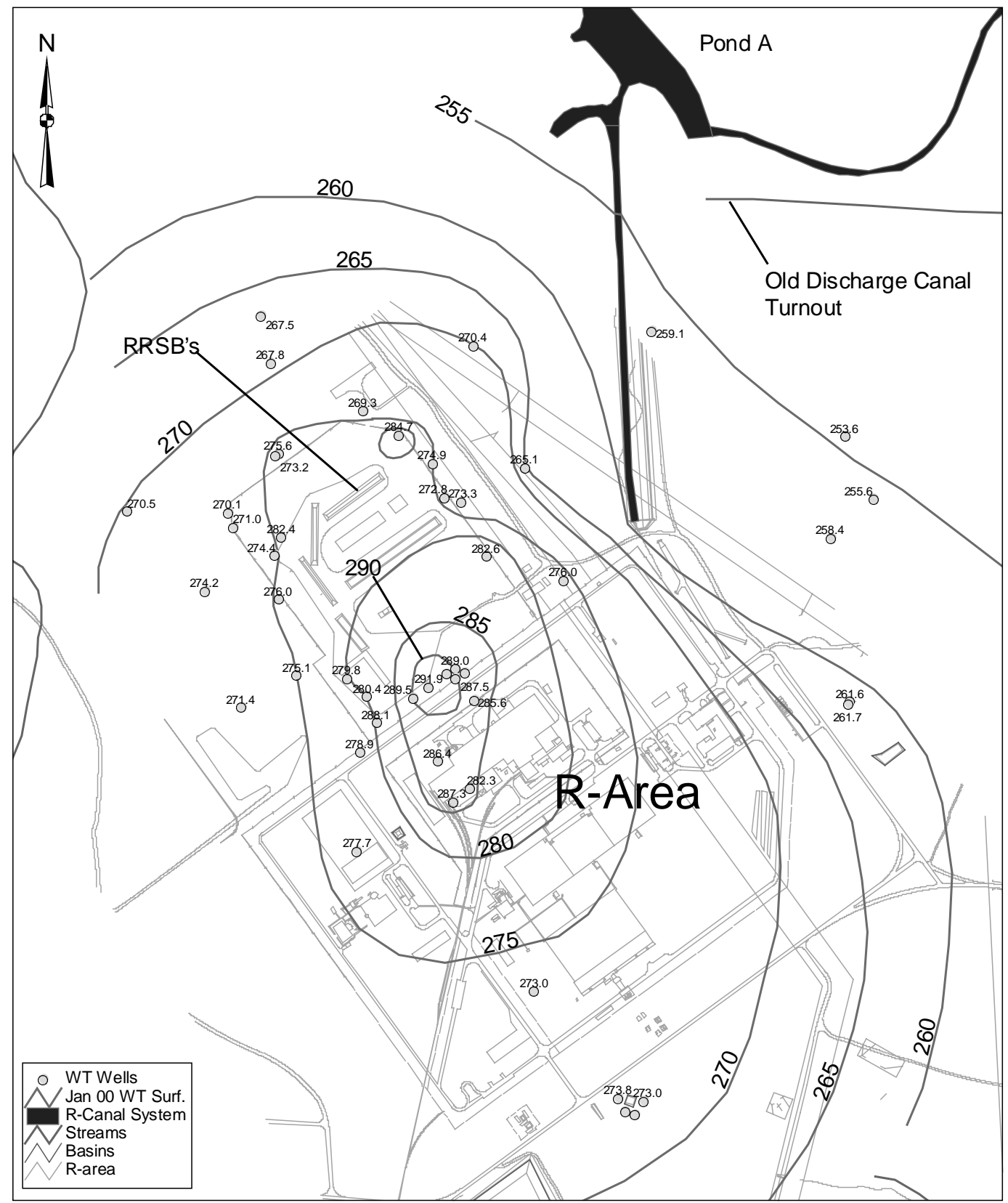

Water Table Configuration - January, 2000

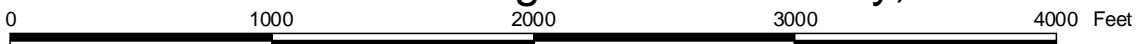

Figure 9: $\quad$ Water Table Surface in R Area (Jan. 2000) 
WSRC-TR-2000-00180, Rev. 0

R-Area Aquifer Tests

\subsection{WELL INSTALLATION AND TESTING}

\subsection{Well Installations}

Cone penetrometer (CPT) work was conducted at the RPT and RPC aquifer test sites to acquire hydrogeologic data needed for aquifer test well installations. This work was conducted from March through October 1999. Later, additional CPT work was performed in October. Well installations began in September in ended in early December 1999. Activities included well installations, but also well development and well testing. Well installation and development activities are described in detail in WSRC-RP-20004058, Field Summary Report for Installation of Pumping and Observation Wells in RArea. A brief summary of activities is presented here.

Field activity to install wells occurred between September 1 and December 7, 1999. Drilling services were provided by Alliance Environmental Drilling, Inc. while the technical oversight was provided by Duke Engineering \& Services. Wells were initially installed at the RPT site, and then at the RPC site. CPT and borehole geophysical logs were used to make final determination of well screen elevations. For wells installed in aquifer units beneath the TCCZ and the GCU steel surface casing was installed. This casing extended from the land surface and penetrated into the respective confining units, prior to installation of the lower part of each well in the targeted aquifer unit. These wells include RPT-3PW, RPT-3PZ, RPT-4PW, RPT-4PZ, RPC-3PW and RPC-3PZ.

Difficulties with "lost circulation" were experienced at the RPC site in the upper portion of the LUTRA. At both RPC-3PW and RPC-3PZ standard rotary drilling could not maintain normal re-circulation of drilling mud in the LUTRA and all further attempts to complete the wells with this drilling methodology had to be abandoned. Rotosonic drilling methodology was later employed to complete well installations in this aquifer unit.

The well construction details for all wells utilized to conduct the aquifer tests at R-Area, including the newly installed wells, are presented below in Table 1. The information presented includes the well coordinates (SRS system), the distance between observation 
WSRC-TR-00-00180, Rev. 0

wells and associated pumping wells, and the elevations of the land surface, the top of casing, and the tops and bottoms of the well screen zones.

\begin{tabular}{|c|c|c|c|c|c|c|c|c|c|}
\hline $\begin{array}{l}\text { Well } \\
\text { Name }\end{array}$ & $\begin{array}{l}\text { Well } \\
\text { Type }\end{array}$ & $\begin{array}{c}\text { Surveyed } \\
\text { SRS E }\end{array}$ & $\begin{array}{c}\text { Coordinates } \\
\text { SRS N }\end{array}$ & $\begin{array}{c}\begin{array}{c}\text { Distance } \\
\text { to }\end{array} \\
\text { Pumping } \\
\text { Well (ft.) }\end{array}$ & $\begin{array}{c}\text { Well } \\
\text { Diam. } \\
\text { (in.) }\end{array}$ & $\begin{array}{l}\text { Surface } \\
\text { Elevation }\end{array}$ & $\begin{array}{l}\text { Elev. } \\
\text { TOC }\end{array}$ & $\begin{array}{l}\text { Elev. } \\
\text { Top Sz }\end{array}$ & $\begin{array}{c}\text { Elev. } \\
\text { Bot. Sz. }\end{array}$ \\
\hline RPT-4PW & Pump & 76566.26 & 56106.15 & & 6 & 287.5 & 289.7 & 56.1 & 16.1 \\
\hline RPT-4PZ & Obs. & 76558.8 & 55934.97 & 171.3 & 2 & 289.1 & 291.33 & 53.7 & 43.8 \\
\hline P-20B & Obs. & 76816.7 & 56081.7 & 251.6 & 4 & 287.6 & 289.3 & 48.1 & 28.1 \\
\hline RPT-3PW & Pump & 76565.66 & 56127.15 & & 4 & 287.6 & 289.8 & 138.6 & 98.6 \\
\hline RPT-3PZ & Obs. & 76553.27 & 55956.27 & 171.3 & 2 & 289.4 & 289.4 & 125.4 & 115.4 \\
\hline P-20C & Obs. & 76814 & 56067.7 & 255.4 & 4 & 287.5 & 288.9 & 148 & 138.0 \\
\hline RPT-2PW & Pump & 76789.92 & 56089.13 & & 4 & 287.7 & 289.9 & 209.6 & 194.7 \\
\hline RPT-2PZ & Obs. & 76653.72 & 56001.02 & 162.2 & 2 & 288.4 & 290.8 & 206.4 & 196.4 \\
\hline RPT-30PZ & Pump & 76753.77 & 56067.92 & & 2 & 287.5 & 289.7 & 272.5 & 232.5 \\
\hline RPT-15PZ & Obs. & 76769.05 & 56069.52 & 15.4 & 2 & 287.5 & 289.7 & 272.5 & 227.5 \\
\hline P-20D & Obs. & 76784.5 & 56075.2 & 31.6 & 4 & 287.4 & 289.1 & 244.4 & 225.4 \\
\hline RPC-1PW & Pump & 74187.63 & 57938.27 & & 2 & 305.2 & 307.6 & 285.7 & 270.7 \\
\hline RPC-1PZ & Obs. & 74171.38 & 57936.93 & 16.3 & 2 & 305.6 & 307.8 & 285.6 & 270.6 \\
\hline RPC-2PR & Pump & 74150.35 & 57942.83 & & 4 & 305.9 & 307.9 & 270.9 & 230.9 \\
\hline RPC-1TR & Obs. & 73976.1 & 57918.93 & 175.9 & 2 & 309 & 311.5 & 260 & 240 \\
\hline RPC-9DL & Obs. & 74507.87 & 57908.37 & 359.2 & 2 & 301.4 & 303.9 & 226.4 & 216.4 \\
\hline RPC-3PW & Pump & 74069.58 & 57913.93 & & 4 & 307.6 & 309.1 & 202.6 & 162.6 \\
\hline RPC-3PZ & Obs. & 73940.63 & 57736.65 & 219.2 & 2 & 309.2 & 311.4 & 189.2 & 179.2 \\
\hline RPC-1CL & Obs. & 74261.9 & 57923.3 & 192.5 & 2 & 304.3 & 306.8 & 113.3 & 103.3 \\
\hline
\end{tabular}

Table 1: Well Information for aquifer tests conducted at R-Area

Pumping well screens in the LUTA and Gordon aquifers (RPT-4PW, RPT-3PW and RPC-3PW) are not fully penetrating, however an attempt was made to place the screen sections in the center of the aquifers. This relationship is illustrated in Figures 4-6, the cross-sections of the hydrogeologic conditions at each test site. An exception to this was RPC-3PW, which has its screen positioned in the upper part of the aquifer. For these wells, the gravel pack material surrounding the screen was back-filled to extend upward to the base of the overlying confining unit. The rationale for this was to minimize any 
partial penetration effects. The pumping wells finished in the TZ (RPT-2PW and RPC2PR) both have screens that fully penetrate the aquifer unit. This was possible because the TZ thickness is considerably less than the two deeper aquifers. Likewise, the overlying A/AA pumping wells (RPT-30PZ and RPC-1PW) were installed to have their screen zones more fully penetrate the water table aquifer.

Observation wells installed in the LUTRA and Gordon Aquifer were constructed with shorter screen lengths of 10 feet and were placed in a vertical position that fit entirely within the screen length of the pumping well for those aquifers. These wells (RPT-4PZ, RPT-3PZ andRPC-3PZ) are all located sufficiently far away from the associated pumping well in the same aquifer that partial penetration effects are not a factor. Observation wells finished in the TZ also were constructed to have their screen placed in a vertical position that fit within the screen lengths of the associated pumping wells. The two TZ observation wells, RPC-1TR and RPT-2PZ, have screen lengths of 10 and 20 feet and are situated in a vertical position that is adjacent to the associated pumping wells. These wells are more fully penetrating of the $\mathrm{TZ}$ than are observation wells of the LUTRA and GA and are sufficiently far away from the pumping wells that partial penetration effects are not a factor. Observation wells finished in the A/AA Horizon have longer screen sections and to fully-penetrate the water table aquifer. Well spacing for these wells had to be closer to the pumping wells due to the expected conditions of lower hydraulic conductivity material.

\subsection{Well Development and preliminary testing}

Well development was performed on all pumping and observation wells following installation. The general process involved an initial airlift to remove the heavy drilling fluid, mud and sand. Following this, the wells were developed by alternatively swabbing and pumping. This was accomplished by lowering a pump into the well and purging at the maximum achievable rate. After periods of purging, the pump was removed and a swab inserted into the well and the swabbing action performed over the entire length of the screen. A surfactant (Barafos) was added to the wells during the swabbing process to enhance the removal of clay and colloidal materials from the aquifer material immediately surrounding the well screens. Following these activities, each well was 
WSRC-TR-00-00180, Rev. 0

pumped until the field parameters ( $\mathrm{pH}$, temperature, specific conductance, and turbidity) stabilized.

After each well was developed, well tests were conducted at each of the pumping wells to determine the maximum pumping rate that could be achieved with the selected pump. This work was conducted between November 2 and November 23, 1999. Each well test involved obtaining measurements of the depth to the water level in the pumping well as it was being pumped as well as the discharge rate. These parameters were acquired to calculate the specific capacity $(\mathrm{Q} / \mathrm{s})$ for each well. Only in one well, RPC-3PW, was this not possible, owing to an inability to insert an electric tape into the well while the pump was installed. Well pumping rates were estimated by filling a container of known volume with water being purged from the well and timing how long it took to fill this container with a stopwatch. Table 2 below summarizes the well testing information.

\begin{tabular}{|l|c|c|c|c||}
\hline \hline Well & Date Tested & Flow Rate (gpm) & Duration (hrs) & Q/s (gpm/ft) \\
\hline & & & & \\
\hline RPT-4PW & $11 / 4 / 99$ & 44.7 & 4 & 0.97 \\
\hline RPT-3PW & $11 / 8 / 99$ & 37.9 & 3 & 0.46 \\
\hline RPT-2PW & $11 / 9 / 99$ & 5.9 & 2.5 & 0.12 \\
\hline RPT-30PZ & $11 / 23 / 99$ & 3.04 & 2.5 & 0.2 \\
\hline RPC-3PW & $11 / 19 / 99$ & 50.3 & 4.5 & Not available \\
\hline RPC-2PR & $11 / 22 / 99$ & 21.2 & 2 & 0.83 \\
\hline
\end{tabular}

Table 2: Results of initial pumping well evaluations.

\subsection{Instrumentation and Conducting of Tests}

Work to instrument and conduct a multiple-well aquifer test at each pumping well location was performed between December 1, 1999 and February 16, 2000. Instrumentation for each aquifer test included the following: 
- installation of a submersible pump in the pumping well,

- configuration of the well head such that a flow meter was installed on the discharge line,

- extending the discharge line to the water disposal point, and

- installing transducers in each of the primary and secondary observation wells selected to monitor hydraulic responses

Tests were conducted in such a fashion as to be consistent with the general guidance for conducting aquifer tests as presented in ASTM 4050, Standard Test Method for Withdrawal and Injection Well Tests for Determining Hydraulic Properties of Aquifer Systems.

The aquifer test at RPT-4PW was conducted on December 13, 1999. Pumping was initiated at 11:00 am and continued until December 15 at 1:47 am. The average pumping rate was 43.2 gallons per minute. Hydraulic responses to pumping were recorded automatically in primary observation wells RPT-4PZ and P-20B and secondary observation wells RPT-3PW and P-20C. Measurements were obtained using pressure transducers and data loggers and additional measurements were periodically obtained manually using an electric tape. Water levels were also monitored in the other distinct phases of the test, the antecedent period and the recovery period. The antecedent period began on December 10, 1999 at 2:12 p.m. and continued until the commencement of pumping. The recovery period began at the time pumping ceased and continued until December 16, 1999 at 1:00 p.m. Pumping pre-maturely terminated after 37.9 hours as the result of the circuit breaker tripping on the portable generator at a time when the test was unattended in the middle of the night. The data logger was pre-programmed to capture frequent measurements in the event that water levels should begin to change rapidly, hence the recovery of water levels was adequately characterized following the cessation of pumping. The aquifer test was not repeated since preliminary examination of the drawdown date at that time indicated that reliable estimates of hydraulic parameters were attainable with the recorded data. 
The aquifer test at RPT-3PW was conducted on January 10, 2000. Pumping was initiated at 12:00 p.m. on that day and continued until 10:40 am on January 13, a period of 71.7 hours. The average pumping rate was determined to be 42.7 gallons per minute. Hydraulic responses to pumping were recorded automatically in primary observation wells RPT-3PZ and P-20C and secondary observation wells RPT-2PW and RPT-2PZ. Measurements were obtained using pressure transducers and data loggers and additional measurements were periodically obtained manually using an electric tape. Water levels were also monitored in the other distinct phases of the test, the antecedent period and the recovery period. The antecedent period began on January 7, 2000 at 3:54 p.m. and continued until the commencement of pumping. The recovery period began at the time pumping ceased and continued until January 14, 2000 at 3:28 p.m.

The aquifer test at RPT-2PW was conducted on December 6, 1999. Pumping was initiated at 11:00 am on that day and continued until 12:00 p.m. on December 8, 1999, a period of 49 hours. The average pumping rate was determined to be 5.7 gallons per minute. Hydraulic responses to pumping were recorded automatically in primary observation wells RPT-2PZ and secondary observation wells P-20C, P-20D and RPT30PZ. Measurements were obtained using pressure transducers and data loggers and additional measurements were periodically obtained manually using an electric tape. Water levels were also monitored in the other distinct phases of the test, the antecedent period and the recovery period. The antecedent period began on December 2 at 3:44 p.m. and continued until the commencement of pumping. The recovery period began at the time pumping ceased and continued until December 10, 2000 at 9:06 am.

The aquifer test at RPT-30PZ was conducted on January 3, 2000. Pumping was initiated at 11:00 am on that day and continued until 3:01 p.m. on January 5, 2000, a period of 52 hours. The average pumping rate was determined to be 3.3 gallons per minute. Hydraulic responses to pumping were recorded automatically in primary observation wells P-20D and RPT-15PZ and secondary observation well RPT-2PW. Measurements were obtained using pressure transducers and data loggers and additional measurements were periodically obtained manually using an electric tape. Water levels were also monitored in the other distinct phases of the test, the antecedent period and the recovery 
period. The antecedent period began on December 22 at 12:52 p.m. and continued until the commencement of pumping. The recovery period began at the time pumping ceased and continued until January 7, 2000 at 2:00 p.m.

The aquifer test at RPC-3PW was conducted on January 31, 2000. Pumping was initiated at 12:00 p.m. on that day and continued until 12:00 p.m. on February 3, 2000, a period of 72 hours. The average pumping rate was determined to be 59.2 gallons per minute. Hydraulic responses to pumping were recorded automatically in primary observation wells RPC-3PZ and RPC-1CL and secondary observation well RPC-9DL and RPC-1TR. Measurements were obtained using pressure transducers and data loggers and additional measurements were periodically obtained manually using an electric tape. Water levels were also monitored in the other distinct phases of the test, the antecedent period and the recovery period. The antecedent period began on January 27 at 12:27 p.m. and continued until the commencement of pumping. The recovery period began at the time pumping ceased and continued until February 8, 2000 at 12:00 p.m.

The aquifer test at RPC-2PR was conducted on January 18, 2000. Pumping was initiated at 10:00 am on that day and continued until 10:00 am on January 21, 2000, a period of 72 hours. The average pumping rate was determined to be 21.2 gallons per minute. Hydraulic responses to pumping were recorded automatically in the primary observation well RPC-1TR and also in the secondary observation wells RPC-1PZ, RPC-1CL and RPC-1PW. Measurements were obtained using pressure transducers and data loggers and additional measurements were periodically obtained manually using an electric tape. Water levels were also monitored in the other distinct phases of the test, the antecedent period and the recovery period. The antecedent period began on January 14 at 4:08 p.m. and continued until the commencement of pumping. The recovery period began at the time pumping ceased and continued until January 24, 2000 at 9:54 am. A second test was conducted to monitor hydraulic responses in RPC-9DL. This test was conducted on February 14, 2000 when pumping in RPC-2PR was initiated. Pumping continued until 9:02 on February 15, 2000, a period of 22.5 hours. Water levels were monitored in the recovery period, beginning at the cessation of pumping and continuing until 10:06 am on February 16, 2000. Water levels were not monitored immediately before the start of 
WSRC-TR-00-00180, Rev. 0

R-Area Aquifer Tests

pumping at RPC-2PR. The primary purpose for this test was to qualitatively determine if a distinct drawdown and recovery could be observed to occur in response to pumping in RPC-2PR and not to define curves from which hydraulic parameters could be calculated. Hence, antecedent water levels were not needed to identify pre-test trends or select a barometric efficiency for that well.

A summary of the tests performed as a part of this investigation is provided below in Table 3. This table includes a listing of primary and secondary observation wells associated with each pumping well. Also included is the beginning and ending date and time of each monitoring period associated with each of the tests. 


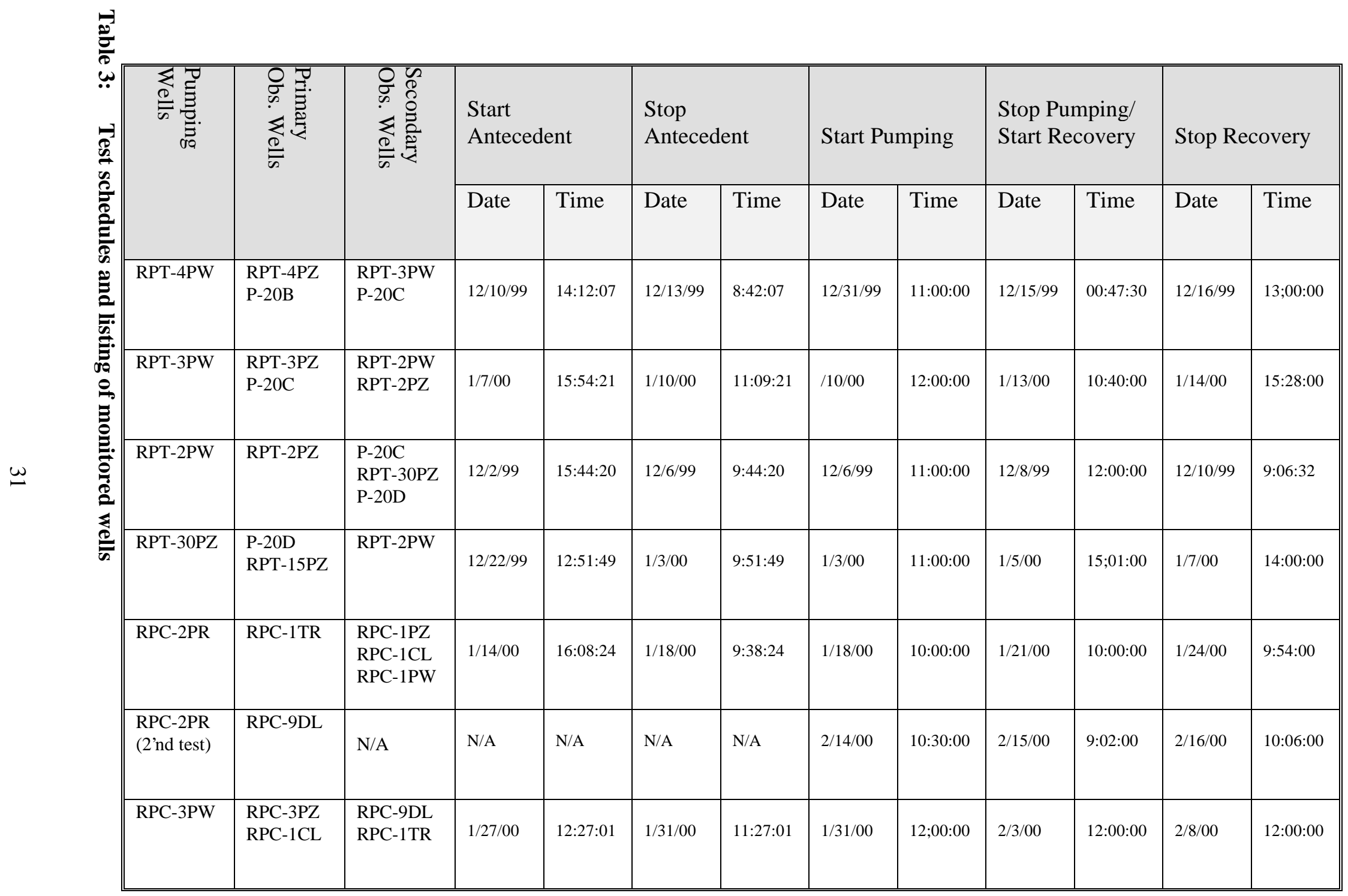


WSRC-TR-00-00180, Rev. 0

R-Area Aquifer Tests

This Page Intentionally Left Blank 


\subsection{DATA ANALYSIS}

The initial field data acquired during aquifer testing requires extensive processing in order to perform the subsequent data analysis for hydraulic properties. The steps of the electronic processing of initial field data are described below.

\subsection{Normalization of Data}

Normalization of the acquired data refers primarily to the standardization of measurements with respect to time. Initially, before each test, the laptop computer used to program the data loggers was synchronized with the wristwatch of the test director. The laptop was then used to synchronize the clocks of each data logger utilized to acquire measurements during the test. Following completion of the test, the data logger clocks were compared against one another and against the test director's wristwatch. In all cases the instruments varied less than a few tens of seconds from one another at the termination of monitoring activities. This level of accuracy is considered adequate for the purposes of parameter calculation.

In addition to synchronized clocks, different phases of the test were monitored with different recording algorithms on the data loggers, resulting in the creation of separate files. These files were later appended to one another such that continuous graphs could be created of water levels, from the beginning of the antecedent period to the end of the recovery phase. Time measurements were then normalized in these files by setting the time at the beginning of the pumping period equal to zero. Time measurements obtained prior to the start of pumping are reported as negative values while time measurements obtained after the start of pumping are reported as positive values.

\subsection{Data correction for Atmospheric Pressure variation}

Changes in atmospheric pressure (or barometric pressure) typically produce slight changes in water levels in wells. Corrections were made to the raw measurements of water level obtained at the time of each aquifer test using the following equation (Ferris, et al., 1962)

$$
\Delta \mathrm{WL}=(\mathrm{BE}) *(\Delta \mathrm{Bp}) / 100
$$


In this equation

$\Delta \mathrm{WL}=$ the change in water level relative to the reference water level

$\Delta \mathrm{Bp}=$ the change in barometric pressure relative to the reference barometric pressure,

$\mathrm{BE}=$ the barometric efficiency of the well,

where, by definition, $\mathrm{BE}=(\Delta \mathrm{WL}) *(100) /(\Delta \mathrm{Bp})$

This relationship was applied to the uncorrected water level measurements in an Excel spreadsheet to obtain a new water level that was compensated for the changes in atmospheric pressure that occurred during the tests. An optimal BE was selected for each well, based on repetitive visual examination of the well hydrographs to evaluate the effectiveness of different BE's in creating a smoother hydrograph. Corrected water levels were later used to perform the calculations of hydraulic parameters.

The atmospheric pressure measurements required to make the water level corrections were obtained during each test with a pressure transducer mounted within the Hermit 3000 data logger. One or more Troll data loggers were also utilized during each test to monitor water levels in individual wells, however these did not have the ability to monitor atmospheric pressure. Since different data capture frequencies were employed in the different data loggers, atmospheric pressure measurements could not be directly utilized for correcting water level measurements obtained with Troll data loggers. To obtain atmospheric pressure readings at the time of each Troll measurement, a Microsoft Excel program was employed to interpolate atmospheric pressures readings obtained in the Hermit 3000 to the appropriate Troll recording times.

\subsection{Quality Control}

Instruments utilized in the performance of the aquifer tests were calibrated at the SRTC Calibrations Laboratory prior to their use to acquire field measurements. All of the pressure transducers were calibrated relative to pressures that were applied to them. In addition, the volume container used to measure pumping rates during the field tests was calibrated by the SRTC Calibrations Laboratory. 
Once instruments were deployed to the field, a check of the transducers was performed by lowering the transducer cable a measured distance and observing the change in water level detected by the transducer. These field checks indicated that all transducers employed for monitoring water levels performed adequately.

Measurements of water levels were also obtained during the aquifer tests using electric tapes. These measurements were obtained to validate the water level measurements obtained from pressure transducers in primary and secondary observation wells during drawdown and recovery phases of each test. For each test, the drawdowns calculated from both the electric tape and transducer measurements track extremely close together when plotted together on graphs. This correspondence validates the accuracy of measurements obtained with the pressure transducers.

With regard to pumping rates, measurements were obtained during each test. Redundant measurements were obtained by different methodologies, thus serving as a check of one another. The primary method of measuring pumping rates was by use of an online flow meter. The second measurement methodology was to fill a calibrated vessel with water from the discharge line and determining how long it took to fill the vessel. Measurements obtained from both methods corresponded closely to one another. These measurements are presented for each test in Appendix C and D.

\subsection{Pumping Test Flow Rates}

Flow rates were monitored by two different methods during aquifer testing. An online totalizing flow meter was use to periodically record readings while a calibrated vessel was periodically filled using the discharge line and a stopwatch used to time how long it took to fill the vessel.

For all tests, flow rates from flow meter measurements varied by less than $\pm 5 \%$ of the average rate obtained during each of the tests. Flow rate measurements obtained using the calibrated vessel varied by less than $\pm 2.5 \%$ for tests conducted at RPT- 4 PW, RPT30PZ, RPC-2PR, and RPC-3PW. However, flow rates measured with this method during tests at RPT-3PW and RPT-2PW had flow rate variations that were slightly higher. 
Flow rates obtained by filling the vessel varied by approximately $\pm 8 \%$ of the average flow rate during the RPT-3PW test. The higher variability was caused by the two highest measurements, both obtained in the first hour of the test, and the two lowest measurements which were obtained using improper measurement techniques. The latter measurements were eliminated from the variability calculation, resulting in the variability being reduced to be $\pm 5 \%$ of the average flow rate. This level of variability is regarded as acceptable.

Flow rates obtained by filing the vessel during testing at RPT-2PW varied by $\pm 13 \%$, compared to the variability of $\pm 4 \%$ obtained from flow meter derived measurements for this test. The higher degree of variability was caused by adjustments made to the flow rate early in the test (in the first 183 minutes of the 2880-minute test) in an effort to stabilize the dynamic pumping level several feet above the pump. The flow rate was much steadier after this initial period. Another factor that contributes to the apparently high flow rate variability is that the average flow rate of this test was a relatively low 5.7 gpm. As a result, all variations were calculated to be a much larger percentage of the average flow compared to the other tests, which had higher pumping rates and lower flow rate variability. Because the major variations in flow rate occurred in the first 183 minutes of the test and because the flow rate was much steadier during the remaining 2700 minutes, the level of variability is regarded as acceptable.

\subsection{Water Level Responses at Observation Wells}

Water levels were monitored in primary observation wells (screened in the target aquifer) and in secondary observation wells (screened in adjacent aquifers). Hydraulic responses observed in primary observation wells were used to calculate hydraulic parameters while responses observed in secondary observation wells were used to qualitatively assess the degree of hydraulic communication between adjacent aquifers. Hydrographs from all wells monitored during each test are illustrated on schematic diagrams of the hydrostratigraphic layers in Figures 10 through16, located at the end of this chapter. These diagrams are useful in illustrating the relative degree of hydraulic 
connection between adjacent aquifers. Responses observed in primary observation wells are described in detail in the following sections.

\subsubsection{RPT-4PW test wells}

Monitoring of water levels for the RPT-4PW test began on 12/10/99 when antecedent water levels were recorded in the primary and secondary observation wells. Monitoring continued until 12/16/99 when monitoring of water level recoveries following pumping was completed. Hydrographs of the RPT-4PZ and $\mathrm{P}-20 \mathrm{~B}$ are presented in Appendix E illustrating the antecedent, pumping and recovery phases of the test. The antecedent period lasted 67 hours, followed by a pumping period of nearly 38 hours and recovery periods of 7.3 hours (RPT-4PZ) and 36 hours (P-20B). In both wells the antecedent water levels varied very little, affected only by changes in atmospheric pressure. Following the commencement of pumping, water levels in both wells declined rapidly at first, then continued to decline at a decreasing rate. The maximum drawdown observed was approximately 2.5 feet in RPT-4PZ and 2.3 feet in P-20B. In P-20B, water levels recovered to within 0.2 feet of the pre-pumping water level.

\subsubsection{RPT-3PW test wells}

Monitoring of water levels for the RPT-3PW test began on 1/07/00 when antecedent water levels were recorded in the primary and secondary observation wells. Monitoring continued until 1/14/99 when monitoring of water level recoveries following pumping was completed. Hydrographs of the RPT-3PZ and P-20C are presented in Appendix E illustrating the antecedent, pumping and recovery phases of the test. The antecedent period lasted 67 hours, followed by a pumping period of nearly 71 hours and a recovery period of 29 hours. In both wells the antecedent water levels varied very little, affected only by changes in atmospheric pressure. Following the commencement of pumping, water levels in both wells declined rapidly at first, then continued to decline at a decreasing rate. The maximum drawdown observed was approximately 11.5 feet in RPT-3PZ and 15.5 feet in P-20C. A break of approximately 10 hours occurs in the record at P$20 \mathrm{C}$ when greater than expected drawdown caused the water level to drop below 
the transducer during the first night of the pumping period. The transducer was lowered below the water level to enable monitoring to continue. In P-20C, water levels recovered to the pre-pumping water level.

\subsubsection{RPT-2PW test wells}

Monitoring of water levels for the RPT-2PW test began on 12/02/99 when antecedent water levels were recorded in the primary and secondary observation wells. Monitoring continued until 12/10/99 when monitoring of water level recoveries following pumping was completed. Hydrographs of the RPT-2PZ is presented in Appendix E illustrating the antecedent, pumping and recovery phases of the test. The antecedent period lasted 90 hours, followed by a pumping period of 49 hours and recovery periods of 47 hours. The antecedent water levels varied very little, affected only by changes in atmospheric pressure. Following the commencement of pumping, water levels in RPT-2PZ declined rapidly at first, then continued to decline at a decreasing rate. The maximum drawdown observed was approximately 3.5 feet in RPT-2PZ. Water levels recovered to within 0.1 feet of the pre-pumping water level during the recovery monitoring period.

\subsubsection{RPT-30PZ test wells}

Monitoring of water levels for the RPT-30PZ test began on 12/22/99 when antecedent water levels were recorded in the primary and secondary observation wells. Monitoring continued until 1/07/00 when monitoring of water level recoveries following pumping was completed. Hydrographs of the RPT-15PZ and P-20D are presented Appendix E illustrating the antecedent, pumping and recovery phases of the test. The antecedent period lasted 309 hours, followed by a pumping period of 52 hours and recovery periods of 47 hours. In both wells the antecedent water levels varied very little, affected only by changes in atmospheric pressure. The distinct effect of atmospheric tides can be seen in this part of the hydrograph. Following the commencement of pumping, water levels in both wells declined rapidly at first, then continued to decline at a decreasing rate. The maximum drawdown observed was approximately 1.6 feet in RPT-15PZ and 1.3 feet in P-20D. In P-20D, water levels recovered to the pre-pumping water level 
WSRC-TR-2000-00180, Rev. 0

R-Area Aquifer Tests

while they recovered to within 0.1 feet of the pre-pumping level in RPC-15PZ.

\subsubsection{RPC-3PW test wells}

Monitoring of water levels for the RPC 3PW test began on 1/27/00 when antecedent water levels were recorded in the primary and secondary observation wells. Monitoring continued until 2/08/00 when monitoring of water level recoveries following pumping was completed. Hydrographs of the RPT-3PZ and RPC-1CL are presented in Appendix E illustrating the antecedent, pumping and recovery phase of the test. The antecedent period lasted 95 hours, followed by a pumping period of 72 hours and recovery periods of 120 hours. The antecedent water levels varied very little, affected only by changes in atmospheric pressure. Following the commencement of pumping, water levels in both wells declined rapidly and continued at a slightly reduced rate for the duration of the pumping period. The maximum drawdown observed was approximately 2.3 feet in RPT$3 \mathrm{PZ}$ and 2.4 feet in RPC-1CL. In both wells the water levels recovered to within 0.3 feet of the pre-pumping water level.

\subsubsection{RPC-2PR test wells}

Monitoring of water levels for the first RPT-2PR test began on 1214/00 when antecedent water levels were recorded in the primary and secondary observation wells. Monitoring continued until 1/24/00 when monitoring of water level recoveries following pumping was completed. A second test was conducted monitor water level responses in RPC-9DL. This test began on 2/14/00 when pumping was initiated and ended on 2/16/00 when monitoring of the water level recovery was completed. Hydrographs from wells PRC-1TR (first test) and RPC9DL (second test) are presented in Appendix E. In the initial test, the antecedent period lasted 90 hours, followed by a pumping period of 72 hours and recovery periods of 72 hours. In RPC-1TR the antecedent water levels varied very little, affected only by changes in atmospheric pressure. Following the commencement of pumping, water levels declined relatively rapidly at first, then continued to decline at a slower rate. The maximum drawdown observed was approximately 0.7 feet. Water levels recovered to within 0.25 feet of the initial level. For the 
second test, antecedent water levels were not monitored. The pumping period lasted nearly 22 hours followed by a recovery period of 26 hours. The maximum drawdown observed in RPC-9DL was 0.35 feet and the recovery was to within 0.15 feet of the initial water level.

\subsection{Data Analysis}

Water level responses to pumping were analyzed for all of the primary observation wells. For these wells, hydraulic responses to pumping were analyzed by comparing each drawdown curve to theoretical curves developed for particular hydrogeological settings. The analysis was primarily conducted using the software program Aqtesolv ${ }^{\mathrm{TM}}$ (Ver. 2.50.002), which was utilized to automate the curve matching process. Analyses were also conducted on the recovery data from certain wells. These analyses were conducted outside of Aqtesolv ${ }^{\mathrm{TM}}$ (Ver. 2.50.002) in Microsoft Excel spreadsheets and charts.

Specialized files for each primary observation well were prepared to accommodate the Aqtesolv $^{\mathrm{TM}}$ (Ver. 2.50.002) input format. The input format requires water level displacement (drawdown), an associated time (since the beginning of pumping) and weighting factor. Data processing for each well was performed in a Microsoft Excel spreadsheet. Fluid levels corrected for atmospheric pressure variation were utilized to calculate the amount of water level decline following the start of pumping at each test. Finally, a weighting factor was assigned to each time-drawdown measurement based upon the relative number of data points occurring within each log cycle of time on a time-drawdown graph for each well. Weighting factors are used to ensure that the automatic curve-matching algorithm in Aqtesolv ${ }^{\mathrm{TM}}$ (Ver. 2.50.002) assigns equal weight to all parts of the field curve when it matches it to an analytical curve.

In addition to time-drawdown data, specific information about the pumping well and observation well are required. This information includes the well locations, screen elevations and position within the aquifer unit, well diameters and pumping rates. This information is summarized on the Aqtesolv ${ }^{\mathrm{TM}}$ (Ver. 2.50.002) test summary reports, which are presented in the appendices of this report. 
The hydrogeologic setting for most of the tests was that of a "leaky" confined aquifer. Analytical solutions appropriate for these settings were selected for use in analyzing the field drawdown curves. The solution described by Hantush and Jacob (1955) generally provided the closest match between field drawdown curves and analytical curves. For that reason, it was selected as the most appropriate analytical model for all of the confined/leaky aquifer units that were tested. Some of the tests were under water table conditions and therefore a different analytical solution was selected for analyzing those field drawdown curves. In these cases, the analytical model described by Neuman (1974) was utilized to estimate hydraulic parameters. For the analysis of the recovery of water levels in certain wells, the analysis method described by Jacob (1963) was used to obtain estimates of field parameters. The generalized graphical method for evaluating hydraulic parameters described in Cooper and Jacob (1946) was also used for analysis of drawdown response data. 
WSRC-TR-00-00180, Rev. 0

R-Area Aquifer Tests

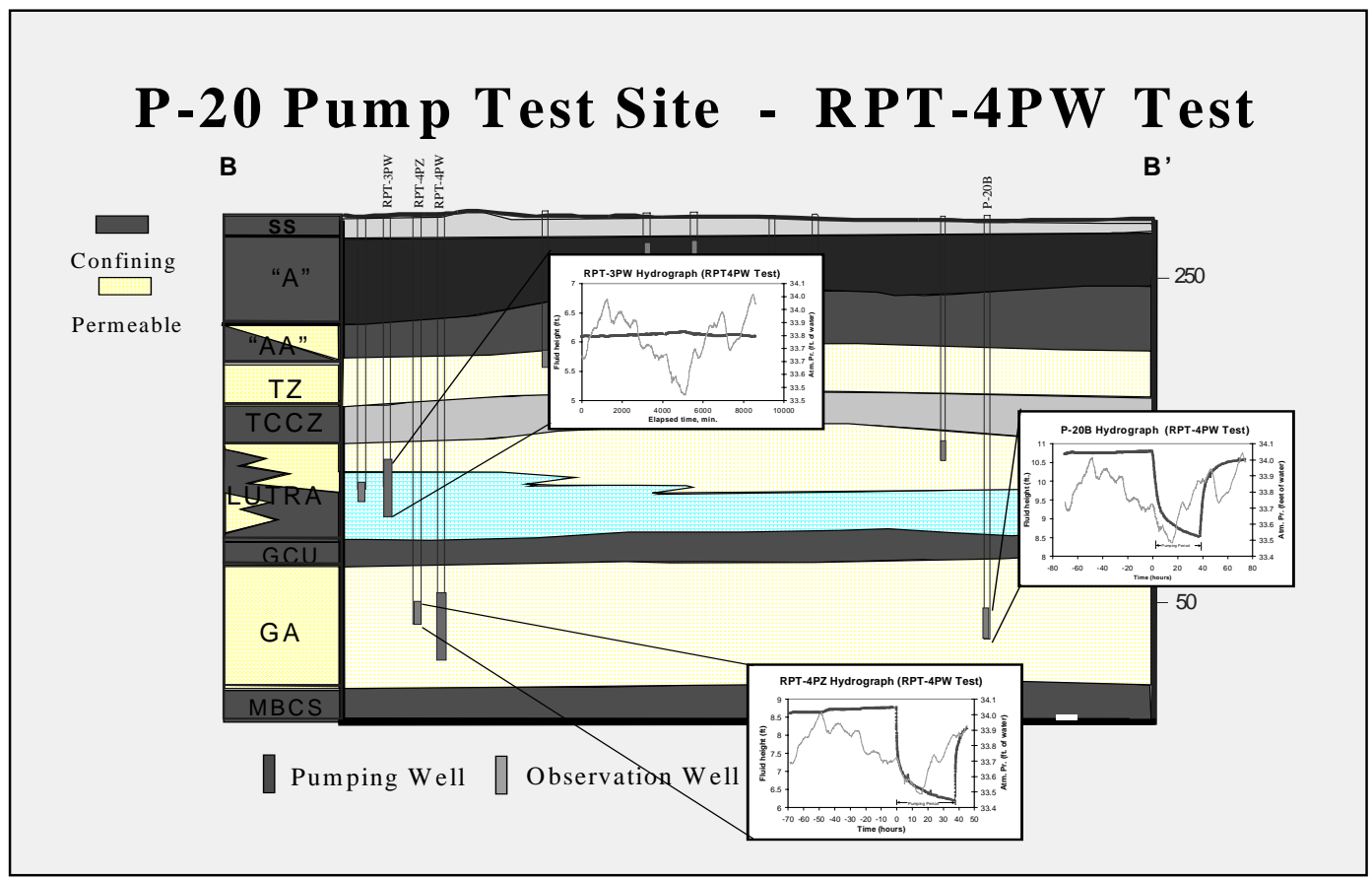

Figure 10: Hydraulic responses observed while pumping RPT-4PW

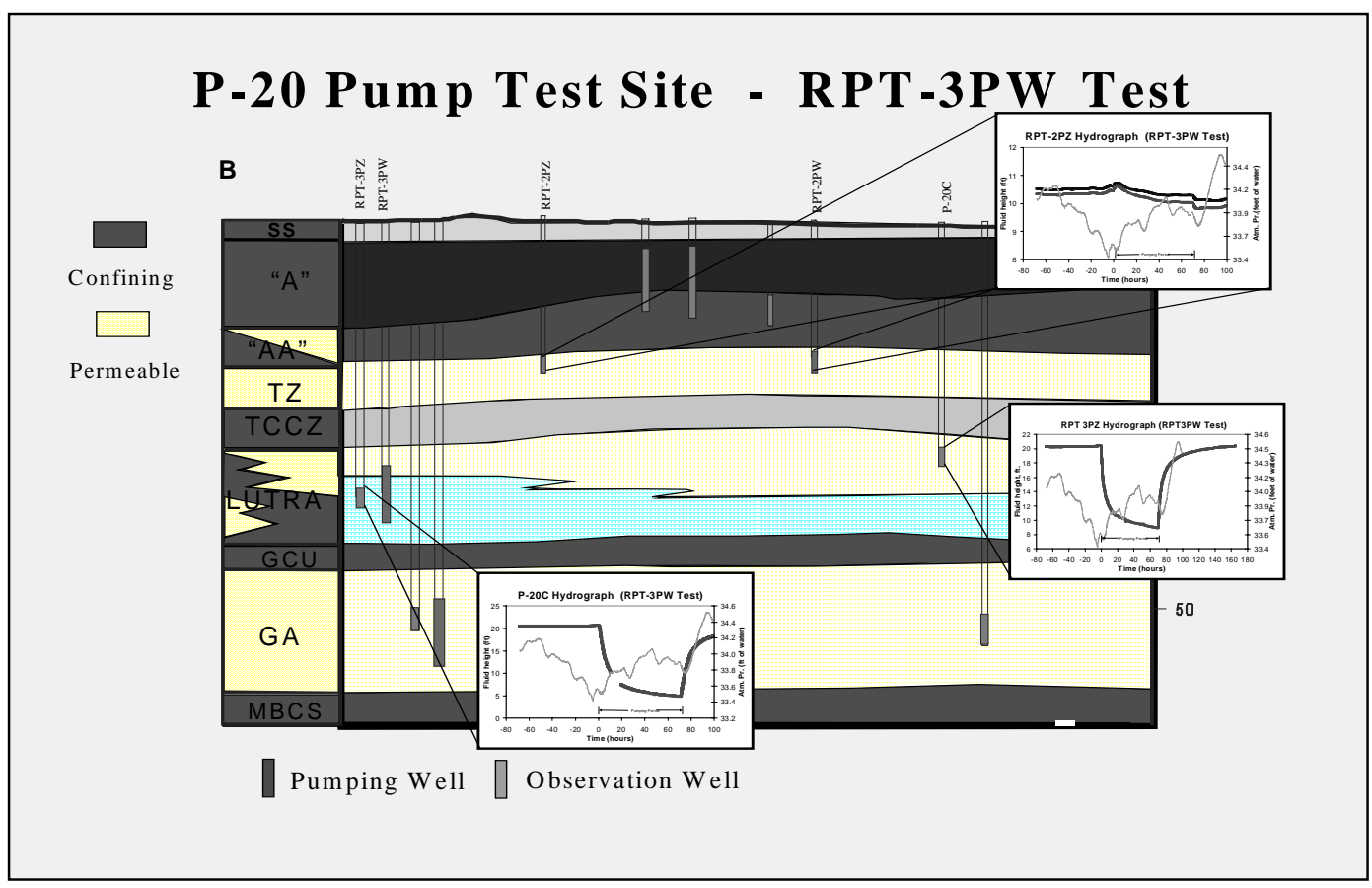

Figure 11: Hydraulic responses observed while pumping RPT-3PW 


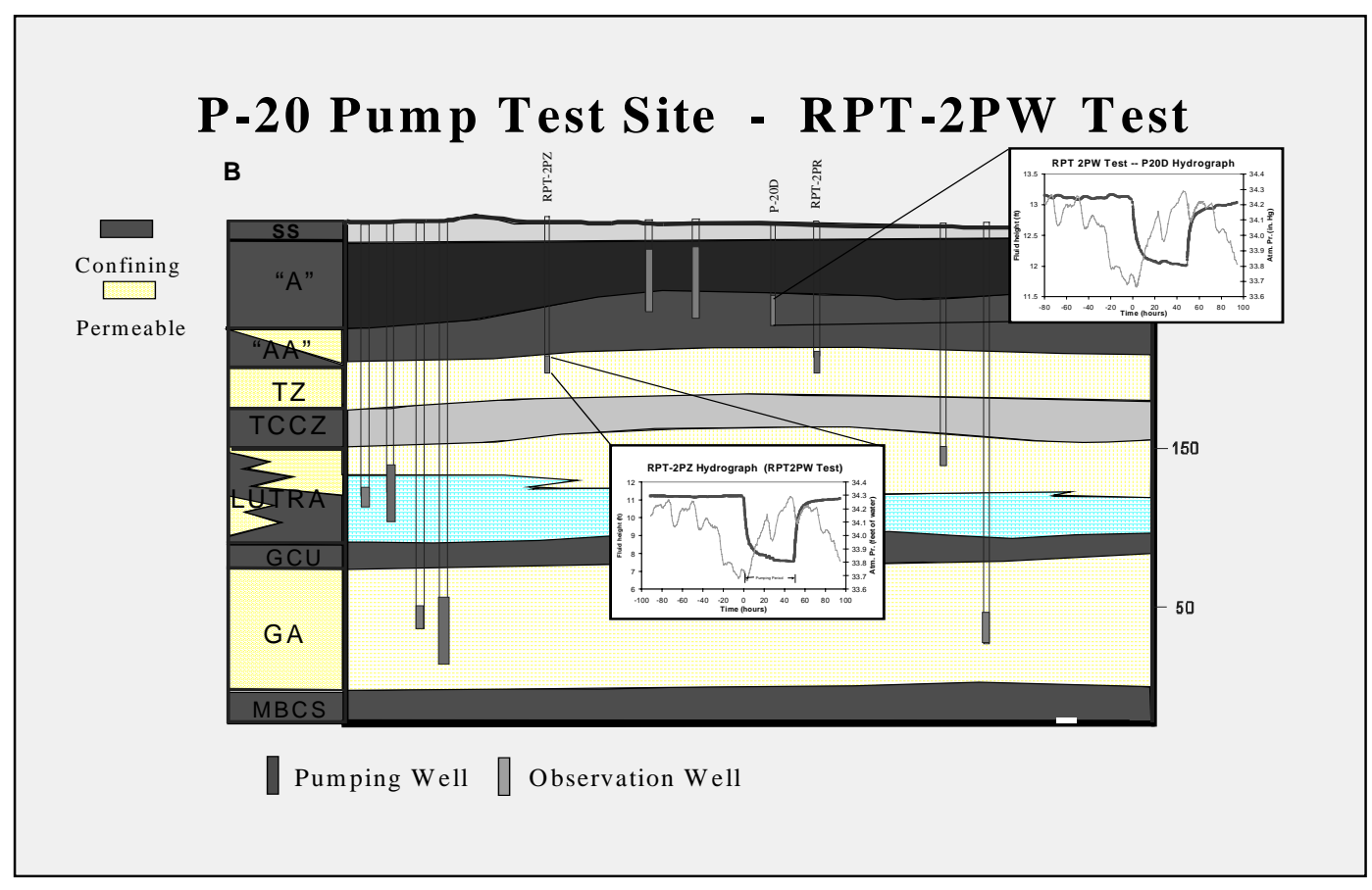

Figure 12: Hydraulic responses observed while pumping RPT-2PW

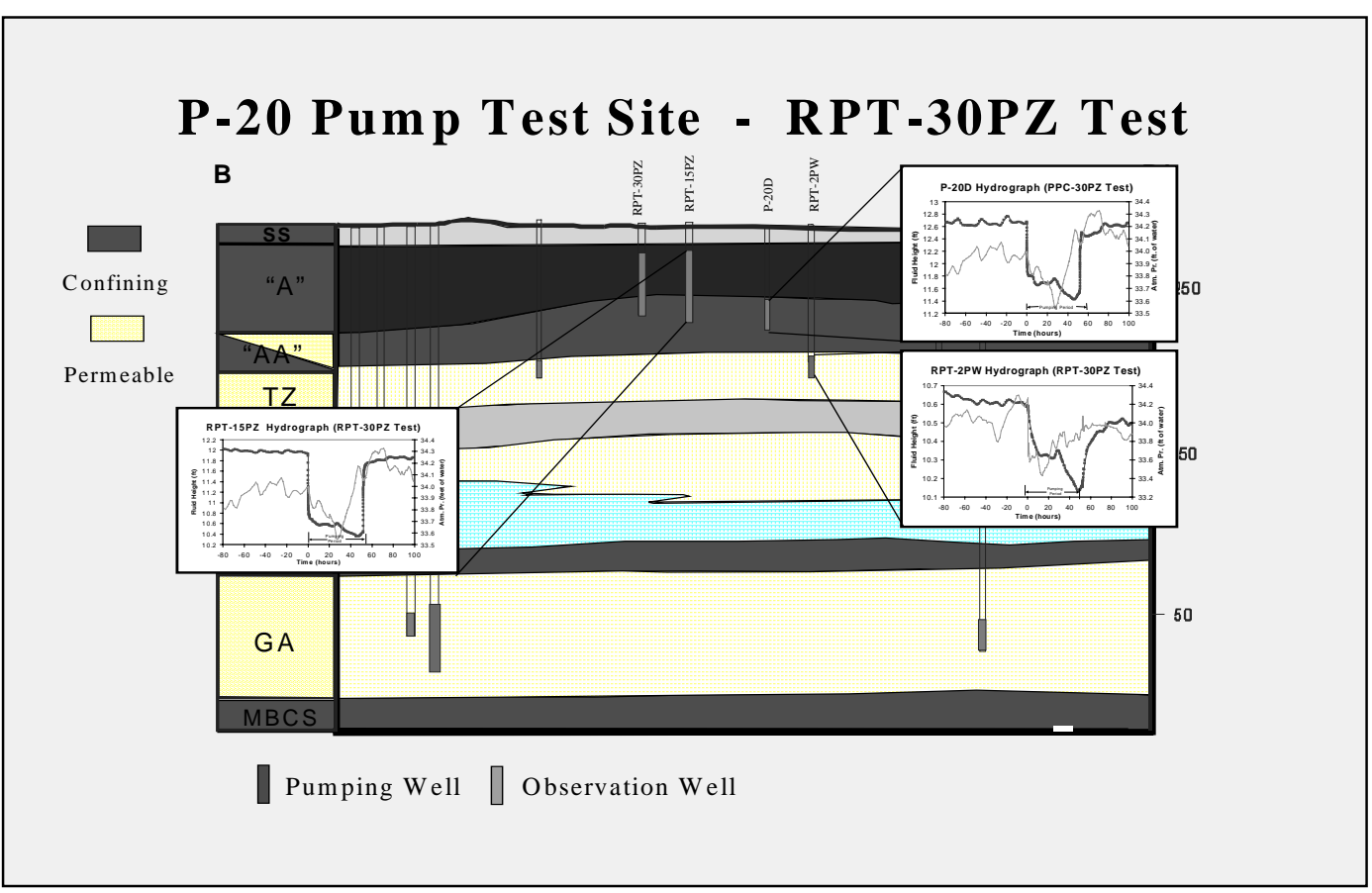

Figure 13: Hydraulic responses observed while pumping RPT-30PZ. 
WSRC-TR-00-00180, Rev. 0

R-Area Aquifer Tests

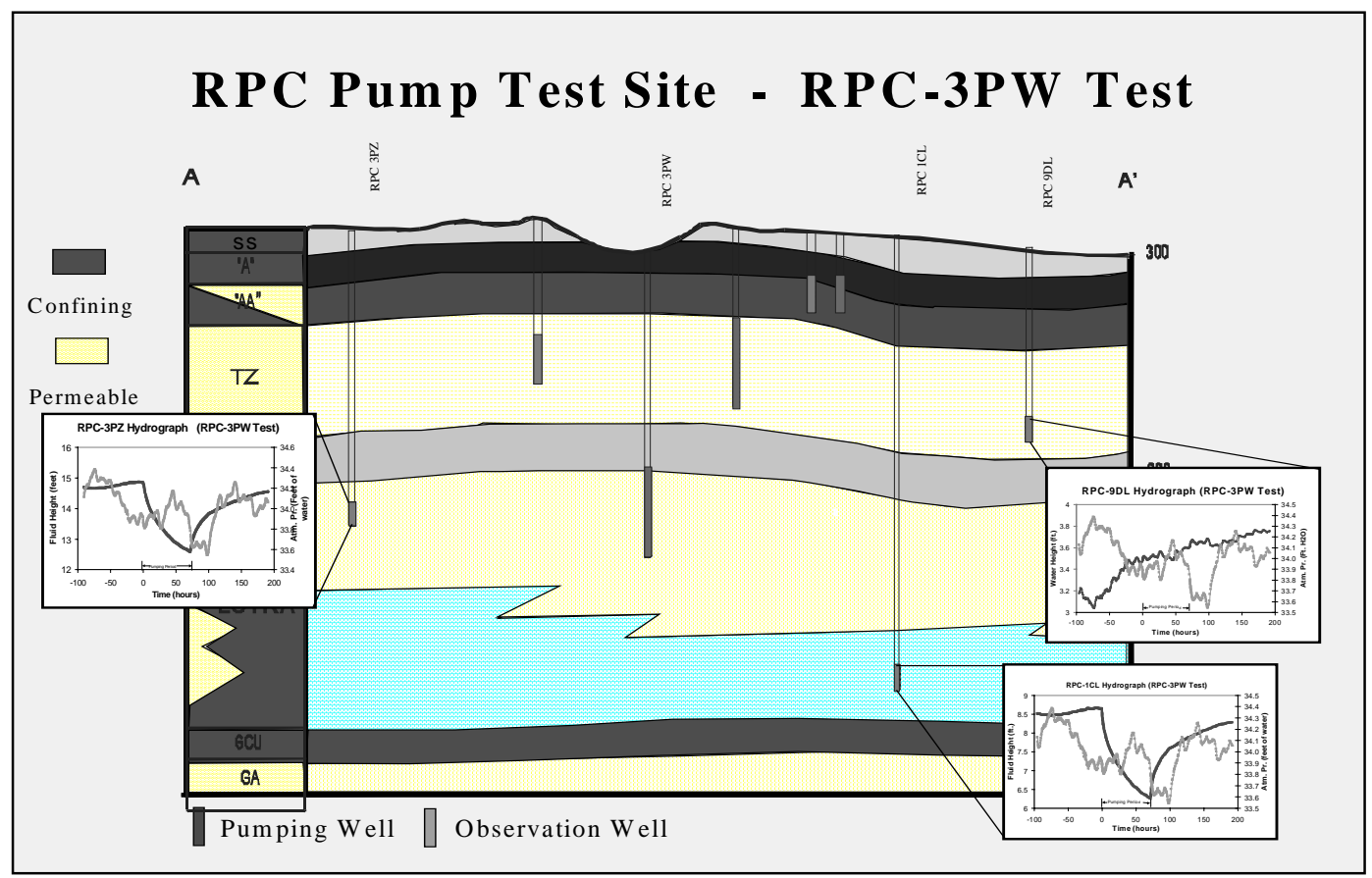

Figure 14: Hydraulic responses observed while pumping RPT-3PW

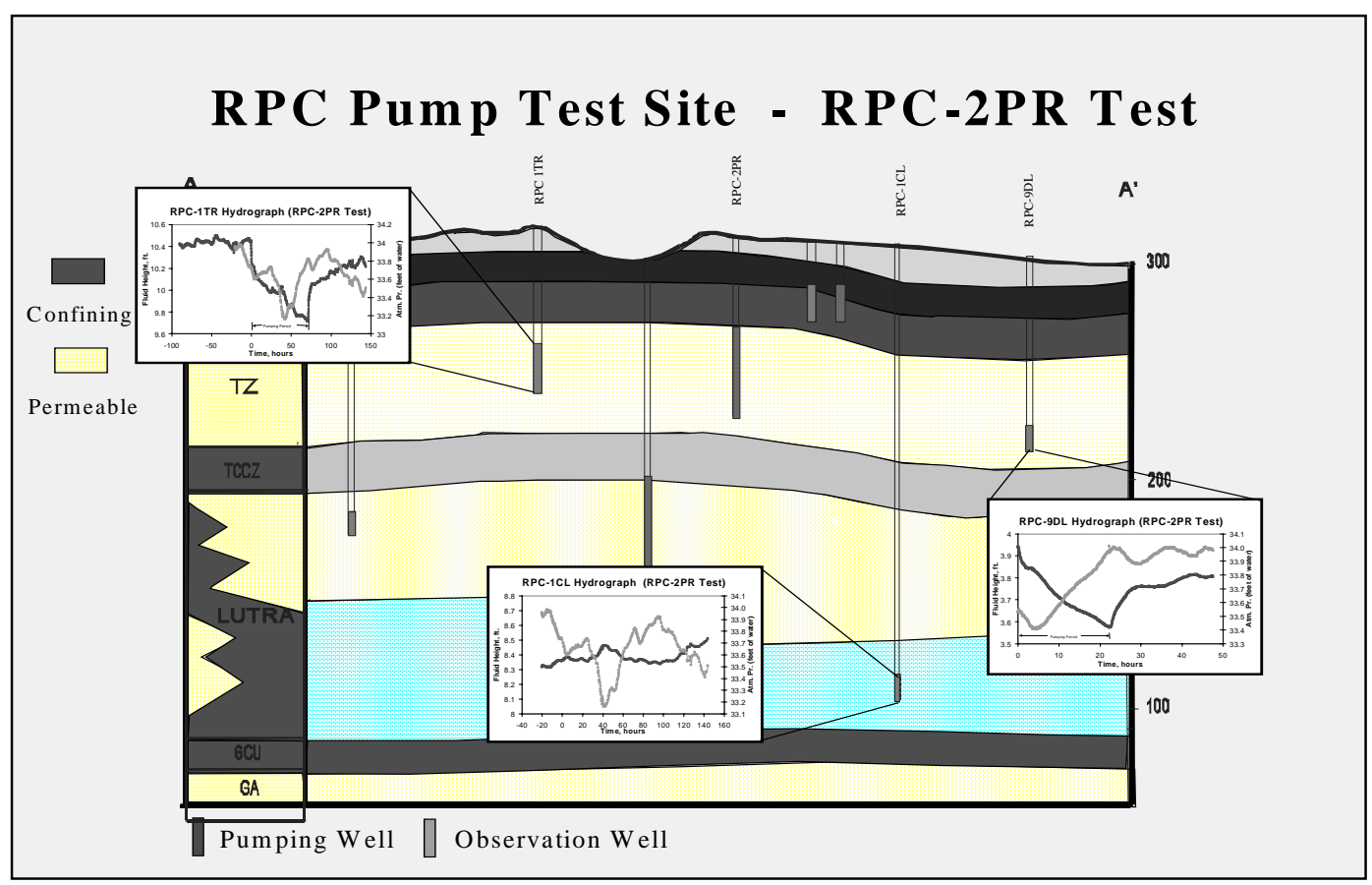

Figure 15: Hydraulic responses observed while pumping RPT-2PR 


\subsection{RESULTS}

The individual test analyses obtained estimates of the hydraulic parameters: transmissivity, storage coefficient, and leakance. These estimates are discussed below in detail. The results of all water level drawdown and recovery analyses are presented in graphic format in Appendix $\mathrm{F}$ and $\mathrm{G}$ for tests conducted at RPT-4PW, RPT-3PW, RPT-2PW, RPT-30PZ, RPC-3PW and RPC-2PR.

\section{$5.1 \quad$ RPT-4PW Test}

\subsubsection{Drawdown and recovery results}

Analyses were conducted on hydraulic response data obtained in RPT-4PZ and P20B, both finished in the Gordon Aquifer. The Hantush-Jacob (1955) analytical model gave the best fit between the field drawdown curves and the analytical curves. The estimates of $\mathrm{T}, \mathrm{S}, \mathrm{r} / \mathrm{B}$ obtained at RPT-4PZ were $1.35 \mathrm{ft}^{2} / \mathrm{min}$., 1.22E-4, and 2.9E-3, respectively. At P-20B, estimates of T, S, and r/B obtained were 3.92E-1 $\mathrm{ft}^{2} / \mathrm{min} ., 2.75 \mathrm{E}-3$, and $4.87 \mathrm{E}-1$, respectively. Using an aquifer thickness of $86 \mathrm{ft}$., the $\mathrm{K}$ was calculated to be $22.6 \mathrm{ft} . / \mathrm{day}$ at RPT-4PZ and 6.56 ft./day at P-20B. Analysis of the recovery data using the Cooper-Jacob method yielded $\mathrm{T}$ values of 1.29 and $0.66 \mathrm{ft}^{2} / \mathrm{min}$. for RPT-4PZ and P-20B, respectively.

\subsubsection{Hydraulic responses in adjacent aquifers}

When pumping was conducted in the Gordon Aquifer at RPT-4PW, a transducer was used to monitor hydraulic responses in the overlying LUTRA. This transducer was positioned in the RPT-3PW well, located approximately 15 feet from the pumping well. At this location close to the pumping well, where the maximum drawdown in the Gordon Aquifer would occur, this was thought to be the location with the greatest chance of observing any cross-formation response to pumping. The water levels recorded in RPT-3PW exhibited no hydraulic response to pumping in the Gordon Aquifer whatsoever. 
WSRC-TR-00-00180, Rev. 0

R-Area Aquifer Tests

\subsection{RPT-3PW Test}

\subsubsection{Drawdown and recovery results}

Analyses were conducted on hydraulic response data obtained in RPT-3PZ and P20C, both finished in the LUTRA. The Hantush-Jacob (1955) analytical model gave the best fit between the field drawdown curves and the analytical curves. The estimates of T, S, r/B obtained at RPT-3PZ were $1.51 \mathrm{E}-1 \mathrm{ft}^{2} / \mathrm{min}$., 3.7E-4, and 1.55E-1, respectively. At P-20C, estimates of $\mathrm{T}, \mathrm{S}$, and $\mathrm{r} / \mathrm{B}$ obtained were 5.3E- $2 \mathrm{ft}^{2} / \mathrm{min}$., 3.11E-4, and 5.06E-1, respectively. Using an aquifer thickness of $74 \mathrm{ft}$., the $\mathrm{K}$ was calculated to be $2.94 \mathrm{ft} . /$ day at RPT-3PZ and $1.03 \mathrm{ft} . /$ day at P20C. Analysis of the recovery data using the Cooper-Jacob method yielded $\mathrm{T}$ values of 0.134 and $0.094 \mathrm{ft}^{2} / \mathrm{min}$. for RPT-3PZ and P-20C, respectively.

\subsubsection{Hydraulic responses in adjacent aquifers}

When pumping RPT-3PW a transducer was used to monitor water levels in RPT2PZ and PPT-2PW in the TZ. Water levels appear to decline slightly, in the order of 0.5 feet during the pumping period, however there was no distinct rebound in water levels when pumping was shut off in RPT-3PW. There appears to be only a very slight hydraulic connection between these aquifers. Monitoring of RPT4PW in the GAU was conducted using the electric tape during pumping at RPT3PW. No changes in water levels were observed during the pumping or recovery periods, other than those attributable to atmospheric pressure changes. This corroborates the lack of response in RPT-3PW when RPT-4PW was pumped.

\subsection{RPT-2PW Test}

\subsubsection{Drawdown and recovery results}

Analyses were conducted on hydraulic response data obtained in RPT-2PZ, which is finished in the Transmissive Zone. The Hantush-Jacob (1955) analytical model gave the best fit between the field drawdown curve and the analytical curve. The estimates of T, S, r/B obtained at RPT-2PZ were $2.4 \mathrm{E}-2 \mathrm{ft}^{2} / \mathrm{min}$., $2.3 \mathrm{E}-4$, and $6.79 \mathrm{E}-2$, respectively. Using an aquifer thickness of $15 \mathrm{ft}$., the $\mathrm{K}$ was calculated to be $2.3 \mathrm{ft} . /$ day at RPT-2PZ. Analysis of the recovery data using the CooperJacob method yielded a $\mathrm{T}$ value of $0.044 \mathrm{ft}^{2} / \mathrm{min}$. 


\subsubsection{Hydraulic responses in adjacent aquifers}

While RPT-2PW was pumped, water levels were monitored with transducers in the overlying aquifer (A/AA Horizons) at RPT-30PZ and P-20D and in the underlying aquifer (LUTRA) at P-20C. Water levels in RPT-30PZ and P-20D both exhibit responses to pumping in RPT-2PW, with drawdowns of 0.75 and 1.1 feet, respectively. Water levels in P-20C exhibited a small but distinct response to pumping and an associated recovery in water level following termination of pumping. The magnitude of this response was approximately 0.2 feet.

\subsection{RPT-30PZ TEST}

\subsubsection{Drawdown and recovery results}

Analyses were conducted on hydraulic response data obtained in RPT-15PZ and P-20D, both finished in the water table, or A/AA Horizons. The Neuman (1974) analytical model gave the best fit between the field drawdown curves and the analytical curves. The estimates of T, S, and Sy obtained at RPT-15PZ were 3.7E-2 $\mathrm{ft}^{2} / \min ., 2.6 \mathrm{E}-3$, and 5.0E-1, respectively. At P-20D, estimates of $\mathrm{T}, \mathrm{S}$, and Sy obtained were $3.9 \mathrm{E}-2 \mathrm{ft}^{2} / \mathrm{min}$., $1.12 \mathrm{E}-3$, and $1.65 \mathrm{E}-1$, respectively. Using an aquifer thickness of $34 \mathrm{ft}$., the $\mathrm{K}$ was calculated to be $1.57 \mathrm{ft}$./day at RPT-15PZ and $1.65 \mathrm{ft} . /$ day at P-20D

\subsubsection{Hydraulic responses in adjacent aquifers}

While RPT-30PZ was pumped, water levels were monitored with transducers in the underlying aquifer (Transmissive Zone) at RPT-2PZ. Water levels in RPT$2 \mathrm{PZ}$ exhibited a response to pumping RPT-30PZ, with a drawdown of 0.45 feet. This corroborates the hydraulic responses detected in RPT-30PZ and P-20D when pumping was conducted in RPT-2PW.

\subsection{RPC-3PW Test}

\subsubsection{Drawdown and recovery results}

Water level responses observed in the primary observation wells RPC-3PZ and RPC-1CL while pumping in RPC-3PW did not match well against any analytical 
model. These wells are all completed in the LUTRA. The responses in both observation wells suggest that an impermeable boundary condition may exist in the LUTRA near the test location. Evidence suggesting this hydrogeologic condition is a distinct change in the slope of the semi-log drawdown curve after approximately 800-1000 minutes of pumping, as can be seen on the graphs presented in Appendix G. Water levels responses observed after the changes in slope are encountered cannot be used to calculate hydraulic parameters, however the data obtained prior to this can be analyzed. The modified Theis method was employed to analyze these "early-time" data. Using the "straight-line" technique to obtain $\mathrm{T}$, values of $1.56 \mathrm{ft}^{2} / \mathrm{min}$. and $1.96 \mathrm{ft}^{2} / \mathrm{min}$. were obtained for RPC-3PZ and RPC-1CL, respectively. Using an aquifer thickness of 101 feet, these convert to hydraulic conductivities of $22 \mathrm{ft} / \mathrm{min}$ and $28 \mathrm{ft} /$ day, respectively.

\subsubsection{Hydraulic responses in adjacent aquifers}

While pumping RPC-3PW, water levels were monitored in RPC-9DL and RPC1TR. No water level responses to pumping were observed in these wells. Water levels in both wells rose slightly during the pumping period, probably due to gradual recharge related to rainfall events that occurred prior to the test being conducted.

\subsection{RPC-2PR Test}

\subsubsection{Drawdown and recovery results}

Analyses were conducted on hydraulic response data obtained in RPC-1TZ and RPC-9DL, both finished in the Transmissive Zone. The Neuman (1974) analytical model gave the best fit between field drawdown curve and an analytical model curve for the response observed in RPC-1TZ. The Neuman (1974) analytical model also gave the best fit between the field drawdown curve and an analytical model curve for the response observed in RPC-9DL. The estimates of $\mathrm{T}, \mathrm{S}$, Sy obtained at RPC-1TR were $6.87 \mathrm{E}-1 \mathrm{ft}^{2} / \mathrm{min}$., 9.6E-4, and 2.0E-2, 
respectively. At RPC-9DL, estimates of T, S, and Sy obtained were 6.71E-1 $\mathrm{ft}^{2} / \mathrm{min}$., 8.06E-4, and 5.61E-2, respectively. Using and aquifer thickness of $39 \mathrm{ft}$, the $\mathrm{K}$ was calculated to be $25.4 \mathrm{E} 01 \mathrm{ft} . /$ day at RPT-1TR and $24.8 \mathrm{E} 01 \mathrm{ft}$./day at RPC-9DL.

\subsubsection{Hydraulic responses in adjacent aquifers}

While pumping RPC-2PR, water levels were monitored in RPC-1CL, RPC1PZ and RPC-1PW. No water level responses to pumping were observed in RPC-1CL, the well finished in the underlying aquifer unit. Water levels in RPC-1PZ and RPC-1PW both exhibited water level responses of between 1 and 1.5 feet and clearly exhibited distinct drawdown and recovery periods in the responses. 
WSRC-TR-00-00180, Rev. 0

R-Area Aquifer Tests

This Page Intentionally Left Blank 
WSRC-TR-2000-00180, Rev. 0

R-Area Aquifer Tests

\subsection{INTERPRETATION}

\subsection{Best estimates of hydraulic parameters}

Estimates of hydraulic parameters were obtained primarily using the data obtained during the drawdown phase of each test. Recovery data was used for wells finished in confined aquifers to obtain a separate estimate of transmissivity.

In all cases where drawdown and recovery data was utilized to obtain separate estimates of $\mathrm{T}$, the results were quite similar. For the $\mathrm{R}$ Area aquifer tests, the best estimate for hydraulic parameters was derived from the drawdown phase of the tests. The analytical models utilized consider leakage across confining units which corresponds to the hydrogeologic conditions in this area where aquifers and confining units are laterally interbedded. A summary of the best estimates of $\mathrm{T}, \mathrm{S}$, and $\mathrm{r} / \mathrm{B}$ is presented below in Table 4.

All of the tests, with the exception of the RPT-2PW test, had two primary observation wells from which estimates of hydraulic parameters were obtained. Differences were noted between estimates obtained from different observation wells during the same test. These differences range from a factor of 1.05 to 3.5 and are reasonable for the heterogeneous conditions within the aquifer units in R Area.

At the RPT test location, the T values obtained from RPT-4PZ and P-20B for the Gordon Aquifer $\left(1.35\right.$ and $\left.0.39 \mathrm{ft}^{2} / \mathrm{min}\right)$ are different by a factor of 3.5 . These wells are located at similar distances (170 and $250 \mathrm{ft}$ ) from the pumping well but in directions $90^{\circ}$ different from one another. T values obtained from RPT-3PZ and P-20C for the LUTRA $\left(0.15\right.$ and $\left.0.053 \mathrm{ft}^{2} / \mathrm{min}\right)$ are different by a factor of 2.9 . These wells are also located at similar distances (170 and $255 \mathrm{ft}$ ) from the pumping well but in directions separated by $90^{\circ}$. The T values obtained from RPT-15PZ and P-20D (0.037 and $\left.0.039 \mathrm{ft}^{2} / \mathrm{min}\right)$ for the A/AA Horizons are practically identical. These wells are both located in the same radial direction from the pumping well and are relatively close, being 15 and $32 \mathrm{ft}$ away, respectively. 
WSRC-TR-00-00180, Rev. 0

R-Area Aquifer Tests

At the RPC test location, the T values obtained from RPC-9DL and RPC-1TR for the Transmissive Zone $\left(0.671\right.$ and $\left.0.687 \mathrm{ft}^{2} / \mathrm{min}\right)$ are practically identical. These wells are located in opposite directions from the pumping well and are at distances of 360 and 176 $\mathrm{ft}$ from the pumping well. The $\mathrm{T}$ values from both analyses convert to $\mathrm{K}$ values of 24.8 and $25.4 \mathrm{ft} /$ day when divided by the aquifer thickness of $39 \mathrm{feet}$. These values are in the mid-range of clean sands. T values obtained from RPC-3PZ and RPC-1CL for the LUTRA (1.56 and $\left.1.96 \mathrm{ft}^{2} / \mathrm{min}\right)$ are different by a factor of 1.2. Estimates of transmissivity could not be obtained by the usual calculation method because an apparent hydraulic boundary condition was encountered during testing. Evidence of this condition is illustrated on the time-drawdown graphs for RPC-3PZ and RPC-1CL in Appendix F. The best-fit line exhibits a sharp change in slope after approximately 800-1000 minutes and is indicative that an impermeable boundary was encountered. This type of boundary effect is related to the lithologies encountered at this location. The pumping well was screened in 30 feet of siliciclastic sediments and 10 feet of calcareous sediments. As discussed earlier in Section 2.0 the lower UTRA exhibits dual facies, one that is primarily siliciclastic and the other calcareous resulting in highly permeable sediments directly in contact with lower permeability sediments. These types of lithologies would produce the boundary effect observed during this test.

Only the time-drawdown data acquired prior to the change in slope can be utilized to estimate hydraulic parameters because of the boundary effect. The analytical model used is likely to overestimate the transmissivity because the Cooper-Jacob analysis does not account for leakage across confining units. For this reason, and because of the limited time-drawdown data available for analysis, these estimates are regarded as somewhat less certain than estimates of T obtained in the LUTRA at the RPT well cluster site. 


\begin{tabular}{|c|c|c|c|c|c|c|c|c|c|}
\hline $\begin{array}{l}\text { Pumping } \\
\text { Well }\end{array}$ & $\begin{array}{l}\text { Obs. } \\
\text { Well }\end{array}$ & $\begin{array}{l}\text { Solution } \\
\text { Method }\end{array}$ & $\begin{array}{l}\text { Aquifer } \\
\text { Unit }\end{array}$ & Aquifer Type & $\begin{array}{l}T \\
\left(f^{\wedge}{ }^{\wedge} 2 / \min \right)\end{array}$ & $\begin{array}{l}\text { K } \\
\text { (ft/day) }\end{array}$ & $\mathbf{S}$ & $\mathbf{r} / \mathbf{B}$ & $\begin{array}{l}\text { Aquifer } \\
\text { Thick- } \\
\text { ness, b (ft }\end{array}$ \\
\hline RPT-4PW & RPT-4PZ & Hantush-Jacob & Gordon & Conf./Leaky & 1.35 & $2.26 \mathrm{E} 01$ & $1.22 \mathrm{E}-04$ & $2.9 \mathrm{E}-03$ & 86 \\
\hline RPT-4PW & P-20B & Hantush-Jacob & Gordon & Conf./Leaky & $3.92 \mathrm{E}-01$ & 6.56 & $2.75 \mathrm{E}-03$ & $4.87 \mathrm{E}-01$ & 86 \\
\hline RPT-3PW & RPT-3PZ & Hantush-Jacob & LUTRA & Conf./Leaky & $1.51 \mathrm{E}-01$ & 2.94 & 3.72E-04 & $1.55 \mathrm{E}-01$ & 74 \\
\hline RPT-3PW & P-20C & Hantush-Jacob & LUTRA & Conf./Leaky & $5.3 \mathrm{E}-02$ & 1.03 & 3.11E-04 & $5.06 \mathrm{E}-01$ & 74 \\
\hline RPT-2PW & RPT-2PZ & Hantush-Jacob & $\mathrm{TZ}$ & Conf./Leaky & $2.4 \mathrm{E}-02$ & 2.3 & 2.3E-04 & $6.79 \mathrm{E}-01$ & 15 \\
\hline RPT-30PZ & RPT-15PZ & Neuman & $\mathrm{A} / \mathrm{AA}$ & Unconfined & $3.7 \mathrm{E}-02$ & 1.57 & $2.6 \mathrm{E}-03$ & N/A & 34 \\
\hline RPT-30PZ & P-20D & Neuman & $\mathrm{A} / \mathrm{AA}$ & Unconfined & $3.9 \mathrm{E}-02$ & 1.65 & $2.6 \mathrm{E}-03$ & N/A & 34 \\
\hline RPC-2PR & RPC-1TR & Neuman & $\mathrm{TZ}$ & Unconfined & $6.87 \mathrm{E}-01$ & $2.54 \mathrm{E} 01$ & $2.33 \mathrm{E}-02$ & N/A & 39 \\
\hline RPC-2PR & RPC-9DL & Neuman & $\mathrm{TZ}$ & Unconfined & $6.71 \mathrm{E}-01$ & $2.48 \mathrm{E} 01$ & $1.7 \mathrm{E}-3$ & $2.95 \mathrm{E}-01$ & 39 \\
\hline RPC-3PW & RPC-3PZ & Mod. Theis & LUTRA & Conf. w/boundary & 1.54 & $2.2 \mathrm{E} 01$ & N/A & N/A & 101 \\
\hline RPC-3PW & RPC-1CL & Mod. Theis & LUTRA & Conf. w/boundary & 1.96 & $2.8 \mathrm{E} 01$ & N/A & N/A & 101 \\
\hline
\end{tabular}


WSRC-TR-00-00180, Rev. 0

R-Area Aquifer Tests

\subsection{Hydraulic interconnection between aquifer units}

The results of monitoring water levels in secondary observation wells, situated in aquifer units adjacent to the pumped aquifer, allow a qualitative assessment to be made of the degree of hydraulic interconnection between aquifer units.

\subsubsection{RPT Site (P-20)}

At the RPT location, these results indicate that the Gordon Confining Unit (GCU) is extremely competent from a hydrogeologic standpoint. When pumping was conducted immediately above the GCU, no hydraulic response could be discerned immediately below the unit in a nearby well. Conversely, when pumping was conducted immediately below the unit, not even a slight response could be detected above the unit in a nearby well. The regional continuity of the GCU beneath the central part of the SRS, as well as its characteristic low permeability is confirmed by the results of this testing program.

The TCCZ, which separates the LUTRA from the overlying TZ, appears to be slightly less competent than the GCU. When pumping was conducted in the LUTRA, a slight response in water levels, in the order of 0.5 feet, was noted in observation well RPT-2PZ. This well is located approximately 100 feet away from the LUTRA pumping well. This degree of response is relatively small compared to the 12-15 feet of drawdown that was observed in primary observation wells, which are located at even greater distances from the pumping well than is RPT-2PZ. This slight response indicates that the TCCZ has a slightly higher vertical hydraulic conductivity $\left(\mathrm{K}_{\mathrm{v}}\right)$ than does the GCU. This is likely due to interconnected sandy layers within the TCCZ.

The small hydraulic response observed to occur across the TCCZ was corroborated when the overlying $\mathrm{TZ}$ aquifer was pumped. A small, but measurable response was noted in the LUTRA, well P-20C, which is located 
WSRC-TR-2000-00180, Rev. 0

R-Area Aquifer Tests

approximately 30 feet away from RPT-2PW. This hydrologic connection between the LUTRA and TZ may permit a relatively small groundwater flux to occur across the TCCZ unit under ambient gradients. However, this flux is likely to be small compared to horizontal fluxes in the overlying TZ.

A hydraulic connection between the $\mathrm{TZ}$ and the overlying A/AA Horizons is indicated by the 0.75 and 1.1 foot responses in water levels monitored in RPT30PZ and P-20D when RPT-2PW was pumped. Slug tests conducted throughout R-Area indicate that the A Horizon has an extremely low hydraulic conductivity. Hydraulic interconnection between these units is likely related to the existence of thin, but interconnected, sandy layers that occur within the AA Horizon. RPT30PZ and P-20D have relatively long screen zones that extend across both the A and AA Horizons. Although screened across both horizons, the water levels in these wells respond to $\mathrm{TZ}$ pumping primarily through the interconnected sandy layers of the AA Horizon, occurring in the lower part of the screen zones.

\subsubsection{RPC Site}

No GAU Aquifer tests were performed at the RPC site therefore no measurements were made from the GCU.

Results of monitoring water levels at the RPC site in secondary observation wells indicate that the TCCZ serves as a competent hydraulic seal between the LUTRA and the overlying TZ. No hydraulic response was observed in TZ wells (PRC9DL) and RPC-1TR) when the PRC-3PW was pumped. Conversely, when the TZ pumping well (PRC-2PR) was pumped, there was no hydraulic response in the LUTRA wells (PRC-3PZ) and PRC-1CL). Based on these results, the TCCZ serves as an effective barrier to any potential downward migration of contaminants in this part of R-Area.

Hydraulic responses were observed in PRC-1PZ and PRC-1PW that ranged from 1.0 to1.5 feet when PRC-2PR pumped water from the underlying TZ. The responses between the A/AA Horizons and the TZ appear to be an artifact of well 
construction issues associated with these wells. The bottoms of the screen zones in RPC-1PW and RPC-1PZ are at elevations of 270.7 and 270.6 feet msl, respectively. These elevations are slightly higher $(0.6$ and $0.7 \mathrm{ft})$ than the top of the TZ (270.0 feet msl) at RPC-2PR located approximately 30' away. Both RPC1PW and RPC-1PZ have sumps extending 5 feet below their screens into the TZ. The sumps are surrounded with filter pack material, as are the well screen zones, and consequently the screens in the wells are connected to the underlying TZ via the filter pack material.

However, the responses observed in RPC-1PW and -1PZ during the RPC-2PR test are less than would be expected had the wells been fully screened in the TZ. This muted response is likely due to the lower A/AA Horizons permeability and the narrow connection through the filter pack material in the well annulus. The slug test conductivity $(\mathrm{K})$ values from these wells are 0.29 and $0.27 \mathrm{ft} / \mathrm{day}$ for each well, and are consistent with $\mathrm{K}$ values associated with silty sands. These values are 1-2 orders of magnitude higher than those obtained from slug tests conducted in other R-Area wells completed in the A/AA Horizons but are an order of magnitude lower than the value obtained from RPC-2PR. Thus, the slug test results obtained in RPC-1PW and RPC-1PZ are consistent with the existence of a narrow connection with the $\mathrm{TZ}$ and the relatively lower permeability A/AA Horizons.

Even with the hydraulic connection to the TZ, RPC-1PW was unable to sustain sufficient flow to conduct a multiple-well aquifer test. These low flows are indicative of the known low permeabilities in the A/AA Horizons (WSRC, 1998a) and low measured water levels in this well which were 4 feet above the base of the screen. Several feet of drawdown are typically required to conduct a multiple well aquifer test. Considering these two factors, it is not unusual that even minimal flow rates could not be sustained. 


\subsection{COMPARISON OF R- AREA REGIONAL FLOW MODEL TO PUMPING TEST RESULTS}

The aquifer testing described above was conducted in response to USEPA comments (WSRC, 1998) on the Rev. 0 R-Reactor Seepage Basins RFI/RI Report (WSRC, 1998a), Appendix G, Groundwater Contaminant Transport Modeling for the R-Reactor Seepage Basins (RRSB)/108-4R Overflow Basin Operable Unit. The R-area regional flow model described in Appendix $G$ of the RFI/RI is based on small-scale and/or indirect measures of hydraulic conductivity, including laboratory tests, slug tests, cone penetration testing (CPT) and lithologic core descriptions. These characterization data were correlated to conductivity and upscaled to the model grid resolution as needed to produce the model conductivity field. The USEPA proposed and WSRC agreed that large-scale conductivity estimates from multiple well pumping tests would be beneficial for validating the model conductivity field. A comparison of the $1998 \mathrm{R}$-area regional flow model to the recent pumping tests is provided in this section.

Table 5 summarizes results of R-area aquifer testing. The conductivity $(\mathrm{K})$ values labeled "best estimate" are considered more reliable than the "other estimates" for the reasons discussed in preceding sections. Where multiple "best estimates" are available, a single "recommended value" is computed as the arithmetic average of the more reliable values. Also included in Table 5 is the model conductivity averaged over the entire model domain for each tested hydrostratigraphic unit, denoted by "Model overall". The model conductivity at the location and hydrostratigraphic unit corresponding to each pumped well are also provided.

The conductivities contained in Table 5 are displayed graphically in Figure 16. Because the data span nearly two orders of magnitude, base 10 logarithm of conductivity is plotted so that low values of $\mathrm{K}$ can be distinguished. Pumping test results are denoted by circles, with the large labeled ones indicating "best estimates" and the small unlabeled circles showing "other estimates". Conductivities from the model are denoted by squares, with the larger ones indicating site-specific values and the smaller symbols showing the model-wide average. Comparisons of model $\mathrm{K}$ to pumping test $\mathrm{K}$ for each aquifer are considered in the following order: Gordon Aquifer, "lower" UTRA, transmissive zone, and A/AA horizons. 
WSRC-TR-00-00180, Rev. 0

R-Area Aquifer Tests

\subsection{Gordon aquifer}

The two best-estimate pumping test values are observed in Figure 16 to bracket model conductivity at the RPT-4PW site. From this standpoint, the model is entirely consistent with the field data. The average of these two data, the "recommended" value, is $13.6 \mathrm{ft} / \mathrm{d}$ and low compared to prior estimates of Gordon aquifer conductivity which are centered around roughly $30 \mathrm{ft} / \mathrm{d}$ (e.g. Aadland and others, 1995, Table 5). The model conductivity at the RPT-4PW $(20.0 \mathrm{ft} / \mathrm{d})$, being lower than the overall model average $(30.5 \mathrm{ft} / \mathrm{d})$, reflects this trend. The model value is higher than the recommended test value by a factor of 1.37. However, considering the wide range of conductivities that can be potentially encountered in an aquifer due to heterogeneity, even at the scale of a multiple-well aquifer test, a difference factor of 1.37 is considered to be good agreement. Note for example that the two best-estimate pumping test values differ by a factor of 3 .

\subsection{Lower Upper Three Runs Aquifer (LUTRA)}

Aquifer testing was performed at both the RPT and RPC sites for the LUTRA and produced best-estimate results that differ by more than an order of magnitude (Figure 16). The model conductivities at these locations follow the same spatial trend as the data, but the variation is muted. Model conductivity averaged over entire model domain is bracketed by the test results. The model conductivity at RPT-3PW differs from the recommended test value by a factor of 3.4. The test results at RPC-3PW exceed the model conductivity by a factor of 2.5 , but are also more uncertain for the reasons described previously. These difference factors are larger than those for the other aquifer zones, and probably a result of the LUTRA aquifer being more heterogeneous than the other aquifers considered.

As discussed earlier in Section 2.0 the LUTRA exhibits dual facies, one that is primarily siliciclastic and the other calcareous resulting in highly permeable sediments directly in contact with lower permeability sediments. The wide range of lithologic variability exhibited by the LUTRA is supported by the individual test results that differ by more than an order of magnitude, the boundary effects on drawdown observed at RPC-3PW (discussed previously in Section 6.0), and rotosonic sediment core taken during well installation. The highly heterogeneous nature of this aquifer inherently increases 
hydraulic parameter interpretation. With these considerations, and that the overall model conductivity is bracketed by the field data, the comparison of the pump test results is considered acceptable in relation to modeling results.

\subsection{Transmissive Zone (TZ) in Upper Three Runs Aquifer}

Aquifer testing was performed at both the RPT and RPC sites and produced bestestimate results that differ by an order of magnitude (Figure 16). The model conductivities at these locations follow the same spatial trend and differ from the test data by a factor of 1.6 in both cases. Considering natural aquifer variability, evident from the two widely-differing test results, a difference factor of 1.6 between the model and field data is considered good agreement.

\subsection{A/AA horizons in Upper Three Runs Aquifer}

No pumping test results are available for the RPC site since the wells were unable to sustain a pumping rate. Therefore, only the RPT site is evaluated. The pumping well was screened in both the A and AA horizons, with approximately the lower $30 \%$ in the more permeable AA horizon. Data from two observation wells produced nearly identical results that average $1.6 \mathrm{ft} / \mathrm{d}$ (Figure 16). Model conductivity at the location of RPT-30PZ is $0.3 \mathrm{ft} / \mathrm{d}$ in the A horizon and $5.0 \mathrm{ft} / \mathrm{d}$ in the underlying AA horizon. Averaging these values in proportion to the fraction of screen in each horizon produces a screen-average model conductivity of $2.3 \mathrm{ft} / \mathrm{d}$. The model conductivity differs from the recommended test value by a factor of 1.43 , which is good agreement considering aquifer heterogeneity. 
WSRC-TR-00-00180, Rev. 0

R-Area Aquifer Tests

\begin{tabular}{|c|c|c|c|c|c|c|c|}
\hline SitelD & Unit & $\begin{array}{l}\text { Conductivity } \\
(f t / d)\end{array}$ & Description & $\begin{array}{c}\text { Trans- } \\
\text { missivity } \\
\left(\mathrm{ft}^{2} / \mathrm{min}\right)\end{array}$ & $\begin{array}{c}\text { Unit } \\
\text { Thick- } \\
\text { ness } \\
\text { (ft) }\end{array}$ & $\begin{array}{c}\text { Observation } \\
\text { Well }\end{array}$ & Test \\
\hline \multirow[t]{8}{*}{ RPT-4PW } & Gordon & 20.0 & Model @ RPT-4PW & & & & \\
\hline & & 30.5 & Model overall & & & & \\
\hline & & 22.6 & Best estimate & 1.35 & 86 & RPT-4PZ & Drawdown \\
\hline & & 6.6 & Best estimate & 0.392 & 86 & P-20B & Drawdown \\
\hline & & 21.6 & Other estimate & 1.29 & 86 & RPT-4PZ & Recovery \\
\hline & & 11.1 & Other estimate & 0.66 & 86 & P-20B & Recovery \\
\hline & & 14.6 & Recommended value & & & & \\
\hline & & $(1.37)$ & (Model-Data Ratio) & & & & \\
\hline \multirow[t]{8}{*}{ RPT-3PW } & "lower" UTR & 6.7 & Model @ RPT-3PW & & & & \\
\hline & & 9.6 & Model overall & & & & \\
\hline & & 2.9 & Best estimate & 0.151 & 74 & RPT-3PZ & Drawdown \\
\hline & & 1.0 & Best estimate & 0.053 & 74 & $P-20 C$ & Drawdown \\
\hline & & 2.6 & Other estimate & 0.134 & 74 & RPT-3PZ & Recovery \\
\hline & & 1.8 & Other estimate & 0.094 & 74 & $P-20 C$ & Recovery \\
\hline & & 2.0 & Recommended value & & & & \\
\hline & & (3.38) & (Model-Data Ratio) & & & & \\
\hline \multirow[t]{6}{*}{ RPC-3PW } & "lower" UTR & 10.0 & Model @ RPC-3PW & & & & \\
\hline & & 9.6 & Model overall & & & & \\
\hline & & 22.0 & Best estimate & 1.54 & 101 & RPC-3PZ & Recovery \\
\hline & & 27.9 & Best estimate & 1.96 & 101 & RPC-1CL & Recovery \\
\hline & & 25.0 & Recommended value & & & & \\
\hline & & $(2.50)$ & (Model-Data Ratio) & & & & \\
\hline \multirow[t]{5}{*}{ RPT-2PW } & transmissive & 3.7 & Model @ RPT-2PW & & & & \\
\hline & & 13.0 & Model overall & & & & \\
\hline & & 2.3 & Best estimate & 0.024 & 15 & RPT-2PZ & Drawdown \\
\hline & & 4.2 & Other estimate & 0.044 & 15 & RPT-2PZ & Recovery \\
\hline & & $(1.61)$ & (Model-Data Ratio) & & & & \\
\hline \multirow[t]{6}{*}{ RPC-2PR } & transmissive & 15.7 & Model @ RPC-2PR & & & & \\
\hline & & 13.0 & Model overall & & & & \\
\hline & & 25.4 & Best estimate & 0.687 & 39 & RPC-1TR & Drawdown \\
\hline & & 24.8 & Best estimate & 0.671 & 39 & RPC-9DL & Drawdown \\
\hline & & 25.1 & Recommended value & & & & \\
\hline & & $(1.60)$ & (Model-Data Ratio) & & & & \\
\hline \multirow[t]{7}{*}{ RPT-30PZ } & $\mathrm{A} / \mathrm{AA}$ & 2.3 & Model @ RPT-30PZ & & & & \\
\hline & AA & 9.5 & Model overall & & & & \\
\hline & A & 1.3 & Model overall & & & & \\
\hline & A/AA & 1.6 & Best estimate & 0.037 & 34 & RPT-15PZ & Drawdown \\
\hline & $\mathrm{A} / \mathrm{AA}$ & 1.7 & Best estimate & 0.039 & 34 & P-20D & Drawdown \\
\hline & A/AA & 1.61 & Recommended value & & & & \\
\hline & A/AA & $(1.43)$ & (Model-Data Ratio) & & & & \\
\hline
\end{tabular}

Table 5: Summary of R Area Pump Test Conductivity Estimates and R Area Regional Groundwater Modeling Conductivity Field 
WSRC-TR-2000-00180, Rev. 0

R-Area Aquifer Tests

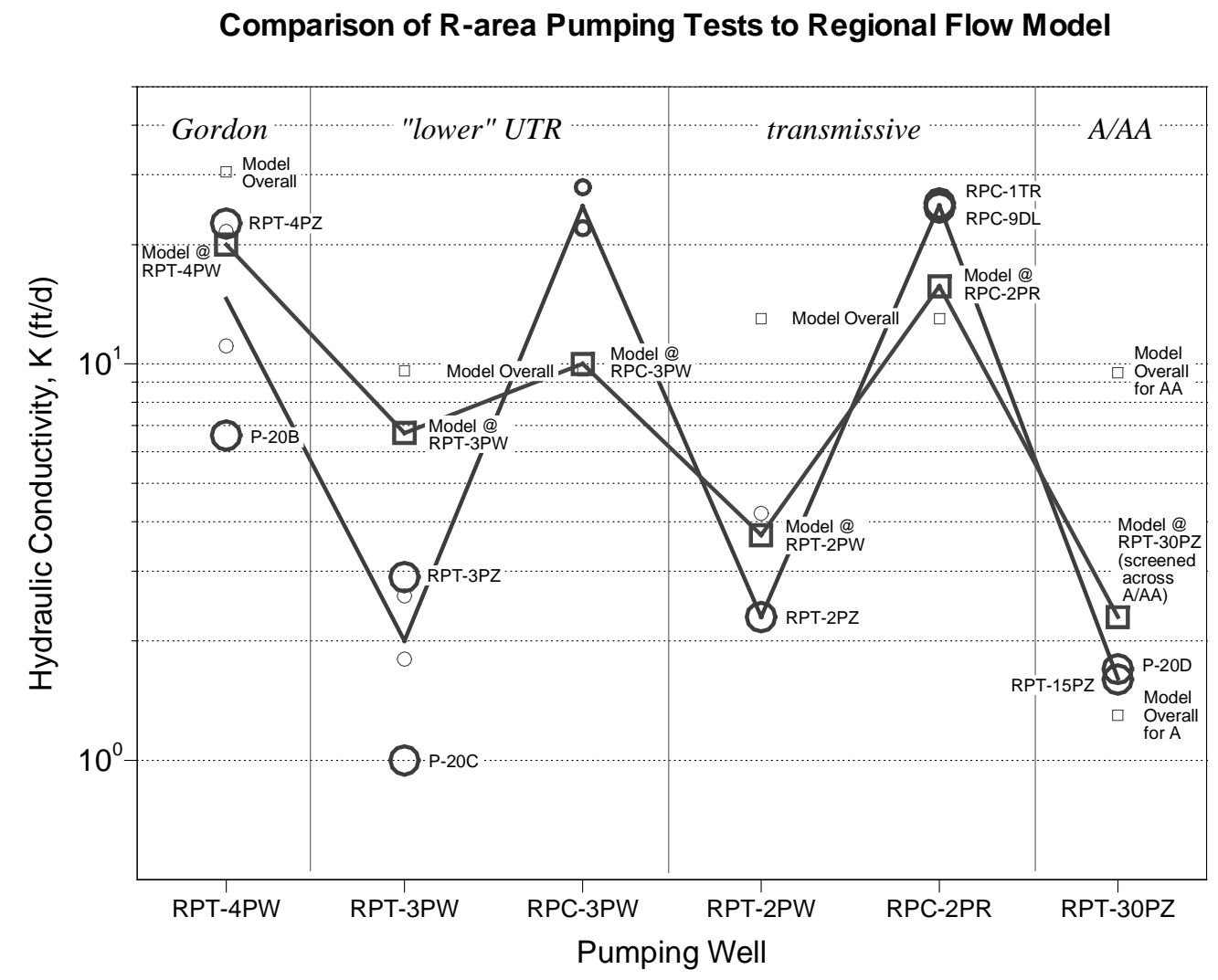

Figure 16: Comparison of R Area Pump Test Data to Groundwater Modeling Results 
WSRC-TR-00-00180, Rev. 0

R-Area Aquifer Tests

This Page Intentionally Left Blank 


\subsection{SUMMARY AND CONCLUSIONS}

The primary purpose of the aquifer testing was to obtain large-scale conductivity estimates from multiple well pumping tests for validation of the 1998 R-Area regional groundwater flow model conductivity field (Jones et al, 1998). The R-area regional flow model described in Appendix $G$ of the RFI/RI is based on small-scale and/or indirect measures of hydraulic conductivity, including laboratory tests, slug tests, cone penetration testing, and lithologic core descriptions. These characterization data were correlated to conductivity and upscaled to the model grid resolution as needed to produce the model conductivity field. EPA proposed and SRS agreed that multiple-well pumping tests would aid in the validation.

Six multiple-well, constant pumping rate tests were performed in the near-surface aquifers, including the A/AA Horizons, the transmissive zone of the Upper Three Runs Aquifer (TZ), the lower zone of the Upper Three Runs Aquifer (LUTRA) and the Gordon Aquifer (GAU) at two locations in R-Area between December 1999 and February 2000. Fourteen new wells, 7 pumping wells and 7 observation wells were installed in close proximity to two existing well clusters, P-20 and RPC-1, near R-Area to facilitate the conducting of these tests. Although 7 pumping wells were installed, only 6 tests could be performed. The hydraulic conductivity and saturated thickness of the A/AA Horizons near the RPC-1 cluster were so low that a minimal pumping rate could not be sustained in the pumping well in order to perform an aquifer test.

Upon completion of the field investigations and data analysis, aquifer test hydraulic conductivities were compared to the 1998 R-area regional groundwater flow model. Good agreement was observed for the GAU and TZ aquifers. For the LUTRA, the comparison was adequate, considering the heterogeneity of the unit. Excellent agreement was observed for the A/AA Horizons. Overall, the results obtained from the aquifer testing agree with the hydraulic parameter spatial distribution utilized within the 1998 R-Area regional groundwater flow model.

\section{RPT Site}

Pumping test results for the GAU are generally in good agreement with other recent pumping tests performed at the SRS (WSRC, 1999) and are indicative of silty to clean sands (6.6 - $22.6 \mathrm{ft} /$ day. The lower value supports the presence of finer grained sands 
WSRC-TR-00-00180, Rev. 0

R-Area Aquifer Tests

or silty interbeds in the vicinity. There was no observed drawdown in the in the overlying LUTRA observations wells. This supports the concept that the GCU is a very effective aquitard in this area.

The LUTRA results are indicative of a silty sand and/or calcareous sediment (1.0 $2.9 \mathrm{ft} /$ day). There was a slight drawdown above the TCCZ in the UTRA observation wells on the order of 0.5 feet but no distinct rebound when pumping was ceased. There appears to be slight hydraulic connection between the upper and lower UTRA zones probably due to interconnected sandy layers within the TCCZ. No drawdown was noted in the GAU observation wells, which is supportive of the effectiveness of the GCU as an aquitard in this area.

The TZ zone results are indicative of a silty to clean sands $(2.3 \mathrm{ft} / \mathrm{day})$. The lithology of the TZ has a distinct silty to clayey interbeds in the middle of the zone. The conductivity values obtained are supportive of these lithologies. Small, but measurable responses were noted in the LUTRA observation wells. This indicates there is a hydrologic connection between the LUTRA and TZ that permits a relatively small groundwater flux to occur across the TCCZ unit under ambient gradients. However, this vertical flux is likely to be small compared to horizontal fluxes in the overlying TZ.

A hydraulic connection exists between the TZ and the overlying A/AA Horizons as indicated by 0.75 and 1.1 foot responses observed in A/AA water levels when pumping occurred in the TZ. The observation wells extend across both the upper A and lower AA Horizons. Although screened across both horizons, the water levels in these wells respond to $\mathrm{TZ}$ pumping primarily through the interconnected sandy layers of the AA Horizon, occurring in the lower part of the screen zones.

\section{RPC Site}

No GAU aquifer tests were performed at the RPC site therefore no observations were made on the GAU and GCU. 
The LUTRA is characterized as a confined aquifer with a boundary condition at the RPC site. Lithologies encountered support a dual facies with a siliciclastic and calcareous component that results in highly permeable sediments directly in contact with lower permeability sediments. The pumping well was screened in 30 feet of siliciclastic sediments at the top and 10' of calcareous sediments at the bottom. The boundary effect encountered prevented standard analysis of this test and only the silciclastic component was hydraulically characterized. Values range from 22 to 28 $\mathrm{ft} / \mathrm{day}$ and are supportive of the lithologies described from coring at this location, which were clean sands.

The $\mathrm{TZ}$ is characterized as a high permeability unit of clean sands. The pump test values based on two observations wells ranged from 24.8 to $25.4 \mathrm{ft} / \mathrm{d}$. No hydraulic response was observed across the TCCZ between the TZ and underlying LUTRA observation wells. Based on this hydraulic response pattern, the TCCZ is an effective aquitard in this region of $\mathrm{R}$ Area.

The A/AA horizons are characterized as low permeability units of highly interbedded sandy silts and clays. The pump test values range from 1.6 to $1.7 \mathrm{ft} / \mathrm{day}$ and are indicative of a silty sand. An artificial hydraulic connection exists between the TZ and observation wells in the overlying A/AA Horizons at the RPC well site. The connection occurs through the filter pack surrounding well sumps extending 5 feet into the TZ. Even with the hydraulic connection to the TZ, RPC-1PW was unable to sustain sufficient flow to conduct a multiple-well aquifer test. These low flows are indicative of the known low permeabilities in the A/AA Horizons (WSRC, 1998a) and low measured water levels in this well which were 4 feet above the base of the screen. Several feet of drawdown are typically required to conduct a multiple well aquifer test. Considering these two factors it is not unusual that even minimal flow rates could be sustained. 
WSRC-TR-00-00180, Rev. 0

R-Area Aquifer Tests

This Page Intentionally Left Blank 
WSRC-TR-2000-00180, Rev. 0

R-Area Aquifer Tests

\subsection{REFERENCES}

ASTM D 4050, Standard Test Methodology (Field Procedure) for Withdrawal and Injection Well Tests for Determining Hydraulic Properties of Aquifer Systems. Current edition approved Oct. 10, 1996. Published Februrary 1997..

Aadland, R. K., Harris, M. K., Lewis, C. M., Gaughan, T. F., and Westbrook, T. M., 1991. Hydrostratigraphy of the General Separations Area, Savannah River Site (SRS), South Carolina. WSRC-RP-91-13, Westinghouse Savannah River Company, Aiken, SC 29808.

Aadland, R. K., Gellici, J. A., and Thayer, P. A., 1995. Hydrogeologic Framework of West-Central South Carolina. Report 5, Water Resources Division, South Carolina Department of Natural Resources, Columbia, SC.

Cooper, H.H., Jr. and C.E.Jacob. 1946. A generalized graphical method for evaluating formation constants and summarizing well field history, Trans. Amer. Geophys. Union, 27, pp.526-534.

Duffield, G.M. 1996. AQTESOLVTM for Windows User's Guide. HydroSOLVE, Inc.

Ferris, J.G., D.B. Knowles, R.H. Browne, and R.W. Stallman. 1962. Theory of aquifer tests. U.S. Geol. Surv. Water-Supply Paper 1536-E.

Flach, G. P. and Harris, M. K., 1997. Integrated Hydrogeological Model of the General Separations Area (U), Volume 2: Groundwater Flow Model (U), WSRC-TR-96-0399, Rev. 0, Westinghouse Savannah River Company, Aiken, SC 29808.

Flach, G. P., M. K. Harris, R. A. Hiergesell, A. D. Smits and K. L. Hawkins, 1999, Regional groundwater flow model for $C, K, L$, and P reactor areas, Savannah River Site, Aiken, South Carolina (U), WSRC-TR-99-00248.

Hantush, M.S. and C.E. Jacob. 1955. Non-steady radial flow in an infinite leaky aquifer, Am. Geophys. Union Tans., vol. 36, pp. 95-100.

Harris, M. K., Aadland, R. K., and Westbrook, T. M., 1990. "Lithological and Hydrological Characteristics of the Tertiary Hydrostratigraphic Systems of the General Separations Area, Savannah River Site, South Carolina". Savannah River Region: Transition Between the Gulf and Atlantic Coastal Plains, Proceedings of the Second Bald Head Island Conference on Coastal Plains Geology, University of North Carolina at Wilmington, pp 68-73.

Harris, M.K., P.A. Thayer, M.B. Amidon. 1997. Sedimentology and depositional environments of middle Eocene terrigenous-carbonate strata, southeastern Atlantic Coastal Plain, USA. Sedimentary Geology, 108, pp 141-161.

Hiergesell, R.A. 1999. Test Plan for Conducting Aquifer Tests near R-Area Reactor, WSRC-RP-9900419, Westinghouse Savannah River Company, Aiken, SC 29808 
WSRC-TR-00-00180, Rev. 0

R-Area Aquifer Tests

Jacob, C.E. 1963. The Recovery Method for Determining the Coefficient of Transmissibility. U.S.

Geological Survey Water-Supply Paper 1536-I, 1963, pp283-292.

Jones, W.F., Haselow, J.S., Harris, M.K., and Denham, M.E., 1998, Groundwater Flow and Contaminant Transport for the R-Reactor Seepage Basins (U), WSRC-OS-00011, Rev. 0 HydroGeoLogic, Inc., Herndon, VA, 406 p.

Neuman, S.P. 1974. Effect of partial penetration on flow in unconfined aquifers considering delayed gravity response, Water Resources Research, vol. 10, no.2, pp. 303-312.

Theis, C.V. 1935. The relation between lowering of the piezometric surface and the rate and duration of discharge of a well using groundwater storage. Trans. Amer. Geophys. Union, 2, pp.519-524.

WSRC, 1998, Response to USEPA December 1998 Comments on the RFI/RI Report for the RReactor Seepage Basins (RRSB)/108-4R Overflow Basin Operable Unit (U), WSRC-RP-9800314, Rev. 0, August 1998, Westinghouse Savannah River Company, Aiken, SC 29808.

WSRC, 1998a, RCRA Facility Investigation Remedial Investigation Report with Baseline Risk Assessment for the R-Reactor Seepage Basins 108-4R Overflow Basin Operable Unit (U), WSRC-RP-00314, Rev. 0, August 1998, Westinghouse Savannah River Company, Aiken, SC 29808.

WSRC, 2000, Field Summary Report for Installation of Pumping and Observation Wells in R Area, $(U)$, WSRC-RP-2000-4058, April 2000, Westinghouse Savannah River Company, Aiken, SC 29808.

WSRC, 1999, Aquifer Testing Results from the Burial Ground Complex (U). Books 1 and2, WSRCRP-99-4069, June 1999, Westinghouse Savannah River Company, Aiken, SC 29808 
WSRC-TR-00-00180, Rev. 0

R-Area Aquifer Tests

APPENDIX A

HYDROSTRATIGRAPHIC PICKS, CPT, AND GEOPHYSICAL LOGS 
WSRC-TR-00-00180, Rev. 0

R-Area Aquifer Tests

This Page Intentionally Left Blank 
WSRC-TR-00-00180, Rev. 0 R-Area Aquifer Tests

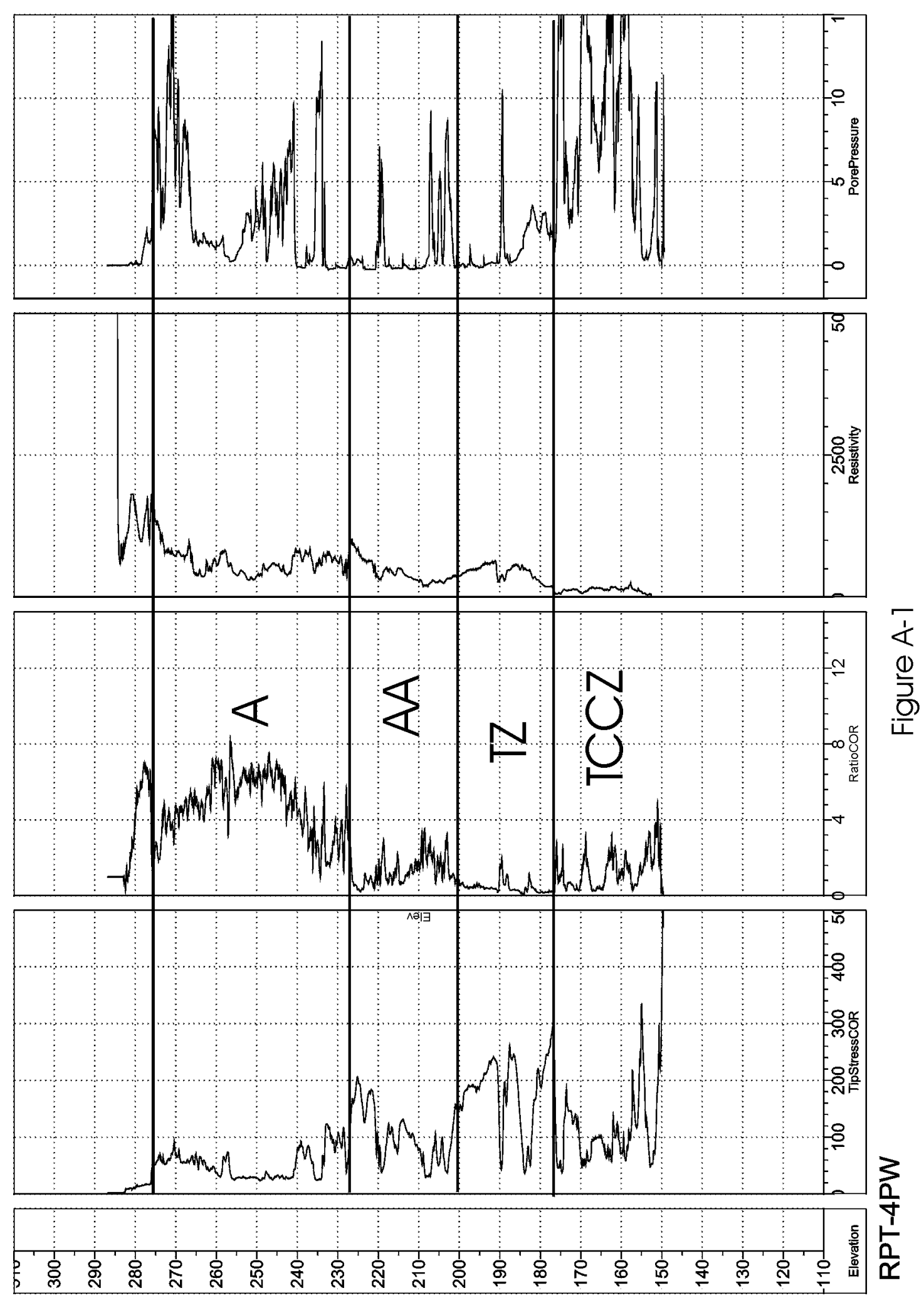


WSRC-TR-00-00180, Rev. 0

R-Area Aquifer Tests

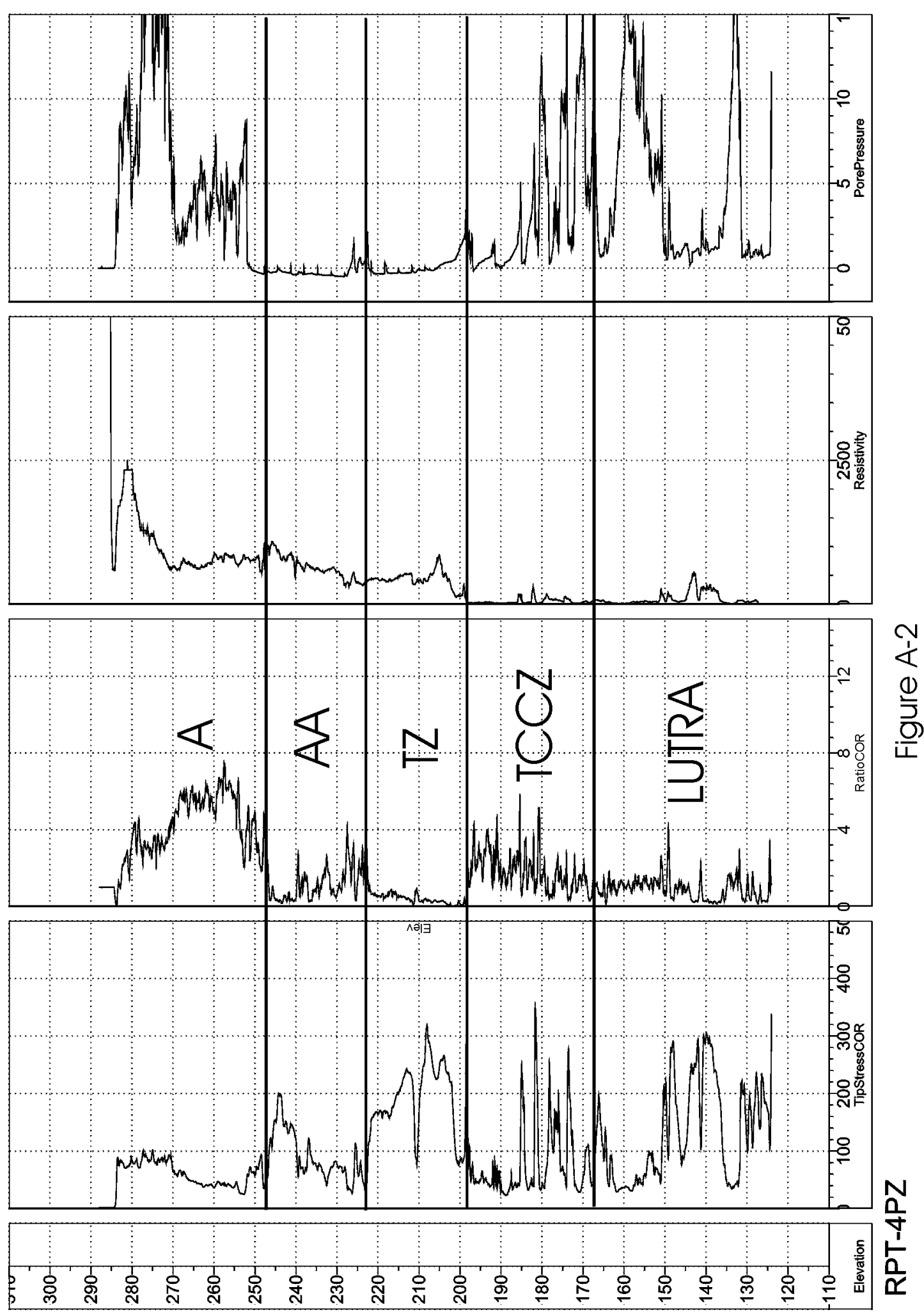


WSRC-TR-00-00180, Rev. 0

R-Area Aquifer Tests

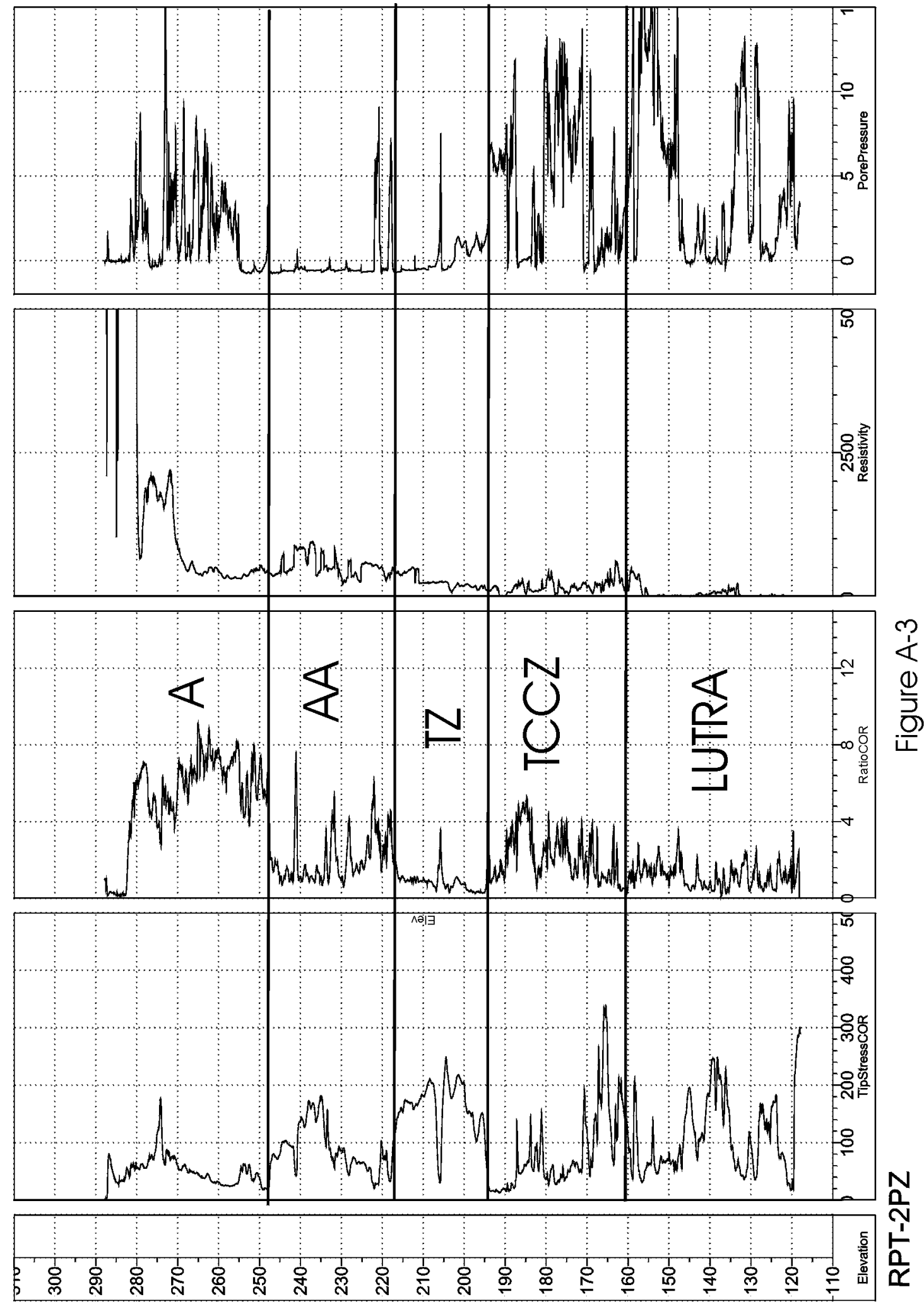


WSRC-TR-00-00180, Rev. 0

R-Area Aquifer Tests

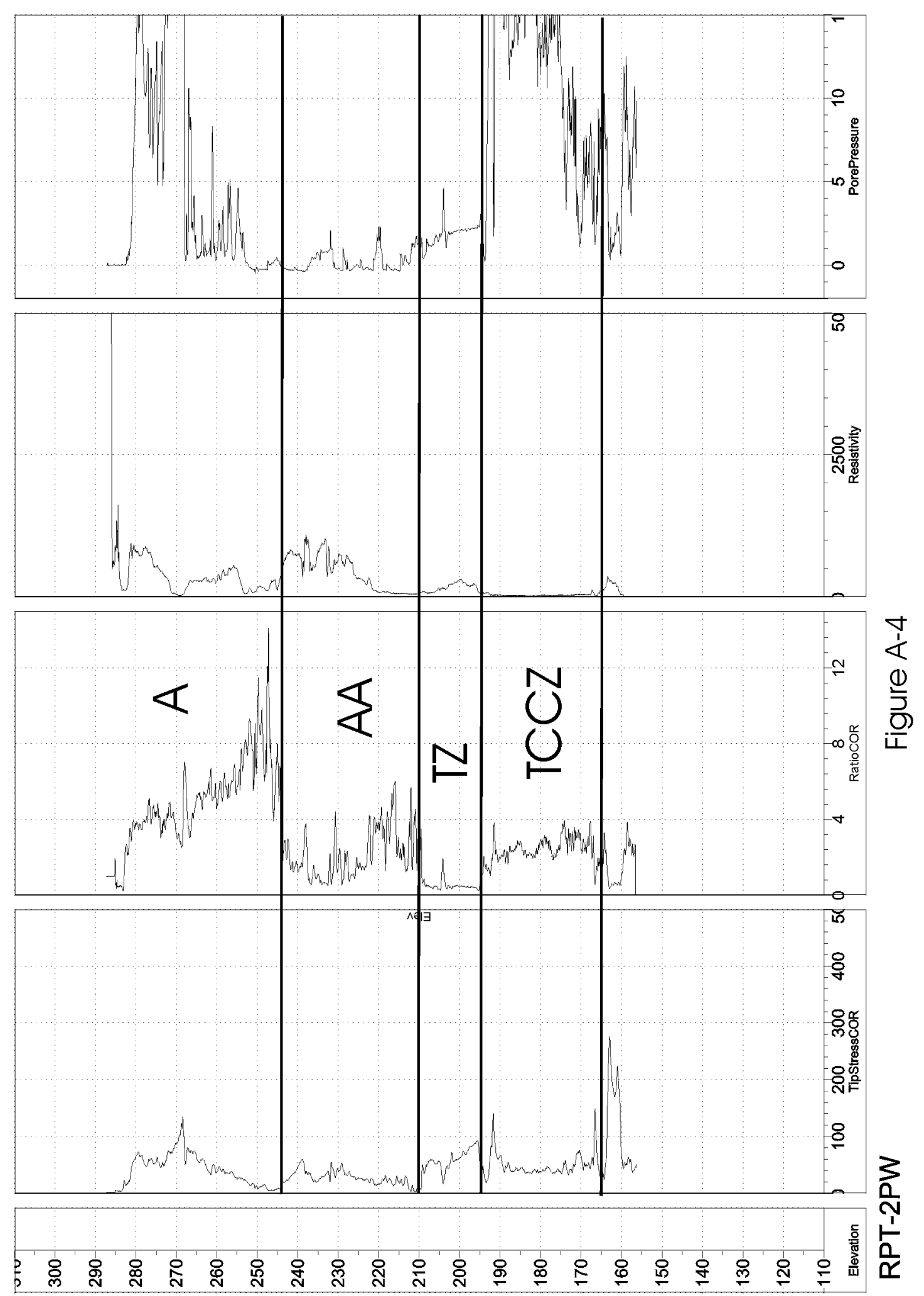



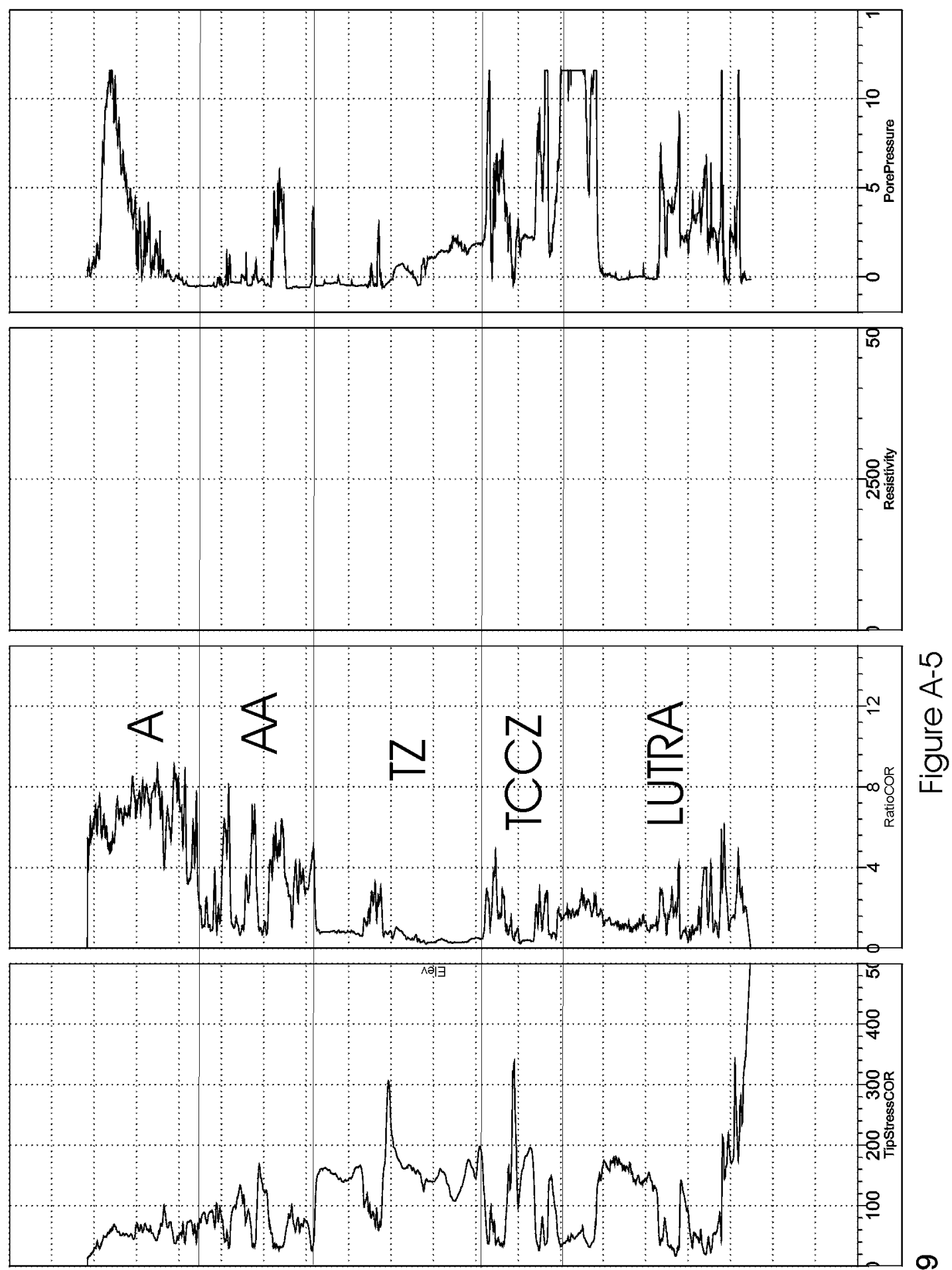

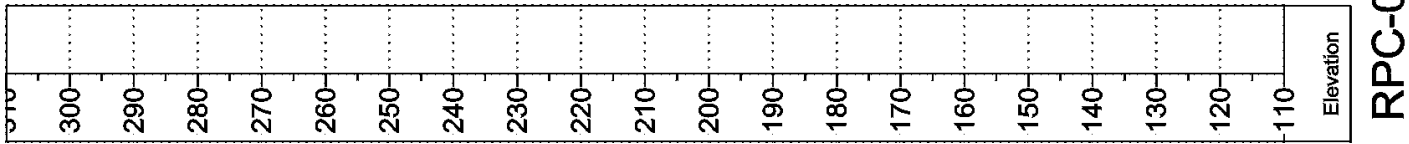


WSRC-TR-00-00180, Rev. 0

R-Area Aquifer Tests
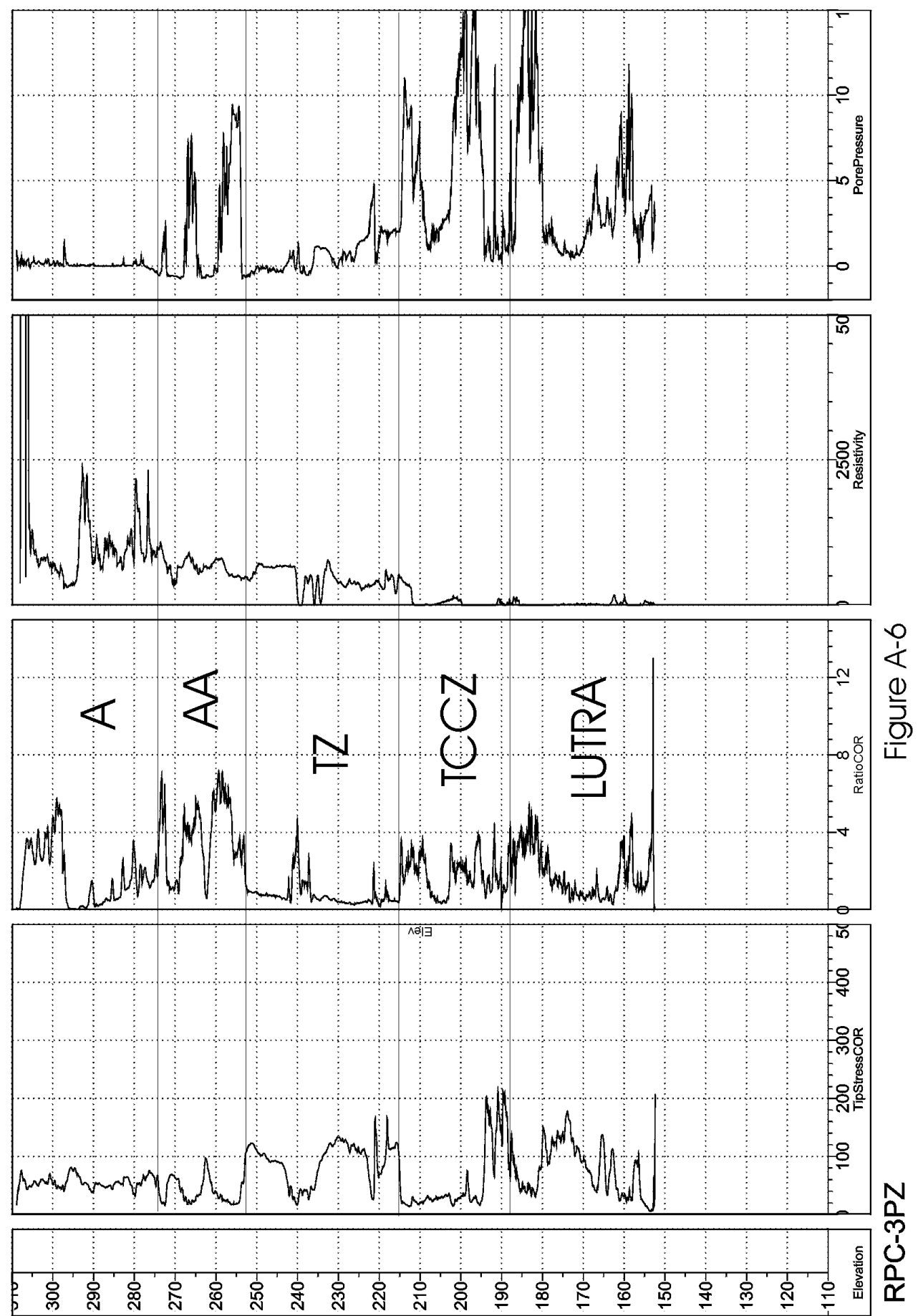


WSRC-TR-00-00180, Rev. 0

R-Area Aquifer Tests
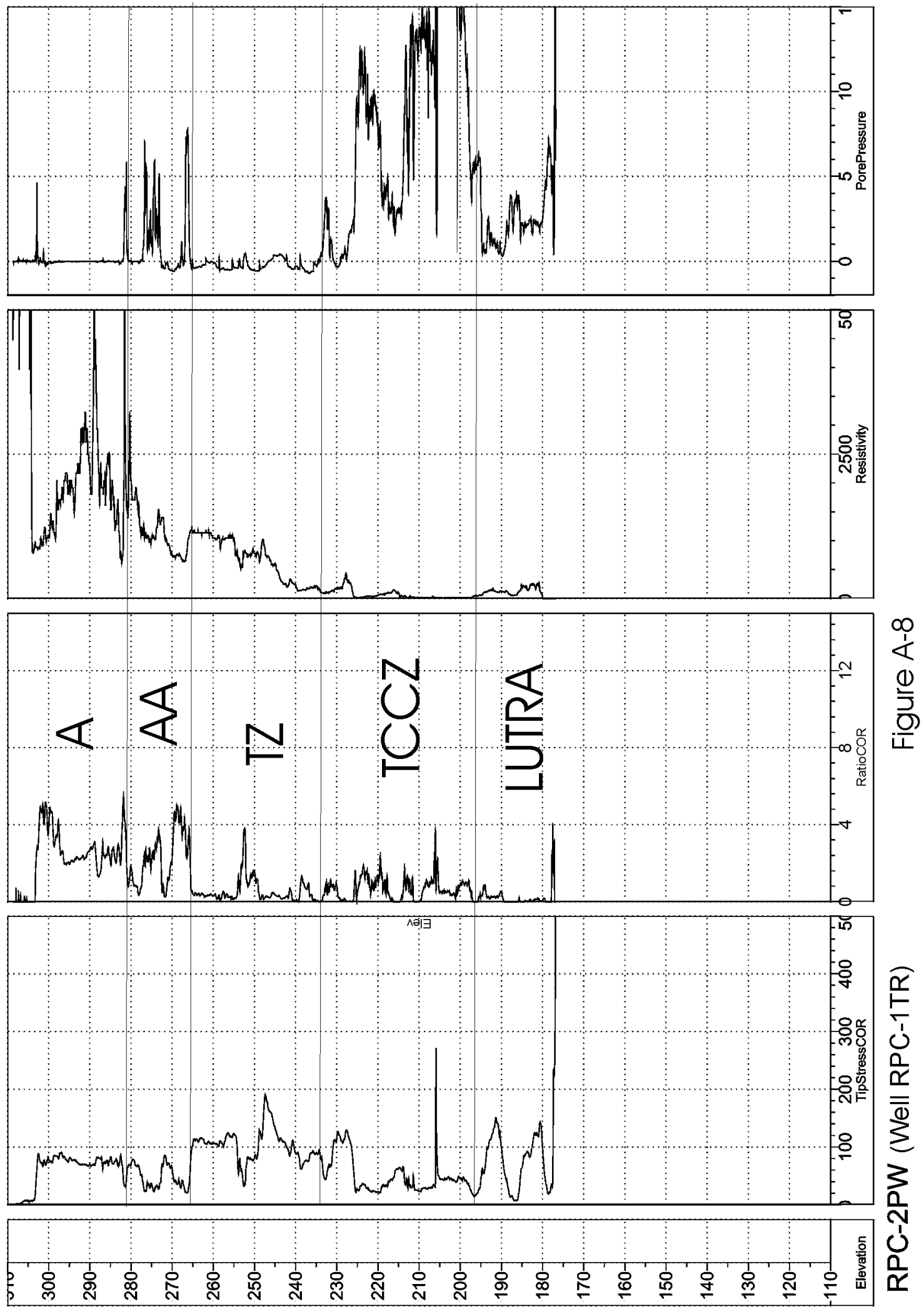

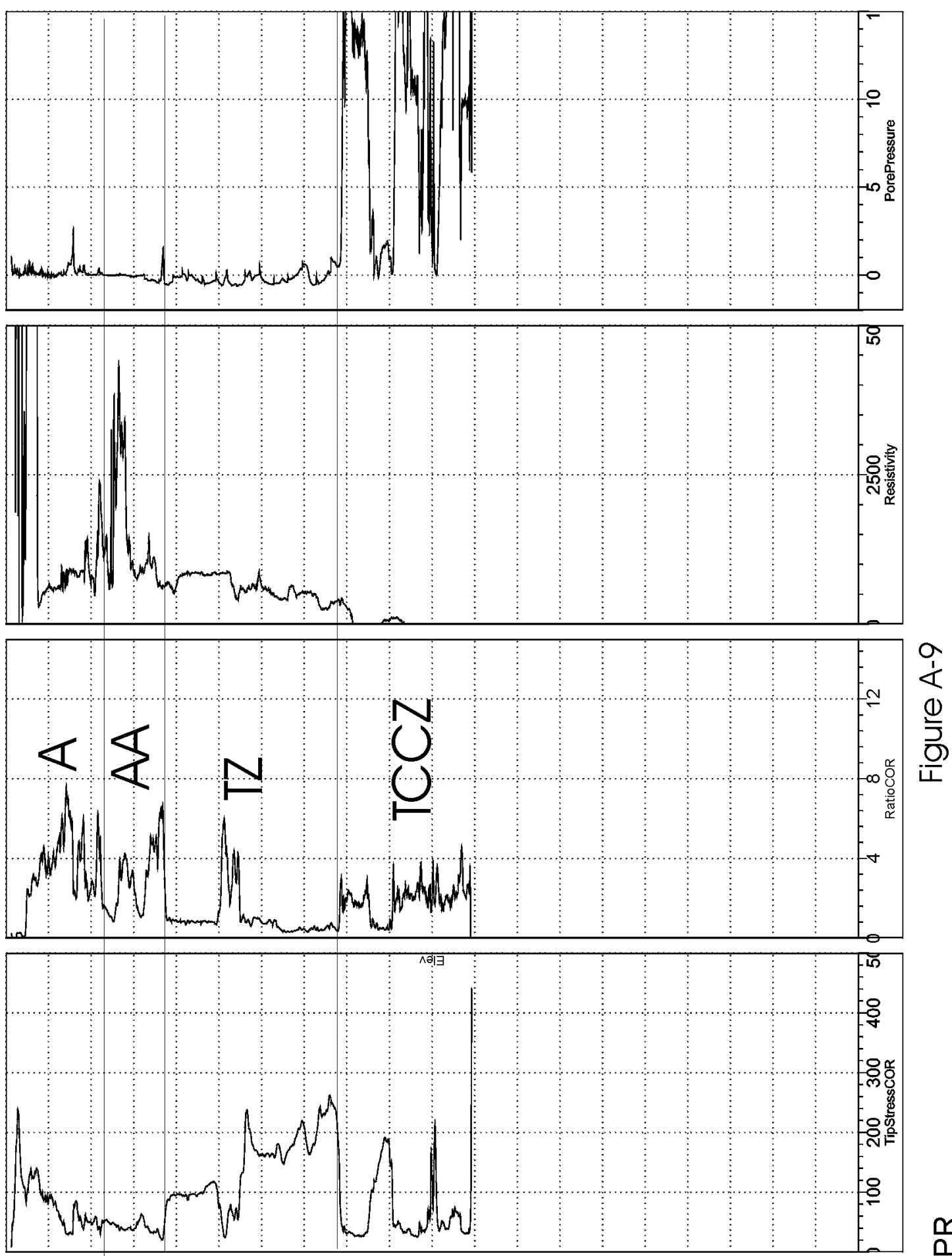

$\frac{\alpha}{n}$

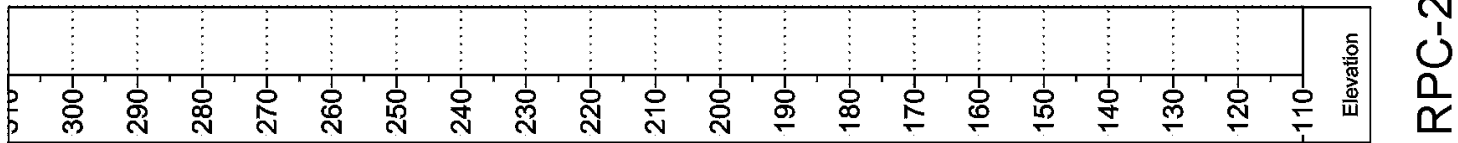


WSRC-TR-00-00180, Rev. 0

R-Area Aquifer Tests
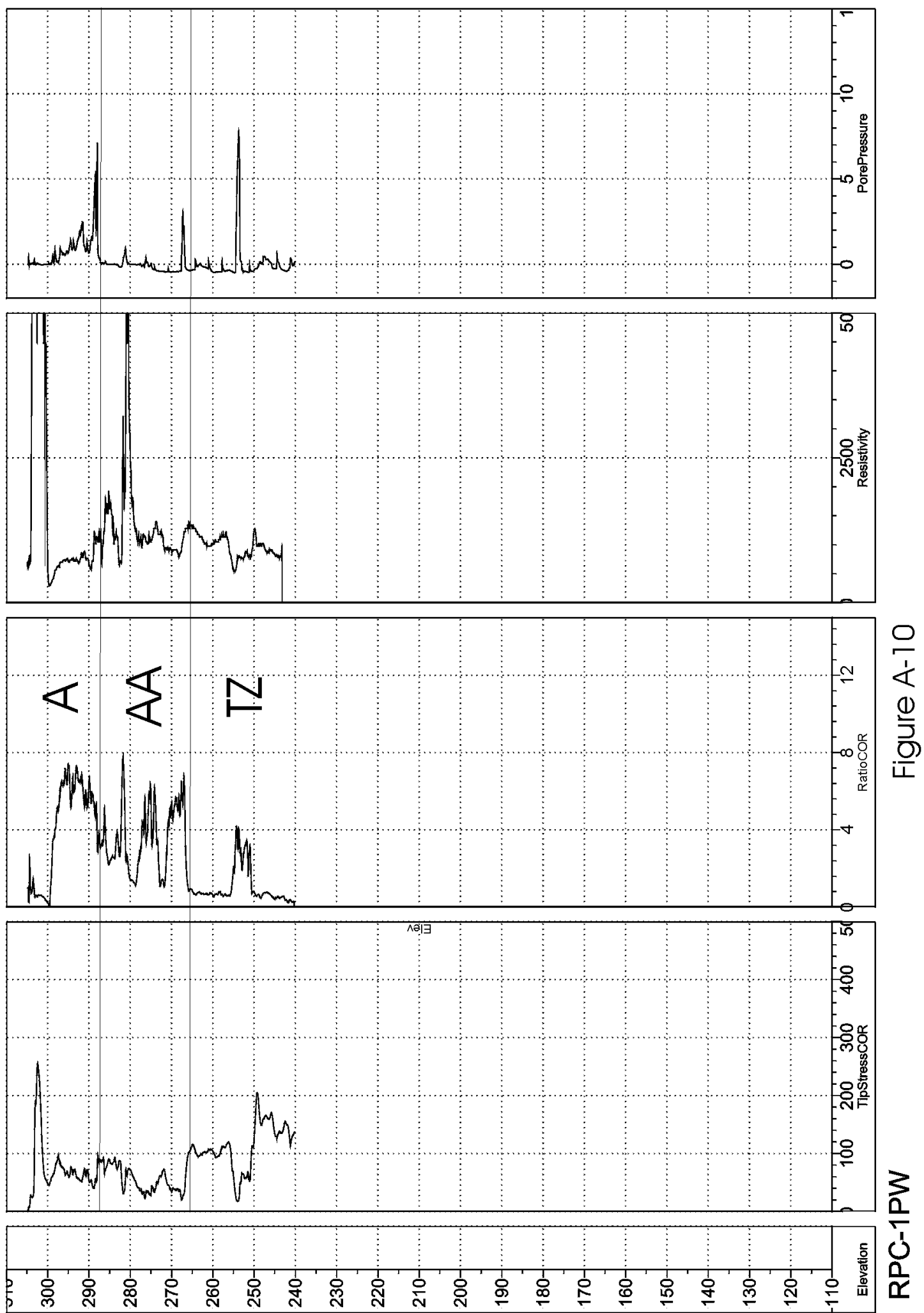
WSRC-TR-00-00180, Rev. 0

R-Area Aquifer Tests
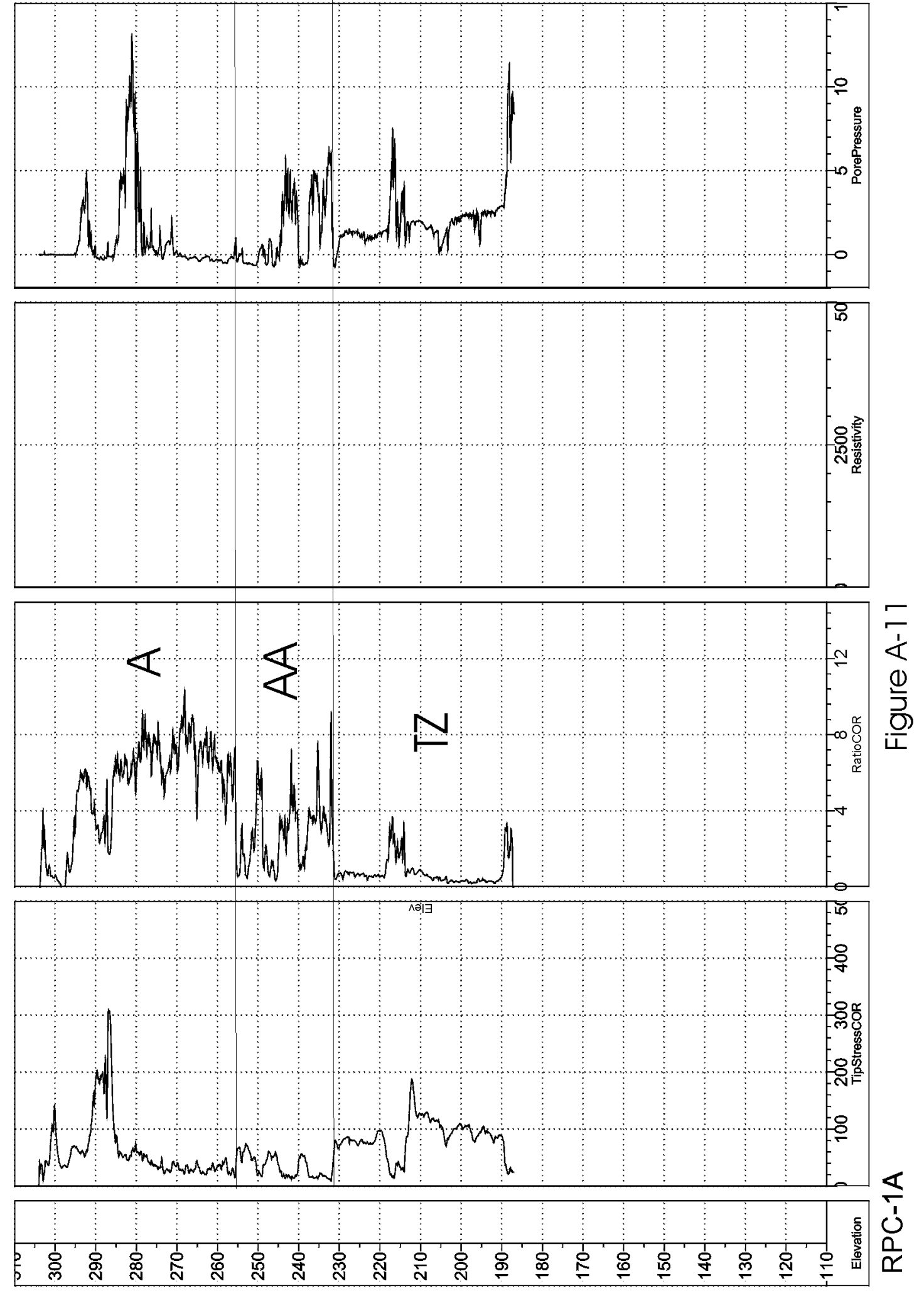
WSRC-TR-00-00180, Rev. 0

R-Area Aquifer Tests
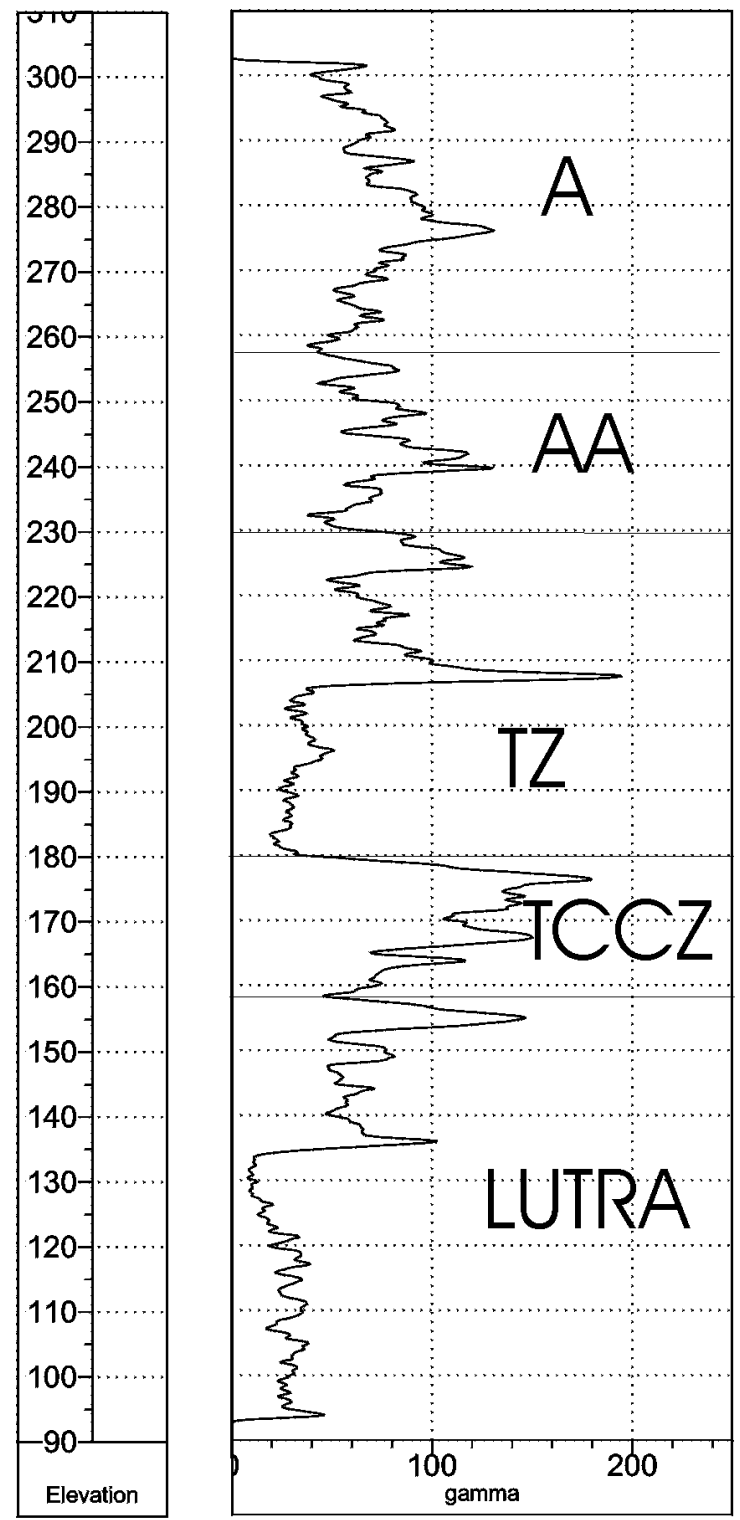

RPC-1CL Gamma Geophysical Log

Figure A-12 


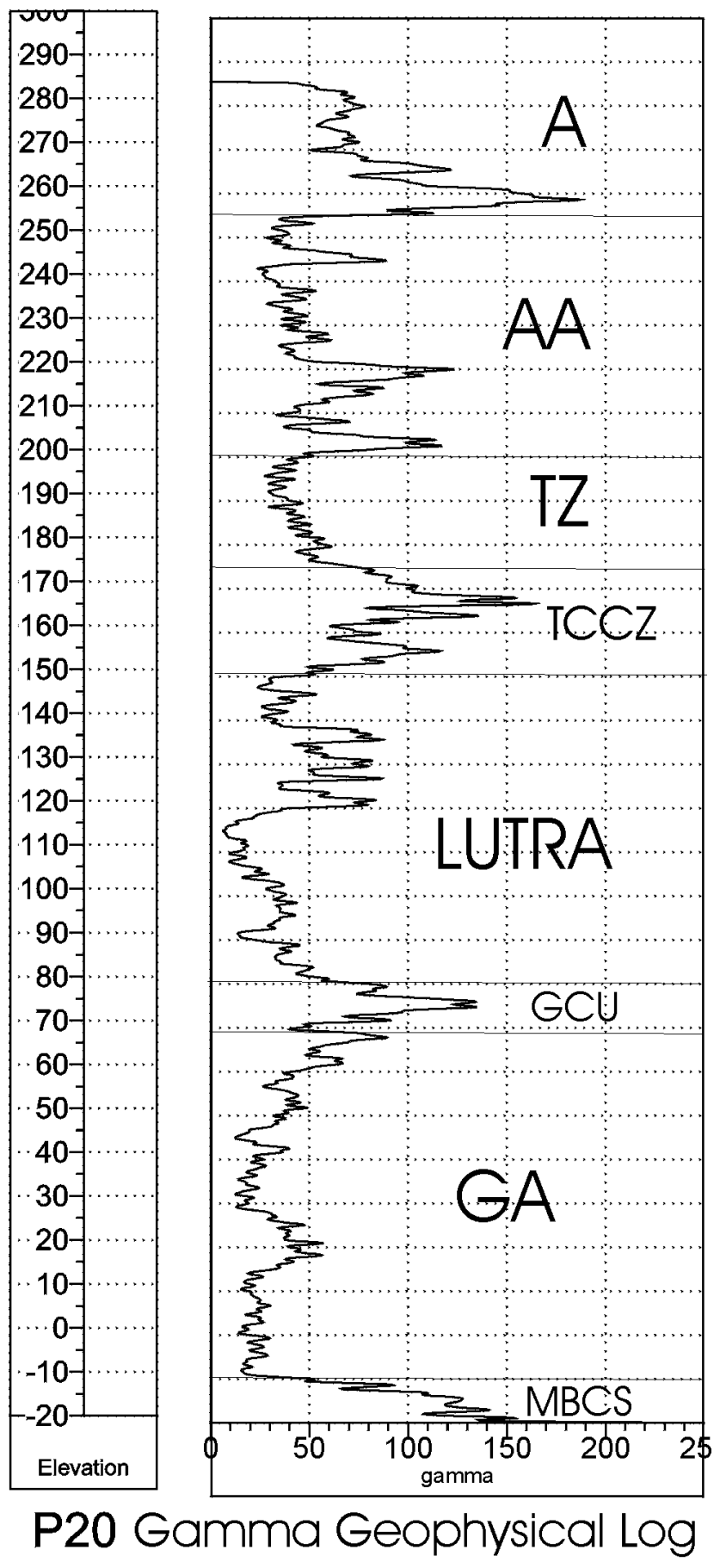

Figure A-13 
WSRC-TR-00-00180, Rev. 0

R-Area Aquifer Tests

This Page Intentionally Left Blank 
WSRC-TR-00-00180, Rev. 0

R-Area Aquifer Tests

\section{APPENDIX B}

\section{SITE-SPECIFIC PERMEABILITY DATA}

Laboratory Falling-Head Permeability Test Results

Slug Test Results 
WSRC-TR-00-00180, Draft, Rev. 0

R-Area Aquifer Tests

This Page Intentionally Left Blank 
WSRC-TR-00-00180, Rev. 0

R-Area Aquifer Tests

Table B-1. R Area Phase I and II Field Investigations Permeability Measurements Summary (Jones et al., 1998)

\begin{tabular}{lcccc}
\hline \multirow{2}{*}{ Hydrostratigraphic Unit } & \multicolumn{2}{c}{ Laboratory Tests (ft/day) } & Slug & Pumping \\
\cline { 2 - 3 } & Vertical & Horizontal & Tests (ft/day) & Tests (ft/day) \\
\hline
\end{tabular}

Surface Soils - R Area

Number of Results

Minimum

8.22E-05

Maximum

9.92E-03

Arithmetic Mean

5.00E-03

Geometric Mean

9.03E-04

Standard Deviation

6.96E-03

“A” Horizon - R Area

Number of Results

Minimum

6.24E-05

9

Maximum

1.25E-02

2.36E-02

Arithmetic Mean

2.84E-03

$1.79 \mathrm{E}+00$

Geometric Mean

1.13E-03

4.79E-01

Standard Deviation

3.52E-03

2.31E-01

“AA” Horizon - R Area

Number of Results

Minimum

9.92E-04

Maximum

$8.50 \mathrm{E}-02$

Arithmetic Mean

2.06E-02

Geometric Mean

8.82E-03

Standard Deviation

2.72E-02

“Transmissive zone"- R Area

Number of Results

6

5.78E-01

Minimum

3.12E-04

18

Maximum

$1.73 \mathrm{E}+00$

1.69E-01

Arithmetic Mean

2.92E-01

$1.48 \mathrm{E}+00$

Geometric Mean

7.92E-03

5.25E-01

Standard Deviation

7.04E-01

4.29E-01

3.67E-01 
WSRC-TR-00-00180, Draft, Rev. 0

R-Area Aquifer Tests

R Area Phase I and II Field Investigations Permeability Measurements Summary (Jones et al., 1998) - Continued

\begin{tabular}{lllcc}
\hline \multirow{3}{*}{ Hydrostratigraphic Unit } & \multicolumn{2}{l}{ Laboratory Tests (ft/day) } & Slug & Pumping \\
\cline { 2 - 3 } & Vertical & Horizontal & Tests (ft/day) & Tests (ft/day)
\end{tabular}

“Tan Clay” CZ - R Area

Number of Results

Minimum

7

Maximum

6.24E-05

Arithmetic Mean

$1.13 \mathrm{E}+00$

Geometric Mean

1.94E-01

Standard Deviation

3.66E-03

4.22E-01

"lower" aquifer zone-central SRS

Number of Results

Minimum

33

31

25

3

Maximum

4.54E-06

1.59E-05

1.30E-01

$1.23 \mathrm{E}+00$

$3.42 \mathrm{E}+00$

$1.11 \mathrm{E}+01$

$2.44 \mathrm{E}+01$

$2.10 \mathrm{E}+00$

Arithmetic Mean

1.77E-01

6.45E-01

$3.90 \mathrm{E}+00$

$1.67 \mathrm{E}+00$

Geometric Mean

2.82E-03

1.02E-02

$1.67 \mathrm{E}+00$

$1.63 \mathrm{E}+00$

Standard Deviation

6.19E-01

$2.03 \mathrm{E}+00$

$6.09 \mathrm{E}+00$

4.35E-01

Gordon Confining Unit -

Number of Results

Minimum

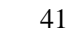

25

1.14E-06

5.40E-06

Maximum

4.27E-01

1.22E-01

Arithmetic Mean

$1.20 \mathrm{E}-02$

$1.06 \mathrm{E}-02$

Geometric Mean

$1.15 \mathrm{E}-04$

$1.62 \mathrm{E}-04$

Standard Deviation

$6.68 \mathrm{E}-02$

3.09E-02

Gordon Aquifer-central SRS

Number of Results

Minimum

23

3.12E-06

24

Maximum

3.62E+01

2.06E-05

$3.26 \mathrm{E}+01$

$1.66 \mathrm{E}+00$

$5.25 \mathrm{E}+00$

7.73E-04

$1.05 \mathrm{E}-02$

Geometric Mean

$7.54 \mathrm{E}+00$

$1.12 \mathrm{E}+01$

27

1.11E-05

$1.50 \mathrm{E}+00$

Maximum

4.26E-06

3.40E-01

8.63E-02

Arithmetic Mean

$1.39 \mathrm{E}-02$

5.52E-04

Geometric Mean

2.47E-04

3.12E-01

Standard Deviation

5.65E-02 
Table B-2. R-Area Falling-Head Permeability (ASTM D5084) Measurements Summary

\begin{tabular}{|c|c|c|c|c|c|}
\hline $\begin{array}{c}\text { Boring } \\
\text { No. }\end{array}$ & $\begin{array}{l}\text { Depth } \\
\text { (ft) }\end{array}$ & $\begin{array}{c}\text { Sample } \\
\text { Description }\end{array}$ & $\begin{array}{c}\text { Vertical } \\
\text { Hydraulic } \\
\text { Conductivity } \\
\text { cm/sec }\end{array}$ & $\begin{array}{c}\text { Vertical } \\
\text { Hydraulic } \\
\text { Conductivity } \\
\text { ft/day }\end{array}$ & $\begin{array}{c}\text { Hydrostratigraphic } \\
\text { Unit }\end{array}$ \\
\hline RPC-2PW & 98.5 & $\begin{array}{c}\text { tan gray } \\
\text { clayey sand }\end{array}$ & 2.70E-08 & 7.64E-05 & Top of LUTRA \\
\hline RPC-2PW & 116.5 & $\begin{array}{l}\text { light gray silty } \\
\text { sand }\end{array}$ & $2.80 \mathrm{E}-06$ & 7.92E-03 & LUTRA \\
\hline RPC-1PW & 40.5 & $\begin{array}{l}\text { purple brown } \\
\text { silty sand }\end{array}$ & $2.50 \mathrm{E}-04$ & 7.08E-01 & Top of TZ \\
\hline RPC-1PW & 50.5 & $\begin{array}{l}\text { purple brown } \\
\text { clayey sand }\end{array}$ & 5.00E-08 & $1.42 \mathrm{E}-04$ & $\mathrm{TZ}$ \\
\hline RPC-3PW & 82 & $\begin{array}{c}\text { red brown } \\
\text { sandy clay } \\
\text { w/sand layers }\end{array}$ & $5.80 \mathrm{E}-07$ & $1.64 \mathrm{E}-03$ & Top of LUTRA \\
\hline CPT-4PZ & 123.5 & $\begin{array}{l}\text { yellow brown } \\
\text { silty sand }\end{array}$ & 9.00E-06 & $2.55 \mathrm{E}-02$ & Top of LUTRA \\
\hline CPT-15PZ & 25 & $\begin{array}{l}\text { red brown } \\
\text { sandy silt }\end{array}$ & $3.20 \mathrm{E}-06$ & $9.06 \mathrm{E}-03$ & A Horizon \\
\hline CPT-15PZ & 46.5 & $\begin{array}{l}\text { light purple } \\
\text { silty sand }\end{array}$ & $2.30 \mathrm{E}-05$ & $6.51 \mathrm{E}-02$ & Bottom of A Horizon \\
\hline CPT-15PZ & 62 & $\begin{array}{l}\text { tan brown } \\
\text { sandy silt }\end{array}$ & $5.00 \mathrm{E}-06$ & $1.42 \mathrm{E}-02$ & AA Horizon \\
\hline CPT-2PW & 36.5 & $\begin{array}{l}\text { reddish brown } \\
\text { silty sand }\end{array}$ & $2.10 \mathrm{E}-05$ & $5.94 \mathrm{E}-02$ & Bottom of A Horizon \\
\hline
\end{tabular}

All data from Law Engineering and Environmental

Services, Inc.

Technical Report "Transmittal of Test Results for: R-Reactor

Pump Tests

Investigation", August 5, 1999 
WSRC-TR-00-00180, Draft, Rev. 0

R-Area Aquifer Tests

Table B-3. R Area Slug Test Estimated Hydraulic Conductivity Summary

\begin{tabular}{|c|c|c|c|c|c|}
\hline $\begin{array}{l}\text { Well } \\
\text { Designation }\end{array}$ & $\begin{array}{l}\text { Falling } \\
\text { Head } \\
\text { Test } \\
\text { (ft/min) }\end{array}$ & $\begin{array}{l}\text { Falling } \\
\text { Head } \\
\text { Test } \\
\text { (ft/day) }\end{array}$ & $\begin{array}{c}\text { Rising Head } \\
\text { Head } \\
\text { Test } \\
\text { (ft/min) }\end{array}$ & $\begin{array}{c}\text { Rising Head } \\
\text { Head } \\
\text { Test } \\
\text { (ft/day) }\end{array}$ & $\begin{array}{c}\text { Hydrostratigraphic } \\
\text { Unit }\end{array}$ \\
\hline RPT-4PW & 1.08E-03 & $1.56 \mathrm{E}+00$ & 1.31E-03 & $1.89 E+00$ & Gordon Aquifer \\
\hline RPT-3PW & $1.09 \mathrm{E}-03$ & $1.57 \mathrm{E}+00$ & $1.18 \mathrm{E}-03$ & $1.70 \mathrm{E}+00$ & LUTRA \\
\hline RPT-2PW & 3.34E-04 & 4.81E-01 & 2.89E-04 & 4.16E-01 & TZ \\
\hline RPT-15PZ & None Listed & None Listed & 1.19E-03 & $1.71 \mathrm{E}+00$ & A/AA Horizons \\
\hline RPT-30PZ & None Listed & None Listed & 6.90E-04 & 9.94E-01 & A/AA Horizons \\
\hline RPT-2PZ & 8.09E-04 & $1.16 \mathrm{E}+00$ & 7.63E-04 & $1.10 \mathrm{E}+00$ & $\mathrm{TZ}$ \\
\hline RPT-3PZ & $1.28 \mathrm{E}-03$ & $1.84 \mathrm{E}+00$ & $1.21 \mathrm{E}-03$ & $1.74 \mathrm{E}+00$ & LUTRA \\
\hline RPT-4PZ & 2.97E-03 & $4.28 \mathrm{E}+00$ & 2.60E-03 & $3.74 \mathrm{E}+00$ & Gordon Aquifer \\
\hline RPC-3PW & 3.12E-02 & $4.49 \mathrm{E}+01$ & 3.60E-02 & $5.18 \mathrm{E}+01$ & LUTRA \\
\hline RPC-2PR & 1.90E-03 & $2.74 \mathrm{E}+00$ & 2.00E-03 & $2.88 \mathrm{E}+00$ & $\mathrm{TZ}$ \\
\hline RPC-3PZ & $3.77 \mathrm{E}-05$ & 5.43E-02 & $7.22 \mathrm{E}-05$ & $1.04 \mathrm{E}-01$ & LUTRA \\
\hline RPC-1TR & 1.69E-03 & $2.43 E+00$ & $1.46 \mathrm{E}-03$ & $2.10 \mathrm{E}+00$ & $\mathrm{TZ}$ \\
\hline RPC-1PW & None Listed & None Listed & 2.02E-04 & 2.91E-01 & A Horizon \\
\hline RPC-1PZ & None Listed & None Listed & $1.91 \mathrm{E}-04$ & $2.75 \mathrm{E}-01$ & A Horizon \\
\hline
\end{tabular}

All data from: Field Summary Report for Installation of Pumping and Observation Wells in R Area (U) WSRC-RP-2000-4058, April 2000. 
WSRC-TR-00-00180, Rev. 0

R-Area Aquifer Tests

\section{APPENDIX C}

Manual water level and pumping rate measurements for RPT tests

$$
\begin{aligned}
& \text { RPT-30PZ } \\
& \text { RPT-2PW } \\
& \text { RPT-3PW } \\
& \text { RPT-4PW }
\end{aligned}
$$


WSRC-TR-00-00180, Rev. 0

R-Area Aquifer Tests

This page intentionally left blank 
WSRC-TR-00-00180, Rev. 0

R-Area Aquifer Tests

\section{Aquifer Test Field Data Extraction Well RPT-30PZ}

Start Antecedent: 12-22-9 @ 12:51

Stop Antecedent: 01-03-00 @ 09:51

Start Extraction: 01-03-00 @ 11:00

Stop Extraction: 01-05-00 @ 15:01

Stop Recovery: 01-07-00 @ 14:00

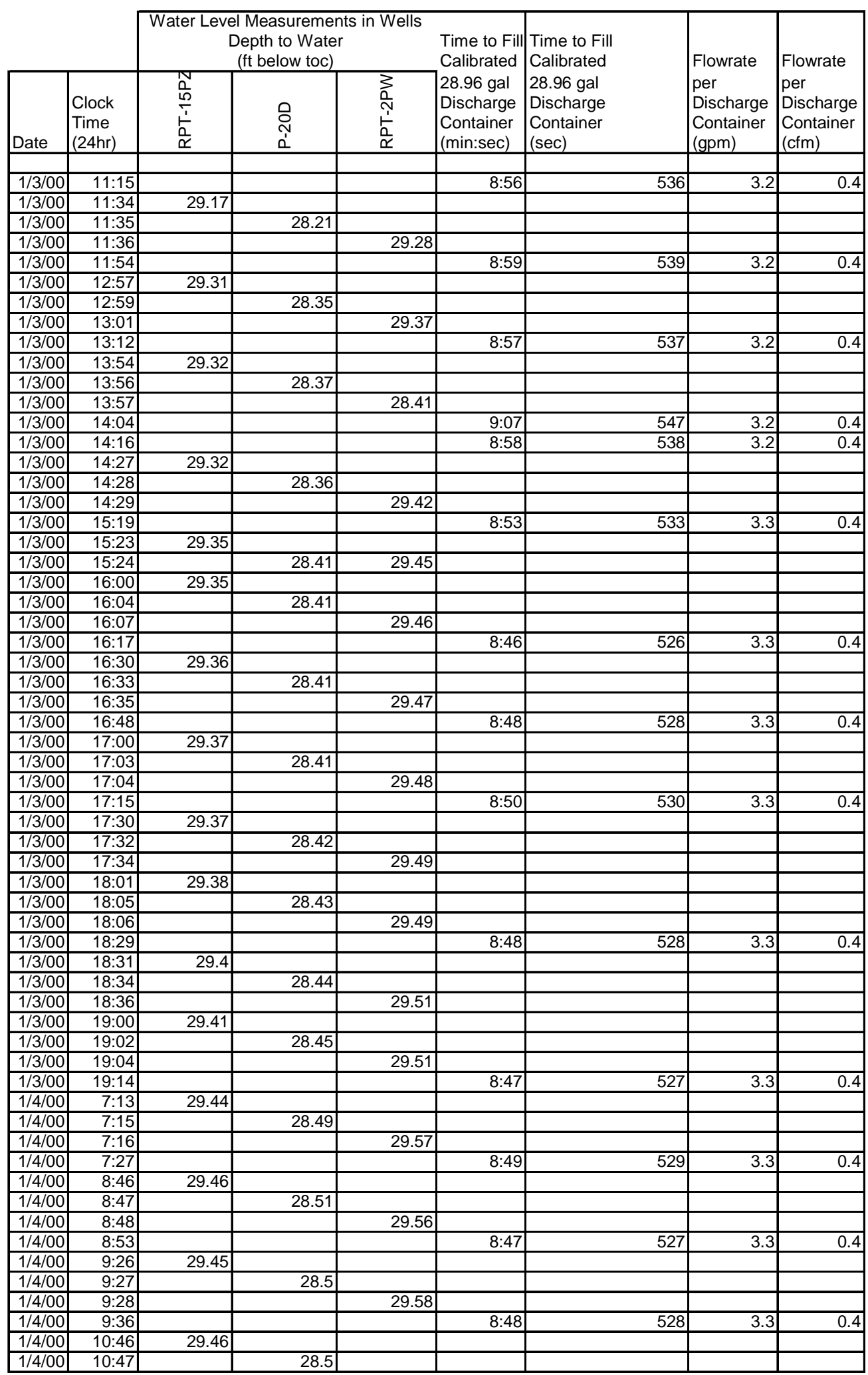


WSRC-TR-00-00180, Rev. 0

R-Area Aquifer Tests

Aquifer Test Field Data Extraction Well RPT-30PZ (cont.)

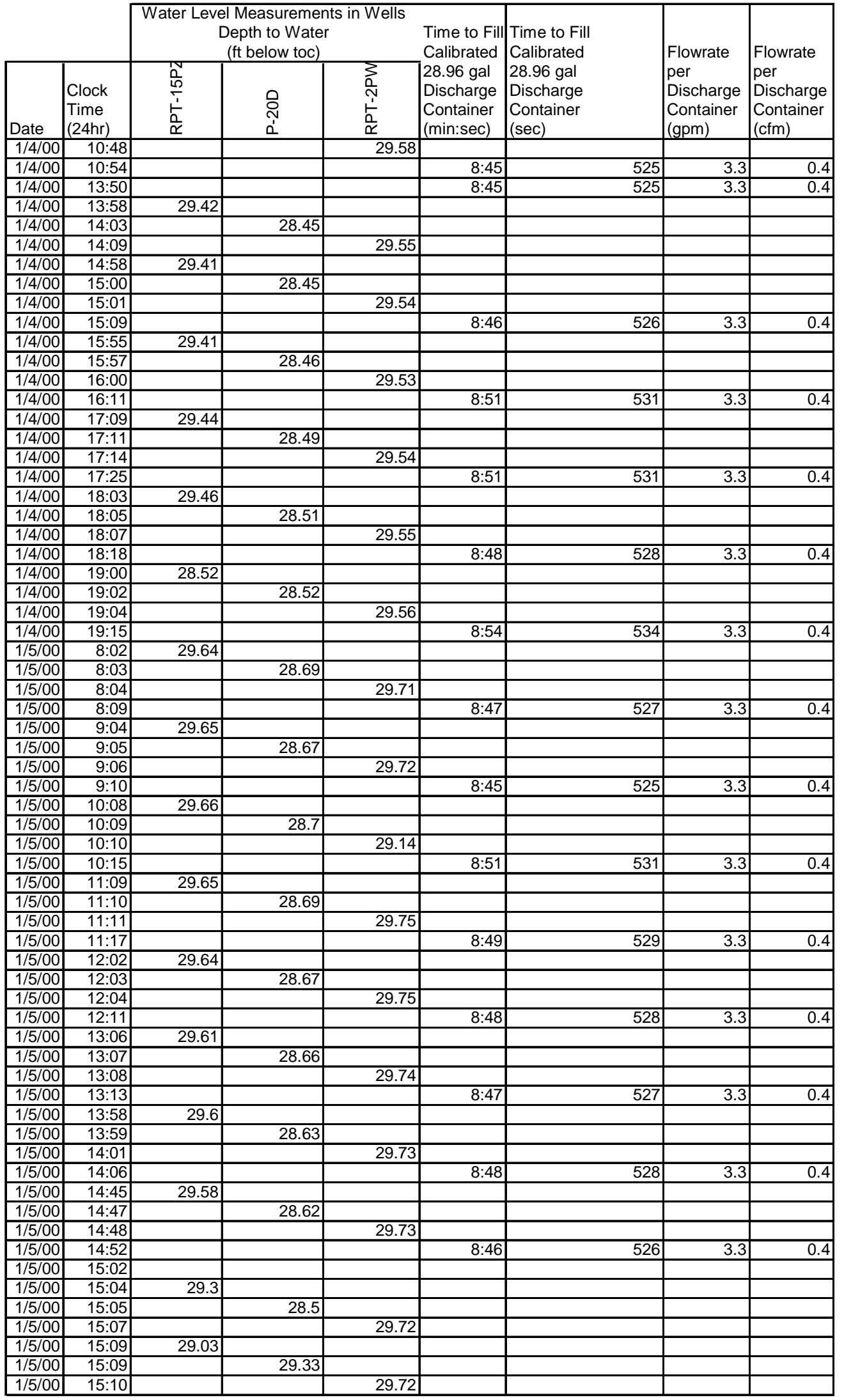


WSRC-TR-00-00180, Rev. 0 R-Area Aquifer Tests

Aquifer Test Field Data Extraction Well RPT-30PZ (cont.)

\begin{tabular}{|c|c|c|c|c|c|c|c|c|}
\hline & \multicolumn{3}{|c|}{$\begin{array}{l}\text { Water Level Measurements in Wells } \\
\text { Depth to Water } \\
\text { (ft below toc) }\end{array}$} & \multirow{2}{*}{$\begin{array}{l}\text { Time to Fill } \\
\text { Calibrated } \\
\text { |28.96 gal } \\
\text { Discharge } \\
\text { Container } \\
\text { (min:sec) }\end{array}$} & \multirow{2}{*}{\begin{tabular}{|l} 
Time to Fill \\
Calibrated \\
28.96 gal \\
Discharge \\
Container \\
(sec)
\end{tabular}} & \multirow[b]{2}{*}{$\begin{array}{l}\text { Flowrate } \\
\text { per } \\
\text { Discharge } \\
\text { Container } \\
\text { (gpm) }\end{array}$} & \multirow[b]{2}{*}{$\begin{array}{l}\text { Flowrate } \\
\text { per } \\
\text { Discharge } \\
\text { Container } \\
(\mathrm{cfm})\end{array}$} \\
\hline Date & $\begin{array}{l}\text { Clock } \\
\text { Time } \\
(24 \mathrm{hr})\end{array}$ & $\begin{array}{l}\frac{1}{0} \\
\frac{10}{5} \\
\frac{1}{n} \\
\frac{1}{x}\end{array}$ & 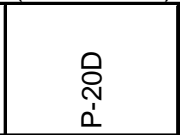 & 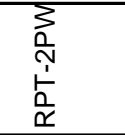 & & & & \\
\hline $1 / 5 / 00$ & $15: 11$ & 28.9 & & & & & & \\
\hline $1 / 5 / 00$ & $15: 11$ & & 28.23 & & & & & \\
\hline $1 / 5 / 00$ & $15: 12$ & & & 29.74 & & & & \\
\hline $1 / 5 / 00$ & $15: 13$ & 28.77 & & & & & & \\
\hline $1 / 5 / 00$ & $15: 14$ & & 28.15 & & & & & \\
\hline $1 / 5 / 00$ & $15: 16$ & 28.71 & & & & & & \\
\hline \begin{tabular}{|l|}
$1 / 5 / 00$ \\
\end{tabular} & $15: 17$ & & 28.08 & & & & & \\
\hline $1 / 5 / 00$ & $15: 20$ & 28.64 & & & & & & \\
\hline $1 / 5 / 00$ & $15: 21$ & & 28.01 & & & & & \\
\hline $1 / 5 / 00$ & $15: 22$ & 28.59 & & & & & & \\
\hline $1 / 5 / 00$ & $15: 23$ & & 27.98 & & & & & \\
\hline $1 / 5 / 00$ & $15: 24$ & & & 29.73 & & & & \\
\hline $1 / 5 / 00$ & $15: 31$ & 28.51 & & & & & & \\
\hline $1 / 5 / 00$ & $15: 32$ & & 27.9 & & & & & \\
\hline $1 / 5 / 00$ & $15: 41$ & 28.46 & & & & & & \\
\hline $1 / 5 / 00$ & $15: 42$ & & 27.85 & & & & & \\
\hline $1 / 5 / 00$ & $15: 43$ & & & 29.71 & & & & \\
\hline $1 / 5 / 00$ & $15: 54$ & 28.39 & & & & & & \\
\hline $1 / 5 / 00$ & $15: 55$ & & 27.81 & & & & & \\
\hline $1 / 5 / 00$ & $15: 58$ & & & 29.7 & & & & \\
\hline $1 / 6 / 00$ & $9: 43$ & 28.19 & & & & & & \\
\hline \begin{tabular}{|l|}
$1 / 6 / 00$ \\
\end{tabular} & $9: 44$ & & 27.6 & & & & & \\
\hline $1 / 6 / 00$ & 9:45 & & & 29.42 & & & & \\
\hline $1 / 6 / 00$ & $11: 29$ & 28.19 & & & & & & \\
\hline $1 / 6 / 00$ & $11: 30$ & & 27.59 & & & & & \\
\hline $1 / 6 / 00$ & $11: 32$ & & & 29.41 & & & & \\
\hline $1 / 6 / 00$ & $16: 14$ & $16: 14$ & & & & & & \\
\hline \begin{tabular}{|l|}
$1 / 6 / 00$ \\
\end{tabular} & $16: 16$ & & 27.53 & & & & & \\
\hline $1 / 6 / 00$ & $16: 17$ & & & 29.37 & & & & \\
\hline \begin{tabular}{|l|}
$1 / 7 / 00$ \\
\end{tabular} & $10: 08$ & 28.17 & & & & & & \\
\hline $1 / 7 / 00$ & $10: 10$ & & 27.57 & & & & & \\
\hline \begin{tabular}{|l|}
$1 / 7 / 00$ \\
\end{tabular} & $10: 11$ & & & 29.38 & & & & \\
\hline $1 / 7 / 00$ & $14: 12$ & 28.12 & & & & & & \\
\hline \begin{tabular}{|l|}
$1 / 7 / 00$ \\
\end{tabular} & $14: 13$ & & 27.53 & & & & & \\
\hline $1 / 7 / 00$ & $14: 15$ & & & 29.37 & & & & \\
\hline & & & & & & Avg. Discharge = & 3.28 & \\
\hline & & & & & & Range $=$ & 0.10 & \\
\hline & & & & & & High = & 3.31 & \\
\hline & & & & & & Low $=$ & 3.18 & \\
\hline & & & & & & Std Dev. = & 0.03 & \\
\hline & & & & & & Variation \% = & 1.5 & \\
\hline & & & & & & 2 Range / Avg. * ${ }^{*} 100$ ) & & \\
\hline
\end{tabular}


WSRC-TR-00-00180, Rev. 0

R-Area Aquifer Tests

\section{Aquifer Test Field Data Extraction Well RPT-2PW}

Start Antecedent: 12-02-99 @ 15:44

Start Extraction: 12-06-99@ 11:00

Stop Antecedent: 12-06-99 @ 09:44

Stop Recovery: 12-10-99 @ 09:06

Stop Extraction: 12-08-99 @ 12:00

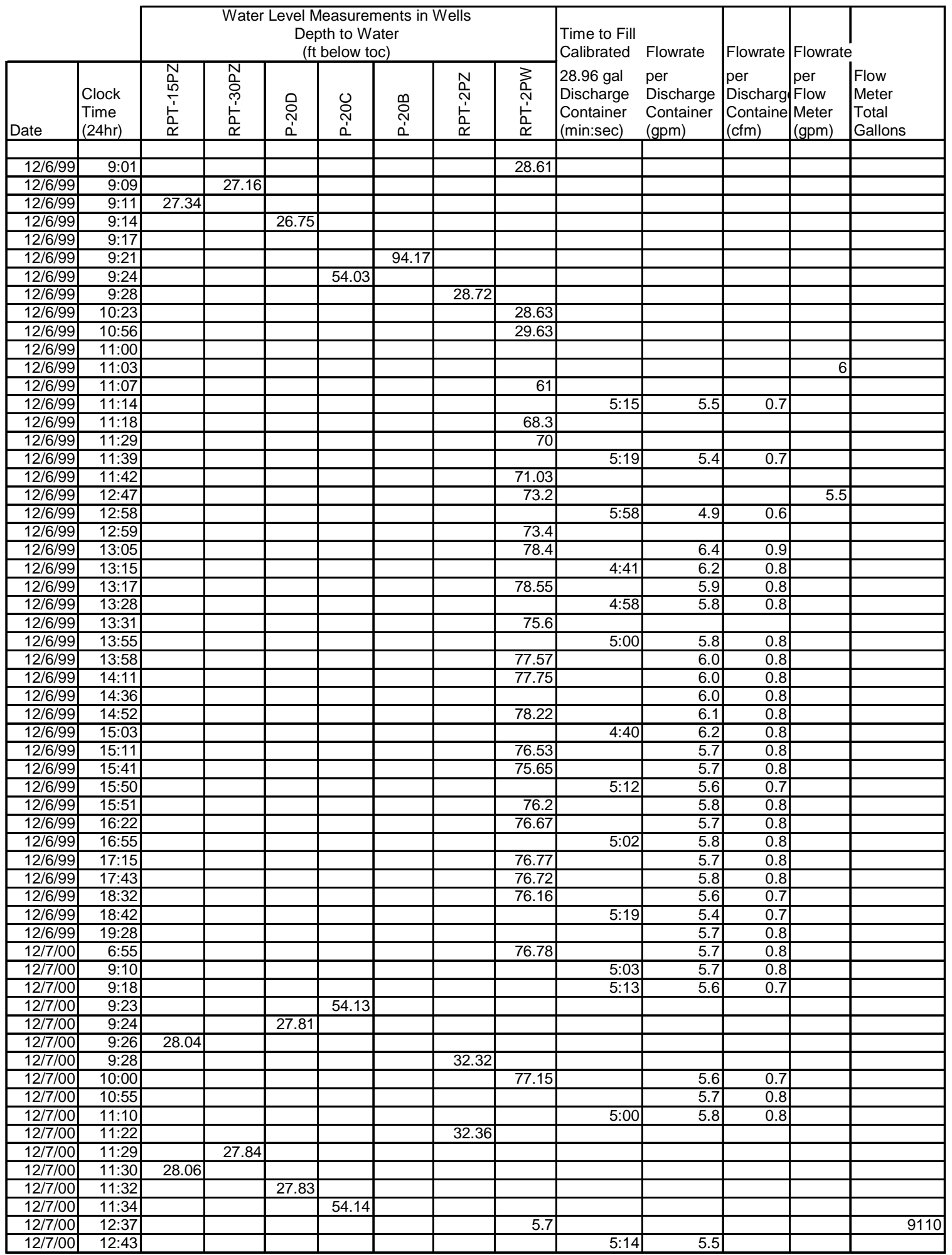


WSRC-TR-00-00180, Rev. 0

R-Area Aquifer Tests

\section{Aquifer Test Field Data Extraction Well RPT-2PW (cont.)}

\begin{tabular}{|c|c|c|c|c|c|c|c|c|c|c|c|c|c|}
\hline \multirow[b]{2}{*}{ Date } & \multirow[b]{2}{*}{$\begin{array}{l}\text { Clock } \\
\text { Time } \\
\text { (24hr) }\end{array}$} & \multicolumn{7}{|c|}{$\begin{array}{l}\text { Water Level Measurements in Wells } \\
\text { Depth to Water } \\
\text { (ft below toc) }\end{array}$} & \multirow{2}{*}{$\begin{array}{l}\text { Time to Fill } \\
\text { Calibrated } \\
28.96 \text { gal } \\
\text { Discharge } \\
\text { Container } \\
\text { (min:sec) }\end{array}$} & \multirow[b]{2}{*}{$\begin{array}{l}\text { Flowrate } \\
\text { per } \\
\text { Discharge } \\
\text { Container } \\
\text { (gpm) }\end{array}$} & \multirow[b]{2}{*}{\begin{tabular}{|l} 
Flowrate \\
per \\
Discharg \\
Containe \\
(cfm)
\end{tabular}} & \multirow[b]{2}{*}{\begin{tabular}{|l|}
$\mid$ Flowrate \\
per \\
Flow \\
Meter \\
(gpm)
\end{tabular}} & \multirow[b]{2}{*}{\begin{tabular}{|l} 
Flow \\
Meter \\
Total \\
Gallons
\end{tabular}} \\
\hline & & $\begin{array}{l}N \\
\frac{N}{10} \\
\frac{1}{1} \\
\frac{1}{\alpha} \\
\alpha\end{array}$ & 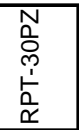 & 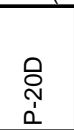 & $\begin{array}{l}\text { O } \\
\text { N } \\
\text { D. }\end{array}$ & 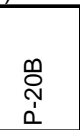 & 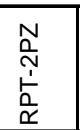 & 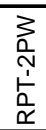 & & & & & \\
\hline \begin{tabular}{|r|}
$12 / 7 / 00$ \\
\end{tabular} & $12: 50$ & & & & & & 32.38 & & & & & & \\
\hline $12 / 7 / 00$ & $12: 52$ & & 27.82 & & & & & & & & & & \\
\hline $12 / 7 / 00$ & $12: 54$ & 28.03 & & & & & & & & & & & \\
\hline $12 / 7 / 00$ & $12: 55$ & & & & & & & & & & & 5.8 & \\
\hline $12 / 7 / 00$ & $12: 56$ & & & 27.8 & & & & & & & & & \\
\hline $12 / 7 / 00$ & $12: 58$ & & & & 54.15 & & & & & & & & \\
\hline $12 / 7 / 00$ & $13: 34$ & & & & & & & & & & & 5.7 & \\
\hline $12 / 7 / 00$ & $13: 43$ & & & & & & & & $5: 10$ & 5.6 & & & \\
\hline $12 / 7 / 00$ & $14: 30$ & & & & & & 32.37 & & & & & & \\
\hline $12 / 7 / 00$ & $14: 32$ & & 27.8 & & & & & & & & & & \\
\hline $12 / 7 / 00$ & $14: 34$ & 27.81 & & & & & & & & & & & \\
\hline $12 / 7 / 00$ & $14: 36$ & & & 27.78 & & & & & & & & & \\
\hline $12 / 7 / 00$ & $14: 37$ & & & & 57.17 & & & & & & & & \\
\hline $12 / 7 / 00$ & $15: 20$ & & & & & & & & & & & 5.7 & 10060 \\
\hline $12 / 7 / 00$ & $15: 37$ & & & & & & & & $5: 05$ & 5.7 & & & \\
\hline $12 / 7 / 00$ & $16: 02$ & & & & & & & & & & & 5.7 & 103057 \\
\hline $12 / 7 / 00$ & $16: 14$ & & & & & & & & $5: 12$ & 5.6 & & & \\
\hline $12 / 7 / 00$ & $16: 19$ & & & & & 94.22 & & & & & & & \\
\hline $12 / 7 / 00$ & $16: 22$ & & & & 54.19 & & & & & & & & \\
\hline $12 / 7 / 00$ & $16: 25$ & & & 27.78 & & & & & & & & & \\
\hline $12 / 7 / 00$ & $16: 29$ & 28 & & & & & & & & & & & \\
\hline $12 / 7 / 00$ & $16: 31$ & & 27.8 & & & & & & & & & & \\
\hline $12 / 7 / 00$ & $16: 33$ & & & & & & 32.36 & & & & & & \\
\hline $12 / 7 / 00$ & $16: 58$ & & & & & & & & & & & 5.8 & 106202 \\
\hline $12 / 7 / 00$ & 17:09 & & & & & & & & $5: 18$ & 5.5 & & & \\
\hline $12 / 7 / 00$ & $17: 11$ & & & & & 94.22 & & & & & & & \\
\hline $12 / 7 / 00$ & 17:13 & & & & 54.17 & & & & & & & & \\
\hline $12 / 7 / 00$ & $17: 16$ & & & 27.79 & & & & & & & & & \\
\hline $12 / 7 / 00$ & $17: 18$ & 28.01 & & & & & & & & & & & \\
\hline $12 / 7 / 00$ & $17: 20$ & & 27.8 & & & & & & & & & & \\
\hline $12 / 7 / 00$ & $17: 22$ & & & & & & 32.35 & & & & & & \\
\hline $12 / 7 / 00$ & $17: 55$ & & & & & & & & & & & 5.7 & 109407 \\
\hline $12 / 7 / 00$ & $18: 04$ & & & & & & & & $5: 14$ & 5.5 & & & \\
\hline $12 / 7 / 00$ & $18: 09$ & & & & & 94.22 & & & & & & & \\
\hline $12 / 7 / 00$ & $18: 13$ & & & & 54.14 & & 32.35 & & & & & & \\
\hline $12 / 7 / 00$ & $18: 15$ & & & 27.8 & & & & & & & & & \\
\hline $12 / 7 / 00$ & $18: 17$ & 28.03 & & & & & & & & & & & \\
\hline $12 / 7 / 00$ & $18: 19$ & & 27.81 & & & & & & & & & & \\
\hline $12 / 7 / 00$ & $18: 22$ & & & & & & 32.35 & & & & & & \\
\hline $12 / 7 / 00$ & $18: 48$ & & & & & & & & & & & 5.6 & 112456 \\
\hline $12 / 7 / 00$ & $18: 59$ & & & & & & & & $5: 12$ & 5.6 & & & \\
\hline $12 / 7 / 00$ & 19:02 & & & & & 94.23 & & & & & & & \\
\hline $12 / 7 / 00$ & $19: 04$ & & & & 54.18 & & & & & & & & \\
\hline $12 / 7 / 00$ & 19:06 & & & 28.8 & & & & & & & & & \\
\hline $12 / 7 / 00$ & $19: 08$ & 28.04 & & & & & & & & & & & \\
\hline $12 / 7 / 00$ & $19: 10$ & & 27.81 & & & & & & & & & & \\
\hline $12 / 8 / 99$ & $7: 55$ & & & & & & & & & & & 5.7 & 15725 \\
\hline $12 / 8 / 99$ & $8: 06$ & & & & & & & & $5: 10$ & 5.6 & & & \\
\hline $12 / 8 / 99$ & $9: 20$ & & & & & & 32.42 & & & & & & \\
\hline $12 / 8 / 99$ & $9: 22$ & & 27.88 & & & & & & & & & & \\
\hline $12 / 8 / 99$ & $9: 24$ & 28.09 & & & & & & & & & & & \\
\hline $12 / 8 / 99$ & $9: 25$ & & & 27.86 & & & & & & & & & \\
\hline $12 / 8 / 99$ & $9: 27$ & & & & 54.25 & & & & & & & & \\
\hline $12 / 8 / 99$ & $10: 25$ & & & & & & & & & & & 5.7 & 16572 \\
\hline $12 / 8 / 99$ & $10: 35$ & & & & & & & & $5: 12$ & 5.6 & & & \\
\hline $12 / 8 / 99$ & $10: 53$ & & & & & & 32.43 & & & & & & \\
\hline $12 / 8 / 99$ & $10: 56$ & & 28.88 & & & & & & & & & & \\
\hline $12 / 8 / 99$ & $10: 58$ & 28.09 & & & & & & & & & & & \\
\hline $12 / 8 / 99$ & $10: 59$ & & & 27.88 & & & & & & & & & \\
\hline $12 / 8 / 99$ & $11: 01$ & & & & 54.24 & & & & & & & & \\
\hline $12 / 8 / 99$ & $11: 40$ & & & & & & & & & & & 5.7 & 17002 \\
\hline $12 / 8 / 99$ & $11: 49$ & & & & & & & & $5: 12$ & & & & \\
\hline $12 / 8 / 99$ & $11: 53$ & & & & & & 32.42 & & & & & & \\
\hline $12 / 8 / 99$ & $11: 56$ & & 27.87 & & & & & & & & & & \\
\hline $12 / 8 / 99$ & 11:57 & 28.08 & & & & & & & & & & & \\
\hline
\end{tabular}


WSRC-TR-00-00180, Rev. 0

R-Area Aquifer Tests

Aquifer Test Field Data Extraction Well RPT-2PW (cont.)

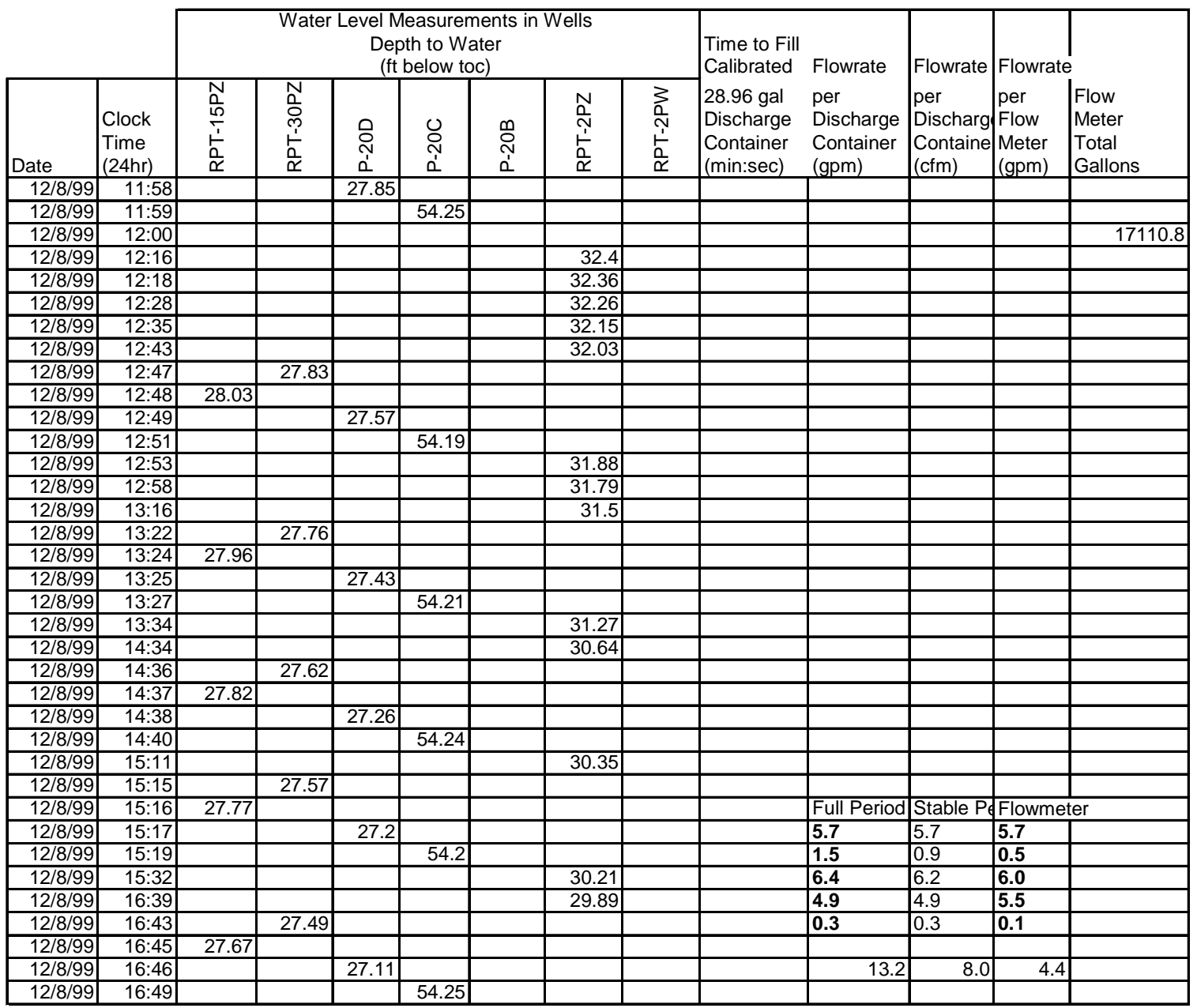


WSRC-TR-00-00180, Rev. 0

R-Area Aquifer Tests

\title{
Aquifer Test Field Data Extraction Well RPT-3PW
}

\author{
Start Antecedent: 01-07-00 @ 15:54_Stop Antecedent: 01-10-00 @ 11:09 \\ Start Extraction: 01-10-00 @ 12:00 Stop Extraction: 01-13-00 @ 10:40 \\ Stop Recovery: 01-14-00 @15:28 Avg. Discharge = $42.7 \mathrm{gpm} / 5.7 \mathrm{cfm}$ \\ Initial Flowmeter Reading: $400732 \quad$ Final Flowmeter Reading: 560530
}

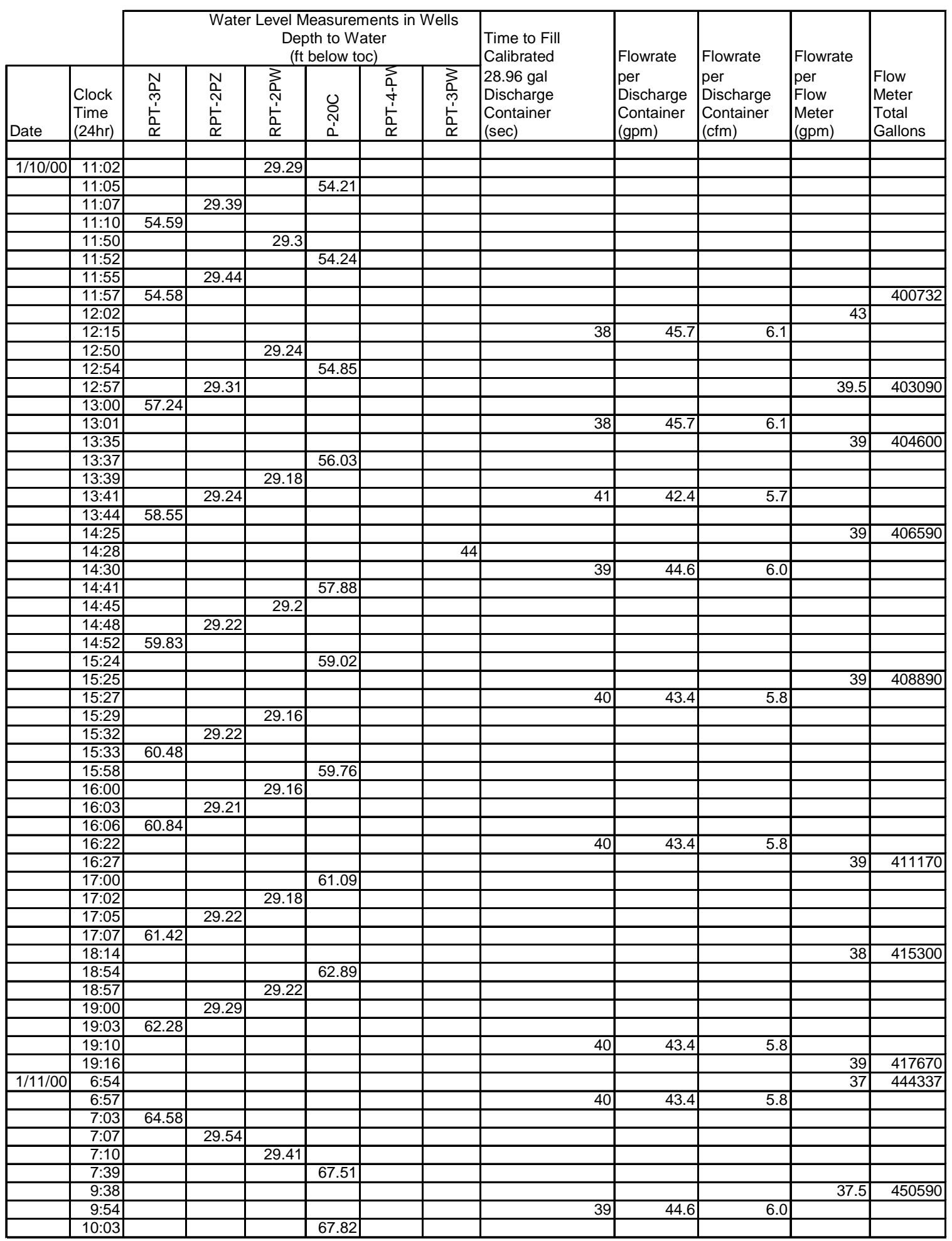


WSRC-TR-00-00180, Rev. 0

R-Area Aquifer Tests

\section{Aquifer Test Field Data Extraction Well RPT-3PW (cont.)}

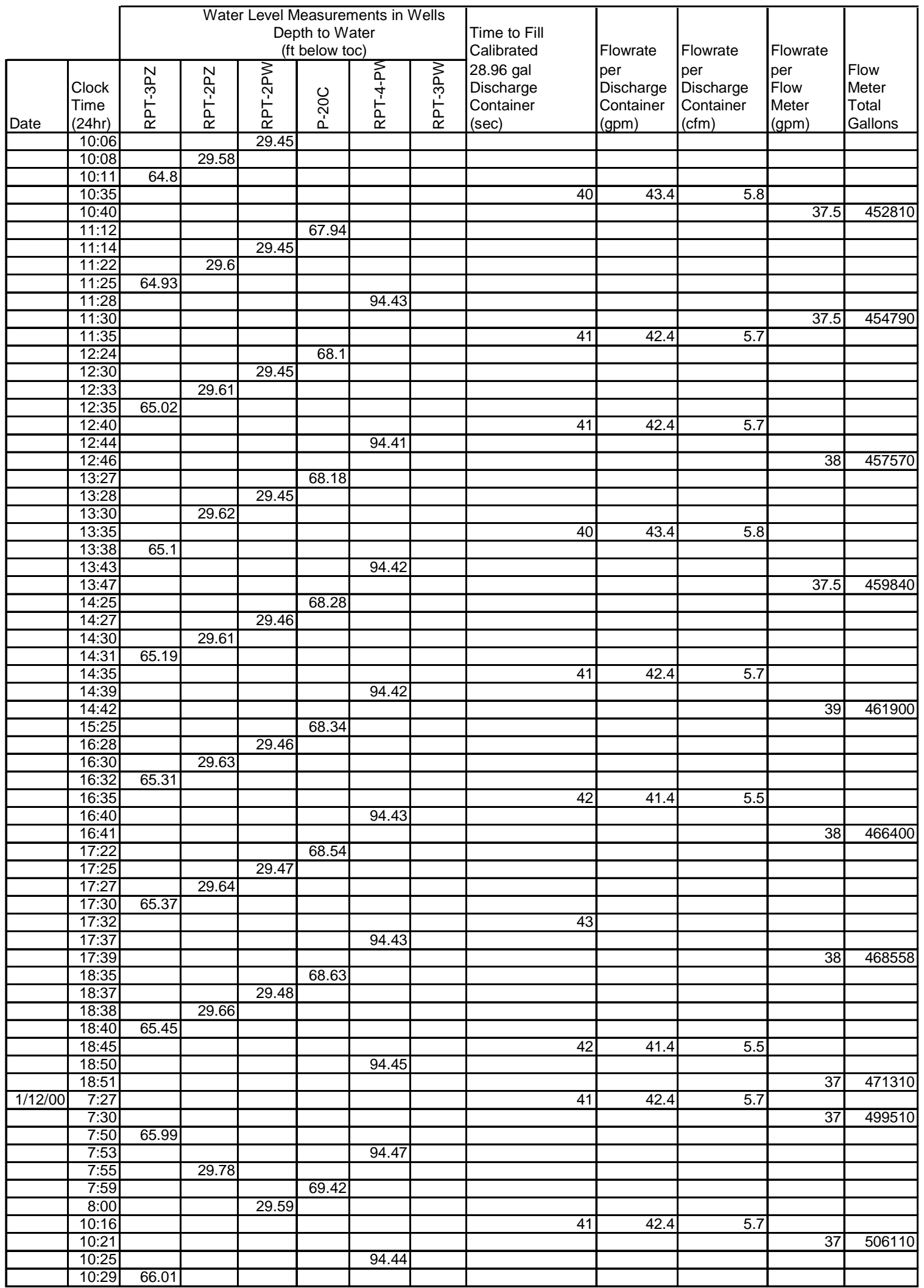


WSRC-TR-00-00180, Rev. 0

R-Area Aquifer Tests

Aquifer Test Field Data Extraction Well RPT-3PW (cont.)

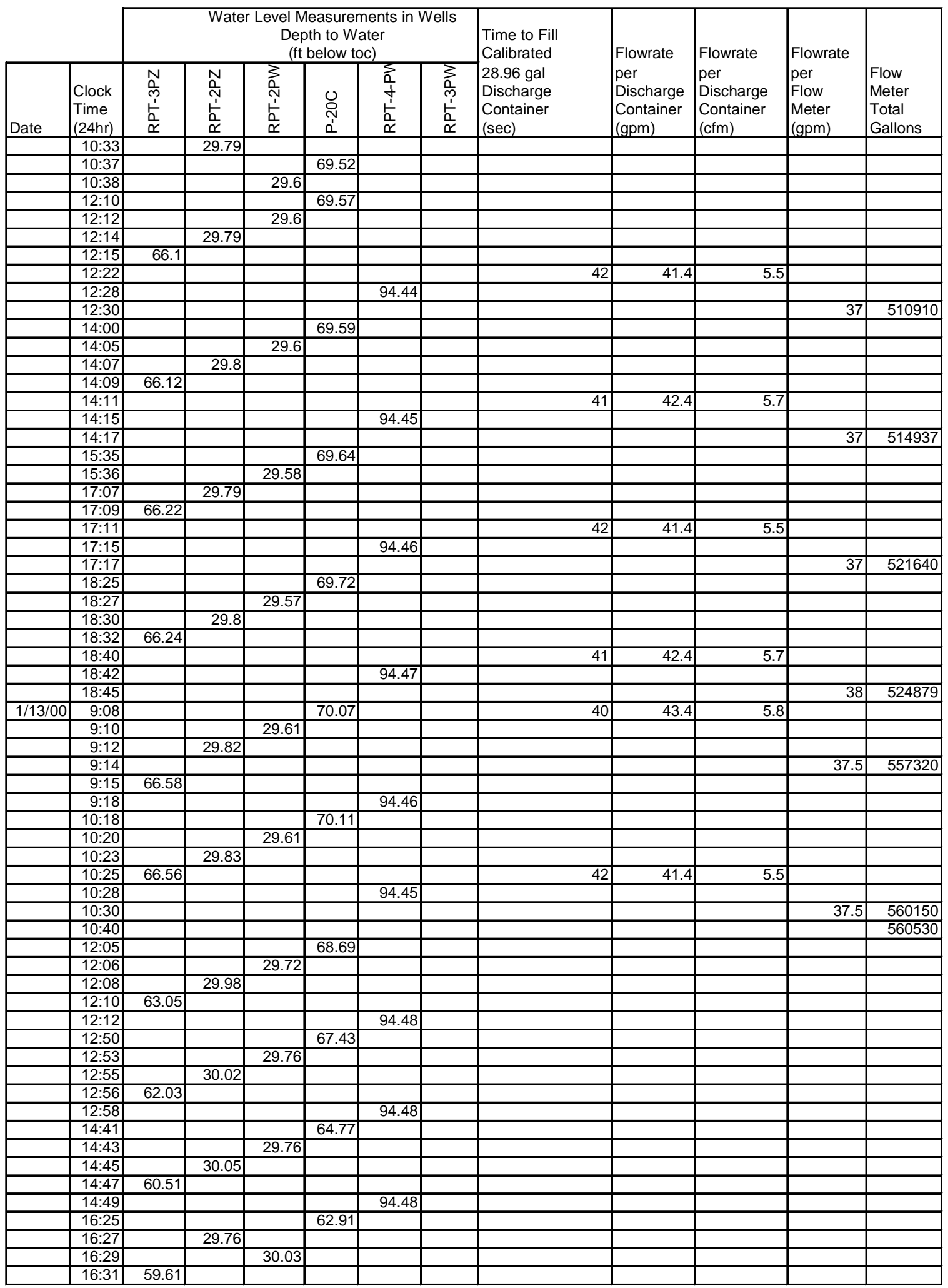


WSRC-TR-00-00180, Rev. 0

R-Area Aquifer Tests

Aquifer Test Field Data Extraction Well RPT-3PW (cont.)

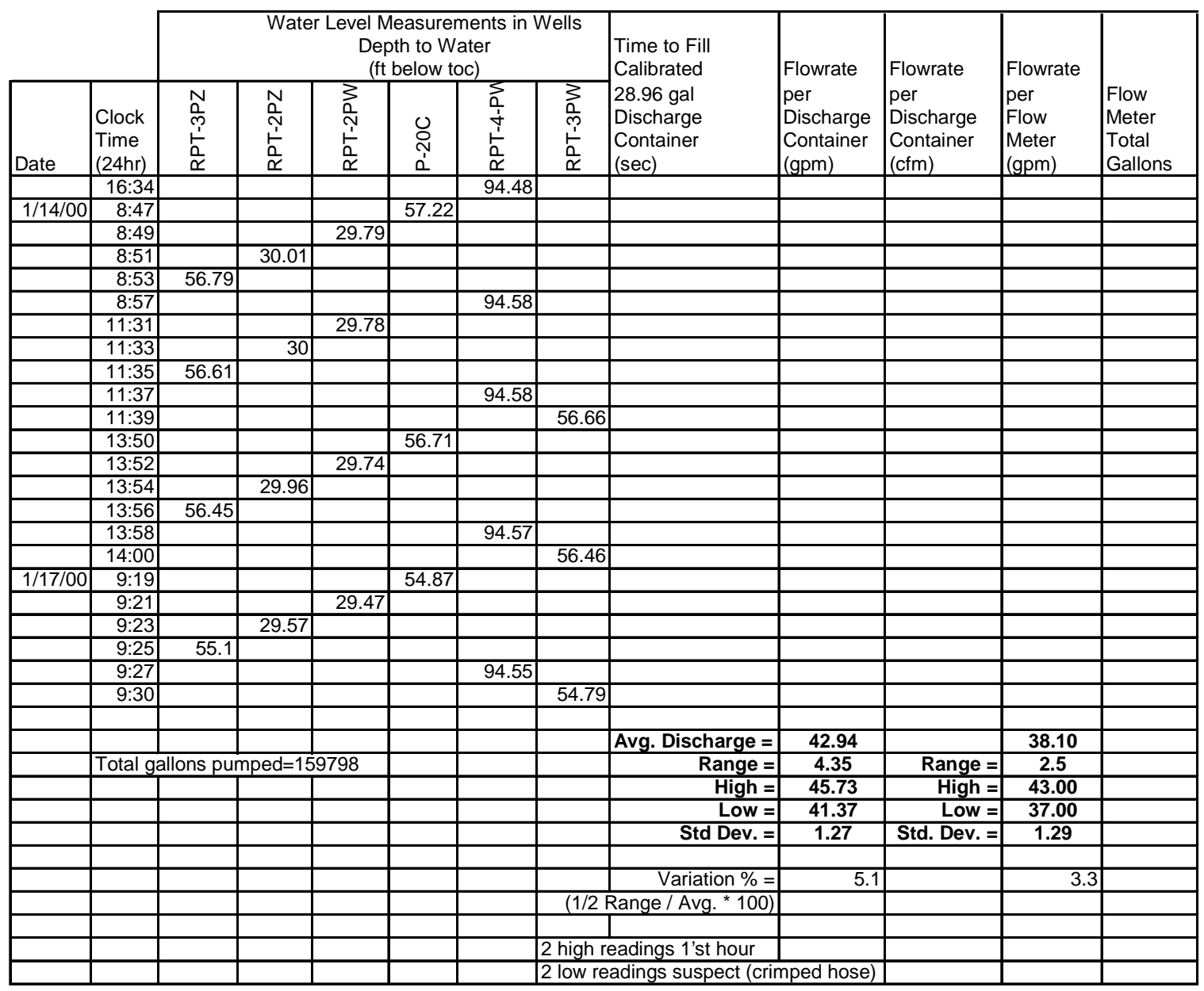


WSRC-TR-00-00180, Rev. 0

R-Area Aquifer Tests

\section{Aquifer Test Field Data Extraction Well RPT-4PW}

Start Antecedent: 12-10-99 @ 14:12 Stop Antecedent: 12-13-99 @ 08:42

Start Extraction: 12-13-99 @ 11:00 Stop Extraction: 12-15-99 @ 00:47

Stop Recovery: 12-16-99 @13:00 Avg. Discharge = 43.2 gpm $/ 5.8 \mathrm{cfm}$

Initial Flowmeter Reading: 209070 Final Flowmeter Reading: 399112

\begin{tabular}{|c|c|c|c|c|c|c|c|c|c|c|c|}
\hline \multirow{3}{*}{$\begin{array}{l}\text { Date } \\
12 / 13 / 99 \\
\end{array}$} & \multirow[b]{2}{*}{$\begin{array}{l}\text { Clock } \\
\text { Time } \\
(24 \mathrm{hr}) \\
\end{array}$} & \multicolumn{5}{|c|}{$\begin{array}{l}\text { Depth to Water } \\
\text { (ft below toc) }\end{array}$} & \multirow{2}{*}{\begin{tabular}{|l} 
Time to Fill \\
Calibrated \\
28.96 gal \\
Discharge \\
Container \\
(sec)
\end{tabular}} & \multirow{2}{*}{\begin{tabular}{|l} 
Flowrate \\
per \\
Discharge \\
Container \\
(gpm) \\
\end{tabular}} & \multirow{2}{*}{\begin{tabular}{|l} 
Flowrate \\
per \\
Discharge \\
Container \\
(cfm)
\end{tabular}} & \multirow{2}{*}{\begin{tabular}{|l} 
Flowrate \\
per \\
Flow \\
Meter \\
(gpm) \\
\end{tabular}} & \multirow[b]{2}{*}{$\begin{array}{l}\text { Flow } \\
\text { Meter } \\
\text { Total } \\
\text { Gallons }\end{array}$} \\
\hline & & 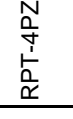 & 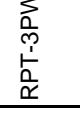 & 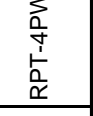 & $\begin{array}{l}\mathscr{O} \\
\text { N } \\
\text { i }\end{array}$ & $\begin{array}{l}\text { O } \\
\text { N } \\
i \\
\end{array}$ & & & & & \\
\hline & 11:05 & & & & & & & & & 40 & 309070 \\
\hline & $11: 17$ & & & & & & 41 & 42.4 & 5.7 & & \\
\hline & $11: 33$ & & & & & & & & & 39 & \\
\hline & $11: 38$ & & & 147.15 & & & & & & & \\
\hline & $11: 43$ & 97.46 & & & & & & & & & \\
\hline & $11: 46$ & & & & & & 39 & 44.6 & 6.0 & & \\
\hline & $11: 56$ & & & & 94.48 & & & & & & \\
\hline & $11: 58$ & & & & & 54.15 & & & & & \\
\hline & $12: 02$ & 97.57 & & & & & & & & & \\
\hline & $12: 18$ & & & 146.82 & & & & & & 40 & \\
\hline & $13: 35$ & & & 146.67 & & & & & & 39 & \\
\hline & $13: 38$ & & 53.92 & & & & & & & & \\
\hline & $13: 55$ & 97.93 & & & & & & & & & \\
\hline & 13:58 & & & & & & 40 & 43.4 & 5.8 & & \\
\hline & $14: 24$ & & & & 95.27 & & & & & & \\
\hline & $14: 27$ & & & & & 54.14 & & & & & \\
\hline & $14: 39$ & & & & & & & & & 40 & \\
\hline & $14: 44$ & & & 146.66 & & & & & & & \\
\hline & $14: 45$ & & 53.92 & & & & & & & & \\
\hline & $15: 10$ & 98.05 & & & & & & & & & \\
\hline & $15: 15$ & & & & & & 41 & 42.4 & 5.7 & & \\
\hline & $15: 25$ & & & & 95.57 & & & & & & \\
\hline & $15: 27$ & & & & & 54.12 & & & & & \\
\hline & $15: 50$ & & 53.92 & & & & & & & & \\
\hline & 15:55 & & & 146.62 & & & & & & 40 & 321500 \\
\hline & $16: 10$ & 98.12 & & & & & 41 & 42.4 & 5.7 & & \\
\hline & $16: 20$ & & & & 95.65 & 54.1 & & & & & \\
\hline & $17: 20$ & & 53.92 & & & & & & & & \\
\hline & $17: 25$ & & & 146.72 & & & & & & 40 & 325000 \\
\hline & $17: 32$ & 98.21 & & & & & & & & & \\
\hline & $17: 35$ & & & & & & 41 & 42.4 & 5.7 & & \\
\hline & $17: 42$ & & & & 95.82 & & & & & & \\
\hline & $17: 45$ & & & & & 54.09 & & & & & \\
\hline & $18: 15$ & & 53.91 & & & & & & & & \\
\hline & $18: 18$ & & & & & & & & & 40 & 327710 \\
\hline & $18: 32$ & 98.21 & & & & & & & & & \\
\hline & $18: 38$ & & & & 95.88 & & & & & & \\
\hline & $18: 42$ & & & & & 54.08 & & & & & \\
\hline $12 / 14 / 99$ & $7: 20$ & & & & & & & & & 39 & 357700 \\
\hline & $7: 25$ & & 53.92 & & & & & & & & \\
\hline & $7: 26$ & & & 145.93 & & & & & & & \\
\hline & $7: 34$ & 98.61 & & & & & & & & & \\
\hline & $7: 46$ & & & & & & 40.5 & 42.9 & 5.7 & & \\
\hline & $7: 54$ & & & & 96.32 & & & & & & \\
\hline & $7: 56$ & & & & & 54.12 & & & & & \\
\hline & $8: 51$ & & & & & & & & & 40 & 361260 \\
\hline & $8: 54$ & & 53.93 & & & & & & & & \\
\hline & $8: 56$ & & & 146.07 & & & & & & & \\
\hline & $9: 03$ & 98.64 & & & & & & & & & \\
\hline & $9: 12$ & & & & & & 40.5 & 42.9 & 5.7 & & \\
\hline & $9: 19$ & & & & 96.36 & & & & & & \\
\hline & $9: 22$ & & & & & 54.15 & & & & & \\
\hline & $10: 28$ & & & & & & & & & 39.5 & 365160 \\
\hline & $10: 30$ & & 53.94 & & & & & & & & \\
\hline & $10: 32$ & & & 145.85 & & & & & & & \\
\hline & $10: 37$ & 98.66 & & & & & & & & & \\
\hline & $10: 45$ & & & & & & 40 & 43.4 & 5.8 & & \\
\hline & $10: 59$ & & & & 96.37 & & & & & & \\
\hline & $11: 01$ & & & & & 54.18 & & & & & \\
\hline & $11: 50$ & & & & & & & & & 40 & 368360 \\
\hline
\end{tabular}


WSRC-TR-00-00180, Rev. 0

R-Area Aquifer Tests

\section{Aquifer Test Field Data Extraction Well RPT-4PW (cont.)}

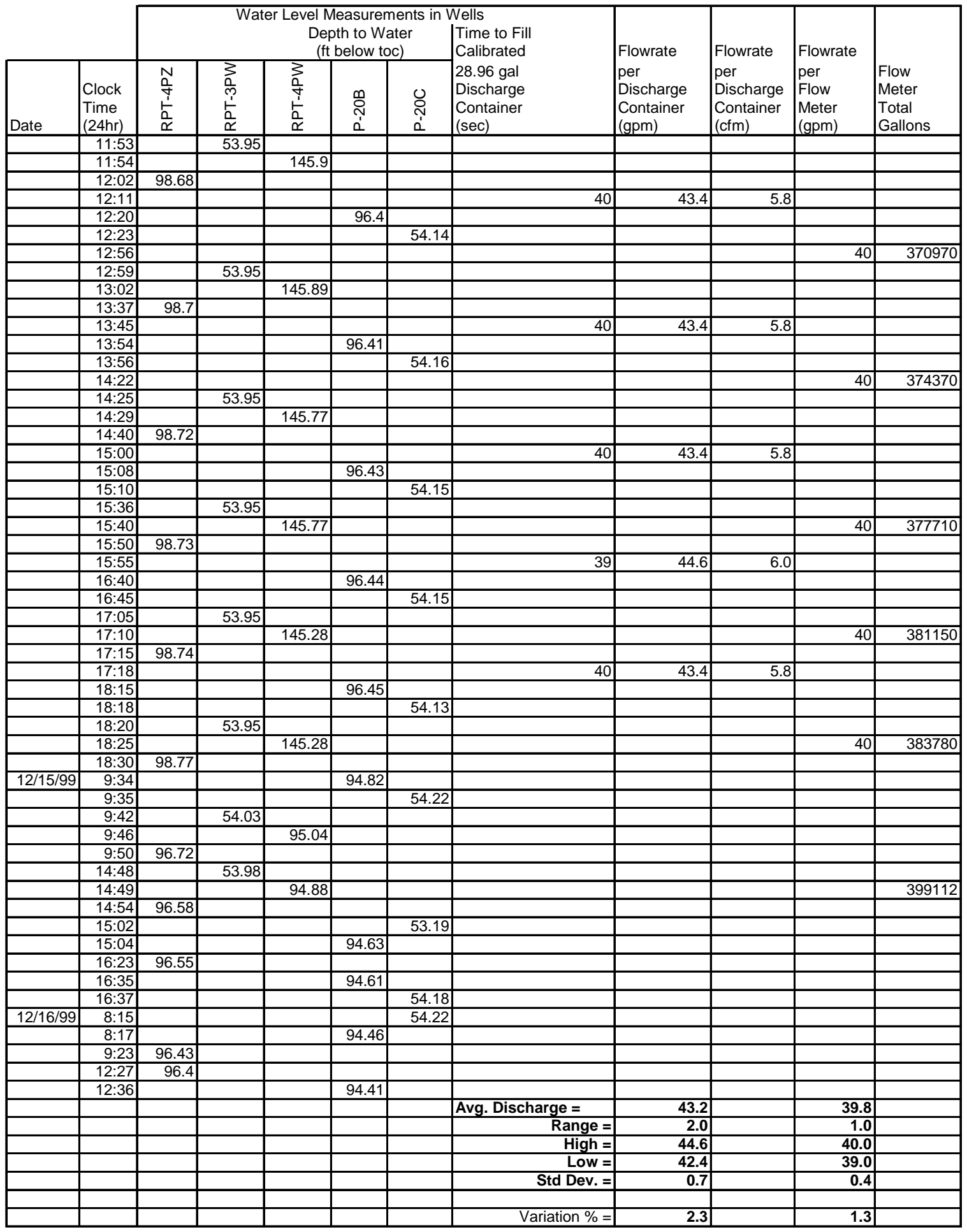


WSRC-TR-00-00180, Rev. 0

R-Area Aquifer Tests

\section{APPENDIX D}

Manual water level and pumping rate measurements for RPC tests

RPC-2PR

RPC-2PR (second test)

RPC-3PW 
WSRC-TR-00-00180, Rev. 0

R-Area Aquifer Tests

This pageis intentionally left blank 
WSRC-TR-00-00180, Rev. 0

R-Area Aquifer Tests

\section{Aquifer Test Field Data Extraction Well RPC-2PR}

Start Antecedent: 01-14-00 @ 16:08_Stop Antecedent: 01-18-00 @ 09:38

Start Extraction: 01-18-00 @ 10:00

Stop Extraction: 01-21-00 @ 10:00

Stop Recovery: 01-24-00 @09:54

Initial Flowmeter Reading: 'Avg. Discharge $=21.2 \mathrm{gpm} / 2.8 \mathrm{cfm}$

Final Flowmeter Reading: Approximately 108346

\begin{tabular}{|c|c|c|c|c|c|c|c|c|c|c|c|c|c|}
\hline Date & \begin{tabular}{|l} 
Clock \\
Time \\
(24hr)
\end{tabular} & 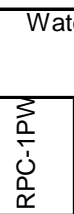 & $\begin{array}{r}\begin{array}{r}\text { Level } \\
\text { De } \\
(\mathrm{f}\end{array} \\
N \\
\frac{N}{\vdots} \\
\frac{0}{\tilde{\alpha}}\end{array}$ & 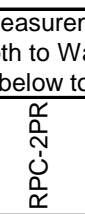 & 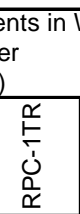 & $\begin{array}{l}\overrightarrow{1} \\
\text { ơ } \\
0 \\
0 \\
\end{array}$ & $\begin{array}{l}\dot{0} \\
\overline{0} \\
\dot{0} \\
\check{\alpha}\end{array}$ & $\begin{array}{l}\text { Time to Fill } \\
\text { Calibrated } \\
28.96 \text { gal } \\
\text { Discharge } \\
\text { Container } \\
\text { (min:sec) }\end{array}$ & $\begin{array}{l}\text { Time to Fill } \\
\text { Calibrated } \\
28.96 \text { gal } \\
\text { Discharge } \\
\text { Container } \\
\text { (sec) }\end{array}$ & \begin{tabular}{|l} 
Flowrate \\
per \\
Discharge \\
Container \\
(gpm)
\end{tabular} & $\begin{array}{l}\text { Flowrate } \\
\text { per } \\
\text { Discharge } \\
\text { Container } \\
\text { (cfm) }\end{array}$ & $\begin{array}{l}\text { Flowrate } \\
\text { per } \\
\text { Flow } \\
\text { Meter } \\
\text { (gpm) }\end{array}$ & $\mid \begin{array}{l}\text { Flow } \\
\text { Meter } \\
\text { Total } \\
\text { Gallons }\end{array}$ \\
\hline & & & & & & & & & & & & & \\
\hline $1 / 18 / 00$ & & & & 33.64 & & & & & & & & & \\
\hline $1 / 18 / 00$ & 9:53 & & & & 36.53 & & & & & & & & 18472 \\
\hline $1 / 18 / 00$ & 9:58 & 33.18 & & & & & & & & & & & \\
\hline $1 / 18 / 00$ & $9: 59$ & & 33.38 & & & & & & & & & & \\
\hline $1 / 18 / 00$ & $10: 02$ & & & & & & & & & & & 21 & 18500 \\
\hline $1 / 18 / 00$ & $10: 08$ & & & & & & & $1: 22$ & 82 & 21.2 & 2.8 & & \\
\hline $1 / 18 / 00$ & $10: 16$ & & & 52.73 & & & & & & & & & \\
\hline $1 / 18 / 00$ & $10: 38$ & & & 53.06 & & & & $1: 23$ & 83 & 20.9 & 2.8 & 20.7 & \\
\hline $1 / 18 / 00$ & $10: 55$ & & 33.45 & & & & & & & & & & \\
\hline $1 / 18 / 00$ & $10: 47$ & & & & & & & & & & & & 19450 \\
\hline $1 / 18 / 00$ & $10: 49$ & & & & 36.72 & & & & & & & & \\
\hline $1 / 18 / 00$ & $11: 41$ & & & & & & 51.58 & & & & & & \\
\hline $1 / 18 / 00$ & 11:44 & 33.25 & & & & & & & & & & & \\
\hline $1 / 18 / 00$ & $11: 45$ & & & & & & & & & & & 20.6 & 20650 \\
\hline $1 / 18 / 00$ & $11: 46$ & & 33.51 & & & & & & & & & & \\
\hline $1 / 18 / 00$ & $11: 49$ & & & 53.15 & & & & $1: 23$ & 83 & 20.9 & 2.8 & & \\
\hline $1 / 18 / 00$ & $11: 52$ & & & & 36.79 & & & & & & & & \\
\hline $1 / 18 / 00$ & $12: 05$ & & & & & 30.22 & & & & & & & \\
\hline $1 / 18 / 00$ & $12: 59$ & & & & & & 51.59 & & & & & & \\
\hline $1 / 18 / 00$ & $13: 00$ & 33.28 & & & & & & & & & & & \\
\hline $1 / 18 / 00$ & $13: 02$ & & 33.56 & & & & & & & & & & \\
\hline $1 / 18 / 00$ & 13:05 & & & 53.28 & & & & & & & & & \\
\hline $1 / 18 / 00$ & $13: 07$ & & & & 36.79 & & & & & & & & \\
\hline $1 / 18 / 00$ & $13: 12$ & & & & & 30.24 & & & & & & & \\
\hline $1 / 18 / 00$ & $13: 20$ & & & & & & & $1: 23$ & 83 & 20.9 & 2.8 & & \\
\hline $1 / 18 / 00$ & 13:24 & & & & & & & & & & & 21 & 22740 \\
\hline $1 / 18 / 00$ & 14:15 & & & & & & & & & & & 20.8 & 23800 \\
\hline $1 / 18 / 00$ & $14: 18$ & & & & & 30.27 & & $1: 22$ & 82 & 21.2 & 2.8 & & \\
\hline $1 / 18 / 00$ & 14:20 & & & & & & 51.57 & & & & & & \\
\hline $1 / 18 / 00$ & $14: 22$ & 33.33 & & & & & & & & & & & \\
\hline $1 / 18 / 00$ & $14: 24$ & & 33.61 & & & & & & & & & & \\
\hline $1 / 18 / 00$ & $14: 25$ & & & 53.35 & & & & & & & & & \\
\hline $1 / 18 / 00$ & $14: 27$ & & & & 36.79 & & & & & & & & \\
\hline $1 / 18 / 00$ & $15: 10$ & & & & & 30.27 & & & & & & & \\
\hline $1 / 18 / 00$ & $15: 13$ & & & & & & 51.58 & & & & & & \\
\hline $1 / 18 / 00$ & $15: 15$ & 33.37 & & & & & & & & & & & \\
\hline $1 / 18 / 00$ & 15:17 & & 33.65 & & & & & & & & & & \\
\hline $1 / 18 / 00$ & $15: 19$ & & & 53.38 & & & & & & & & & \\
\hline $1 / 18 / 00$ & $15: 20$ & & & & & & & & & & & 20.7 & 25180 \\
\hline $1 / 18 / 00$ & $15: 23$ & & & & 36.85 & & & & & & & & \\
\hline $1 / 18 / 00$ & $15: 26$ & & & & & & & $1: 21$ & 81 & 21.5 & 2.9 & & \\
\hline $1 / 18 / 00$ & $16: 15$ & & & & & 30.28 & & & & & & & \\
\hline $1 / 18 / 00$ & $16: 17$ & & & & & & 51.59 & & & & & & \\
\hline $1 / 18 / 00$ & $16: 19$ & 33.41 & & & & & & & & & & & \\
\hline $1 / 18 / 00$ & $16: 20$ & & 33.71 & & & & & & & & & & \\
\hline $1 / 18 / 00$ & $16: 22$ & & & 53.39 & & & & & & & & & \\
\hline $1 / 18 / 00$ & $16: 24$ & & & & & & & & & & & 20.7 & 26510 \\
\hline $1 / 18 / 00$ & $16: 26$ & & & & 36.88 & & & & & & & & \\
\hline $1 / 18 / 00$ & $16: 30$ & & & & & & & $1: 22$ & 82 & 21.2 & 2.8 & & \\
\hline $1 / 18 / 00$ & 17:11 & & & & & 30.29 & & & & & & & \\
\hline $1 / 18 / 00$ & $17: 15$ & & & & & & 51.59 & & & & & & \\
\hline $1 / 18 / 00$ & 17:17 & 33.42 & & & & & & & & & & & \\
\hline $1 / 18 / 00$ & $17: 19$ & & 33.76 & & & & & & & & & & \\
\hline $1 / 18 / 00$ & $17: 20$ & & & 53.35 & & & & & & & & & \\
\hline $1 / 18 / 00$ & $17: 21$ & & & & & & & & & & & 20.7 & 27706 \\
\hline $1 / 18 / 00$ & $17: 25$ & & & & 36.89 & & & & & & & & \\
\hline $1 / 18 / 00$ & $17: 27$ & & & & & & & $1: 22$ & 82 & 21.2 & 2.8 & & \\
\hline $1 / 18 / 00$ & $18: 15$ & & & & & 30.3 & & & & & & & \\
\hline $1 / 18 / 00$ & $18: 20$ & & & & & & 51.6 & & & & & & \\
\hline
\end{tabular}


WSRC-TR-00-00180, Rev. 0

R-Area Aquifer Tests

Aquifer Test Field Data Extraction Well RPC-2PR (cont.)

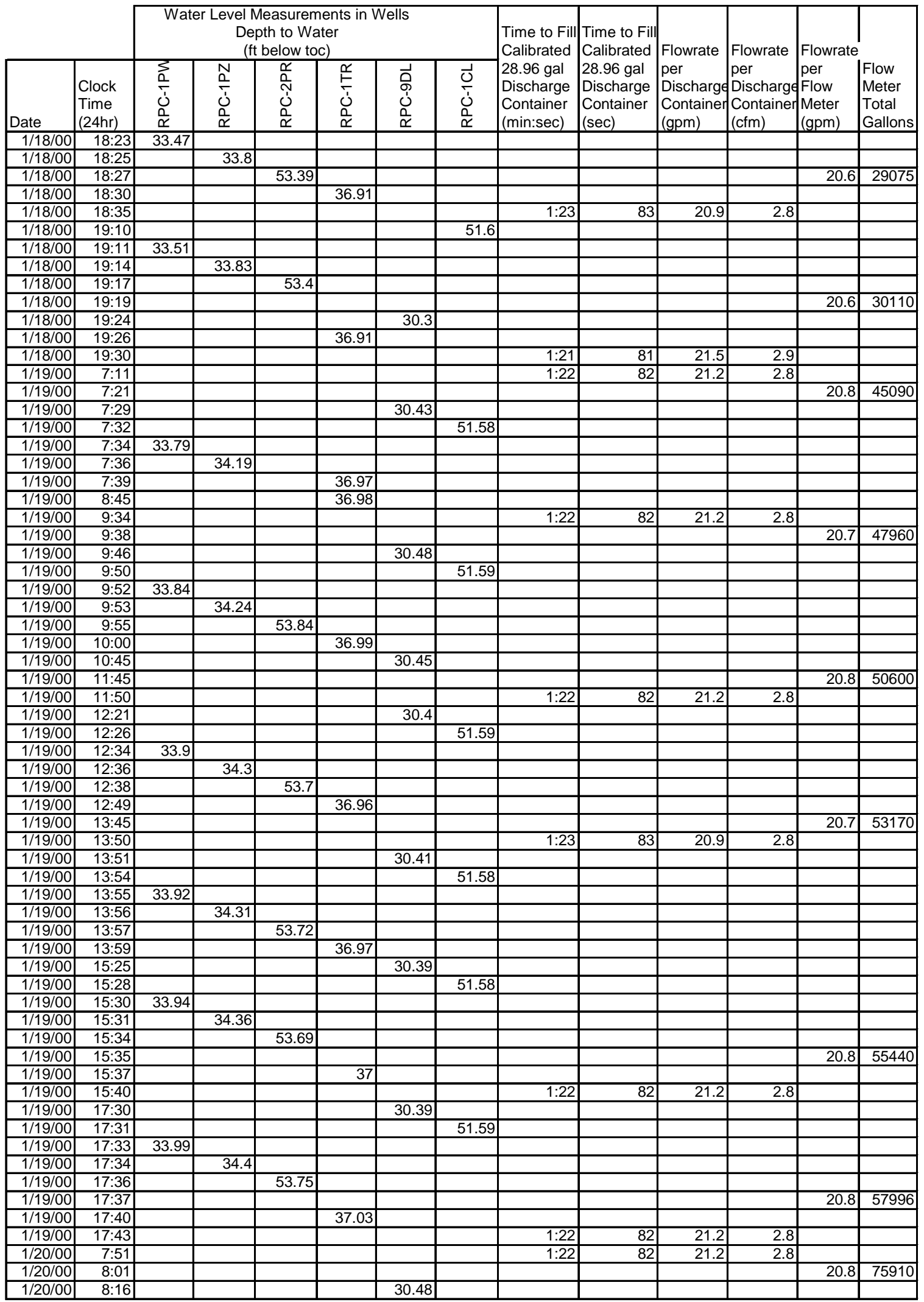


WSRC-TR-00-00180, Rev. 0

R-Area Aquifer Tests

Aquifer Test Field Data Extraction Well RPC-2PR (cont.)

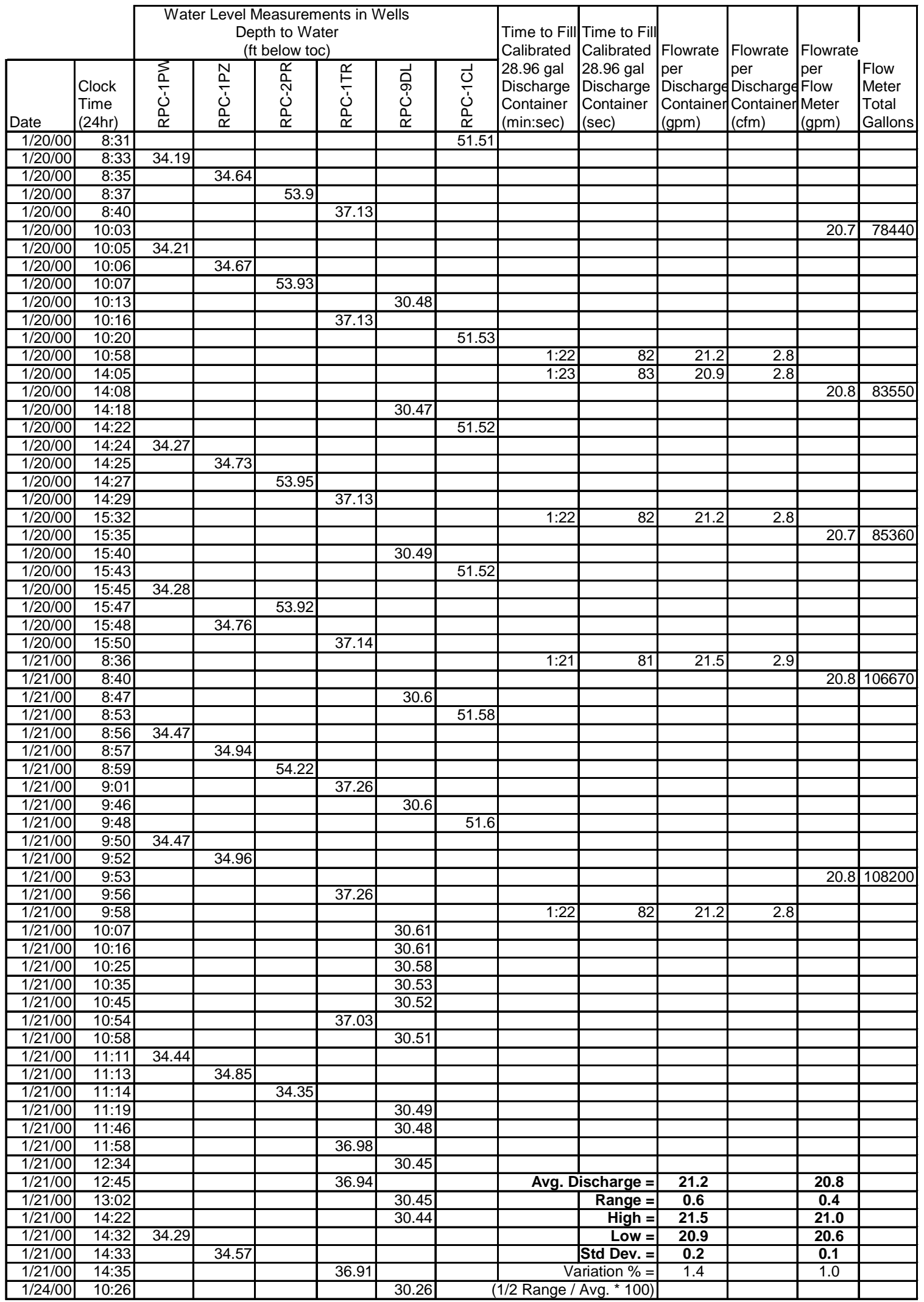


WSRC-TR-00-00180, Rev. 0

R-Area Aquifer Tests

\section{Aquifer Test Field Data Extraction Well RPC-2PR (second test)}

Pumping Start: 2/14/00 @ 10:30 Initial Flow Meter Reading:108266
Pumping Stop: 2/15/00@09:02

Final Flow Meter Reading: 136373

\begin{tabular}{|c|c|c|c|c|c|c|c|c|c|}
\hline \multirow[b]{2}{*}{ Date } & \multicolumn{4}{|c|}{$\begin{array}{c}\text { Depth to Water } \\
\text { (ft below toc) }\end{array}$} & \multirow{2}{*}{$\begin{array}{l}\text { Time to Fill } \\
\text { Calibrated } \\
28.96 \text { gal } \\
\text { Discharge } \\
\text { Container } \\
\text { (min:sec) }\end{array}$} & \multirow{2}{*}{$\begin{array}{l}\text { Time to Fill } \\
\text { Calibrated } \\
28.96 \text { gal } \\
\text { Discharge } \\
\text { Container } \\
\text { (sec) }\end{array}$} & \multirow{2}{*}{$\begin{array}{c}\text { Flowrate } \\
\text { per } \\
\text { Discharge } \\
\text { Container } \\
\text { (gpm) }\end{array}$} & \multirow{2}{*}{$\begin{array}{c}\text { Flowrate } \\
\text { per } \\
\text { Discharge } \\
\text { Container } \\
\text { (cfm) } \\
\end{array}$} & \multirow[b]{2}{*}{$\begin{array}{c}\text { Flow } \\
\text { Meter } \\
\text { Total } \\
\text { Gallons } \\
\end{array}$} \\
\hline & \begin{tabular}{|l} 
Clock \\
Time \\
(24hr) \\
\end{tabular} & $\begin{array}{l}\overrightarrow{1} \\
\text { ô } \\
0 \\
0 \\
0 \\
\simeq\end{array}$ & 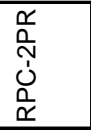 & 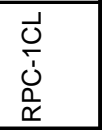 & & & & & \\
\hline & & & & & & & & & \\
\hline $2 / 14 / 00$ & 9:11 & 29.05 & & & & & & & \\
\hline $2 / 14 / 00$ & $9: 52$ & 29.08 & 32.27 & 51.21 & & & & & 108266 \\
\hline $2 / 14 / 00$ & $10: 40$ & & & & $1: 22$ & 82 & 21.19 & 2.83 & \\
\hline $2 / 14 / 00$ & $10: 45$ & & & & & & & & 108570 \\
\hline $2 / 14 / 00$ & $10: 53$ & 29.1 & & & & & & & \\
\hline $2 / 14 / 00$ & $10: 56$ & & 53.05 & & & & & & 108820 \\
\hline $2 / 14 / 00$ & $11: 36$ & & & & $1: 22$ & 82 & 21.19 & 2.83 & \\
\hline $2 / 14 / 00$ & $11: 39$ & & 53.19 & & & & & & 109690 \\
\hline $2 / 14 / 00$ & $11: 42$ & 29.15 & & & & & & & \\
\hline $2 / 14 / 00$ & $12: 12$ & & 53.18 & & & & & & 110390 \\
\hline $2 / 14 / 00$ & $12: 16$ & & & & $1: 22$ & 82 & 21.19 & 2.83 & \\
\hline $2 / 14 / 00$ & $12: 20$ & 29.18 & & & & & & & \\
\hline $2 / 14 / 00$ & 13:19 & 29.18 & & & & & & & \\
\hline $2 / 14 / 00$ & $13: 22$ & & 53.21 & & & & & & 111840 \\
\hline $2 / 14 / 00$ & $13: 27$ & & & & $1: 21$ & 81 & 21.45 & 2.87 & \\
\hline $2 / 14 / 00$ & $14: 02$ & 29.18 & & & & & & & \\
\hline $2 / 14 / 00$ & $14: 12$ & & & & $1: 21$ & 81 & 21.45 & 2.87 & \\
\hline $2 / 14 / 00$ & $14: 14$ & & 53.2 & & & & & & 112920 \\
\hline $2 / 14 / 00$ & $15: 06$ & 29.2 & & & & & & & \\
\hline $2 / 14 / 00$ & $15: 10$ & & 53.31 & & & & & & 114080 \\
\hline $2 / 14 / 00$ & $15: 15$ & & & & $1: 22$ & 82 & 21.19 & 2.83 & \\
\hline $2 / 14 / 00$ & $16: 00$ & 29.21 & & & & & & & \\
\hline $2 / 14 / 00$ & $16: 04$ & & 53.36 & & & & & & 115180 \\
\hline $2 / 14 / 00$ & $16: 10$ & & & & $1: 21$ & 81 & 21.45 & 2.87 & \\
\hline $2 / 15 / 00$ & $8: 49$ & 29.43 & & & & & & & \\
\hline $2 / 15 / 00$ & $8: 54$ & & 53.91 & & & & & & 136230 \\
\hline $2 / 15 / 00$ & $8: 57$ & & & & 1:22 & 82 & 21.19 & & \\
\hline $2 / 15 / 00$ & $9: 02$ & & & & & & & & 136373 \\
\hline & & & & & & Avg. Flow = & 21.3 & & \\
\hline & & & & & & Range = & 0.3 & & \\
\hline & & & & & & High = & 21.45 & & \\
\hline & & & & & & Low $=$ & 21.19 & & \\
\hline & & & & & & Std Dev. = & 0.14 & & \\
\hline & & & & & & & & & \\
\hline & & & & & & Variation $\%=$ & 0.70 & & \\
\hline & & & & & & (1/2 Range / Al & lg. $\left.{ }^{*} 100\right)$ & & \\
\hline
\end{tabular}


WSRC-TR-00-00180, Rev. 0

R-Area Aquifer Tests

\section{Aquifer Test Field Data Extraction Well RPC-3PW}

Start Antecedent: 01-27-00 @ 12:27

Start Extraction: 01-31-00 @ 12:00

Stop Recovery: 02-08-00 @ 12:00

Stop Antecedent: 01-31-00 @ 11:27

Initial Flowmeter Reading: 560630

Stop Extraction: 02-03-00 @ 12:00

Final Flowmeter Reading: 785700

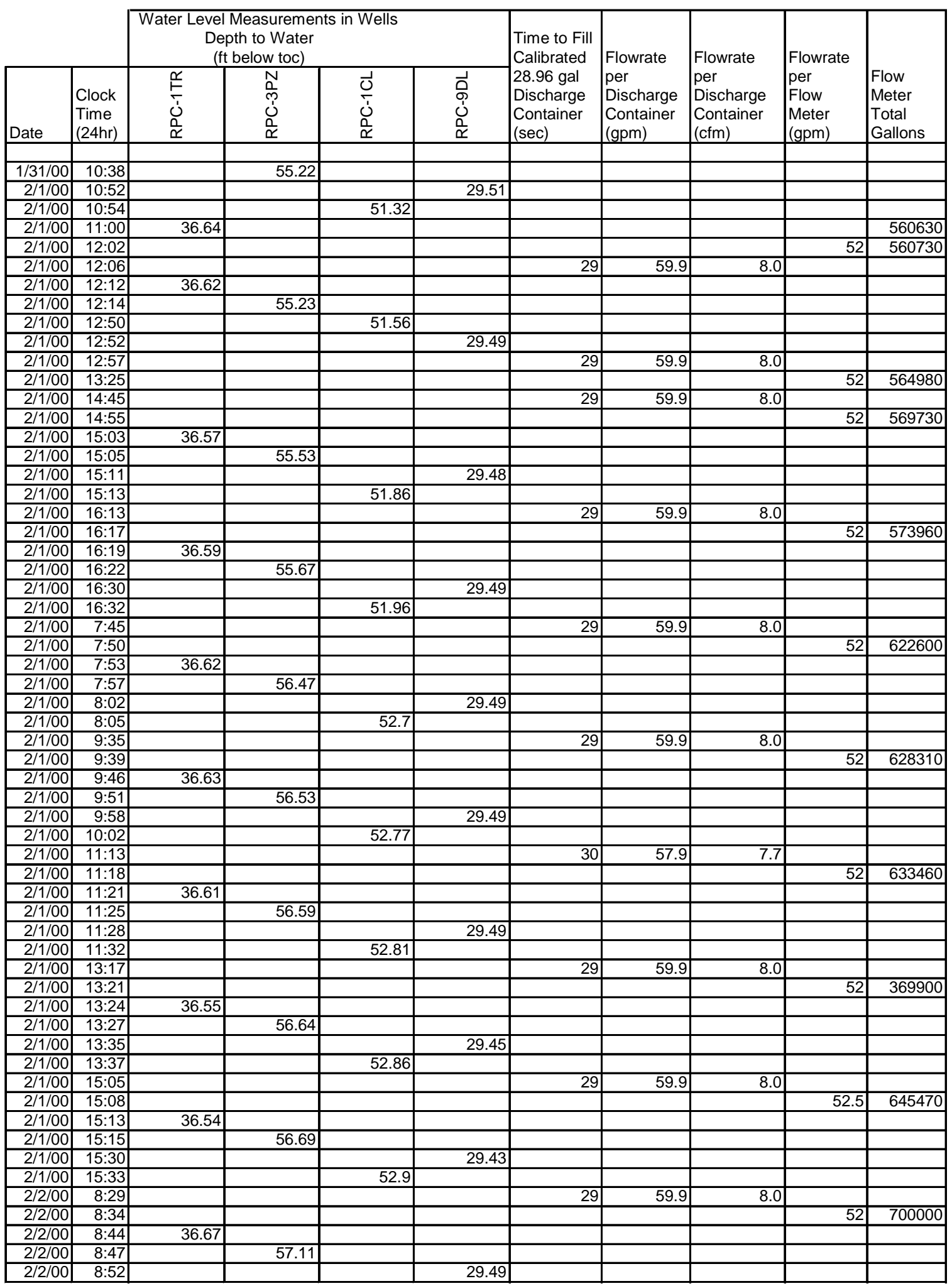


WSRC-TR-00-00180, Rev. 0

R-Area Aquifer Tests

Aquifer Test Field Data Extraction Well RPC-3PW (cont.)

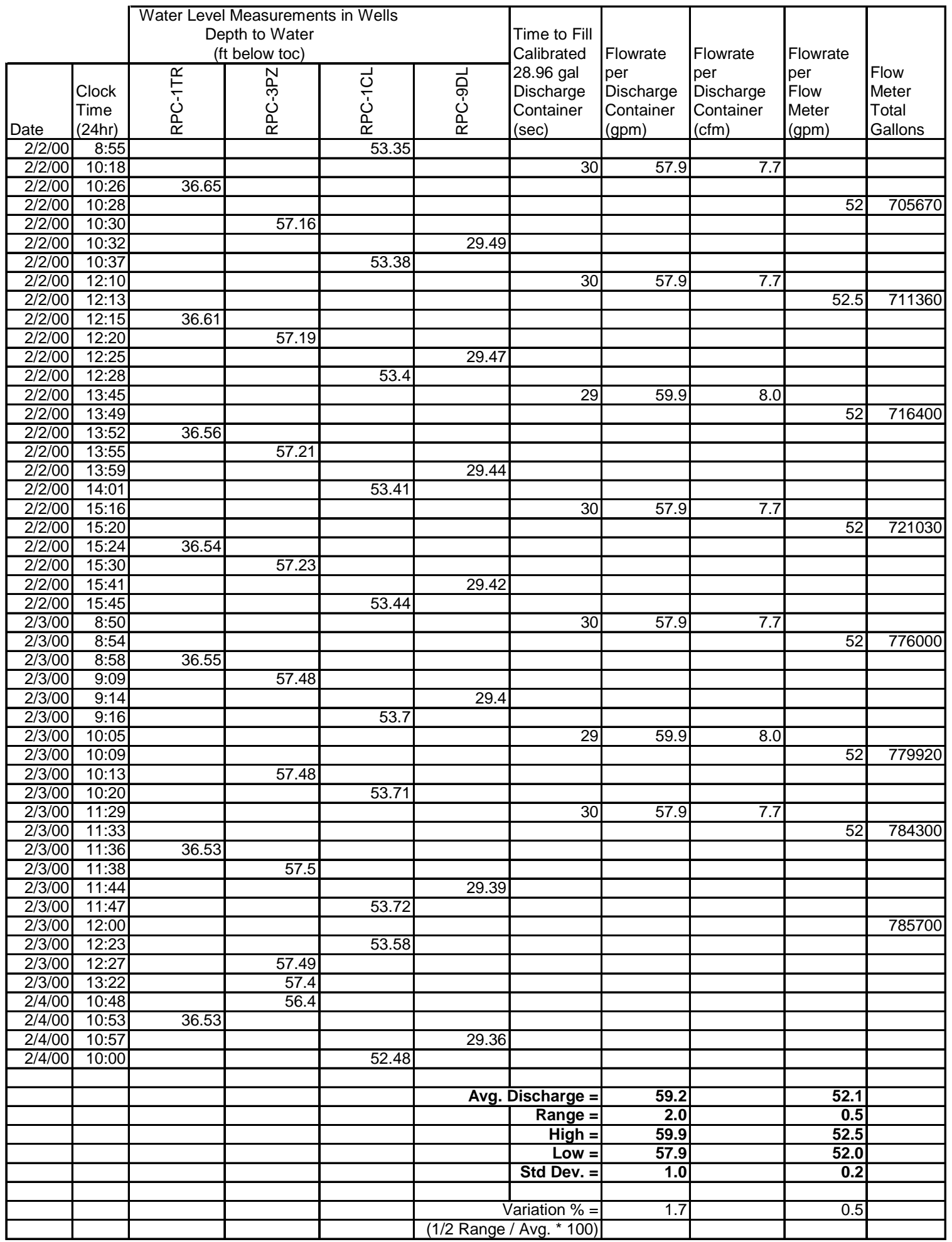


WSRC-TR-00-00180, Rev. 0

R-Area Aquifer Tests

\section{APPENDIX E}

HYDROGRAPHS FOR PRIMARY OBSERVATION WELLS 
WSRC-TR-00-00180, Rev. 0

R-Area Aquifer Tests

This Page Intentionally Left Blank 


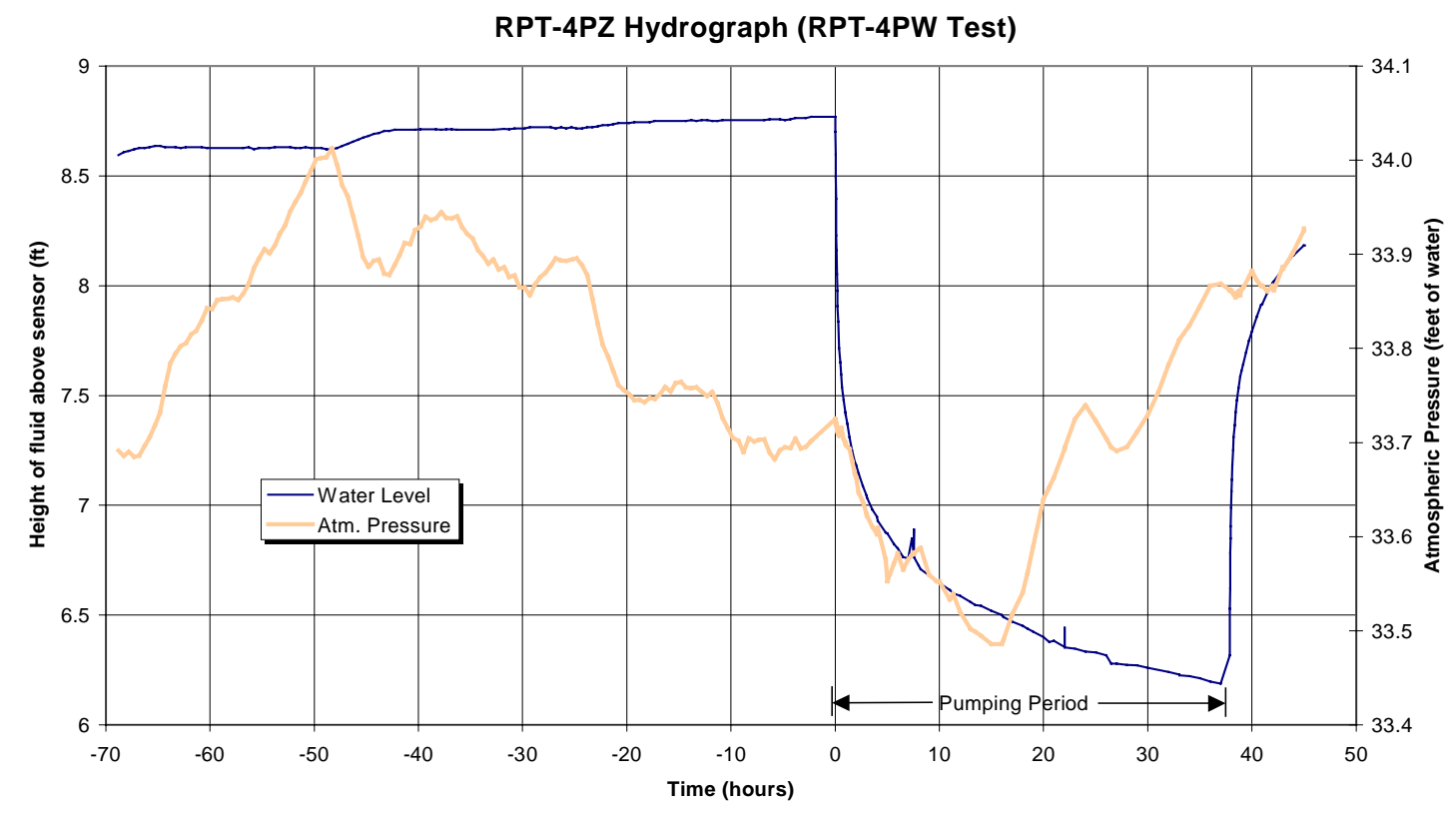

Figure 1E RPT-4PZ Hydrograph (RPT-4PW Test)

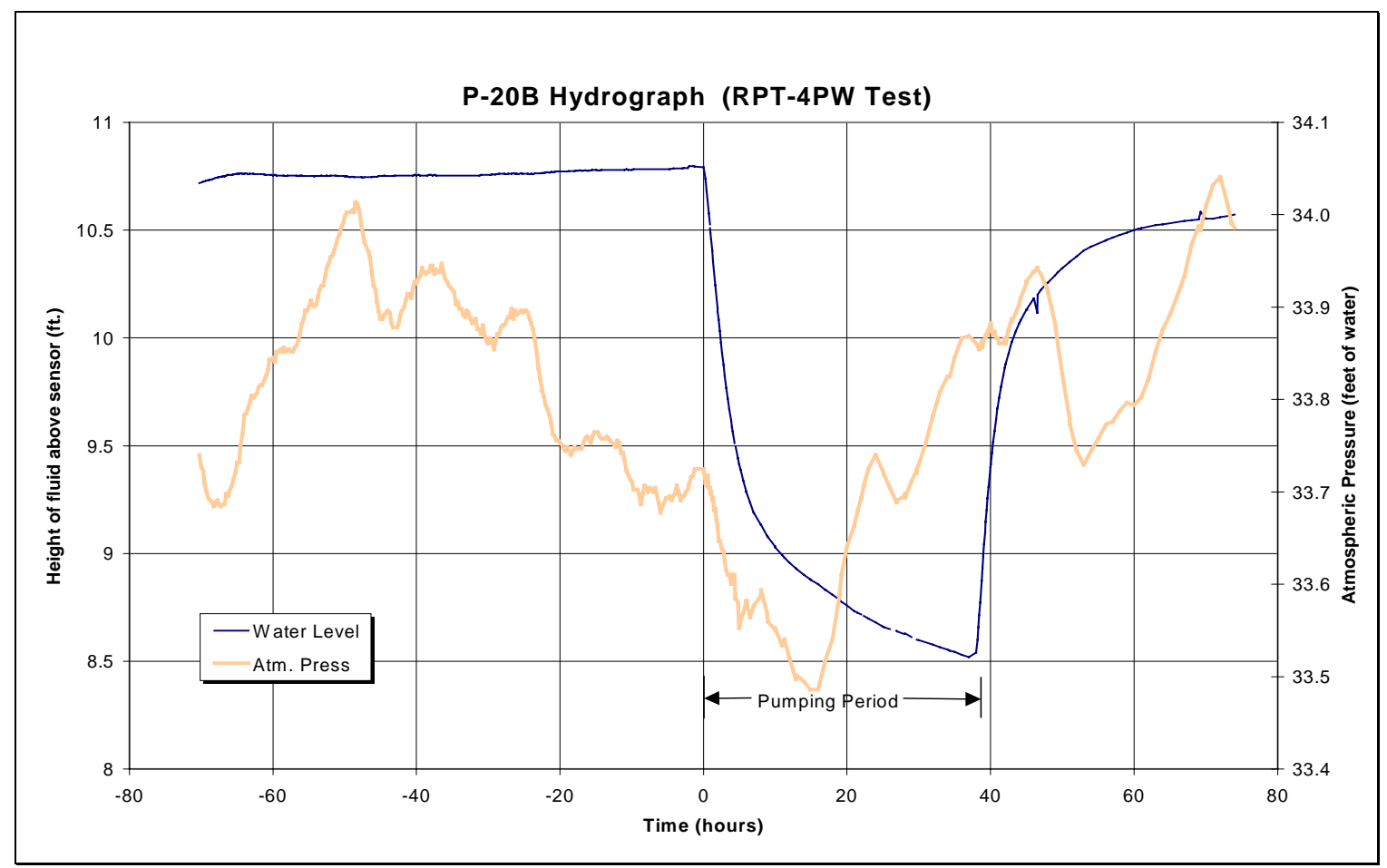

Figure 2E RPT-20B Hydrograph (RPT-4PW Test) 
WSRC-TR-00-00180, Rev. 0

R-Area Aquifer Tests

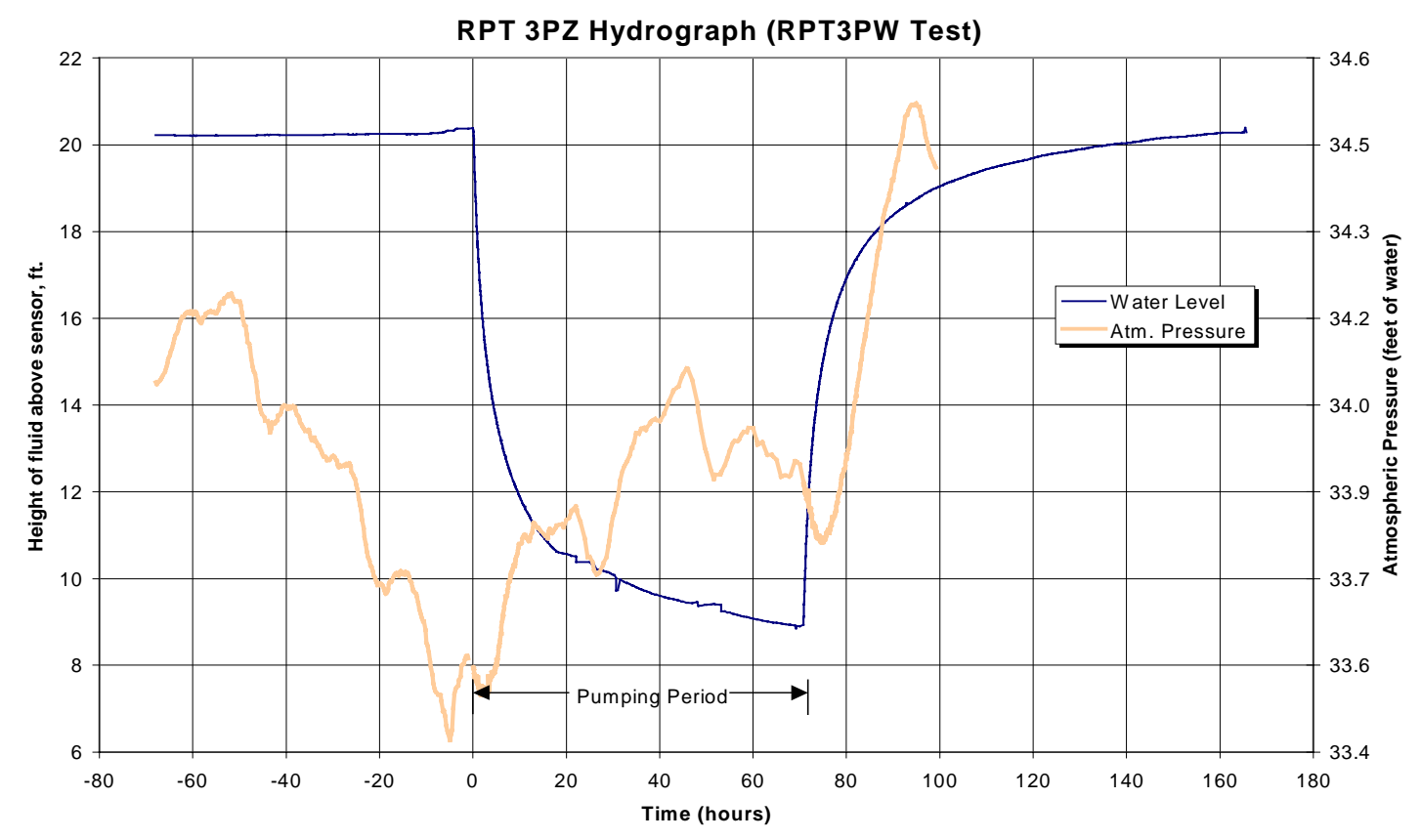

Figure 3E RPT-3PZ Hydrograph (RPT-3PW Test)

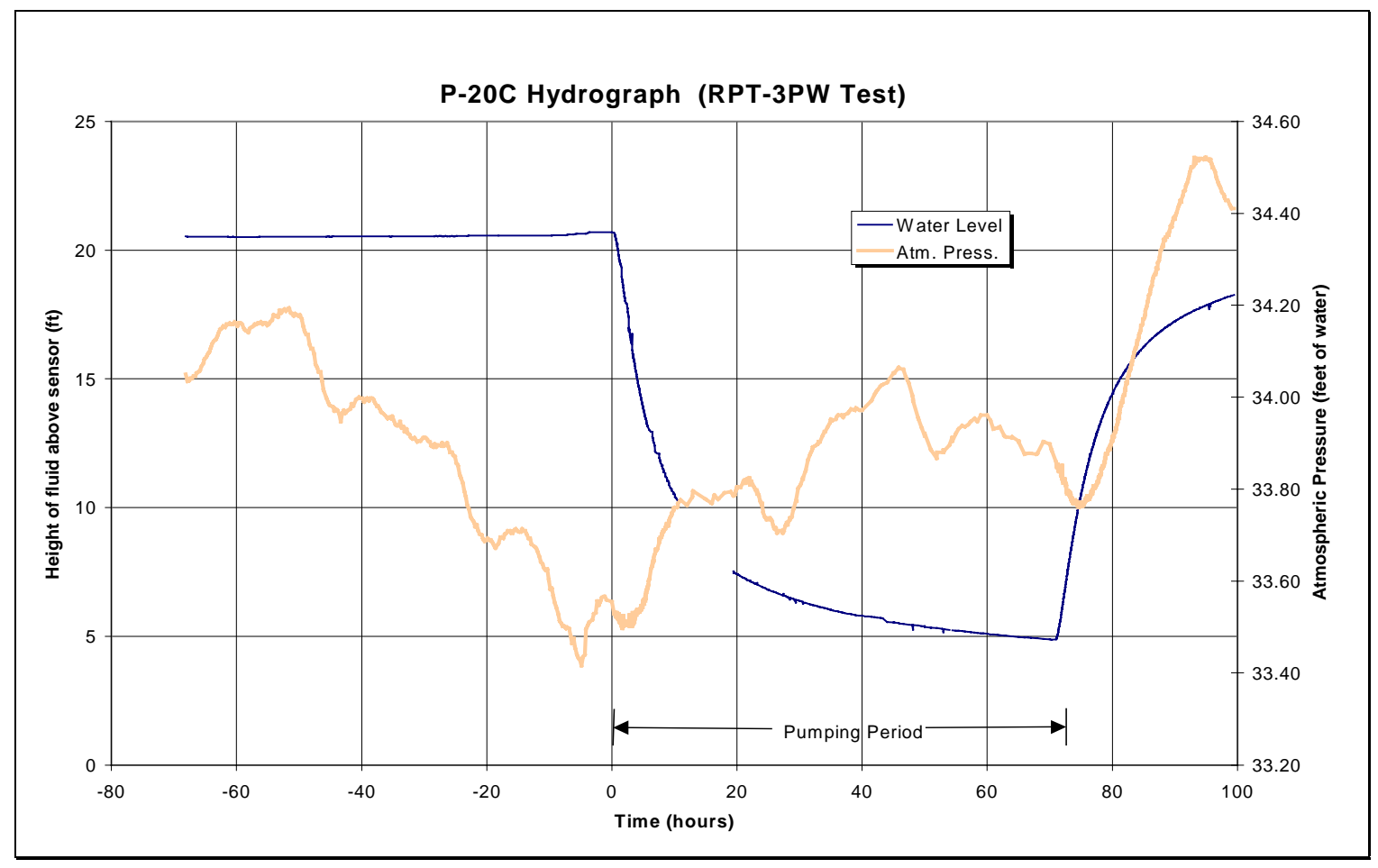

Figure 4E P-20C Hydrograph (RPT-3PW Test) 
WSRC-TR-00-00180, Rev. 0

R-Area Aquifer Tests

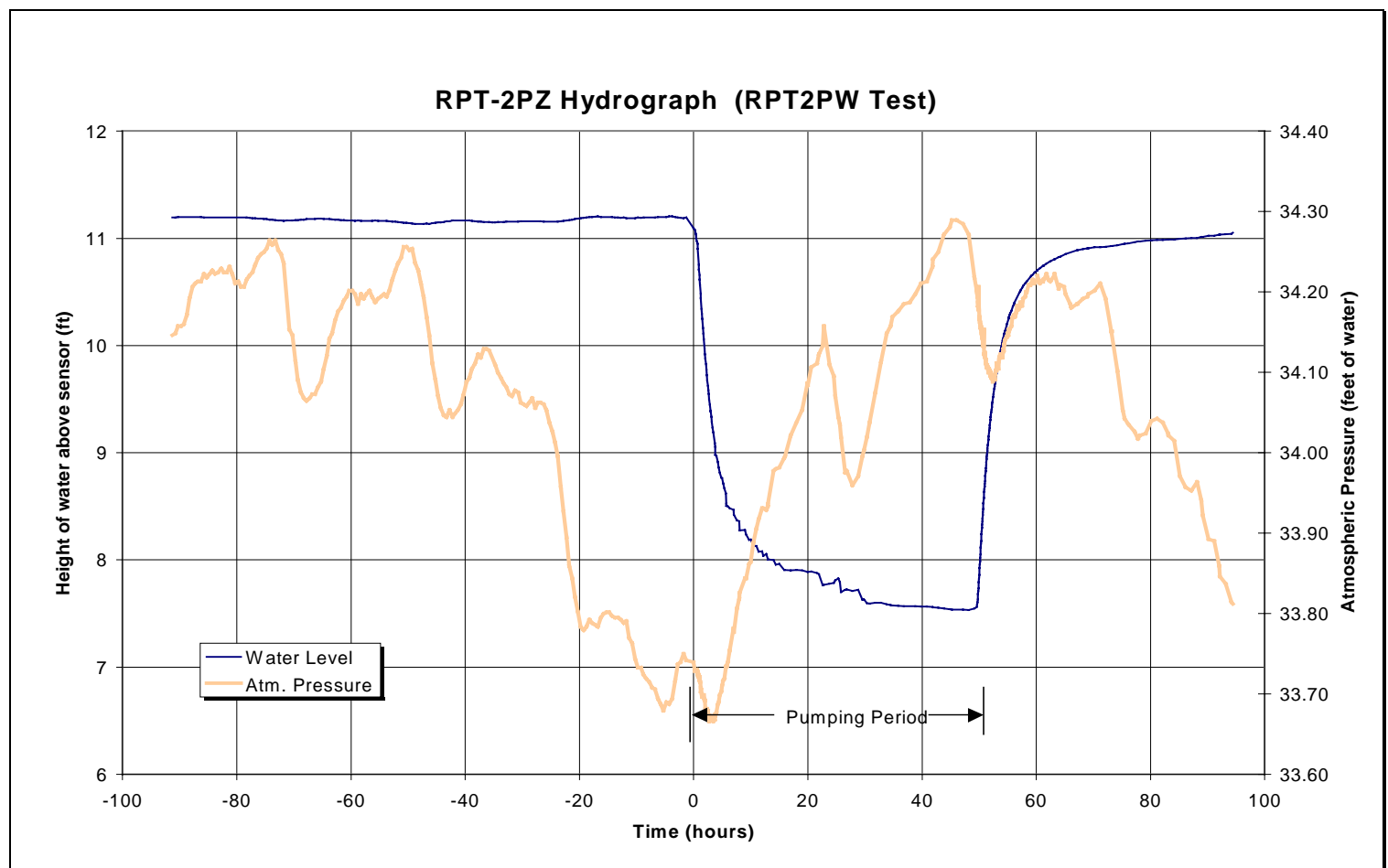

Figure 5E RPT-2PZ Hydrograph (RPT-2PW Test) 
WSRC-TR-00-00180, Rev. 0

R-Area Aquifer Tests

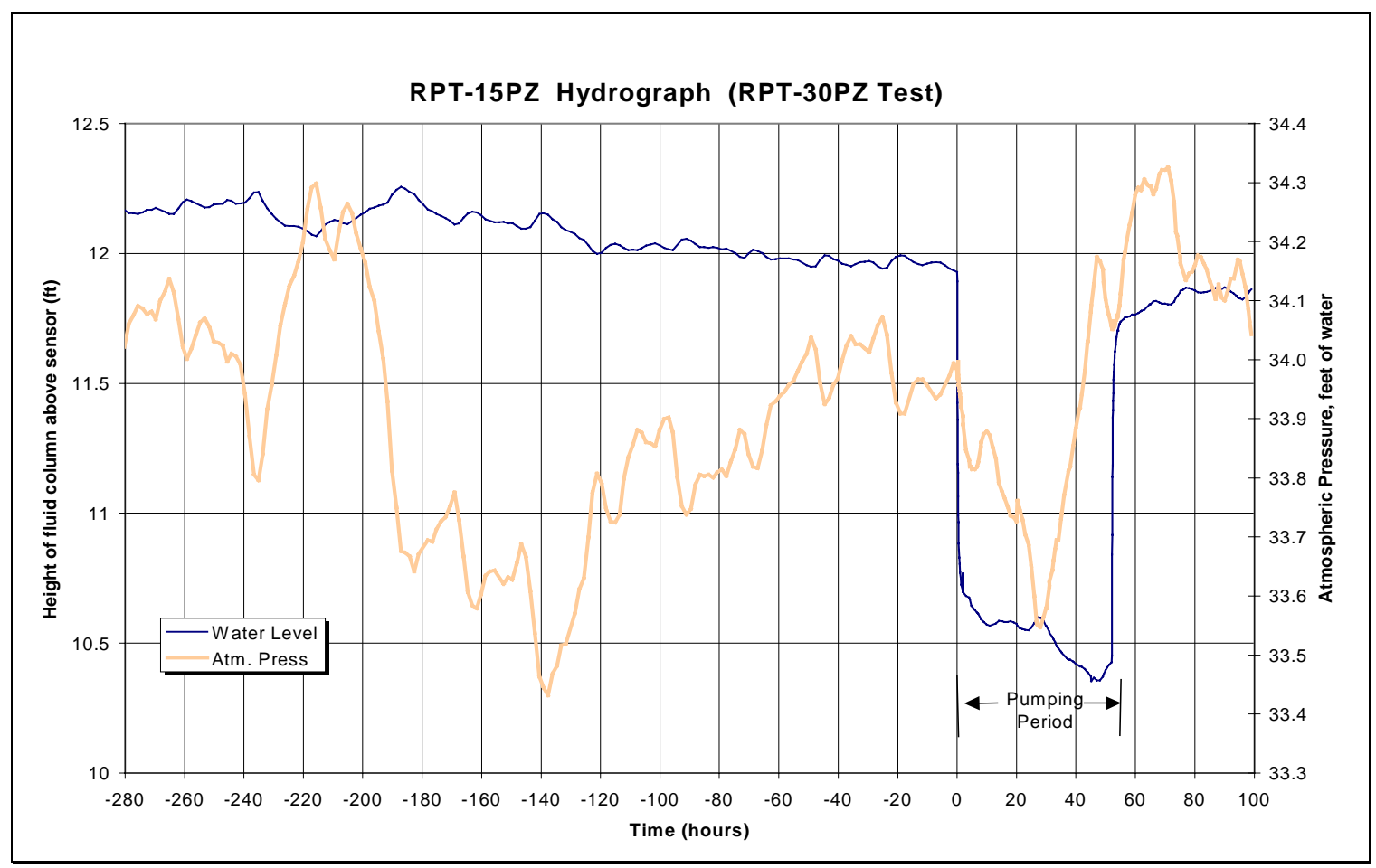

Figure 6E $\quad$ RPT-15 PZ Hydrograph (RPT-30 PZ Test)

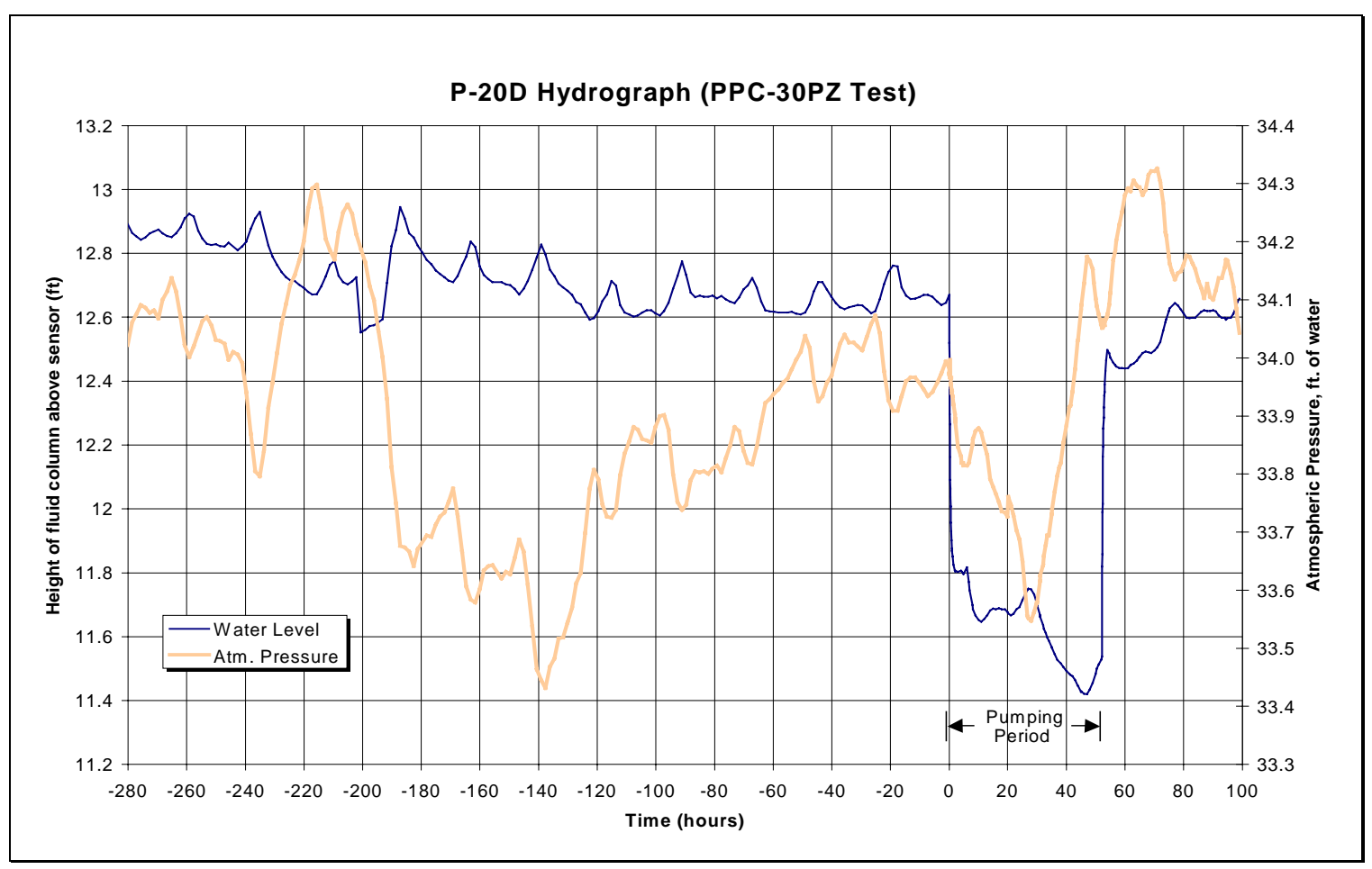

Figure 7E P-20D Hydrograph (RPC-30 PZ Test) 


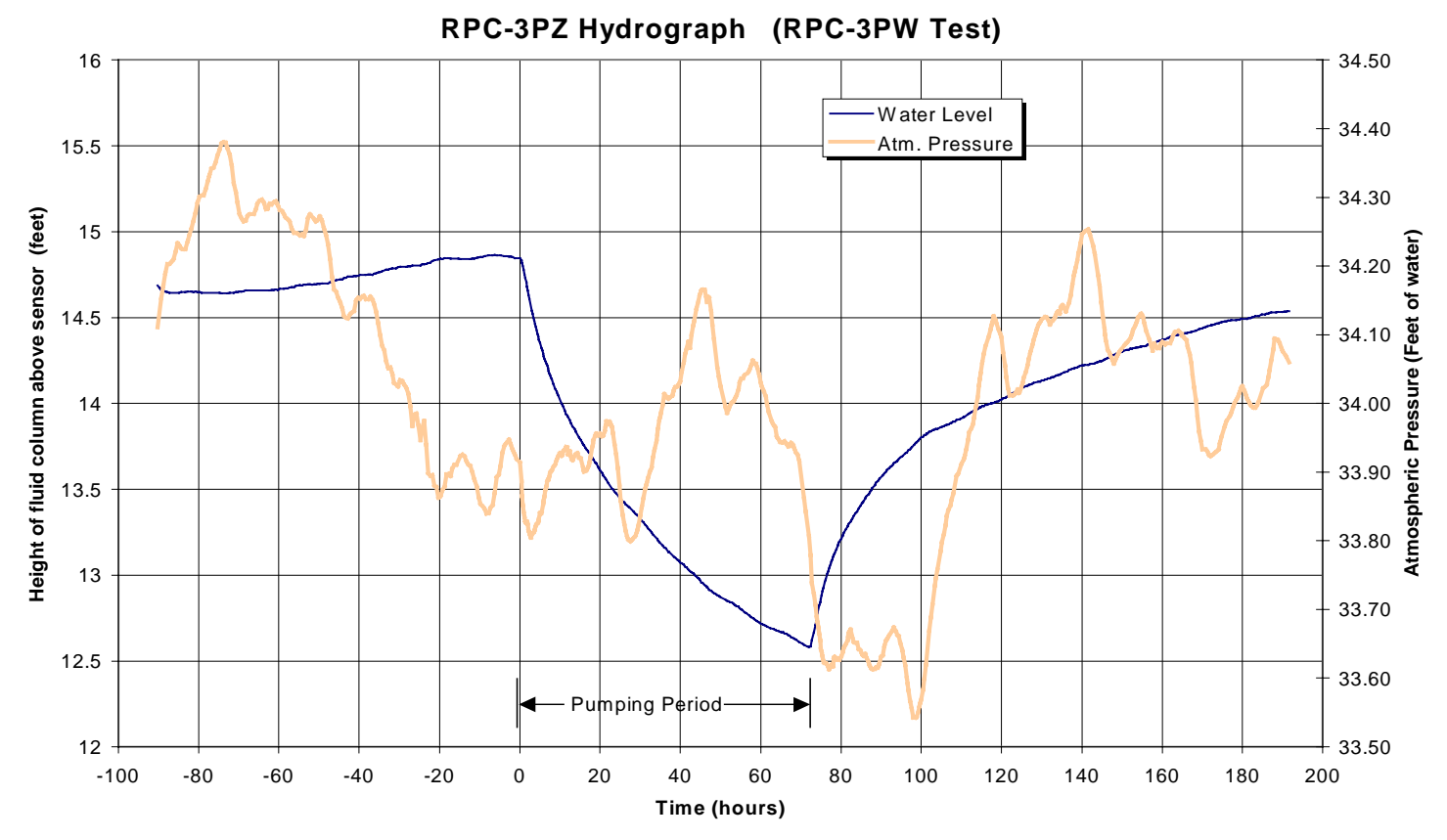

Figure 8E $\quad$ RPC-3PZ Hydrograph (RPC-3PW Test)

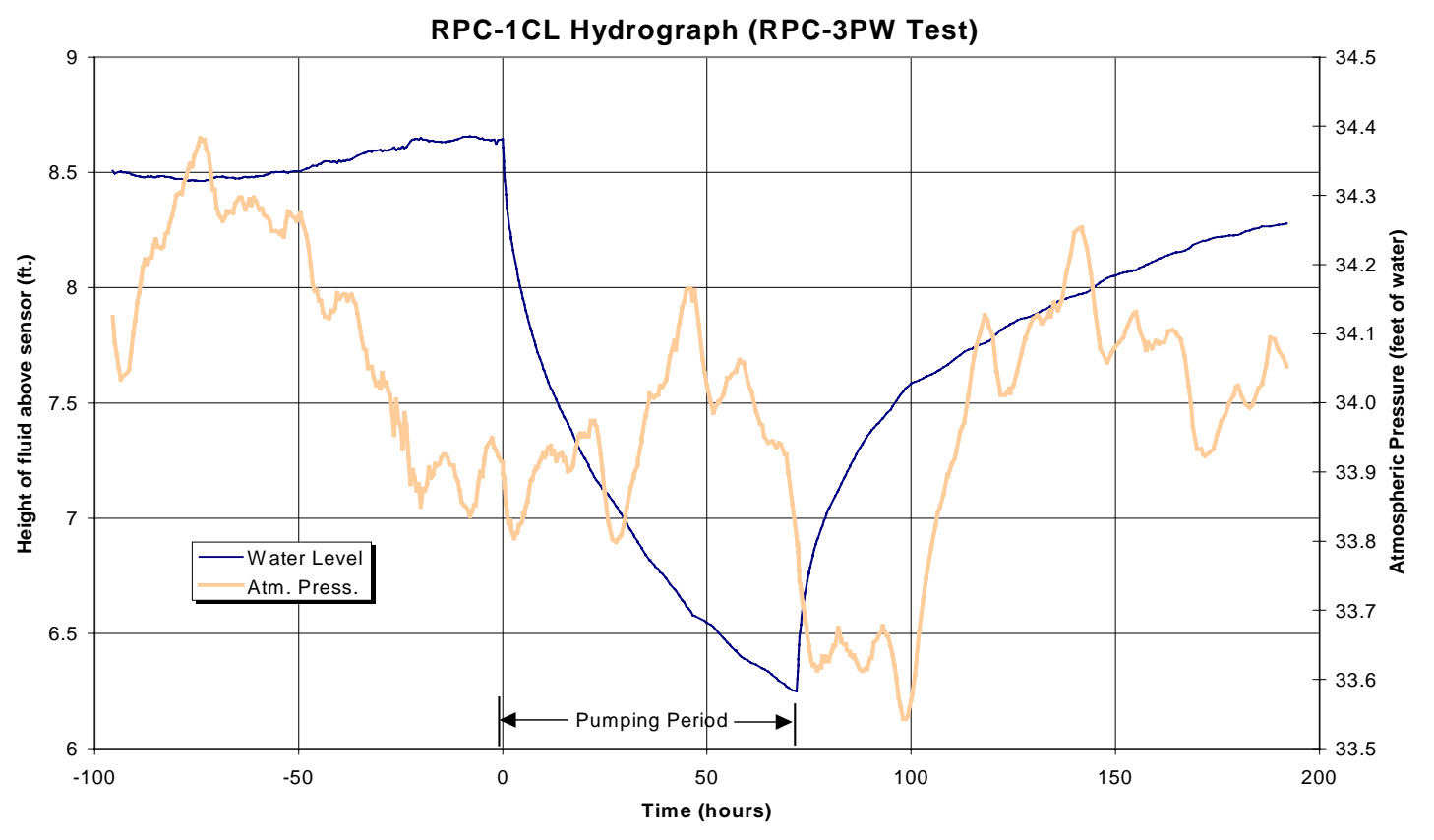

Figure 9E RPC-1CL Hydrograph (RPC-3PW Test) 
WSRC-TR-00-00180, Rev. 0

R-Area Aquifer Tests

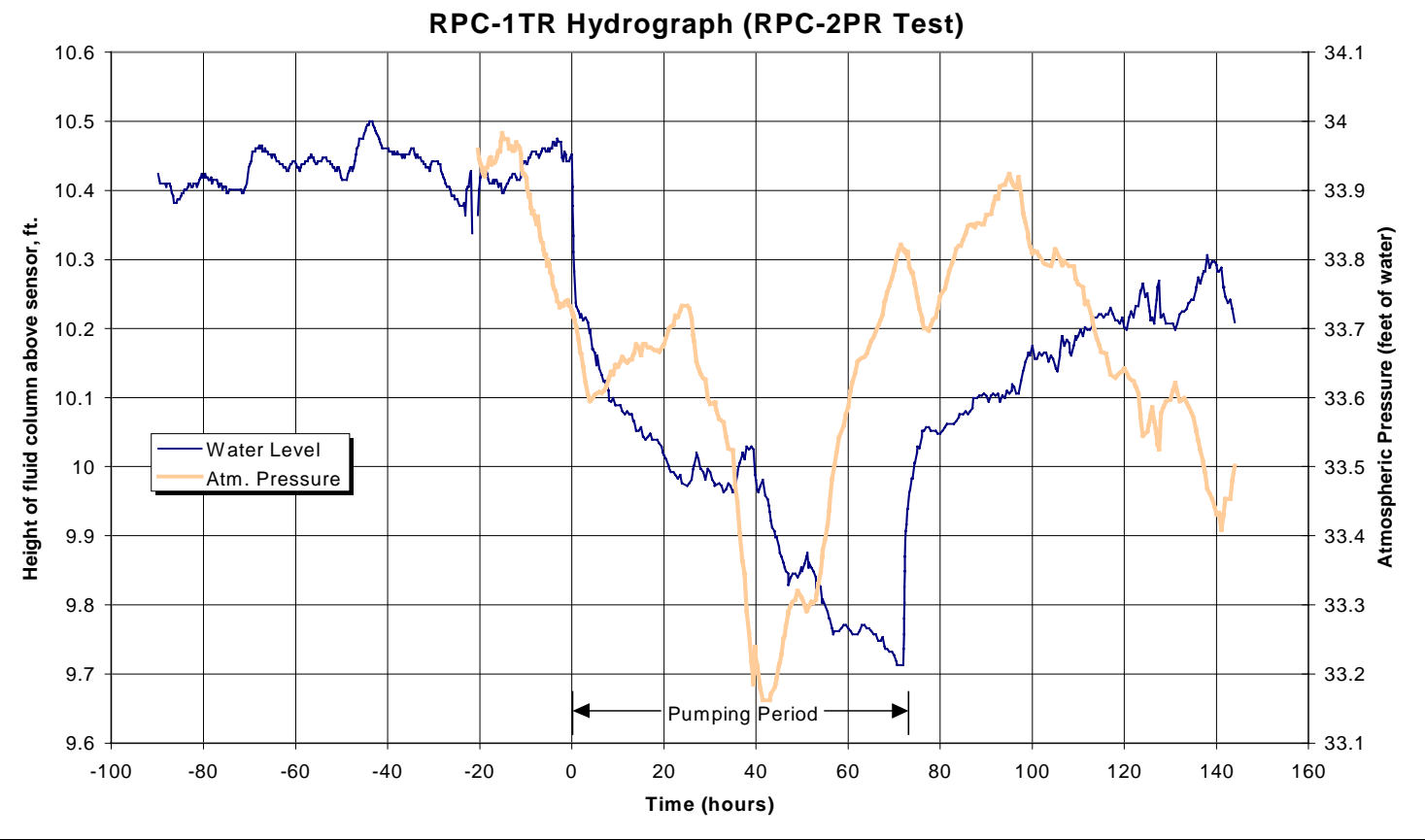

Figure 10E RPC-1TR Hydrograph (RPC-2PR Test)

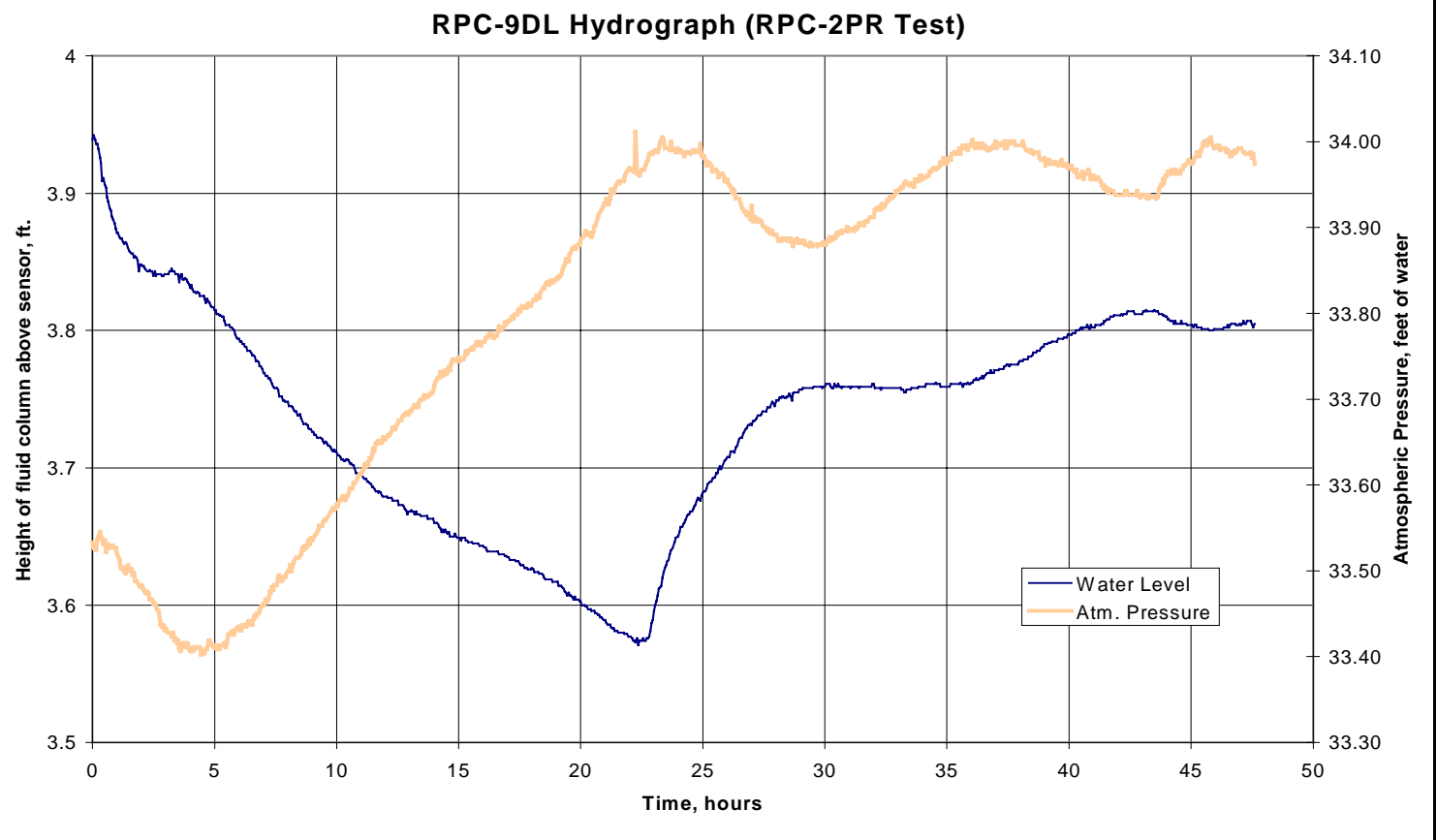

Figure 11E RPC-9DL Hydrograph (RPC-2PR Test) 
1WSRC-TR-00-00180, Rev. 0

R-Area Aquifer Tests

\section{APPENDIX F}

DRAWDOWN ANALYSIS CURVES 
WSRC-TR-00-00180, Rev. 0

R-Area Aquifer Tests

This Page Intentionally Left Blank 
3WSRC-TR-00-00180, Rev. 0

R-Area Aquifer Tests

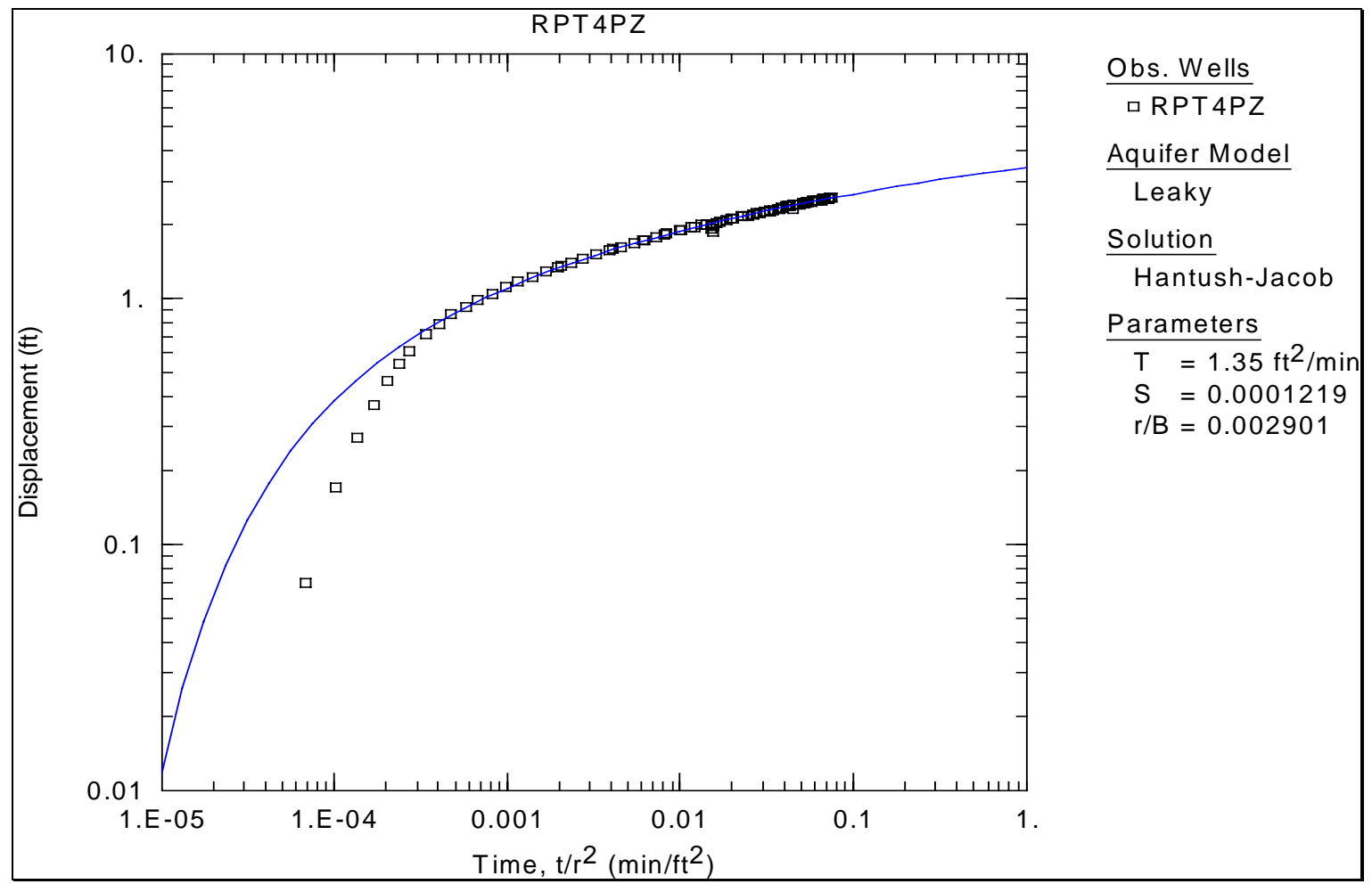

Figure 1F Match of analytical and field curves for RPT-4PZ (RPT-4PW Test)

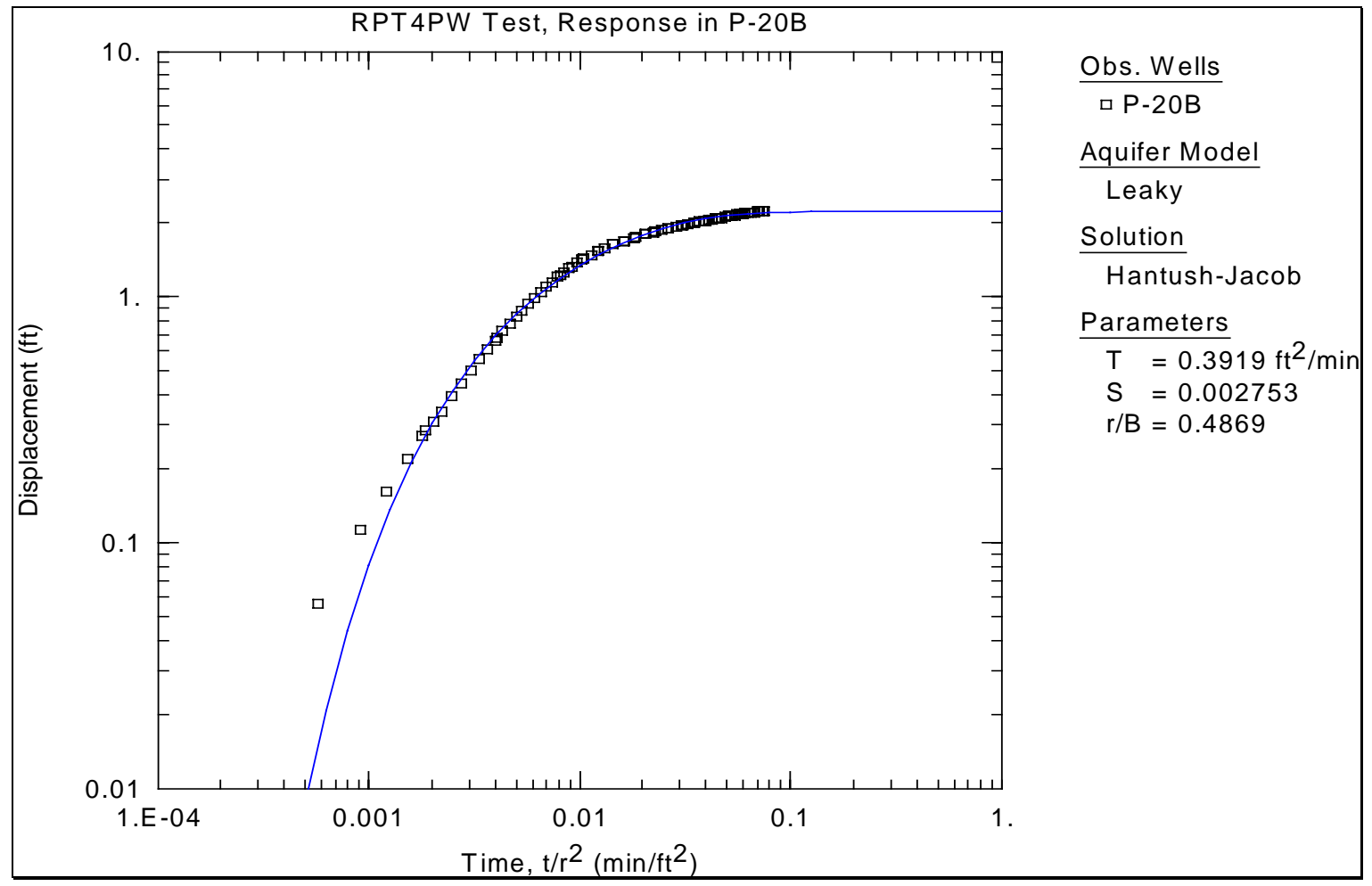

Figure 2F Match of analytical and field curves for P-20B (RPT-4PW Test) 
WSRC-TR-00-00180, Rev. 0

R-Area Aquifer Tests

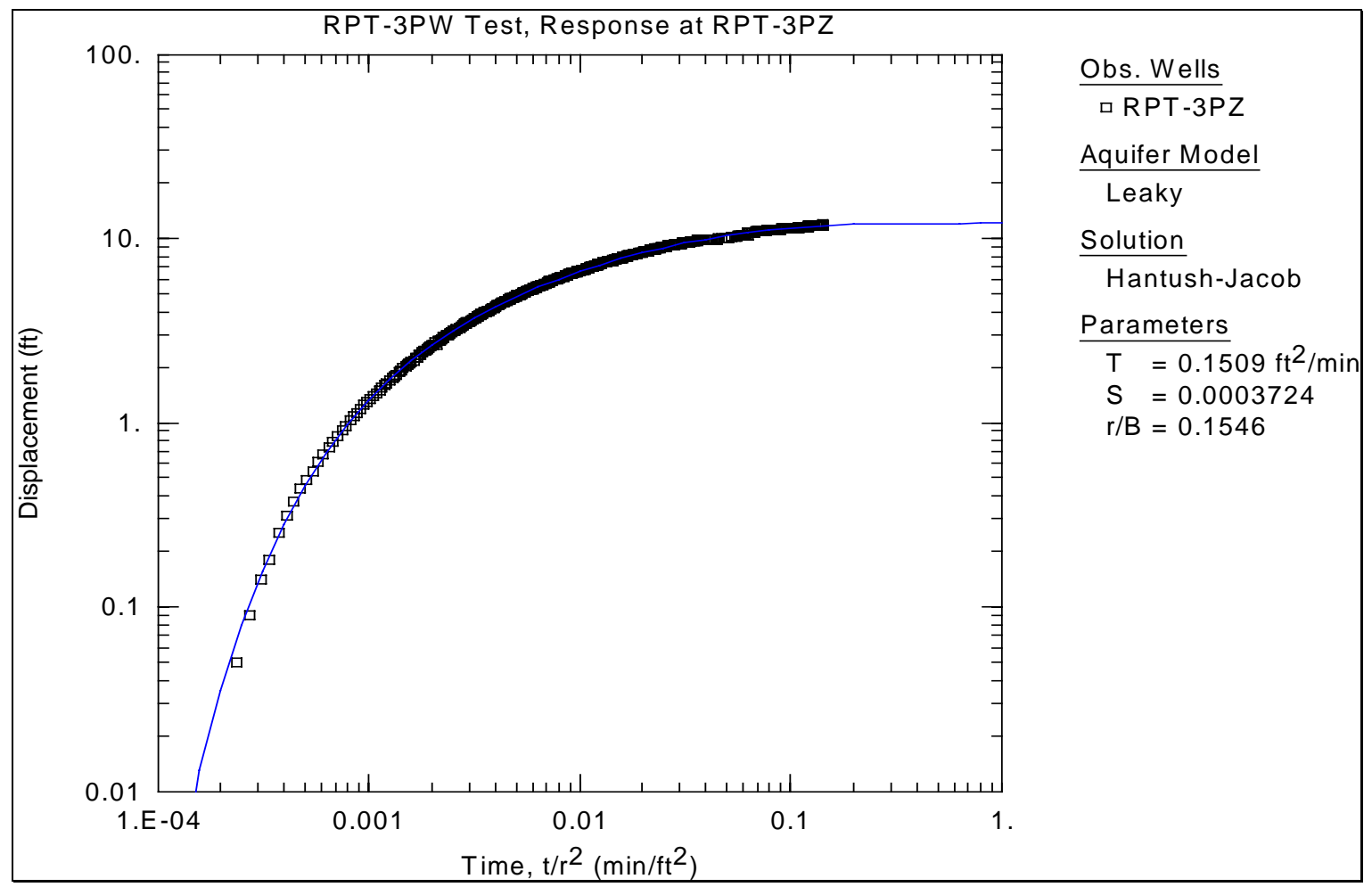

Figure 3F $\quad$ Match of analytical and field curves for RPT-3PZ (RPT-3PW Test)

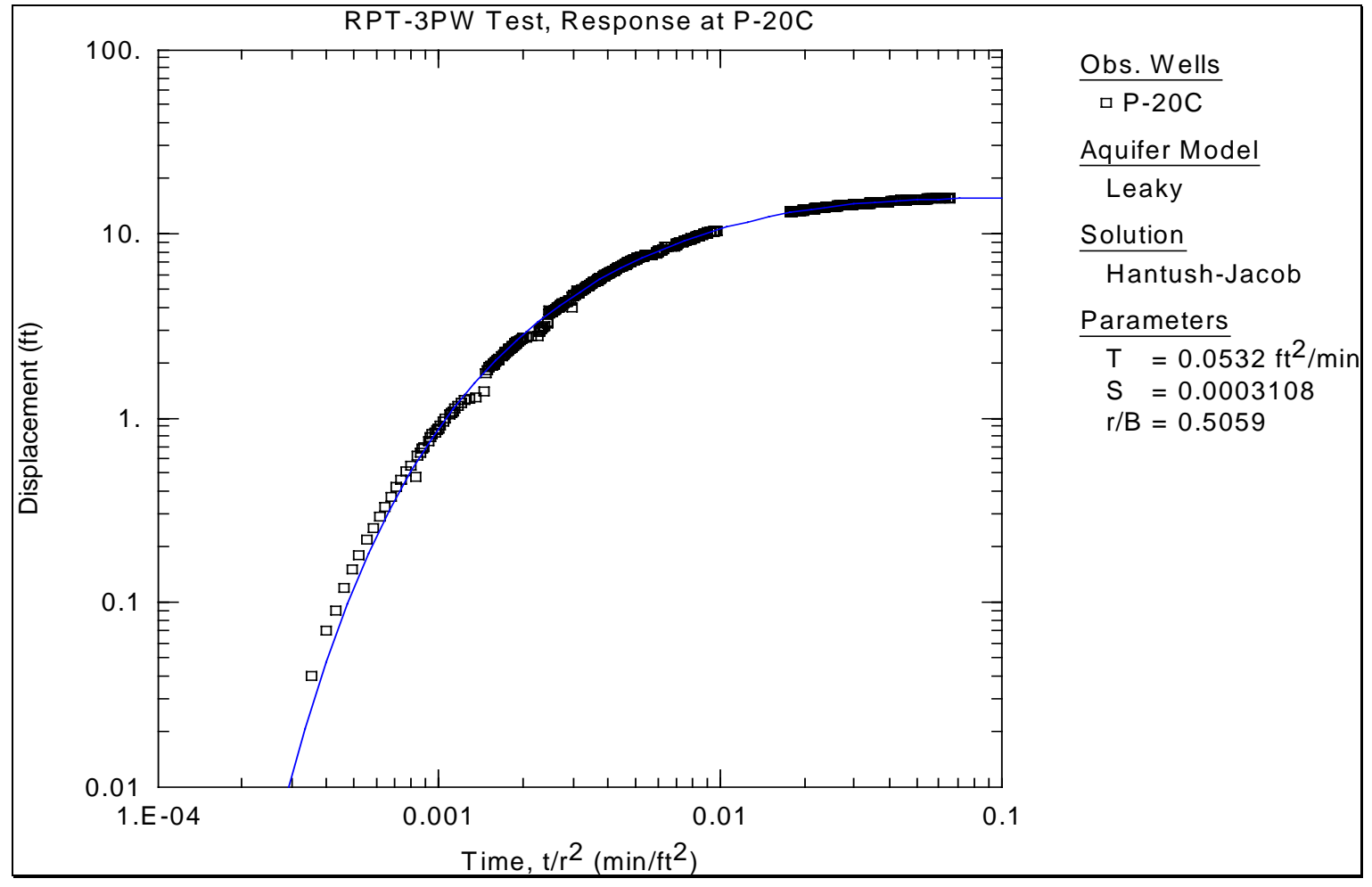

Figure 4F Match of analytical and field curves for P-20C (RPT-3PW Test) 
5WSRC-TR-00-00180, Rev. 0

R-Area Aquifer Tests

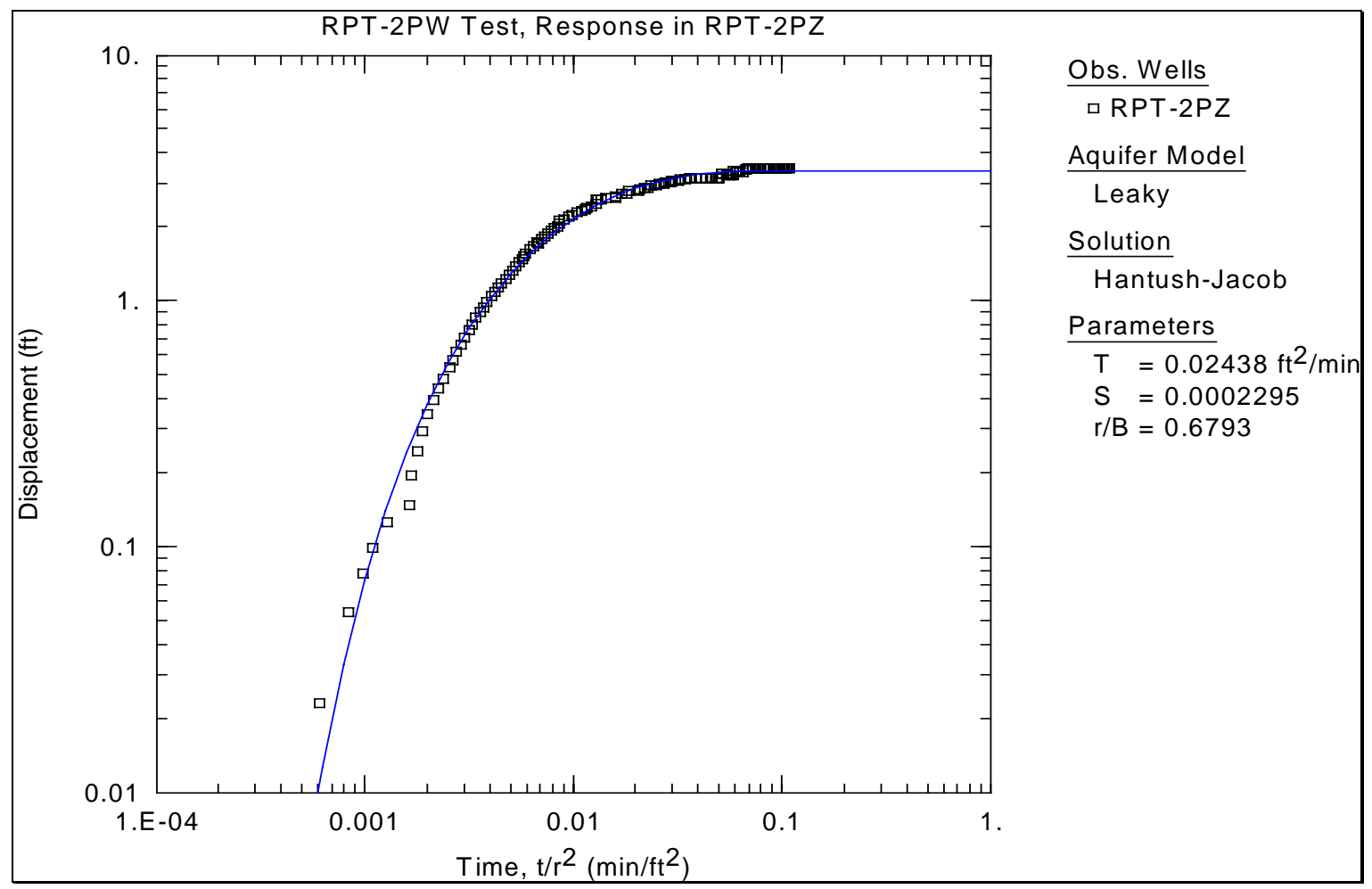

Figure 5F Match of analytical and field curves for RPT-2PZ (RPT-2PW Test) 
WSRC-TR-00-00180, Rev. 0

R-Area Aquifer Tests

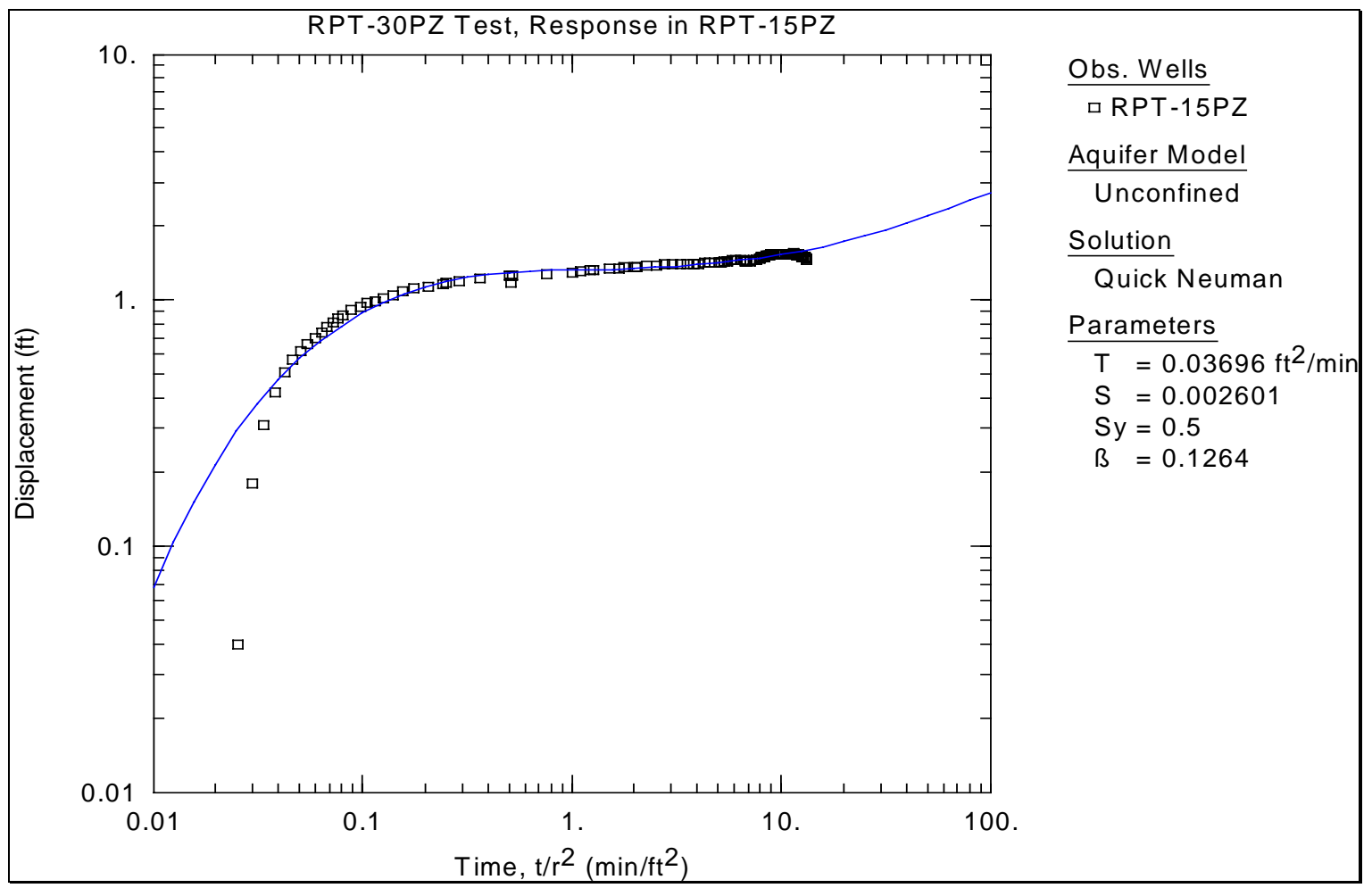

Figure 6F Match of analytical and field curves for RPT-15PZ (RPT-30PZ Test)

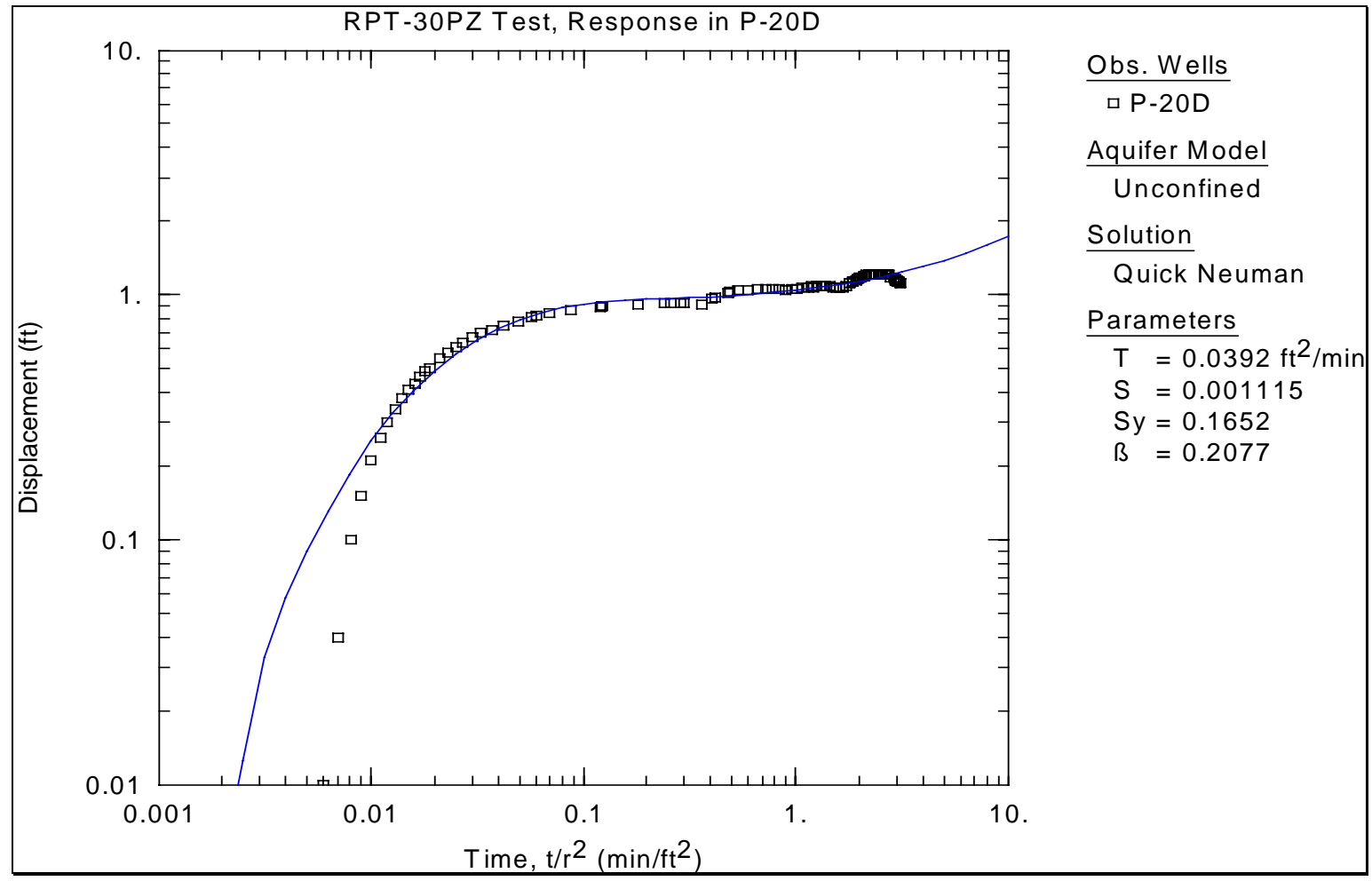

Figure 7F Match of analytical and field curves for P-20D (RPT-30PZ Test) 


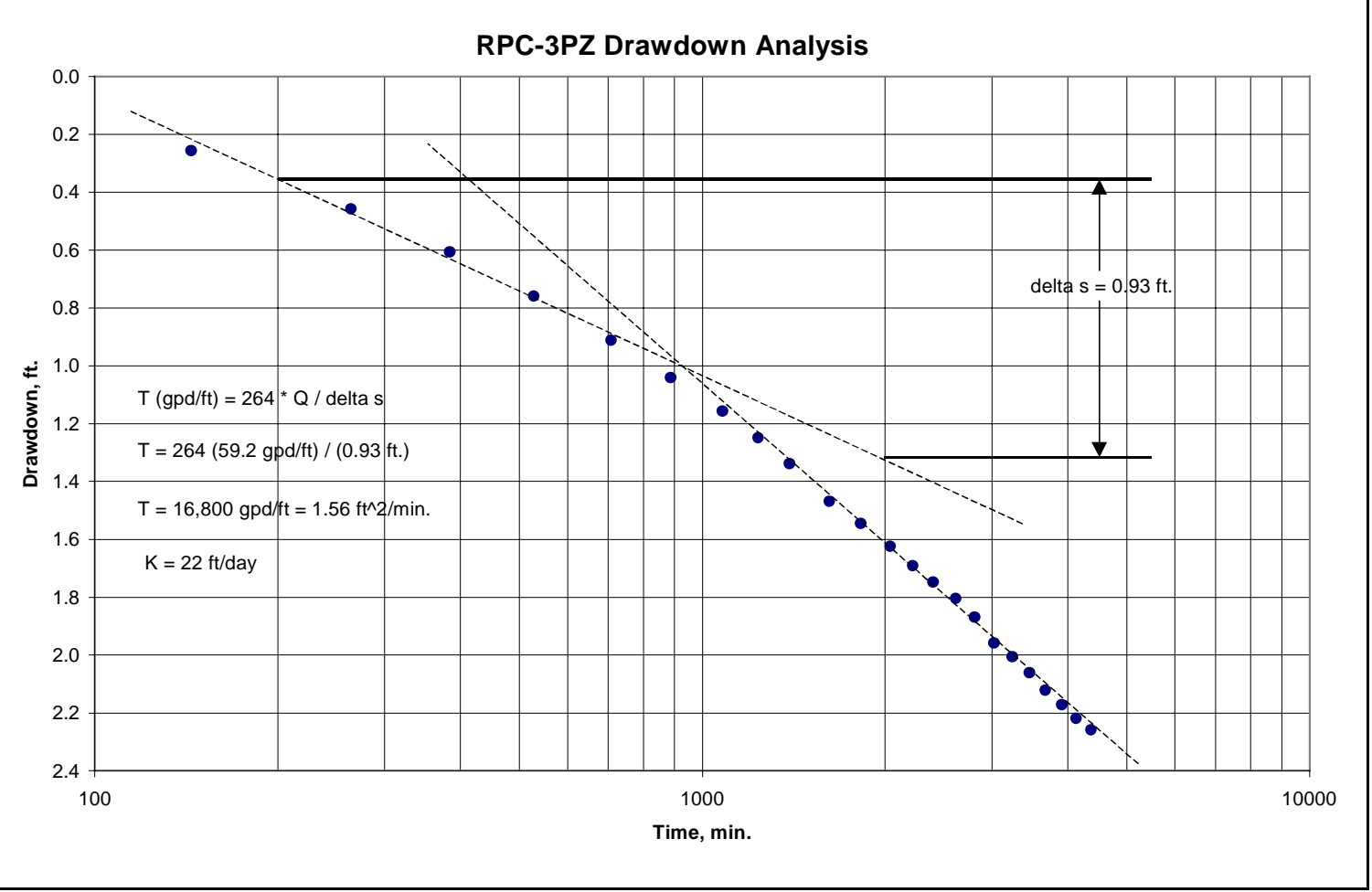

Figure 8F Drawdown data and analysis for RPC-3PZ (RPT-3PW Test)

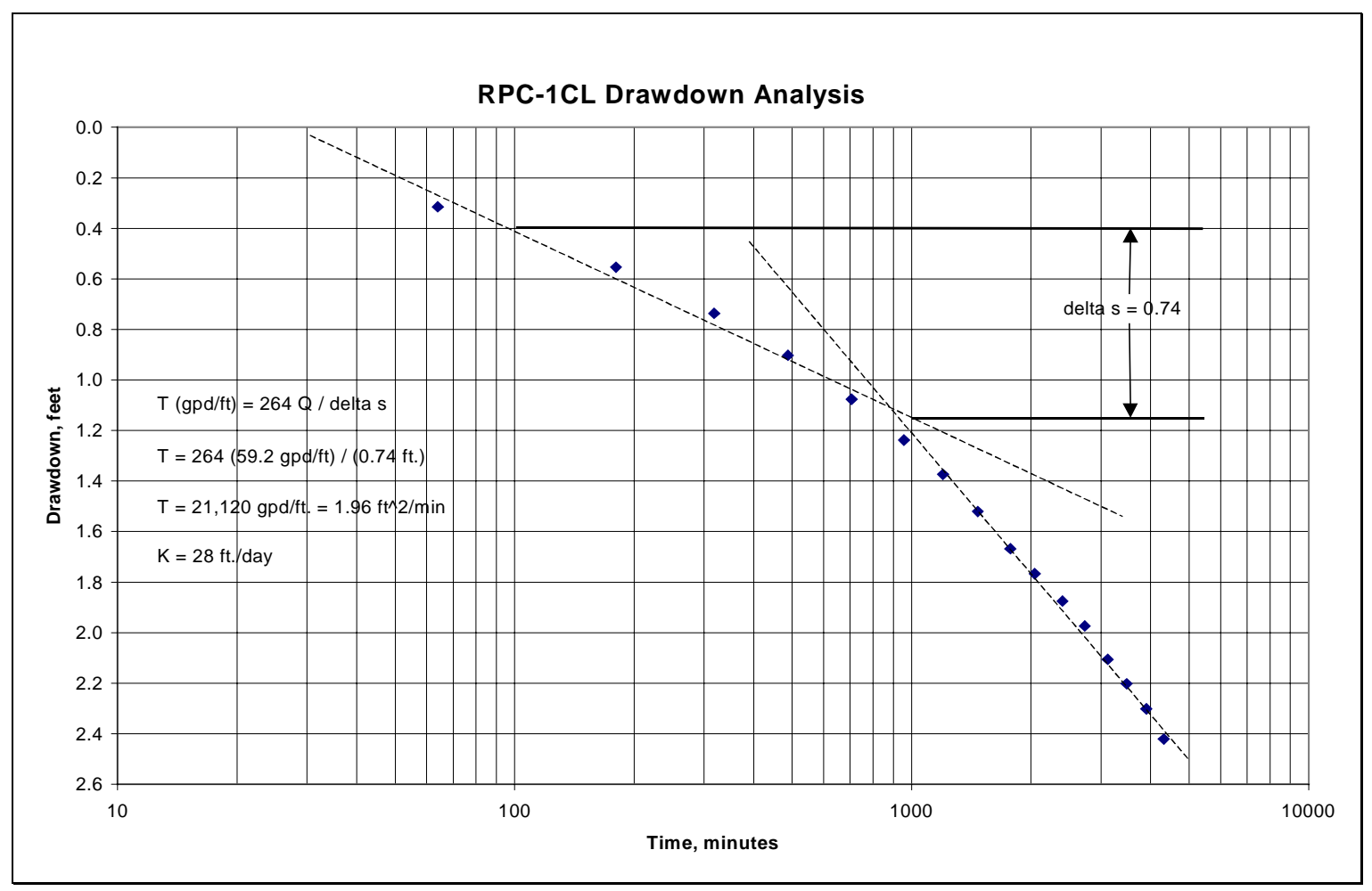

Figure 9F Drawdown data and analysis for RPC-1CL (RPT-3PW Test) 
WSRC-TR-00-00180, Rev. 0

R-Area Aquifer Tests

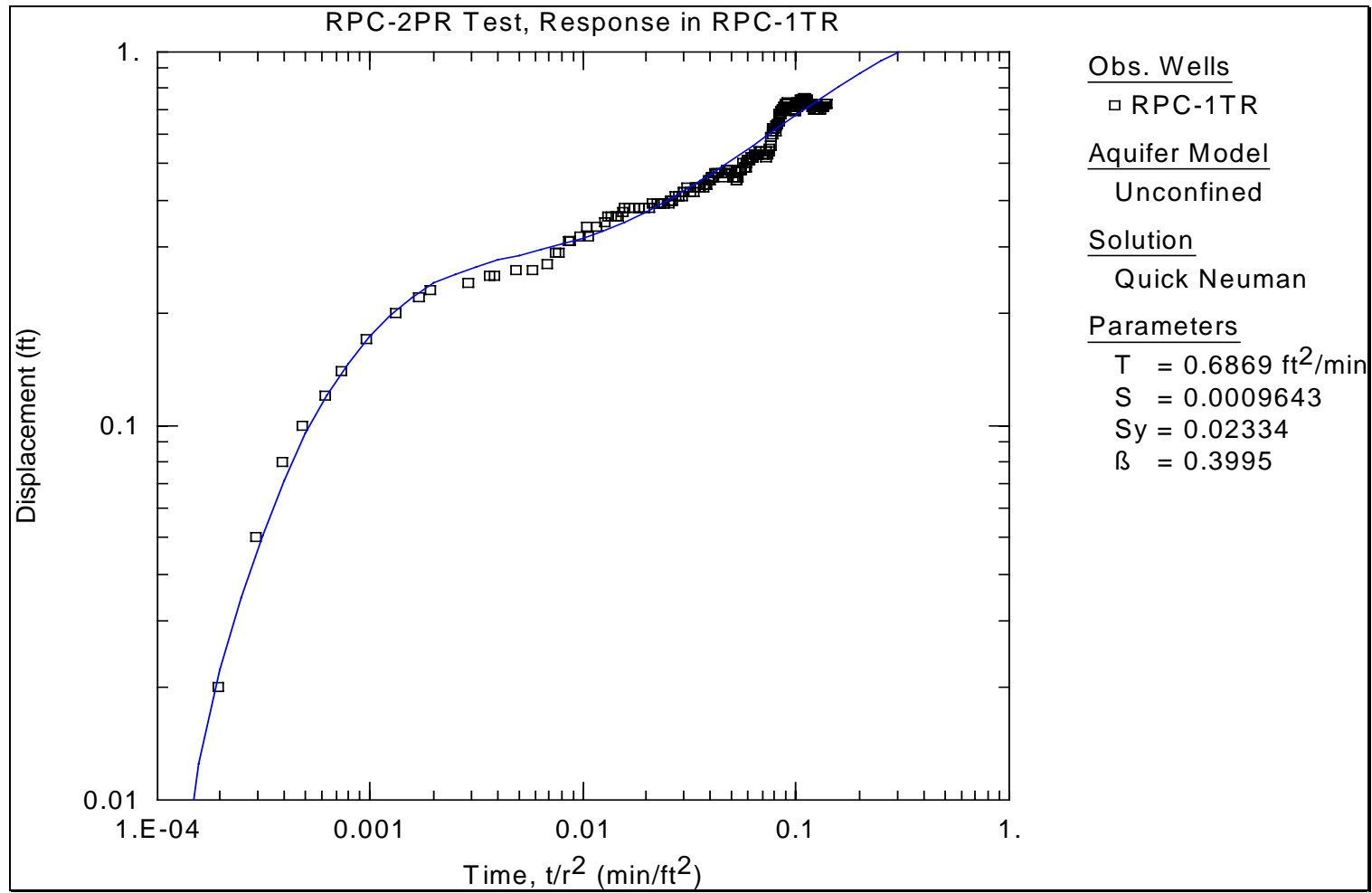

Figure 10F Match of analytical and field curves for RPC-1TR (RPC-2PR Test)

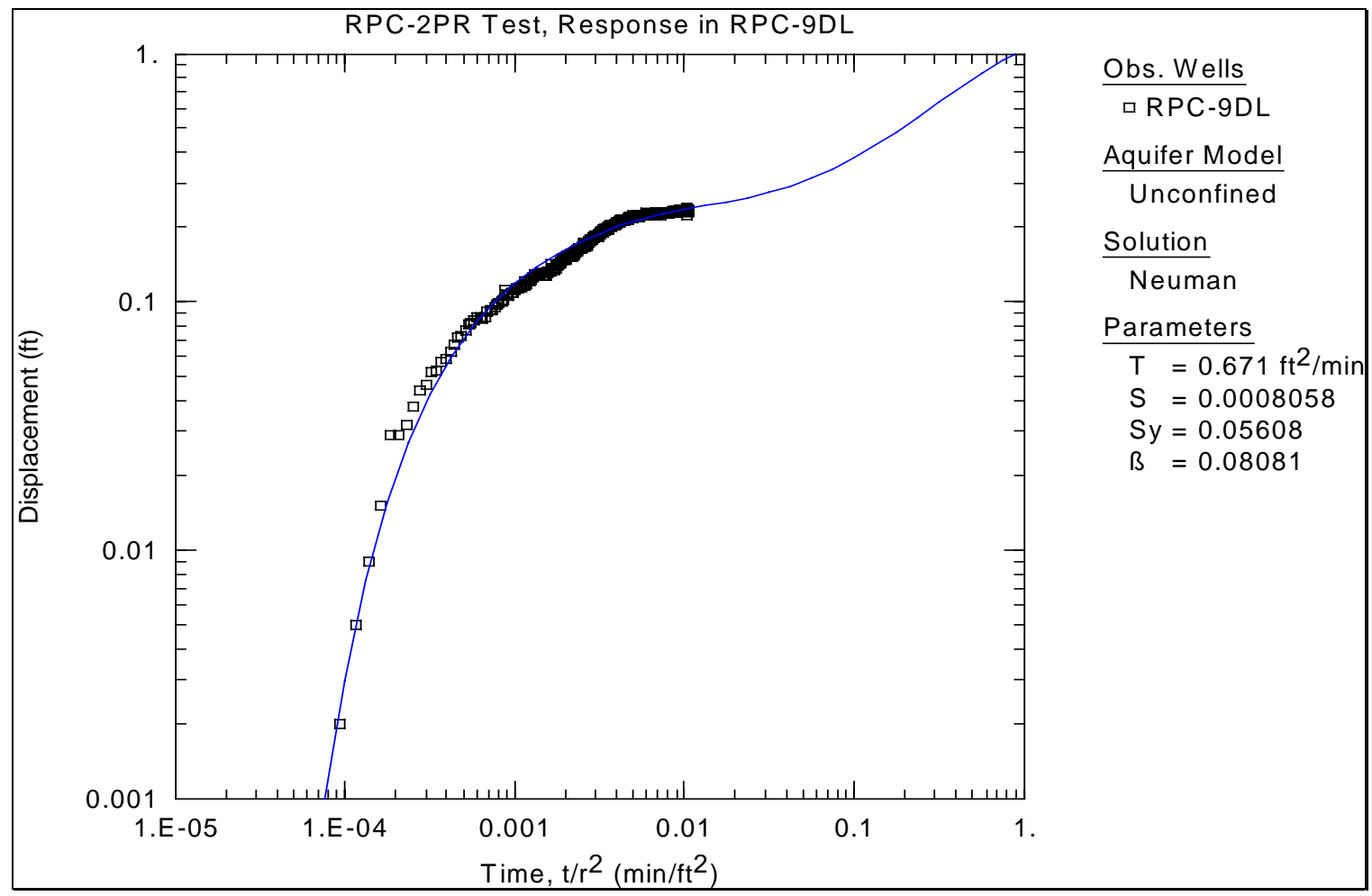

Figure 11F Match of analytical and field curves for RPC-9DL (RPC-2PR Test) 
WSRC-TR-2000-00180, Rev. 0

R-Area Aquifer Tests

APPENDIX G

RECOVERY ANALYSIS CURVES 
WSRC-TR-2000-00180, Rev. 0

R-Area Aquifer Tests

This Page Intentionally Left Blank 
WSRC-TR-2000-00180, Rev. 0

R-Area Aquifer Tests

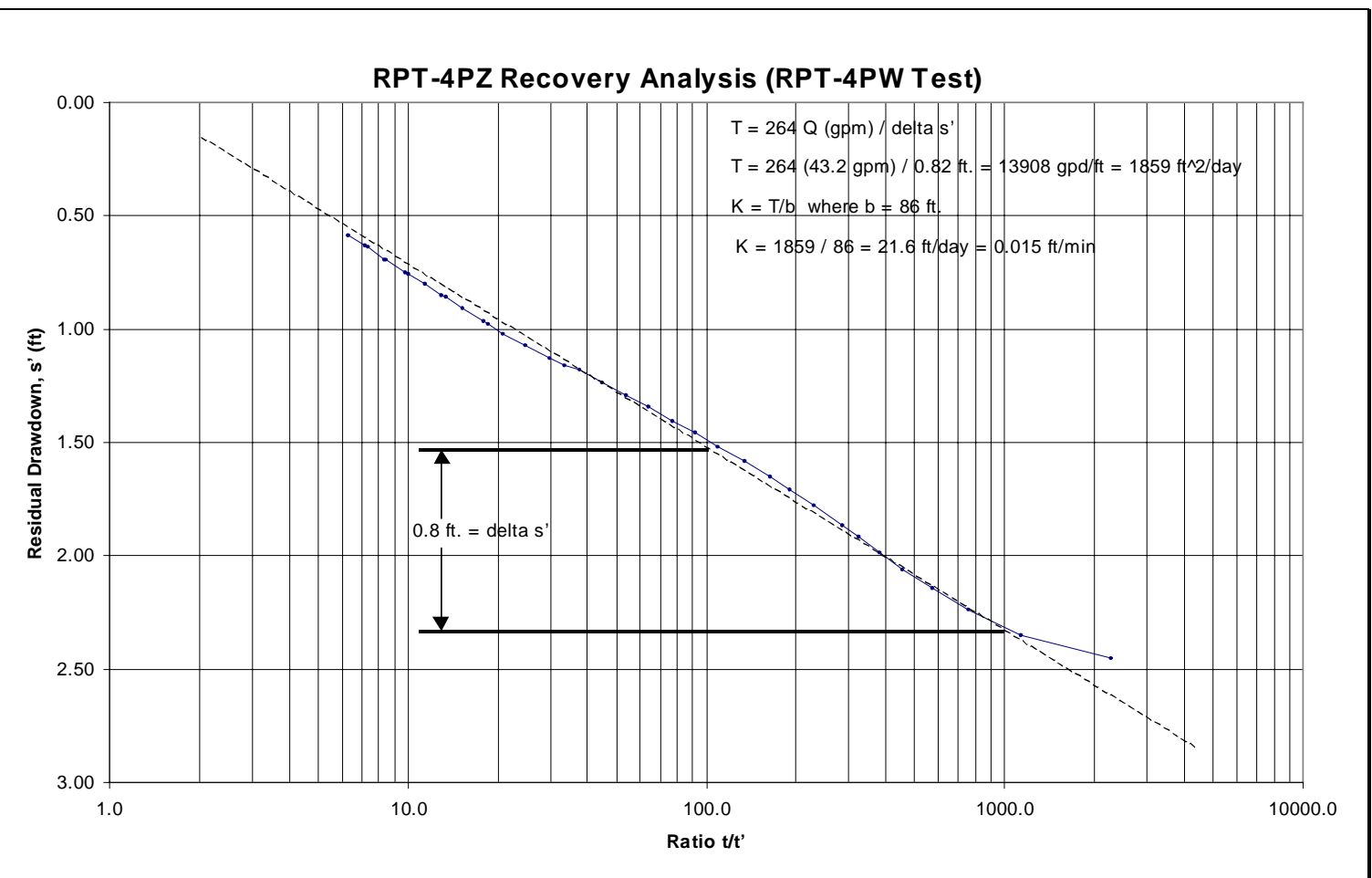

Figure 1G Recovery analysis for RPT-4PZ (RPT-4PW test)

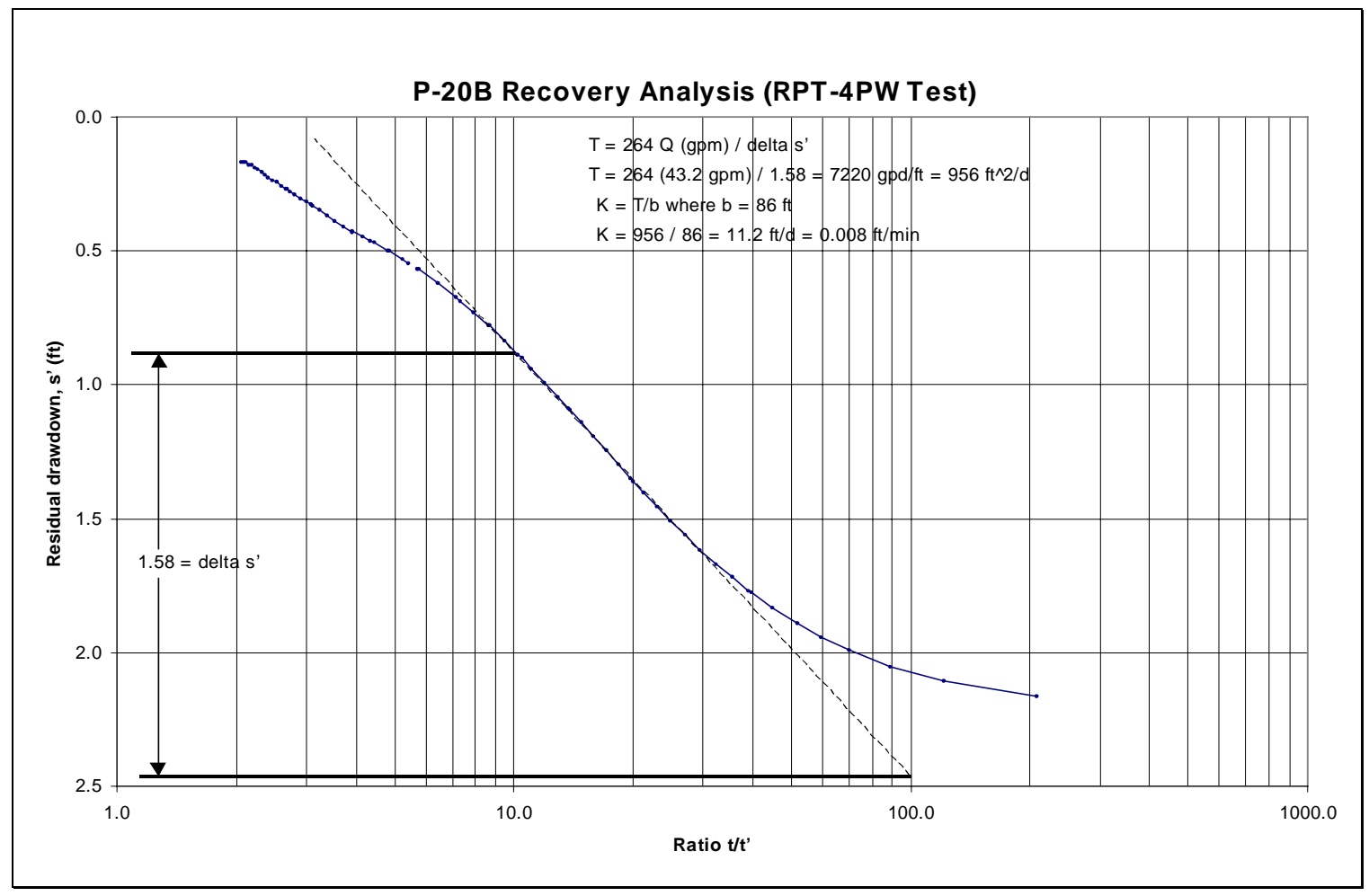

Figure 2G Recovery analysis for P-20B (RPT-4PW test) 
WSRC-TR-2000-00180, Rev. 0

R-Area Aquifer Tests

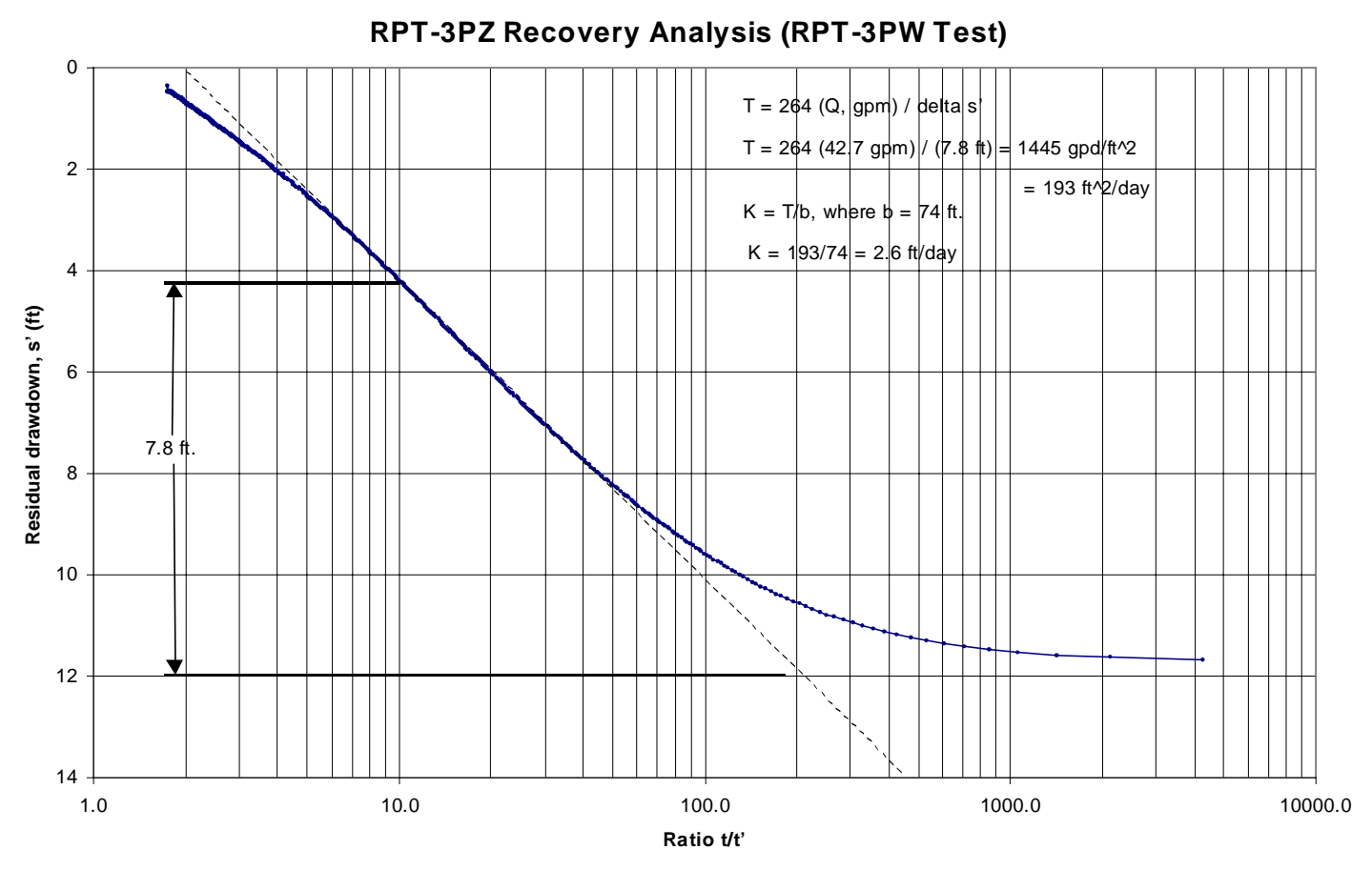

Figure 3G Recovery analysis for RPT-3PZ (RPT-3PW test)

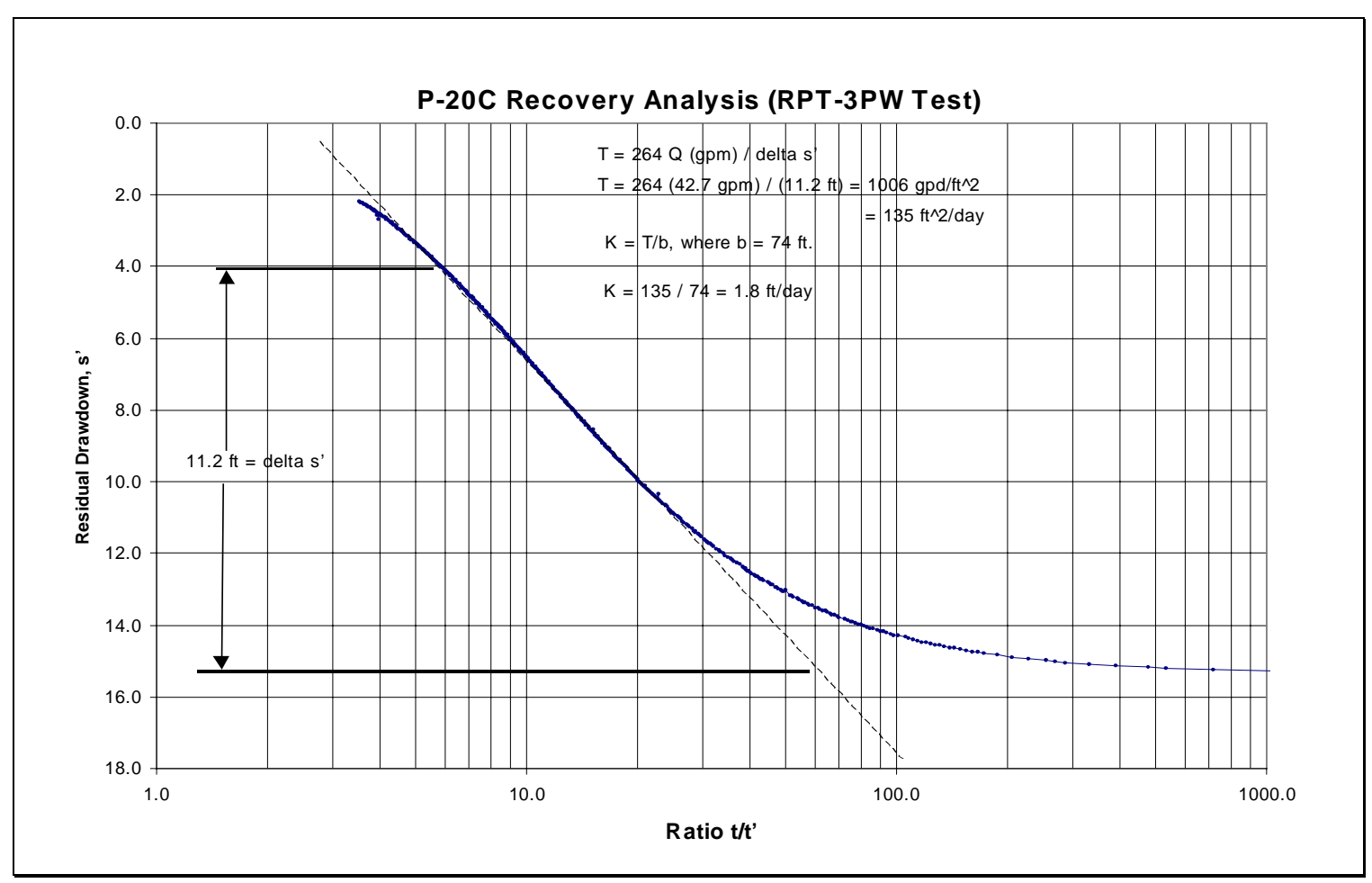

Figure 4G Recovery analysis for P-20B (RPT-3PW test) 
WSRC-TR-2000-00180, Rev. 0

R-Area Aquifer Tests

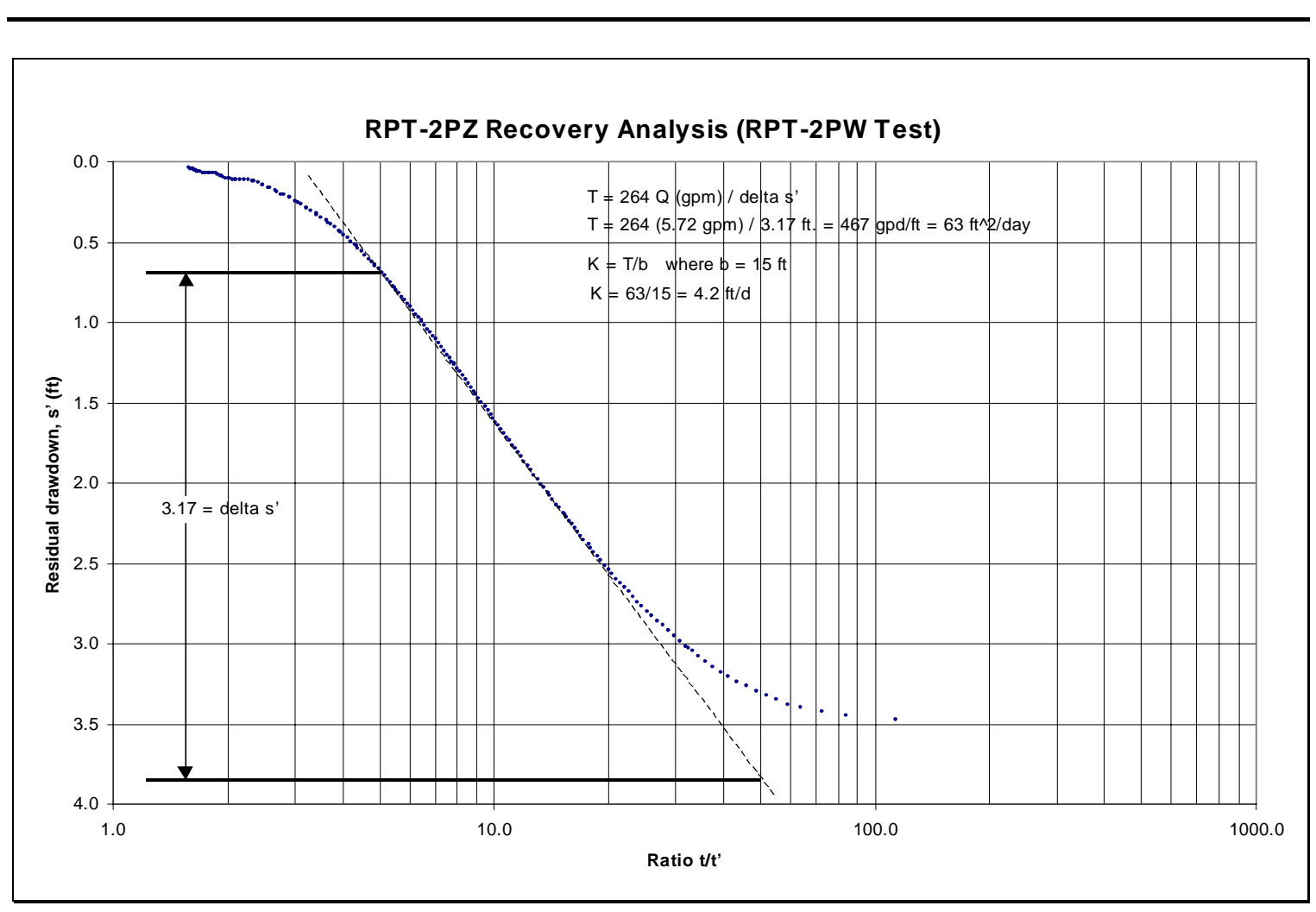

Figure 5G Recovery analysis for RPT-2PZ (RPT-2PW test) 
WSRC-TR-2000-00180, Rev. 0

R-Area Aquifer Tests

This page intentionally left blank 